\title{
SOLAR COMMUNITY ENERGY AND STORAGE SYSTEMS FOR COLD CLIMATES
}

by

Farzin Masoumi Rad

Bachelor of Applied Science (Mechanical Engineering), Shiraz University, Iran, 1986 Master of Applied Science (Mechanical Engineering), Ryerson University, Toronto, Canada, 2009

\author{
A dissertation \\ presented to Ryerson University \\ in partial fulfilment of the \\ requirements for degree of \\ Doctor of Philosophy \\ in the program of \\ Mechanical and Industrial Engineering
}

Toronto, Ontario, Canada, 2016

(C) Farzin M. Rad 2016 


\section{Author's Declaration}

I hereby declare that I am the sole author of this dissertation. This is a true copy of the dissertation, including any required final revisions, as accepted by my examiners.

I authorize Ryerson University to lend this thesis to other institutions or individuals for the purpose of scholarly research.

I further authorize Ryerson University to reproduce this thesis by photocopying or by other means, at the request of other institutions or individuals for the purpose of scholarly research.

I understand that my dissertation may be made electronically available to the public. 


\title{
SOLAR COMMUNITY ENERGY AND STORAGE SYSTEMS FOR COLD CLIMATES
}

\author{
Farzin Masoumi Rad \\ Doctor of Philosophy \\ Department of Mechanical and Industrial Engineering \\ Ryerson University, Toronto, Ontario, Canada, 2016
}

\begin{abstract}
For a hypothetical solar community located in Toronto, Ontario, the viability of two separate combined heating and cooling systems were investigated. Four TRNSYS integrated models were developed for different cases. First, an existing heating only solar community was modeled and compared with published performance data as the base case with suggested improvements. The base case community was then used to develop a hypothetical solar community, located in Toronto, requiring both heating and cooling. In this second model an absorption chiller was added - Solar Thermal Chiller (STC) system. The chiller received its source heat from the solar thermal system with the supplemental heat from a natural gas boiler. The STC system was designed with two borehole thermal energy storage units (BTES). One was high-temperature BTES for the solar thermal energy storage, and another was medium-temperature BTES for the chillers' heat rejection. The twenty year simulation results showed that by the fifth year in the heating season, the community operated with $100 \%$ solar fraction (SF). In the cooling season, the chiller received $18 \%$ of its required energy from the same number of solar collectors as the heating-only community system. The third model was based on the central heat pump system with borehole thermal storage for the heating and cooling, using a PV system as the heat pump power source - Heat Pump Photovoltaics (HPPV) system. The simulation results showed that the system operated favorably from the first year and did not have any significant performance degradation in 20 years. On average, the heat pumps performed with the seasonal COP of 3.3 in the heating mode and 5.9 in the cooling mode. The fourth system, Solar Thermal-Heat Pump Photovoltaics (ST-HPPV), a solar thermal system with borehole thermal energy storage as a
\end{abstract}


supplemental heat source to the HPPV, was investigated. The simulation results showed that this system would be beneficial for a community with the annual heating and cooling difference of more than 75\%. By adding a solar thermal system to the HPPV system, the heat pumps' performance improved by $26 \%$ in the heating mode, and exhibited a negligible drop in the cooling mode. 


\section{Acknowledgements}

I would like to express my great thankful and appreciation to my supervisor Dr. Alan Fung for his valuable suggestions and helpful support throughout the time and development of this research. Also, I would like to thank Dr. David Naylor and Dr. Wey Leong for their time and willingness to guide and provide the technical support. Without their motivation, immense help and interest, I would not be able to accomplish the dissertation successfully.

My special thanks to Dr. Mark Rosen from UOIT for his supports and contributions on publishing a journal paper from Chapter 3 of this thesis.

I would like to thank the Natural Sciences and Engineering Research Council (NSERC) of Canada and the NSERC Smart Net-Zero Energy Building Strategic Research Network (SNEBRN) for their financial support of this research.

Lastly, but most importantly, I would like to thank my wife Roya for her encouragement and support during the production of this thesis. 


\section{Dedication}

My work is dedicated to my wife (Roya) and my daughters (Kathy, Kimia, and Kiana). 


\section{Table of Contents}

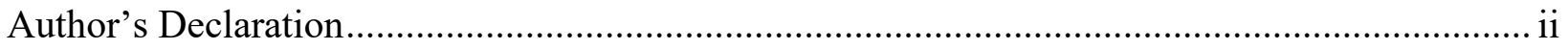

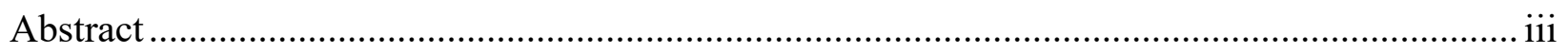

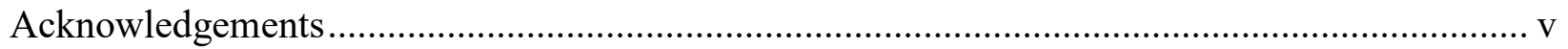

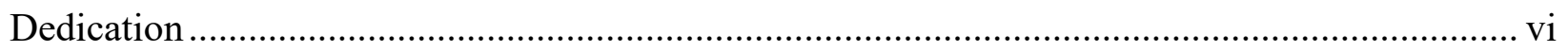

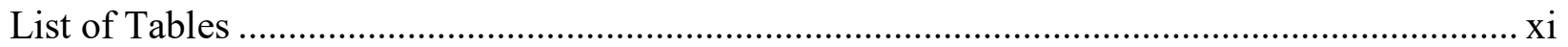

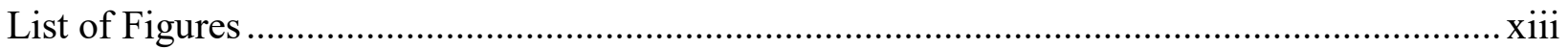

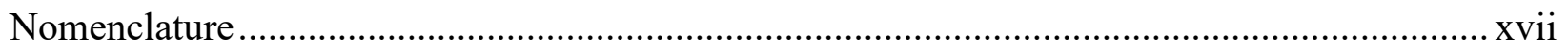

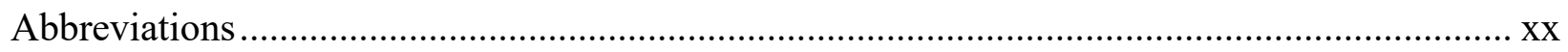

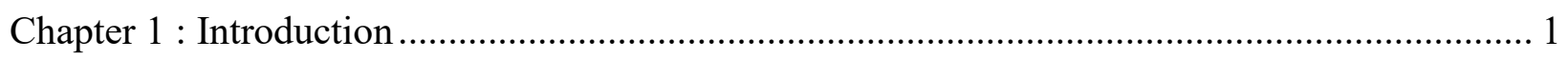

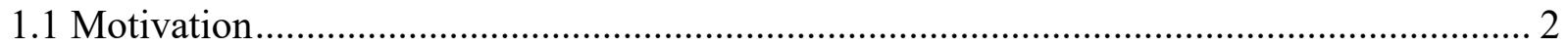

1.2 Purpose and goal of the research ………………......................................................... 3

1.3 Scope of work and approach to research ........................................................................ 3

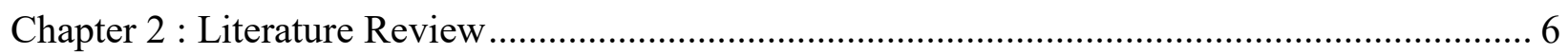

2.1 Solar communities with Seasonal Thermal Energy Storage (STES) …………….............. 6

2.1.1 Underground seasonal thermal energy storage technologies................................ 7

2.1.1.1 Hot water thermal energy storage (HWTES)............................................... 8

2.1.1.2 Gravel-water thermal energy storage (GWTES) ……………………............ 9

2.1.1.3 Aquifer thermal energy storage (ATES) ....................................................... 11

2.1.1.4 Borehole thermal energy storage (BTES) …………………......................... 12

2.1.1.5 Comparison of the storage concepts ……………………............................ 13

2.1.2 BTES - high, medium, and low temperature design .......................................... 14

2.1.2.1 Field experiences with BTES................................................................. 20

2.2 Solar communities with cooling systems ................................................................... 22

2.2.1 Examples of installation of solar assisted cooling system ..................................... 25 


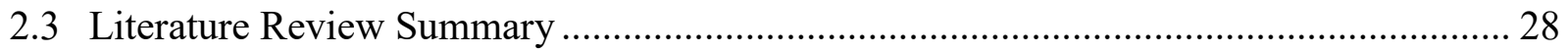

Chapter 3 : Solar Community Heating System with Borehole Thermal Energy Storage.............. 29

3.1 System configuration and community thermal load ....................................................... 30

3.2 System major equipment configuration and model ........................................................ 34

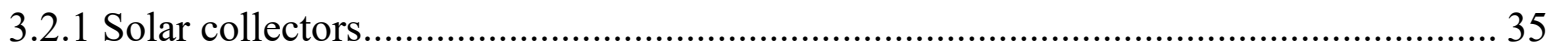

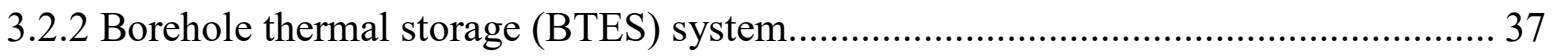

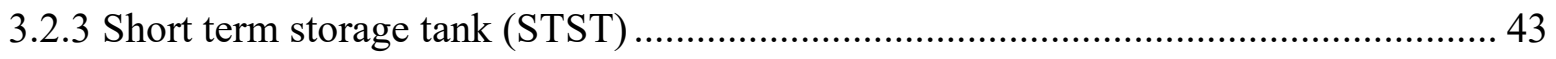

3.2.4 Heat exchangers and pumps................................................................................ 46

3.2.5 Backup boiler and climate data............................................................................. 46

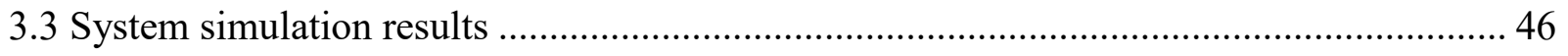

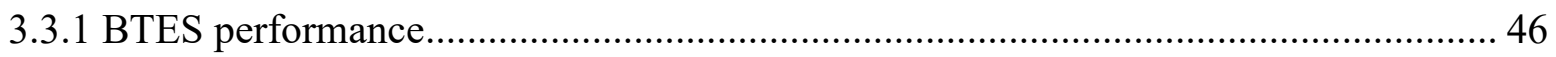

3.3.2 System energy and performance ........................................................................... 48

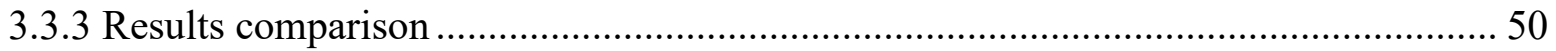

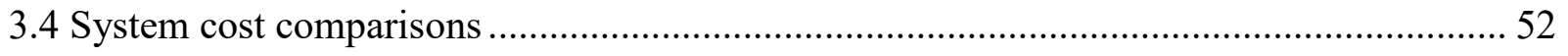

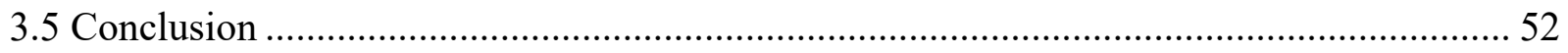

Chapter 4 : Combined Heating and Cooling System for a Solar Community with Borehole

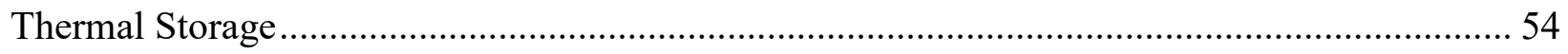

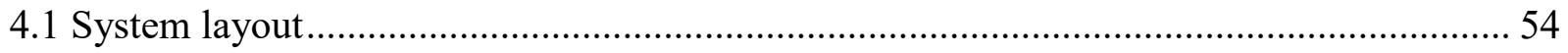

4.2 The community heating and cooling load......................................................................... 57

4.3 System major equipment and methodology ...................................................................... 58

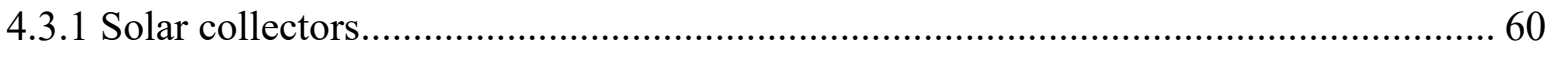

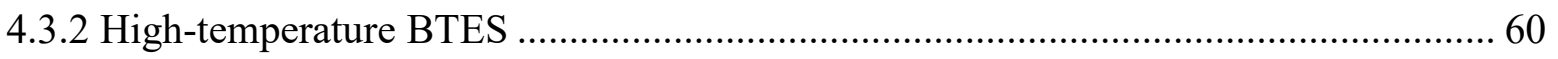

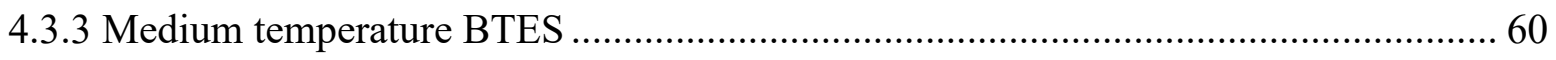

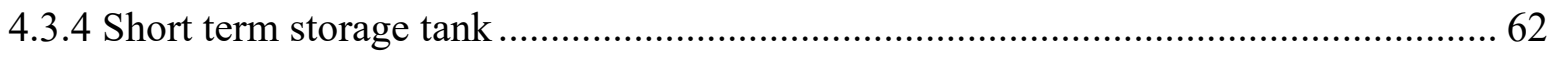

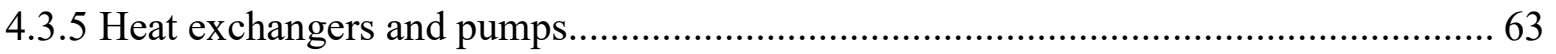




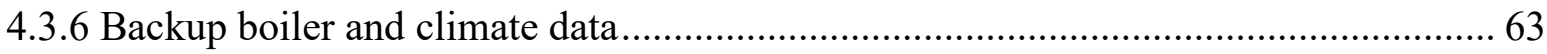

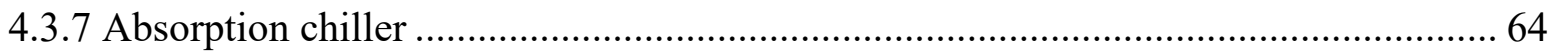

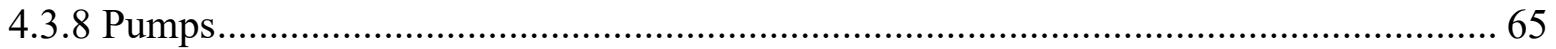

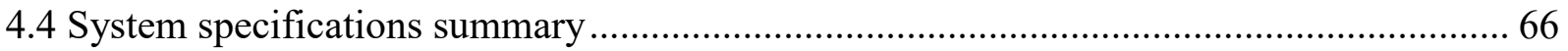

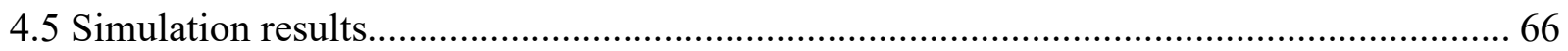

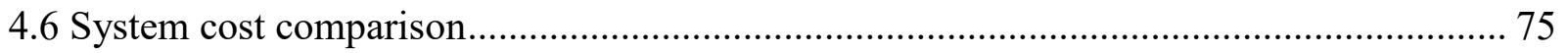

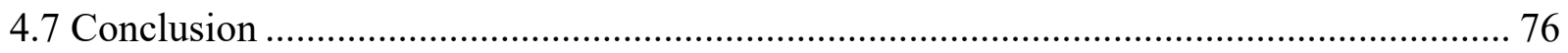

Chapter 5 : Community Heating and Cooling with the Central Heat Pump and Borehole Thermal

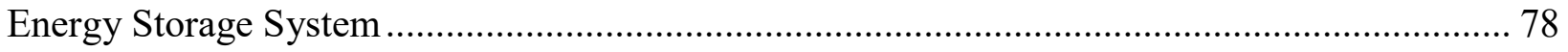

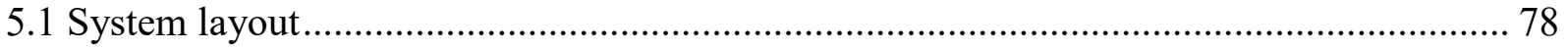

5.2 The community heating and cooling load.................................................................... 79

5.3 System major equipment and methodology ………......................................................... 80

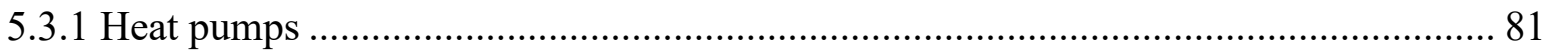

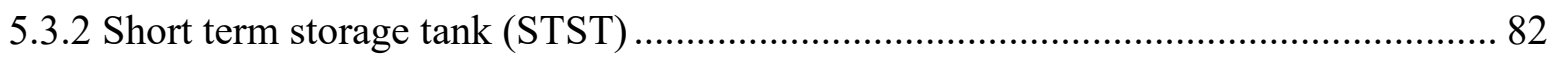

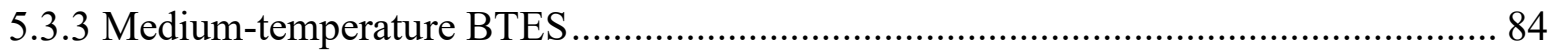

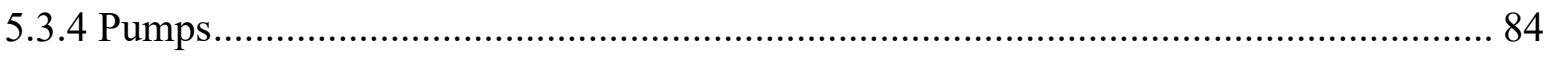

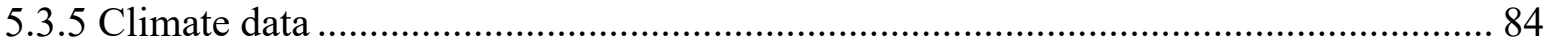

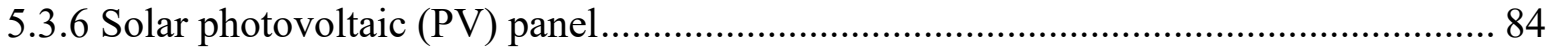

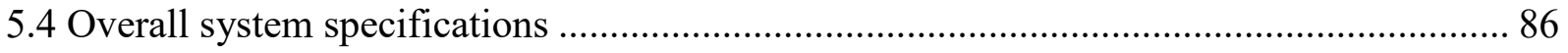

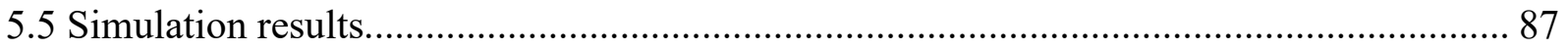

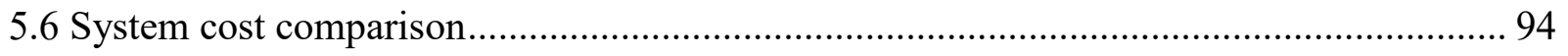

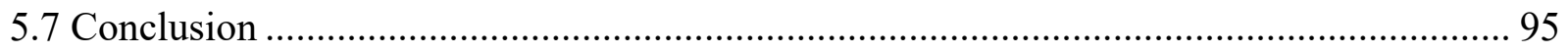

Chapter 6 : Solar Community Heating and Cooling System with Central Heat Pump and

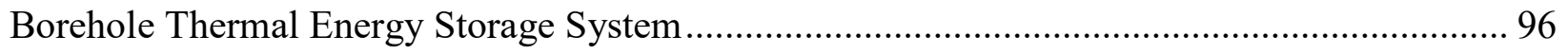

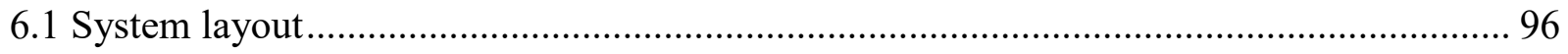

6.2 The community heating and cooling load........................................................................... 99 


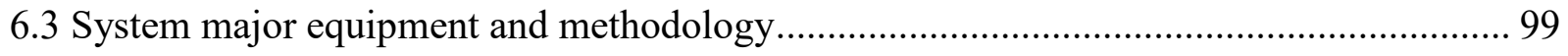

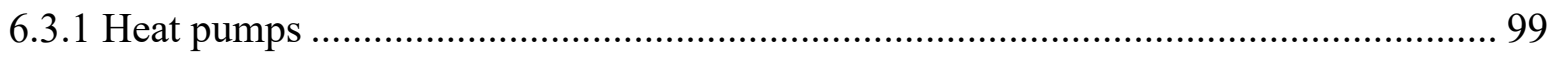

6.3.2 Heat pump short term storage tank (HP-STST) ................................................. 101

6.3.3 Solar short term storage tank (Solar-STST) ...................................................... 101

6.3.4 Medium-temperature BTES (HP-BTES) .................................................... 102

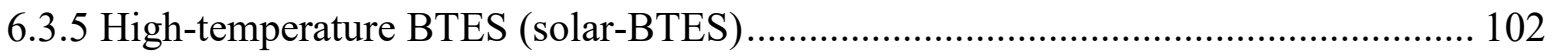

6.3.6 Solar thermal collectors ........................................................................ 102

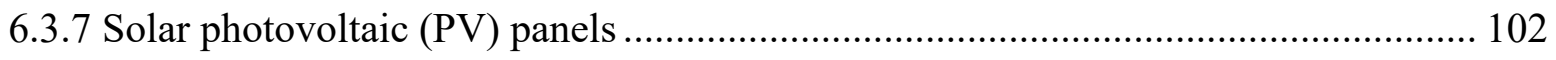

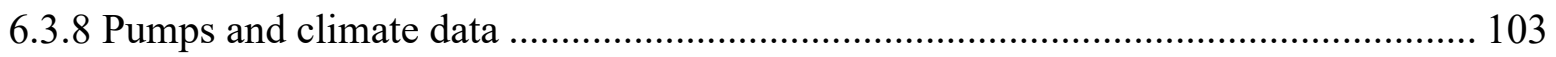

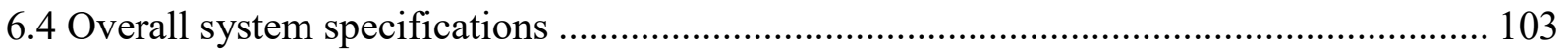

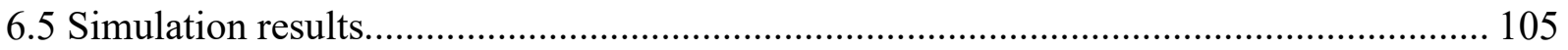

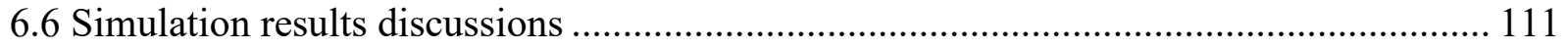

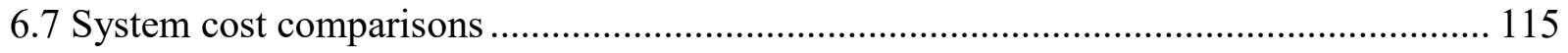

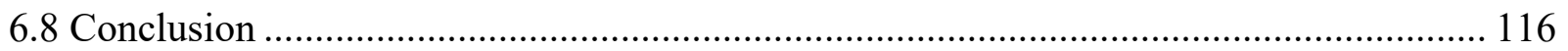

Chapter 7 : Conclusions and Future Work................................................................... 118

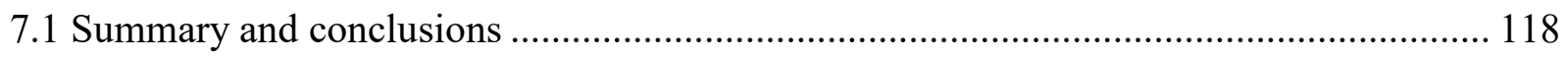

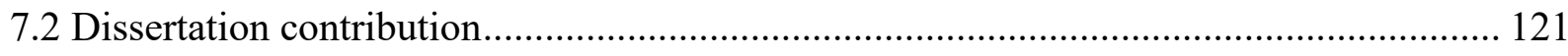

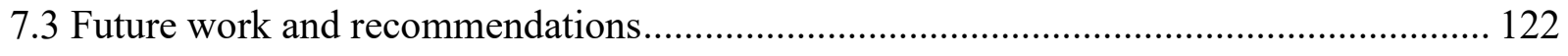

Appendix A: Solar thermal collector manufacturer data sheets ......................................... 124

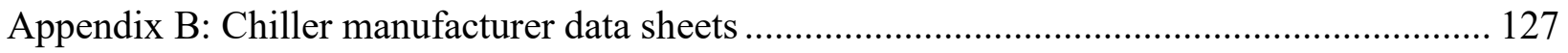

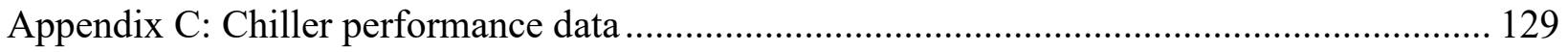

Appendix D: Heat pump manufacturer data sheets ...................................................... 207

Appendix E: Heat pump performance data................................................................. 216

Appendix F: Photovoltaic panel manufacturer data sheets ............................................. 228

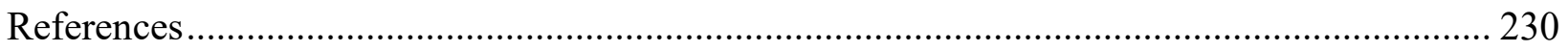




\section{List of Tables}

Table 2-1 Thermal and physical properties of water vs. gravel-water (Pavlov et al., 2011)....... 10

Table 2-2 Hot water thermal energy storage (HWTES) vs. gravel-water thermal energy storage

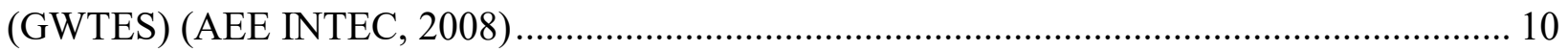

Table 2-3 Comparison of storage concept (Schmidt et al., 2003) ............................................ 14

Table 2-4 Examples of Swedish BTES (Nordell et al., 2000) ............................................... 20

Table 2-5 Central heating plant with BTES (Pavlov et. al., 2011) ......................................... 21

Table 2-6 Examples of solar cooling commercial projects in Europe (Delorme at al., 2004).... 26

Table 3-1 DLSC building envelope features .................................................................... 32

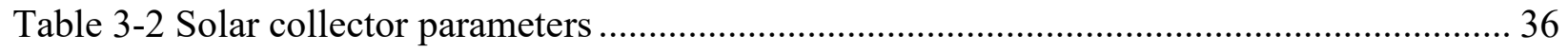

Table 3-3 Ground loop heat exchanger parameters ............................................................ 42

Table 3-4 Short Term Storage Tank (STST) parameters ..................................................... 45

Table 3-5 Year one and year two simulation summary ..................................................... 50

Table 3-6 Year three to year five simulation summary ................................................... 50

Table 3-7 System specifications summary …............................................................. 51

Table 3-8 Comparison of costs for the DLSC and proposed systems ................................. 52

Table 4-1 Chiller ground loop heat exchanger parameters - Type 557................................ 61

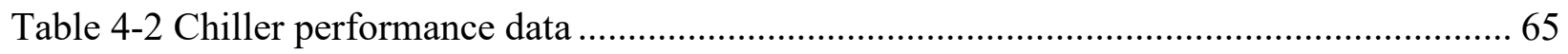

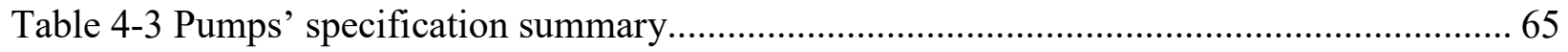

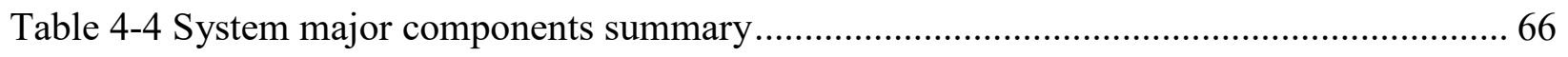

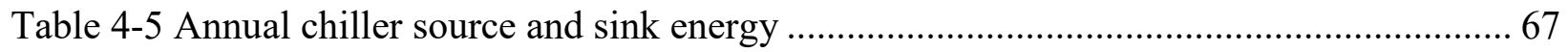

Table 4-6 Annual maximum and minimum ground temperatures ....................................... 69

Table 4-7 Solar-BTES and chiller-BTES annual energy ............................................... 71 


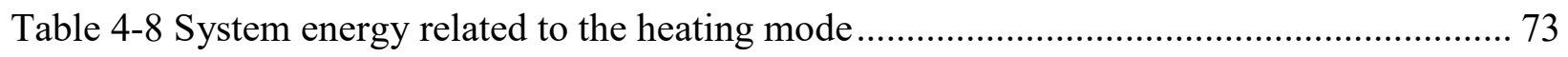

Table 4-9 Annual pumping energy consumptions for the year-one and the year-five ............... 75

Table 4-10 Solar-thermal-chiller (STC) system cost comparison with the DLSC and modified

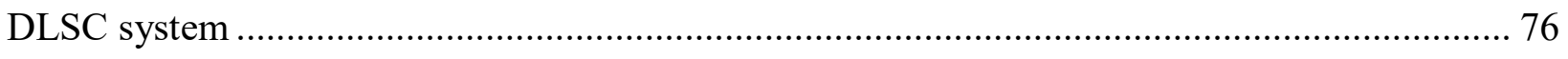

Table 5-1 Individual heat pump specifications by the manufacturer..................................... 81

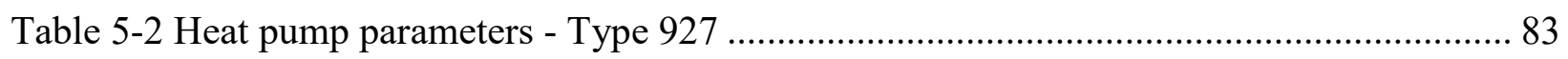

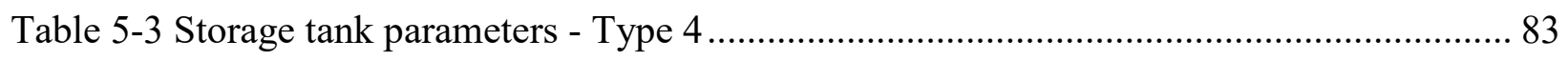

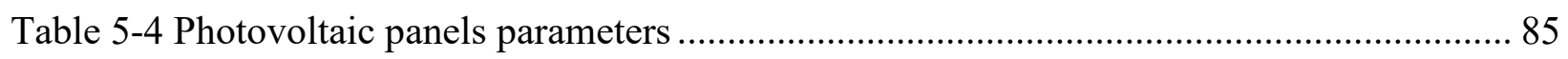

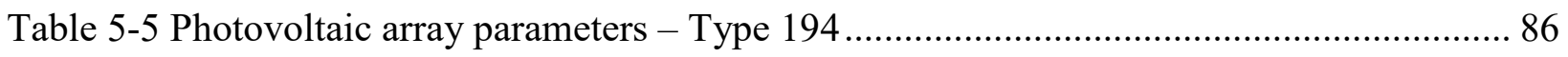

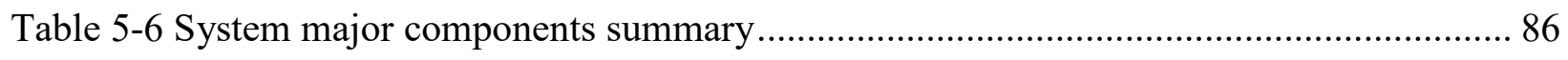

Table 5-7 Annual heat pumps energy and performance ............................................... 88

Table 5-8 Minimum, maximum and average ground temperatures and temperature swing ........ 90

Table 5-9 Heat pump system cost of the DLSC and modified DLSC systems ........................ 94

Table 6-1 Pump specification summary ................................................................... 103

Table 6-2 ST-HPPV system major components summary ............................................. 104

Table 6-3 Annual heat pumps energy and performance of ST-HPPV system ....................... 106

Table 6-4 Community heating and cooling load scenarios............................................... 112

Table 6-5 COPs - Community heating and cooling load scenarios ..................................... 112

Table 6-6 Annual pumping energy - ST-HPPV system .............................................. 114

Table 6-7 Electricity and PV panel requirements for the different scenarios ........................ 115

Table 6-8 ST-HPPV system overall COPs ............................................................... 115

Table 6-9 Cost comparisons of different proposed heating and cooling systems................... 116 


\section{List of Figures}

Figure 1-1 Research scope and modeling process flowchart.................................................. 5

Figure 2-1 Central solar heating plant with seasonal storage (Schmidth et al., 2003) ................... 7

Figure 2-2 Different types of seasonal sensible thermal energy storage solutions (Socaciu, 2011)

Figure 2-3 Construction of hot water heat stores in Friedrichshafen (left) and Hannover (right)

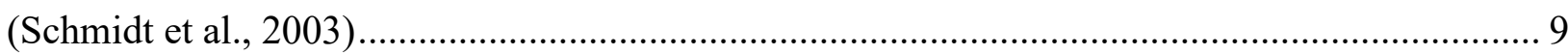

Figure 2-4 Gravel and water store used in Steinfurt (Schmidt et al., 2003) ................................. 10

Figure 2-5 Aquifer thermal energy storage (Socaciu, 2011) .................................................... 11

Figure 2-6 Different types of borehole heat exchangers (Schmidt et al., 2003) ........................... 13

Figure 2-7 Physical ways to convert solar radiation into cooling (Henning, 2007) ...................... 24

Figure 2-8 COP curves of sorption chillers (Henning, 2007 and Grossman, 2002) ..................... 24

Figure 2-9 Operation of the solar cooling system installed at the University Hospital in Freiburg

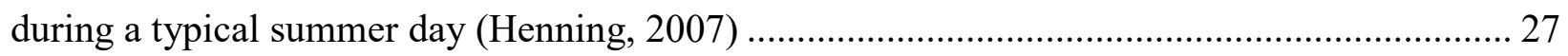

Figure 3-1 Drake Landing Solar Community (DLSC) simplified system schematic .................... 30

Figure 3-2 Solar community heating system with BTES - simplified system schematic.............. 31

Figure 3-3 Simulated community hourly heating load - DLSC replicate …………................... 32

Figure 3-4 Simulated community monthly heating demand - DLC replicate............................... 33

Figure 3-5 Time of the day heating load in the month of January (simulated) ............................. 33

Figure 3-6 Solar community heating system with BTES - TRNSYS model schematic................ 34

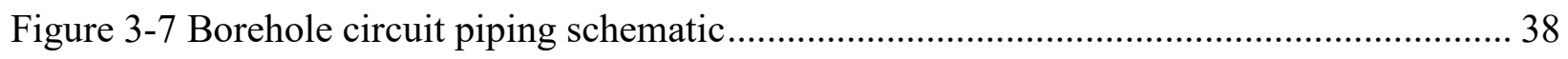

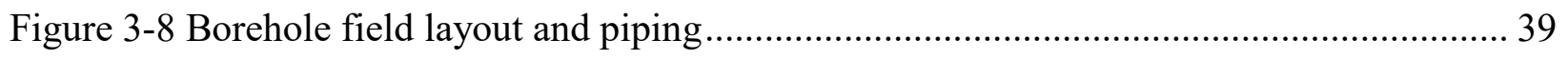

Figure 3-9 Representation of energy flows into a tank's node .................................................... 43 
Figure 3-10 Simplified schematic of short term storage tank. 45

Figure 3-11Annual BTES system accumulated energy and average temperature. 47

Figure 3-12 Annual accumulated thermal energy injected into and extracted from the BTES .... 48

Figure 3-13 Five-year annual accumulated system energy................................................ 49

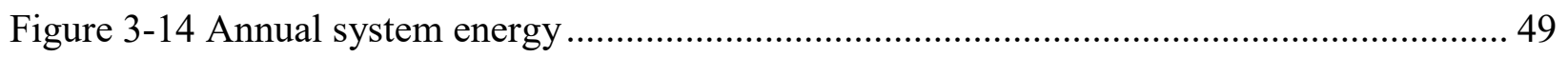

Figure 3-15 Solar fraction comparison, DLSC vs. proposed system................................... 51

Figure 4-1 Overall system schematic - Solar community space heating and cooling system with

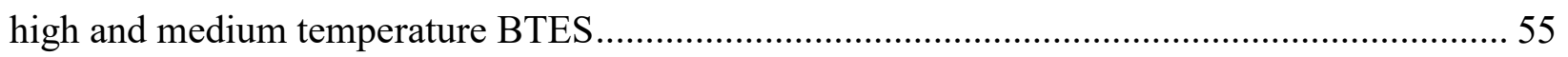

Figure 4-2 System schematic- Solar community space heating and cooling system with high and medium temperature BTES - Heating mode................................................................... 56

Figure 4-3 System schematic- Solar community space heating and cooling system with high and

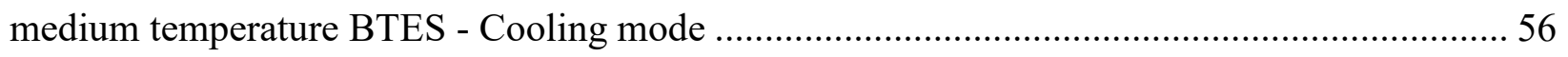

Figure 4-4 Community hourly heating and cooling load ............................................... 57

Figure 4-5 Community monthly heating and cooling demand ........................................5

Figure 4-6 TRNSYS heating and cooling model schematic ............................................ 59

Figure 4-7 Short Term Storage Tank - simplified schematic ............................................ 63

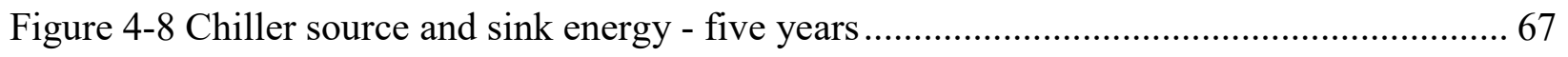

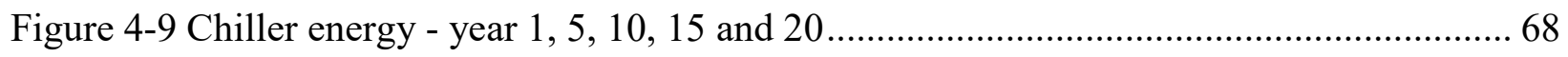

Figure 4-10 Solar and chiller BTES average hourly ground temperature - twenty years ........... 69

Figure 4-11 Solar-BTES and chiller-BTES annual energy comparison ................................ 71

Figure 4-12 Annual system accumulated energy, heating - five years ................................. 72

Figure 4-13 System energy comparison related to heating mode........................................ 72

Figure 4-14 Community Solar Fraction (SF) in heating and cooling mode ............................ 74 
Figure 4-15 Annual pumping energy comparisons for the year-one and the year-five...... 74

Figure 5-1 Overall system schematic - HPPV system ...................................................... 79

Figure 5-2 TRNSYS heat pump heating and cooling model schematic - HPPV system............ 80

Figure 5-3 Heat pump accumulated annual energy - five years ......................................... 87

Figure 5-4 Heat pumps' energy in heating mode - year 1, 5, 10, 15 and 20........................ 88

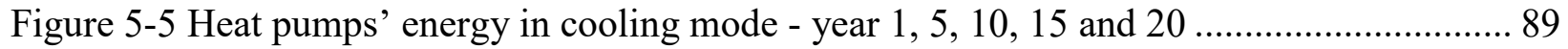

Figure 5-6 Annual accumulated pumping energy of the heat pumps' hydronic loops ............... 90

Figure 5-7 BTES hourly average ground temperature - twenty years .................................. 91

Figure 5-8 Minimum, maximum and average ground temperature - twenty years .................. 91

Figure 5-9 BTES hourly inlet and outlet fluid temperature and average ground temperature ..... 92

Figure 5-10 Annual PV system hourly and cumulative electricity generation......................... 93

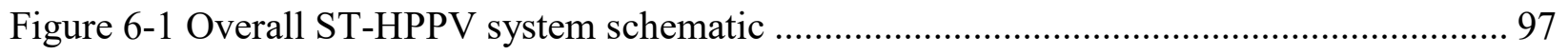

Figure 6-2 ST-HPPV system schematic in cooling mode ............................................. 98

Figure 6-3 ST-HPPV system schematic in heating mode............................................... 98

Figure 6-4 TRNSYS solar thermal-heat pump-PV (ST-HPPV) model schematic ................... 100

Figure 6-5 Solar Thermal Short Term Storage Tank (solar-STST) - simplified schematic ....... 101

Figure 6-6 Heat pumps' energy - heating mode - ST-HPPV vs. HPPV (BC) ........................ 106

Figure 6-7 Heat pumps' energy - cooling mode - ST-HPPV vs. HPPV (BC) ........................ 107

Figure 6-8 Heat pumps COPs - ST-HPPV vs. HPPV (BC) ........................................... 107

Figure 6-9 Heat pumps hourly COPs - ST-HPPV system - five years ................................ 108

Figure 6-10 Heat pumps COPs - HPPV system as the Base Case (BC) - five years ................ 108

Figure 6-11 Solar energy generation and solar-BTES In/Out energy - twenty years ............... 109

Figure 6-12 Solar and heat pump BTES average ground temperature - twenty years ............. 110 
Figure 6-13 Heat pump BTES average ground temperature - solar thermal heat pump (ST-

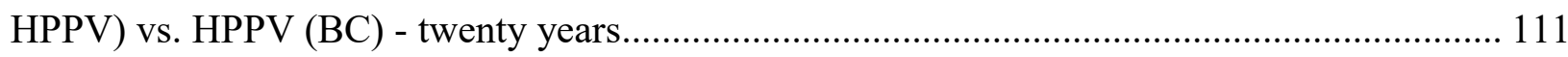

Figure 6-14 Heat pump COPs in reduced community cooling loads - heating mode............... 113

Figure 6-15 Heat pump COPs in reduced community cooling load - cooling mode ................ 113 


\section{Nomenclature}

$\mathrm{A}_{\mathrm{c}, \mathrm{i}} \quad$ cross-section area of node i segment $\left(\mathrm{m}^{2}\right)$

$A_{s, i} \quad$ surface area of node i segment $\left(\mathrm{m}^{2}\right)$

$\mathrm{C}_{\mathrm{p}} \quad$ tank fluid specific heat $(\mathrm{J} / \mathrm{kgK})$

C volumetric heat capacity of soil $\left(\mathrm{J} / \mathrm{m}^{3} \mathrm{~K}\right)$

$\mathrm{D}_{\mathrm{T}} \quad$ thermal moisture diffusivity $(\mathrm{kg} / \mathrm{msK}), \mathrm{D}_{\mathrm{T}}=\mathrm{D}_{\mathrm{TL}}+\mathrm{D}_{\mathrm{TV}}$

$\mathrm{D}_{\mathrm{TL}} \quad$ thermal water diffusion $(\mathrm{kg} / \mathrm{msK})$

$\mathrm{D}_{\mathrm{TV}} \quad$ thermal vapour diffusion $(\mathrm{kg} / \mathrm{msK})$

$\mathrm{D}_{\mathrm{T}}{ }^{*} \quad$ thermal moisture diffusivity in freezing soil $(\mathrm{kg} / \mathrm{msK})$

$\mathrm{D}_{\theta} \quad$ isothermal moisture diffusivity $(\mathrm{kg} / \mathrm{msK}), \mathrm{D}_{\theta}=\mathrm{D}_{\theta \mathrm{L}}+\mathrm{D}_{\theta \mathrm{V}}$

$\mathrm{D}_{\theta \mathrm{L}} \quad$ water diffusion caused by moisture gradient $(\mathrm{kg} / \mathrm{msK})$

$\mathrm{D}_{\theta \mathrm{V}} \quad$ vapour diffusion caused by moisture gradient $(\mathrm{kg} / \mathrm{msK})$

$\mathrm{D}_{\theta}{ }^{*} \quad$ isothermal moisture diffusivity in freezing soil $(\mathrm{kg} / \mathrm{msK})$

$\mathrm{d}_{\mathrm{i}}, \mathrm{d}_{\mathrm{o}}$ inside and outside diameter of heat exchanger tubes (m)

$h_{o} \quad$ outside convection coefficient for internal heat exchanger $\left(\mathrm{W} / \mathrm{m}^{2} \mathrm{~K}\right)$

$\mathrm{H}_{\mathrm{L}} \quad$ specific evaporation enthalpy of water $(\mathrm{J} / \mathrm{kg})$

K soil hydraulic conductivity $(\mathrm{m} / \mathrm{s})$

$\mathrm{K}^{*} \quad$ soil hydraulic conductivity in freezing soil $(\mathrm{m} / \mathrm{s})$

$\mathrm{L} \quad$ latent heat of vaporization of water $(\mathrm{kJ} / \mathrm{kg})$

$\mathrm{L}_{f} \quad$ latent heat of fusion of water $(\mathrm{kJ} / \mathrm{kg})$

$\mathrm{k}_{\mathrm{u}} \quad$ unsaturated water conductivity $(\mathrm{m} / \mathrm{s})$

$\mathrm{M}_{\mathrm{i}} \quad$ mass of node $\mathrm{i}(\mathrm{kg})$

$\dot{\mathrm{m}}_{1 \text { in }}$ mass flowrate entering at inlet $1(\mathrm{~kg} / \mathrm{s})$

$\dot{\mathrm{m}}_{\text {2in }}$ mass flowrate entering at inlet $2(\mathrm{~kg} / \mathrm{s})$

$\dot{\mathrm{m}}_{\text {lout }}$ mass flowrate leaving at outlet $1(\mathrm{~kg} / \mathrm{s})$

$\dot{\mathrm{m}}_{\text {2out }}$ mass flowrate leaving at outlet $2(\mathrm{~kg} / \mathrm{s})$

$\dot{\mathrm{m}}_{\text {down }}$ bulk fluid flowrate down the tank $(\mathrm{kg} / \mathrm{s})$

$\dot{\mathrm{m}}_{\text {up }}$ bulk fluid flowrate up the tank $(\mathrm{kg} / \mathrm{s})$

$\mathrm{n}$ normal outward direction

$\mathrm{q}_{\mathrm{adv}}$ advection heat gain due to rainfall (W) 


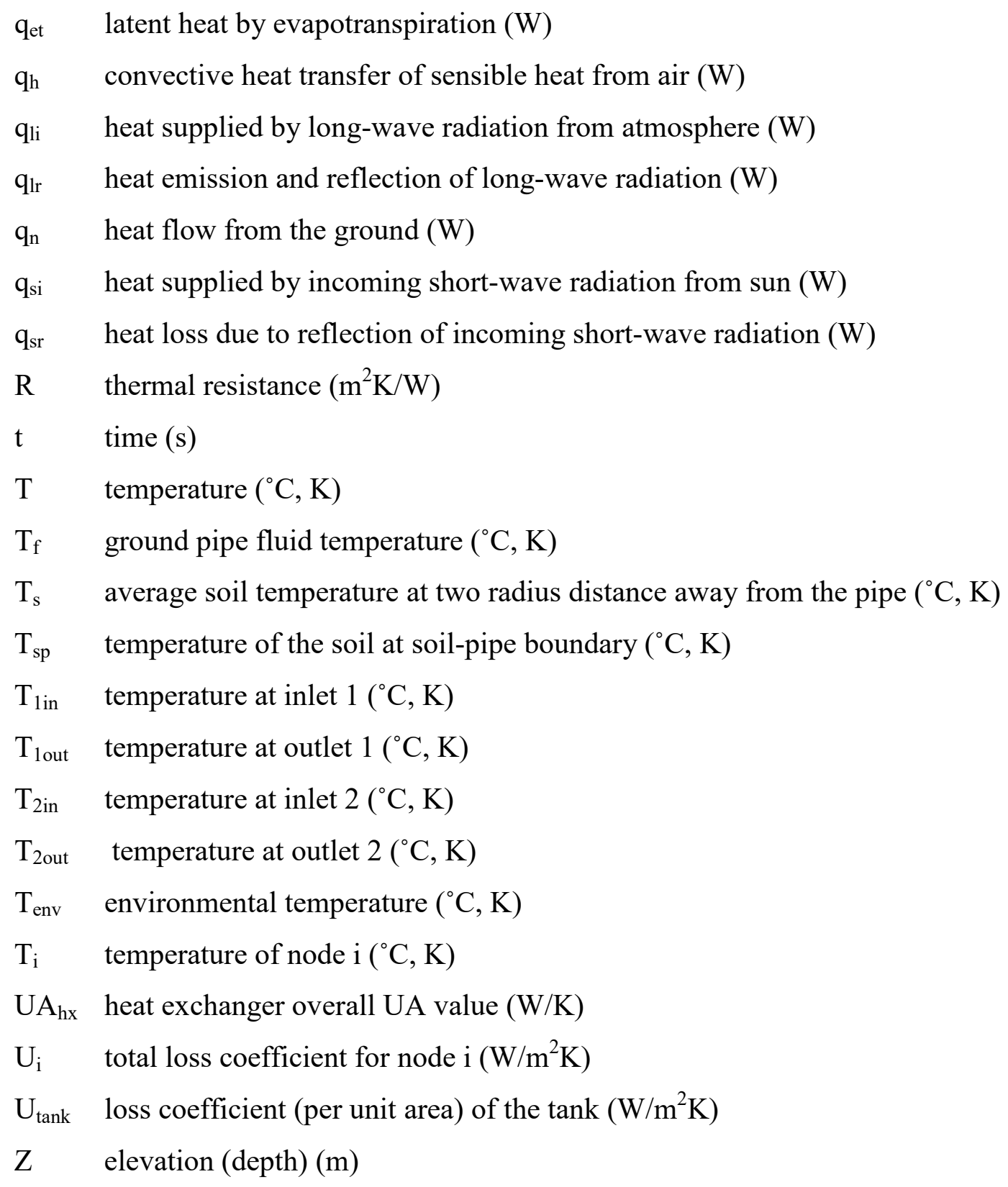

\section{Greek symbols}

$\varepsilon \quad$ phase conversion factor

$\Phi$ total potential for moisture flow

$\lambda$ thermal conductivity of soil $(\mathrm{W} / \mathrm{mK})$

$\theta \quad$ volumetric moisture content $\left(\mathrm{m}^{3} / \mathrm{m}^{3}\right)$

$\rho \quad$ density $\left(\mathrm{kg} / \mathrm{m}^{3}\right)$

$v_{\text {et }} \quad$ flux density of evapotranspiration $\left(\mathrm{kg} / \mathrm{m}^{3} \mathrm{~s}\right)$ 
$v_{\mathrm{m}} \quad$ snow melt water flux $\left(\mathrm{kg} / \mathrm{m}^{3} \mathrm{~s}\right)$

$v_{\mathrm{n}} \quad$ moisture flux from ground $\left(\mathrm{kg} / \mathrm{m}^{3} \mathrm{~s}\right)$

$v_{\mathrm{r}} \quad$ flux density of rainfall $\left(\mathrm{kg} / \mathrm{m}^{3} \mathrm{~s}\right)$

$\Delta \mathrm{k} \quad$ de-stratification conductivity $(\mathrm{W} / \mathrm{mK})$

$\Delta \mathrm{x}_{\mathrm{i}+1 \rightarrow \mathrm{i}}$ center to center distance between node " $\mathrm{i}$ " and the node below it (i+1)

$\Delta \mathrm{x}_{\mathrm{i}-1 \rightarrow \mathrm{i}}$ center to center distance between node " $\mathrm{i}$ " and the node above it (i-1)

$\underline{\text { Subscripts }}$

$\begin{array}{ll}\text { c } & \text { cooling } \\ \text { co } & \text { convective } \\ \text { f } & \text { frozen } \\ \text { i } & \text { ice } \\ \text { l } & \text { liquid } \\ \text { pf } & \text { partly frozen } \\ \text { pw } & \text { pipe wall } \\ \text { s } & \text { soil } \\ \text { tc } & \text { contact at soil-pipe interface } \\ \text { v } & \text { vapour }\end{array}$




\section{Abbreviations}

AGT

ASHRAE

ATES

$\mathrm{BC}$

BTES

CHP

COP

CWEC

DLSC

DST

ESTTP

FCL

FDM

GHEADS

GWTES

HDPE

HFL

HP

HPPV

HP-STST

HWTES

IAM

IEA

$\mathrm{LiBr}$

$\mathrm{MW}_{\text {th }}$

NRCan

PV

QCL

SF

SSTES
Average Ground Temperature

American Society of Heating, Refrigeration and Air-Conditioning Engineers Aquifer Thermal Energy Storage

Base Case

Borehole Thermal Energy Storage

Combined Heat and Power

Coefficient of Performance

Canadian Weather Year for Energy Calculation

Drake Landing Solar Community

Duct Storage Model

European Solar Thermal Technology Platform

Full Cooling Load

Finite Difference Method

Ground Heat Exchanger Analysis Design and Simulation

Gravel Water Thermal Energy Storage

High-Density Polyethylene

Half Cooling Load

Heat Pump

Heat Pump Photovoltaic

Heat Pump Short Term Storage Tank

Hot Water Thermal Energy Storage

Incident Angle Modifier

International Energy Agency

Lithium Bromide

Megawatt-thermal

Natural Resources Canada

Photovoltaic

Quarter Cooling Load

Solar Fraction

Sensible Seasonal Thermal Energy Storage 
ST

STC

ST-HPPV

STST

TRNSYS

VGHE
Solar Thermal

Solar Thermal Chiller

Solar Thermal Heat Pump Photovoltaic

Short Thermal Storage Tank

TRanNsient SYstem Simulation Program

Vertical Ground Heat Exchanger 


\section{Chapter 1 : Introduction}

There is a significant demand to accelerate the development and implementation of advanced clean energy technologies for solving the existing challenges of the energy crisis, climate change, and sustainable processes. Solar heating and cooling technologies are a real clean energy solution. Solar heat can substantially contribute to the world's energy needs. In 2009, International Energy Agency (IEA) reported that "global energy demand for heat represented $47 \%$ of the final energy used, higher than the final energy for electricity (17\%) and transportation (27\%) combined." The IEA technology roadmap (2012) for solar heating and cooling predicts that, by 2050 , more than $16 \%$ of total final energy use for low-temperature heat $\left(<100^{\circ} \mathrm{C}\right)$ and $17 \%$ of total energy used for cooling, will come from solar sources. Therefore, solar thermal energy will become a necessary and important part of the future energy mix for heating and cooling. Based on the European Solar Thermal Technology Platform (ESTTP, 2007) report, in a renewable heating and cooling portfolio, solar thermal (ST) has the following specific benefits:

1) ST always helps to reduce primary energy consumption;

2) ST can be used as a hybrid with almost all kinds of backup heat sources;

3) ST is a source of renewable heat and cooling technologies and relies on a relatively inexhaustible resource;

4) ST can reduce electricity demand, which could reduce investments and increase power generation and transmission capacities;

5) ST could be used nearly everywhere with some limitation at very high latitudes;

6) ST prices are predictable and do not depend on the future of other energy prices such as oil, gas, biomass, or electricity prices; and

7) The life-cycle environmental impact of ST systems is extremely low.

Therefore, solar thermal could be the absolute best option for satisfying the long-term heating and cooling energy demands.

According to the ESTTP report (2007), around 9\% of the total heating needs in Europe are provided by community and district heating systems. In district heating systems, solar thermal energy can be generated on a large-scale with relatively low specific costs. Solar assisted 
district energy system has been proven to be viable in high latitudes as well, such as in Sweden, Denmark, and Canada.

In Europe, on a large-scale, the first solar heating plants were constructed 30 years ago, and the first solar cooling plants were constructed over ten years ago. From 1979 to the middle of 2011, 141 heating and 13 cooling plants were built which all have more than $500 \mathrm{~m}^{2}$ solar collector area or greater than $350 \mathrm{~kW}$ nominal thermal power (Dalenback and Werner, 2012).

The development started two decades ago when large-scale systems began to be built in a number of countries. The solar heating plants need large collector areas. Therefore, the market for large-scale solar collectors has been increasing since 2007 despite a modest increase in such plants per year. The largest plants for solar district heating are located in Denmark (13 $\left.\mathrm{MW}_{\text {th }}\right)$ and Sweden $\left(7 \mathrm{MW}_{\mathrm{th}}\right)$.

In communities where solar thermal collectors are part of heating and cooling systems, thermal energy storage is normally used. Since the solar heat production varies during the days in a year, diurnal storage is one solution to store heat when there is no need for the heat from the solar collectors.

\subsection{Motivation}

Numerous studies have been done on solar district energy systems with thermal storage which are mainly either for heating or cooling only. A combined heating and cooling system which could have both systems integrated together has not yet been addressed. There are questions about the viability of such a system with the integration of two seasonal thermal storage systems at different temperatures, i.e., one seasonal thermal storage system to store thermal energy harvested from the sun and another to store rejected heat from the cooling system. The interaction and control of the two storage units at different temperatures would also be a challenge, and is not clear how to extract the maximum thermal energy out of the storage to use it for the community heating and cooling demand. There is thermally driven cooling equipment that is commercially available in the market, and there are challenges to integrating a suitable system into the heating system. A control system, to optimize the operation on a community-scale, needs to be designed and tested too.

Additionally, a low-temperature heat source, suitable for the use with heat pumps for the solar communities is another option for the heating and cooling system. In this scheme, the source energy production for the heat pumps and its related storage system will be smaller in 
size, compared to the other systems. This could make the entire system more financially feasible while not compromising the energy efficiency of the system.

\subsection{Purpose and goal of the research}

The main objective of this thesis is to investigate the viability of combined solar heating and cooling systems at the community level by modeling, simulation, and energy analysis. An existing heating-only solar community is modeled, and the results are compared with the published performance data. The modeled community system is for the heating-only and is used as the base case for adding a cooling component. Two scenarios for adding a cooling system to the proposed community are presented. One uses an absorption chiller as the cooling component which receives its source heat from the sun and its supplemented heat from a natural gas boiler. The second scenario uses a heat pump system that rejects heat into the borehole thermal storage system in the cooling season and receives source heat from the stored solar energy and summer's rejected heat during the heating season.

\subsection{Scope of work and approach to research}

The thesis is presented in seven chapters as follows:

1- Chapter 2 covers a comprehensive literature review on solar communities with different storage systems and provides the advantages and disadvantages of each type. Existing works on solar cooling systems are also investigated.

2- In Chapter 3, a TRNSYS model on an existing solar community (for heating only) is developed, and the simulation results are compared with the actual field performance results.

3- Chapter 4 presents an integrated model for the solar community's heating and cooling by adding an absorption chiller as a cooling component to the current heating-only model.

4- In Chapter 5, by using the same selected community heating and cooling load, a new system with a geo-exchange heat pump powered by PV is modeled. This system functions without solar thermal integration. Other than investigating the viability of such a system, this model will be used to develop a new model with a solar thermal integration. 
5- Chapter 6 presents a solar community with a central heat pump system. The heat pumps receive their source energy from the harvested solar energy that has a lower temperature source compared to the case with the absorption chiller. In the cooling mode, the heat rejected from the heat pumps is stored in a borehole system and is used in the heating mode in conjunction with the solar thermal storage system.

6- Chapter 7 summarizes the main results plus the conclusion of the work and suggestions for future work.

Figure 1-1 represents the flowchart for the overall scope and the modeling steps of this research. 


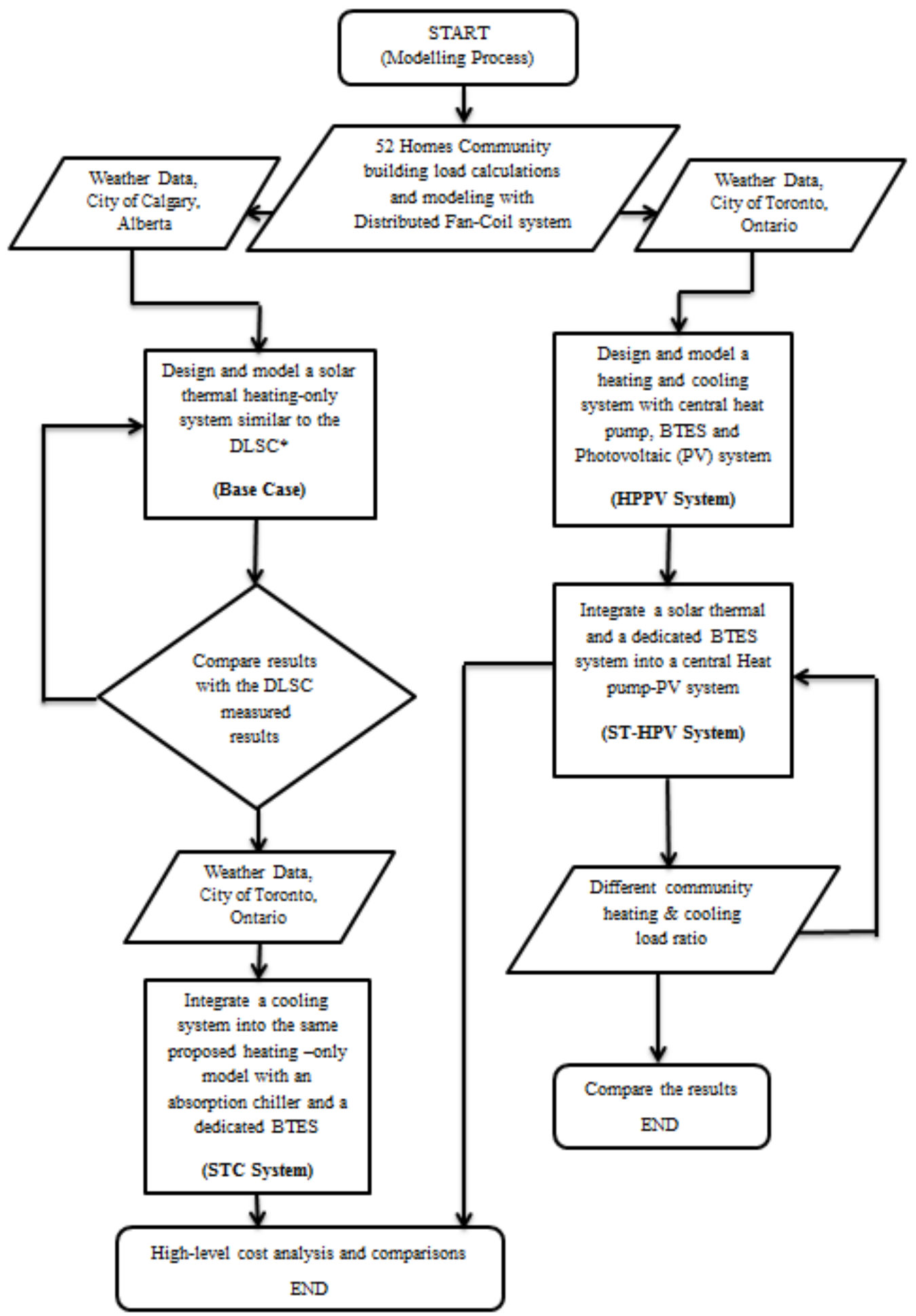

Figure 1-1 Research scope and modeling process flowchart 


\section{Chapter 2 : Literature Review}

\subsection{Solar communities with Seasonal Thermal Energy Storage (STES)}

At the community scale, when solar thermal collectors are used during a season or a year, there is the inconsistent availability of the solar energy which could be used for the heating or cooling system. There are times that solar irradiation is not needed, or thermal energy production is more than the demand. In order to capture the thermal energy produced during the unwanted time, thermal energy storage would be a solution as an integrated part of the district energy system. The thermal energy stored could be used during the time when the solar fraction is low, like winter time or during the nights. Thermal storage helps to utilize the maximum solar energy harvested in a year. It also could balance the community energy demand versus thermal heat generation through solar collectors. In the Combined Heat and Power (CHP) system, thermal energy storage could decouple the thermal production from the electricity production. While the CHP system generates heat and electricity simultaneously, the unwanted or surplus heat production can be stored and saved for the time when the thermal energy is required (Schmidt and Miedaner, 2012).

Since 1970, seasonal thermal storage technology, as part of a district heating system, has been under exploration and study. The purpose of all investigations and studies are storing heat at the time that it is not needed and use it for the time that it is required. Schmidt et al. (2003) had a detailed review in the advances of seasonal thermal energy storage in Germany. Based on his research, with referencing to Dalenback (1988) and Lundin (1985), the first solar plant was constructed in Sweden in 1978/79. Several countries participated in central solar heating plants with seasonal storage working group under the International Energy Agency (IEA) Task VII, since 1979. The aim of this group was to boost the progress of large-scale solar heating technologies like district heating systems. Under this working group participant members exchanged their experiences and shared their activity results. In Germany, the first seasonal heat storage was built at the University of Stuttgart in 1985. The storage at this facility was a gravelwater heat store type (Hahne, 2000). Figure 2-1 shows the system schematics. Solar heat is collected by a large area of solar collectors and is then transferred to the central heating plant. The excess heat from solar collectors, in summer, is directed to the thermal storage. In heating 
season, the stored heat will be directed to the central plant to supply to the district heating system.

Following this project, "Solarthermie-2000," a governmental program in Germany was introduced for researching solar heating plants with large seasonal thermal energy storage since 1993. Eight of such plants have been built in Germany for demonstration within "Solarthermie2000" since 1996. They were all designed for 35- 60\% solar fractions of the total heat demand for space heating and domestic hot water of homes annually (Schmidt et al., 2001).

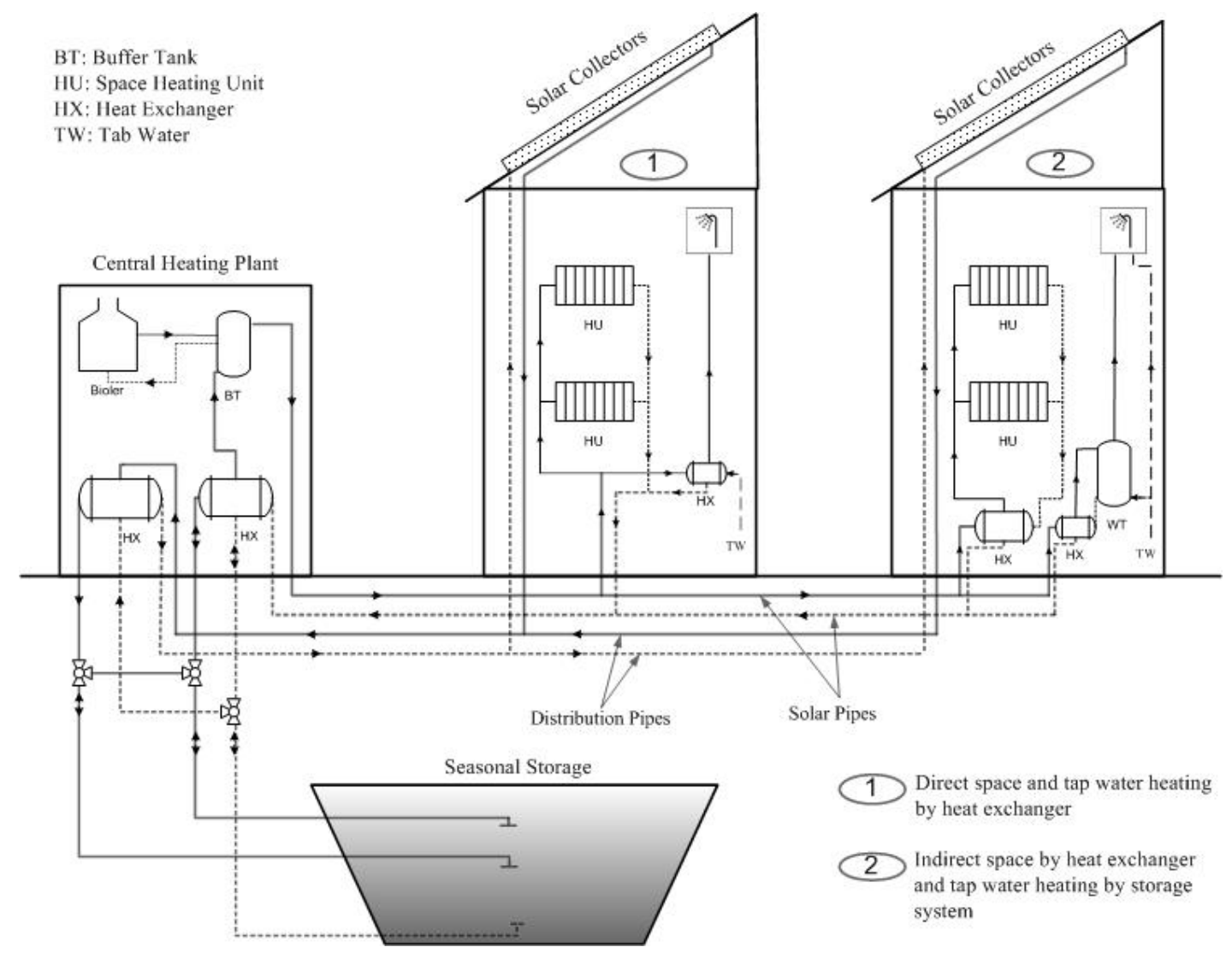

Figure 2-1 Central solar heating plant with seasonal storage (Schmidth et al., 2003)

\subsubsection{Underground seasonal thermal energy storage technologies}

Usually, seasonal thermal energy storage stores heat in a sensible form. For finding the heat transfer and mainly losses through the storage, the main parameters which need to deal with, are thermal properties of the storage medium, time of storage, storage temperature, storage geometry, and volume. In community and district solar-energy heat-storage, the storage volumes 
are relatively large; therefore, ground storage, due to their lower cost and ability to deal with large time scale, make this technology the most-promising medium (Nordell, 2000).

Schmidt et al. (2003), and later many other researchers including Pavlov et al. (2011) and Socaciu (2011), introduced four types of sensible seasonal thermal energy storage (SSTES). They are 1) hot-water thermal energy storage, 2) aquifer thermal energy storage, 3) gravel-water thermal energy storage, and 4) borehole thermal energy storage. Socaciu (2011), after his rigorous research, presented the four types of SSTES relations as shown in Figure 2-2 and created a detailed documentation.

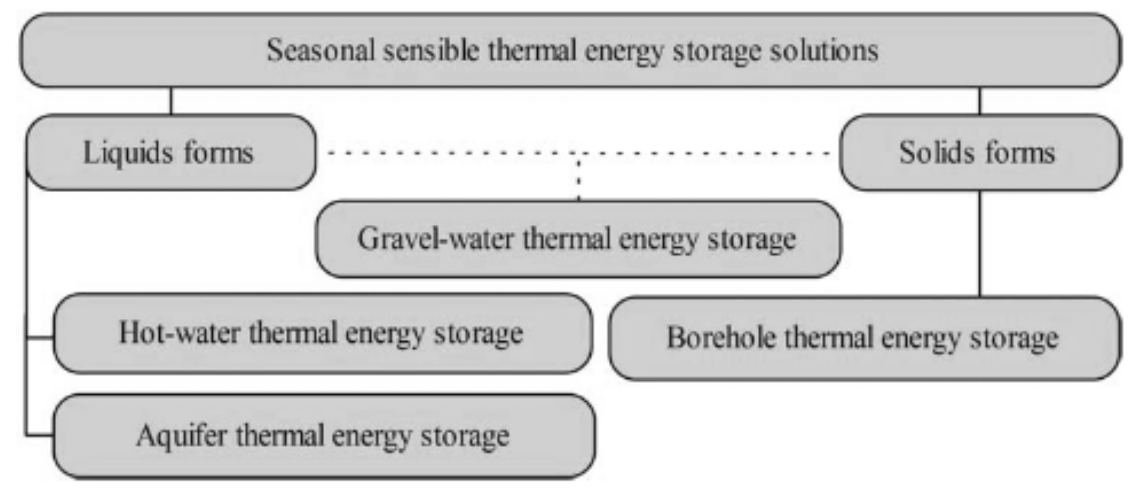

Figure 2-2 Different types of seasonal sensible thermal energy storage solutions (Socaciu, 2011)

\subsubsection{Hot water thermal energy storage (HWTES)}

HWTES is built almost independently from geological conditions; the storage is usually constructed from reinforced concrete or steel. The storage media is water, which has good value for specific heat capacity and heat transfer properties for charging and discharging (Schmidt et al., 2003).

Figure 2-3 shows two methods that were used in HWTES construction in Friedrichshafen and Hannover (Schmidt et al., 2003). The Hannover storage was built recently with a new highdensity concrete. The store is free of an inner steel-liner.

In Friedrichshafen storage, which is older than Hannover model, there are only two locations at top and bottom for charging and discharging whereas, in the Hannover model, another point of charging or discharging has been introduced. This point is located at one-third distance from the top of the storage medium and provides an optimized flexibility for using different water temperatures at various layers of the stratified store. In the Hannover store, a granulated foam glass in textile bags is used for insulation. This kind of insulation material, 
compared to the standard mineral wool, has an excellent drying capability plus easier and faster installation work. As high-density concrete is not able to prevent steam diffusion, a layer of the steam barrier is installed between insulation and concrete layer.
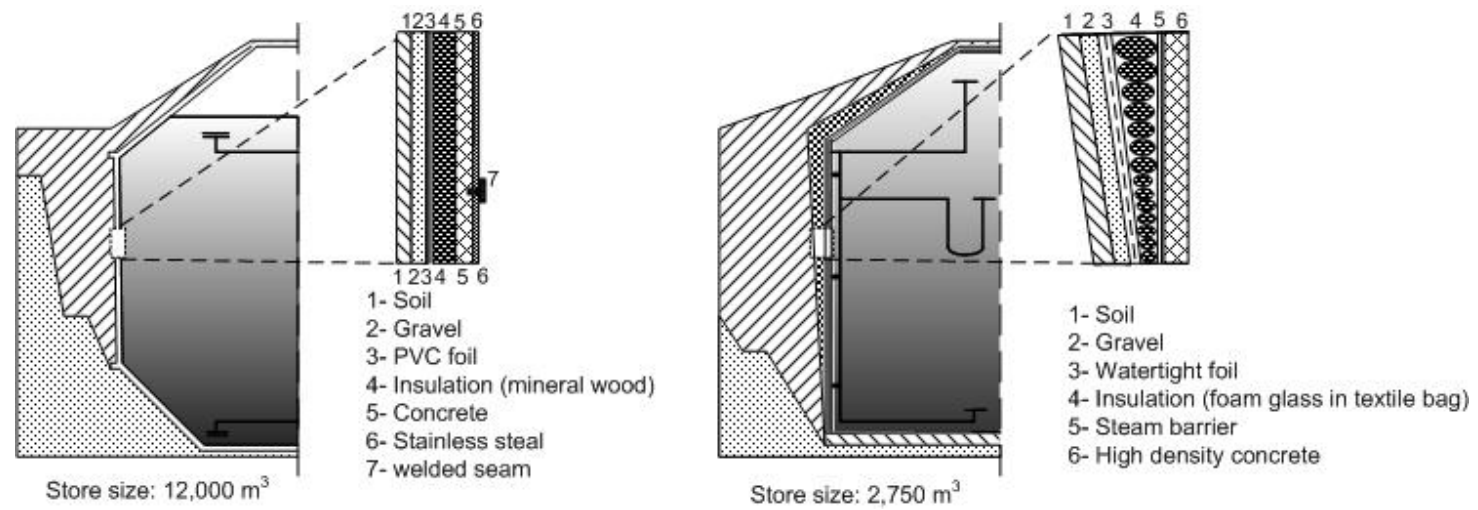

Figure 2-3 Construction of hot water heat stores in Friedrichshafen (left) and Hannover (right) (Schmidt et al., 2003)

\subsubsection{Gravel-water thermal energy storage (GWTES)}

Gravel-water thermal storage is a less-expensive version of tank storage, which is usually buried in the ground. These kinds of storage are mostly insulated on the side and the top. The storage media are usually a gravel and water mixture, which it could also be sand or soil mixture with water. Heat extraction or injection could be either through direct water heat exchanger or by indirect heat transfer through piping installed at a different layer of the store. The pipes, in this case, are made of plastic for their longevity. The storage liner is usually made of advanced polymer material backed up with insulation. Because of the construction material used, the operating temperature is limited to not higher than $95^{\circ} \mathrm{C}$ (Nielsen, 2003). The specific heat of this type of store media is lower than the water, and subsequently, the store size should be constructed approximately $50 \%$ bigger to store the same amount of heat compared to the water storage tanks (Schmidt et al., 2003 and 2004).

Figure 2-4 shows a cross-section of a GWTES, which has been constructed in Steinfurt, Germany. It consists of a double polypropylene (PP) liner, steam barrier, granulated foam glass insulation and drainage system. The liners are equipped with a vacuum control system for detecting any leakage during the construction or operation (Schmidt et al., 2003). 
Table 2-1 shows the thermal and physical properties of storage media for the HWTES and GWTES (Pavlov et al., 2011). Table 2-2 lists the advantages and disadvantages of the two systems, especially when the store is made below places where safety on the top of the storage is concerned; i.e., parking lot, schoolyard, etc. (AEE INTEC, 2008).

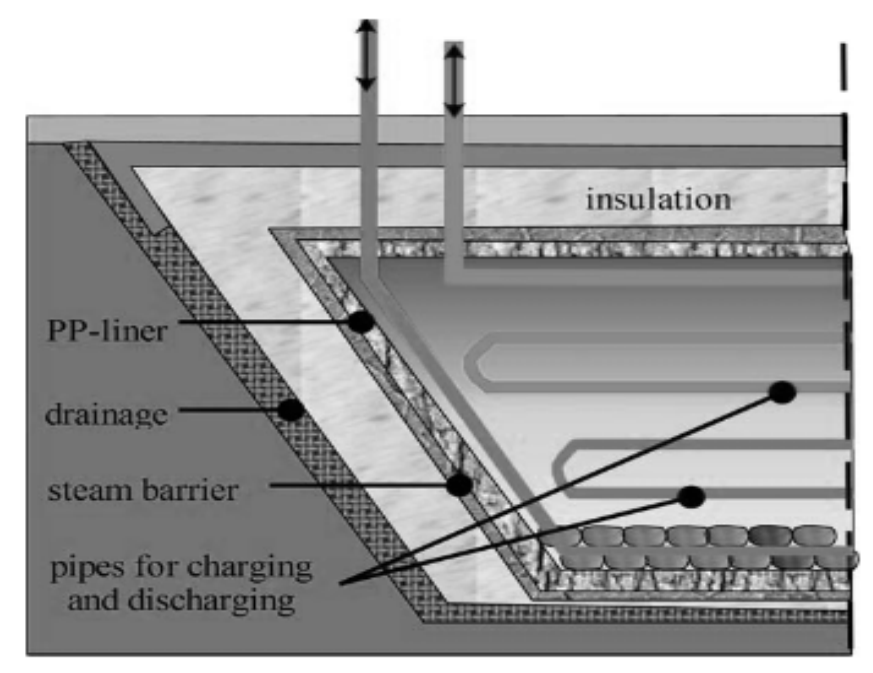

Figure 2-4 Gravel and water store used in Steinfurt (Schmidt et al., 2003)

Table 2-1 Thermal and physical properties of water vs. gravel-water (Pavlov et al., 2011)

\begin{tabular}{|l|c|c|}
\cline { 2 - 3 } \multicolumn{1}{c|}{} & $\begin{array}{c}\text { Water } \\
\left.\text { (at } 20^{\circ} \mathrm{C}\right)\end{array}$ & $\begin{array}{c}\text { Gravel-Water } \\
\text { Mixture }\end{array}$ \\
\hline Porosity & - & 0.37 to 0.43 \\
\hline Density $\left[\mathrm{kg} / \mathrm{m}^{3}\right]$ & 992.2 & 1950 to 2050 \\
\hline Specific Heat Capacity $[\mathrm{kJ} /(\mathrm{kgK})]$ & 4.18 & 2.0 to 2.2 \\
\hline Thermal Conductivity $[\mathrm{W} /(\mathrm{mK})]$ & 0.63 & 1.8 to 2.5 \\
\hline
\end{tabular}

Table 2-2 Hot water thermal energy storage (HWTES) vs. gravel-water thermal energy storage (GWTES) (AEE INTEC, 2008)

\begin{tabular}{|l|l|}
\hline \multicolumn{1}{|c|}{ HWTES } & \multicolumn{1}{c|}{ Advantages } \\
\hline Thermal capacity & Low static requirements to cover the loads \\
\hline Operation characteristic & Simple store cover \\
\hline Thermal stratification & \\
\hline Maintenance and repair & \\
\hline \multicolumn{2}{|c|}{ Disadvantages } \\
\hline Sophisticated and expensive store cover & Lower thermal capacity \\
\hline High static requirements to cover loads & Charging system \\
\hline Cost of removing the excavated soil & Additional buffer storage \\
\hline & Maintenance and repair not possible \\
\hline & Gravel cost \\
\hline
\end{tabular}




\subsubsection{Aquifer thermal energy storage (ATES)}

Aquifers are recognized as a porous media saturated with water which the media could be sand, gravel, sandstone, igneous or metamorphic rock (Sanner, 1999). If the aquifers are confined, meaning that there is low water flow (or no flow), then they could be used as a thermal storage. For injecting or extracting heat to the storage media, two or several wells are drilled to the aquifer. During the charging, water is extracted from the aquifer, is then heated through a heat exchanger before being sent back to the aquifer through another well which is located at some distance from the supply well. At the discharging time, the flow is reversed from the two mentioned wells. Figure 2-5 shows a typical ATES system. In order to get the most benefit from the heat storage, all the physical and chemical parameters of the aquifer should be investigated. In the high-temperature storage understanding the microbiology, geochemistry and mineralogy of the ground will play an important role in thermal storage design.

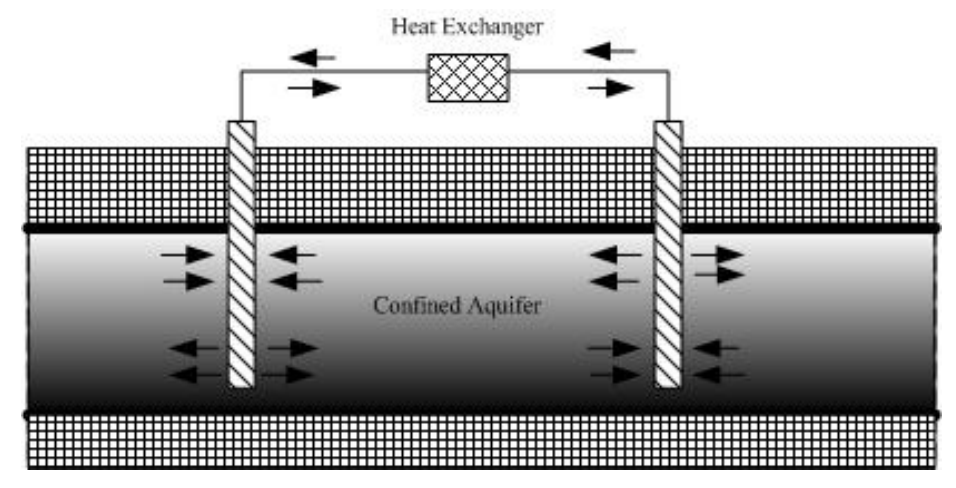

Figure 2-5 Aquifer thermal energy storage (Socaciu, 2011)

The heat loss from the ATES could be substantial, especially for the high-temperature storage media. In order to have a minimum heat loss, the surface to volume ratio or the storage media should be as low as possible. This would apply in particular for storage volume with more than $100,000 \mathrm{~m}^{3}$ (Schmidt et al., 2003). As an example, there is an ATES in Germany, located in Berlin that supplies to the German parliament building. It has two separate storages: 1) a cold storage in depth about $60 \mathrm{~m}$, and 2) a heat storage in depth below $300 \mathrm{~m}$ (Sanner, 1999).

Ghaebi et al. (2014) studied the integration of various ATES with heat pump and solar collectors for heating and cooling of a community. They found that the system annual coefficient of performance (COP) would increase when the ATES is used for both heating and cooling. 


\subsubsection{Borehole thermal energy storage (BTES)}

In borehole thermal energy storage (BTES), the ground itself would be the storage media. This would be achieved through a number of vertical boreholes in the ground. The storage volume is not exactly defined and separated. Geological formation plays a major role in defining the thermal capacity of the storage. Normally rock or water-saturated soil is the most suitable. The vertical boreholes lengths are typically in the range of 30 to $100 \mathrm{~m}$ with approximately 3 to 4 m separation (Schmidt et al., 2003). The borehole depths in recent installations have gone up to $200 \mathrm{~m}$ (Pavlov et al., 2011). In the borehole, the heat is exchanged through a double or single Upipes or concentric pipes. The pipe material is usually made of synthetic material like highdensity polyethylene (HDPE). Figure 2-6, shows borehole heat exchangers sample installation. The fluid in the pipes is mostly water which in some cases, to avoid freezing, the water is mixed with ethanol or glycol. The boreholes are filled with grout which normally is of bentonite, quartz with sand or only water mixture (Northern Europe). Quartz gives the grout a higher thermal conductivity whereas the bentonite provides a sealing and plugging characteristic. The grouted boreholes heat transfer properties have been studied theoretically by Bennet et al. (1987) and Hellstorm (1991), tested in laboratory measurements by Paul (1996) and field measurements by Austin (1998). The range of thermal conductivity of the typical filling material is: stagnate water $(0.6 \mathrm{~W} / \mathrm{mK})$, Bentonite $(0.8-1.0 \mathrm{~W} / \mathrm{mK})$, thermally enhanced grout with quartz $(1.0-1.5 \mathrm{~W} / \mathrm{mK})$, and water saturated quartz sand $(1.5-2.0 \mathrm{~W} / \mathrm{mK})$.

The storage volume of BTES comparing to the HWTES is much bigger in size.

Depending on the ground formation, BTES size should be three to five time higher than the HWTES (Pavlov et al., 2011). For instance for a BTES with a cylindrical earth volume of 35,000 $\mathrm{m}^{3}$ that contains 144 boreholes with the $38 \mathrm{~m}$ depth, the equivalent HWTES storage volume of $8,700 \mathrm{~m}^{3}$ can be used. Un-used or rejected heat is injected through hot fluid circulation in the boreholes and transferred to the ground for the storage. BTES works in seasonal and periodic mode. When the stored heat is needed, the cold fluid is circulated and absorbing the heat which is required. The best and most efficient BTES is with high thermal conductivity adjacent to the boreholes and pipes and less formation thermal conductivity away from the storage volume with no ground water flow (Evans et al., 2006). Lower formation thermal conductivity away from the storage volume cause less storage heat loss. Claystones or water saturated claystone are suitable media due to the high heat capacity and at the same time prevent considerable water flow. 
The BTES efficiency is defined as the ratio of the annual energy injected into and extract from the ground. The efficiencies of the fully charged BTES in the existing installations are mostly in the range of $40 \%$ to $60 \%$. That means the BTES energy losses are around $60 \%$ to $40 \%$ of the energy injected into the ground.

One advantage of BTES from the other types of the storage system is that the size of the storage can be easily extended by drilling addition boreholes and simply connecting the pipes to the existing boreholes.
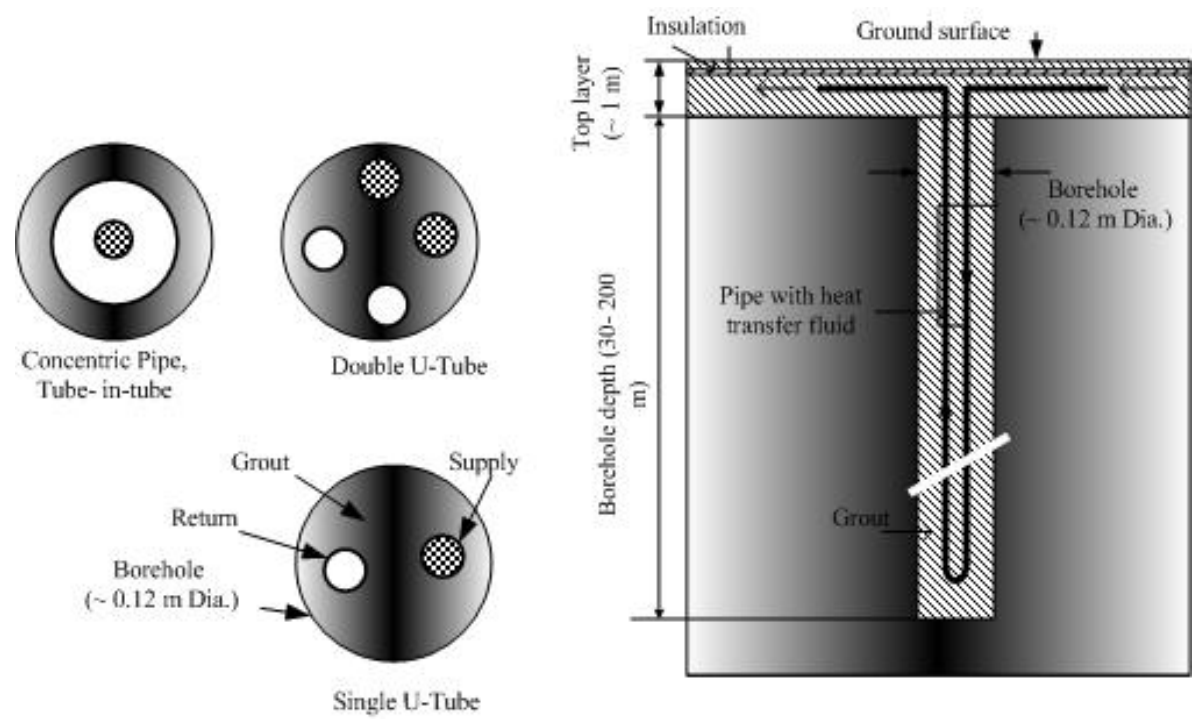

Figure 2-6 Different types of borehole heat exchangers (Schmidt et al., 2003)

\subsubsection{Comparison of the storage concepts}

The cost advantage due to the size and scale of operation is the reason that made most of the thermal storage projects technically and economically viable. For example, BTES is used in heating large district system in Europe since 1990. From that time, Fisch et al. (1998), studied two large-scale solar communities in the heating application. The investigation was on; 1) shortterm thermal storage system to supply $10-20 \%$ of heating demand or $50 \%$ of domestic hot-water use annually, and 2) long-term thermal storage to supply $50-70 \%$ of heating demand annually. In his report, it was concluded that large-scale solar thermal system (seasonal), because of the economy of scale, was three times more economical comparing to the short-term (diurnal) storage, used for just a single-family house.

Since 1993, "Solarthermie-2000," a research and development program in Germany, has been focusing on the study and monitoring of large-scale solar thermal plants. Based on the results of this program, Lottner et al. (2000) explored the economics of such plants. The study 
concluded that because the high cost of the seasonal storage, more efforts should be done to achieve viable systems in both technical and economic aspects. Schmidt et al. (2004) provided an extensive study on the same subject in Solarthermie 2000 program reports and provided some advice about how to design an optimized system to make the system more efficient and economical. Bauer et al. (2010) also explored the monitoring data in the same program. He described the different thermal storage types related to the solar district systems and compared the specific characteristics of different storage types.

Schmidt et al. (2003) presented the key components of various methods for seasonal heat storage which is summarized in Table 2-3. For selecting a specific storage system, all related conditions need to be considered, such as geological requirements, storage size, heat capacities of the storage medium, etc. The final decision should be based on an optimum economical viable case, among all possibilities.

Table 2-3 Comparison of storage concept (Schmidt et al., 2003)

\begin{tabular}{|c|c|c|c|c|}
\hline & HWTES & GWTES & BTES & ATES \\
\hline Storage Meduim & water & gravel-water & ground material & ground material/water \\
\hline Heat Capacity $\left(\mathrm{kWh} / \mathrm{m}^{3}\right)$ & $60-80$ & $30-50$ & $15-30$ & $30-40$ \\
\hline $\begin{array}{l}\text { Storage Volume for } \\
\left(1 \mathrm{~m}^{3} \text { of water equivalant) }\right.\end{array}$ & $1 \mathrm{~m}^{3}$ & $1.3-2 \mathrm{~m}^{3}$ & $3-5 \mathrm{~m}^{3}$ & $2-3 \mathrm{~m}^{3}$ \\
\hline Geological Requirement & $\begin{array}{l}\text { - stable ground } \\
\text { conditions } \\
\text { - preferably no } \\
\text { groundwater } \\
\text { - } 5 \text { - } 15 \mathrm{~m} \text { deep }\end{array}$ & $\begin{array}{l}\text { - stable ground } \\
\text { conditions } \\
\text { - preferably no } \\
\text { groundwater } \\
\text { - } 5-15 \mathrm{~m} \text { deep }\end{array}$ & $\begin{array}{l}\cdot \text { drillable ground } \\
\cdot \text { groundwater favourable } \\
\cdot \text { high heat capacity } \\
\cdot \text { high thermal conductivity } \\
\text { - } \text { low hydraulic conductivity } \\
\cdot \text { natural ground-water flow }<1 \mathrm{~m} / \mathrm{s} \\
\cdot 30-100 \mathrm{~m} \text { deep }\end{array}$ & $\begin{array}{l}\text { - natural aquifer layer with high hydraulic } \\
\text { conductivity } \\
- \text { confining layers on top and below } \\
\text { - no or low natural groundwater flow } \\
\text { - suitable water chemistry at high } \\
\text { temperatures } \\
\text { - aquifer thickness } 20-50 \mathrm{~m}\end{array}$ \\
\hline
\end{tabular}

\subsubsection{BTES - high, medium, and low temperature design}

In the seasonal thermal energy storage, especially in solar thermal district energy system, there is large amount of energy involved. Therefore, the ground has been found to be a favorable media for storing such large amount of energy with relatively low cost. One of the storage types, which uses the ground directly, is BTES (Nordell et al., 2000).

In BTES, heat transfer process in the ground can be considered from the nearby the boreholes and the surrounding ground collectively. It is also called micro-scale and macro-scale process by Nordell et al. (2000). The heat flow from the store into the surrounding ground is responsible for the store losses. The amount of the heat loss depends on the storage geometry such as its size and shape, the average store temperature and ground properties. The ground 
thermal resistance around the boreholes will also rely on the borehole spacing. The spacing, usually, is considered to be uniform and equally spaced. In reality, irregularity in borehole spacing could happen. A study by Hellstrom (1991), shows that such irregular spacing has a small effect on the ground thermal resistance if the storage volume is kept almost the same.

The storage heat losses will substantially increase if ground water flow exists. This flow could be regional flow and/or flow due to natural convection. Van Meurs (1986) investigated the groundwater flow effect through numerical analysis in a porous medium with the uniform permeability. He concluded that if the ground water flow exceeds $0.05 \mathrm{~m} /$ day $(18 \mathrm{~m} / \mathrm{year})$, then the heat storage volume needs a protecting hydraulic screen. The ground water flow subject to natural convection will happen in the vertical direction. The flow amount due to the buoyancy primarily depends on the temperature difference between the storage and the surrounding medium. Other parameters such as the vertical depth of the store and permeability of ground material will also affect the magnitude of the natural convection flow (Hellstrom et al., 1988).

Lund (1985) and van Den Brink (1993) through numerical studies show that if the intrinsic permeability of the ground exceeds $10^{-12} \mathrm{~m}^{2}$, then the storage thermal performance will be affected. However, the natural convection flow will be reduced if impermeable layers exist in the horizontal direction.

Reuss et al., (1997), defined the seasonal thermal storage in two categories, namely 1) low-temperature $\left(0-40^{\circ} \mathrm{C}\right)$ ground storage and 2$)$ high-temperature $\left(40-80^{\circ} \mathrm{C}\right)$ ground storage. Thermal energy for the community is provided either indirectly by a heat pump with lowtemperature storage or directly with high-temperature storage.. In this research, these two categories have been redefined, and three BTES types have been specified as 1) low-temperature $\left.\left(0-30^{\circ} \mathrm{C}\right) \mathrm{BTES}, 2\right)$ medium-temperature $\left(30-60^{\circ} \mathrm{C}\right) \mathrm{BTES}$ and 3$)$ high-temperature $\left(60-80^{\circ} \mathrm{C}\right)$ BTES.

For stores with a limited thermal conductivity, Reuss et al. (1997) claims that the heat losses from the storage are rather moderate, and the storage efficiency could reach up to $70 \%$. Additionally, a proper heat transfer rate per unit of the area of the heat exchanger pipes is also needed. Consequently, a good thermal contact between the exchanger and the ground is required.

In loose and unconsolidated soil, the heat capacity and thermal conductivity of the ground strongly depend on the water contents, especially when the soil temperature goes beyond $60^{\circ} \mathrm{C}$. 
Soil water content can be lost due to the vapor diffusion and high-temperature gradient. This will lead to dry out the soil and causing cracks along the side of the heat exchanger pipes. Subsequently, the thermal resistance of this region increase and heat transfer rate will decrease. Reuss et al. (1997) studied numerically and experimentally the heat and moisture transfer in BTES in unsaturated soil. High-temperature thermal energy input, in the range of 70 to $90^{\circ} \mathrm{C}$ into the ground can cause a substantial high-temperature gradient and simultaneous moisture flow close to heat exchanger pipes. The total heat transfer is through the conduction in the soil and partly by convection which created by liquid, air and vapor movement.

The theory of soil moisture transfer thermally was developed by Philip and De Vries (1957). This theory was never verified for very high-temperature medium. In their methodology, the effect of the soil temperature on vapor pressure and surface tension is considered. This will be the driving forces for the vapor diffusion and liquid moisture flow. A computer model was developed by Reuss et al. (1997) to model and simulate heat and soil moisture transfer in hightemperature ground heat storage. The model contains two parabolic differential equations with the variables of volumetric moisture content and temperature (Van Genuchten, 1980).

For the moisture transport, Equation (2-1) takes into the account the liquid moisture and vapor movement due to the moisture and thermal gradients. The energy transport Equation (2-2) is based on Fourier's Law and considers the latent heat transport by condensation and evaporation of water within the porous medium.

$$
\begin{aligned}
& \rho_{L} \frac{\partial \theta_{L}}{\partial t}=\nabla\left[\left(D_{T L}+D_{T V}\right) \nabla T\right]+\nabla\left[\left(D_{\theta L}+D_{\theta V}\right) \nabla \theta_{L}\right]+\rho_{L} \frac{\partial k_{u}}{\partial z} \\
& C \frac{\partial T}{\partial t}=\nabla(\lambda \nabla T)+\nabla\left(H_{L} D_{\theta V} \nabla \theta_{L}\right)
\end{aligned}
$$

In this thesis, equations (2-1) and (2-2) are used as the basis for the advance borehole heat transfer calculations for the BTES model, i.e., Type 201 TRNSYS component.

Reuss et al. (1997) developed a numerical model for those differential equations by the finite-difference method (FDM) as a general analytical solution is impossible. In addition, the contact resistance between the pipes and the ground are also included, in order to consider the already mentioned drying effects. The model was validated for an entire temperature range of 0 $90^{\circ} \mathrm{C}$ with the data from several laboratory and field experiments. By using this model and changing the various parameters, a new pilot plant was designed. Subsequently, an optimum system from a technical and economic point was selected. The system was a $15000 \mathrm{~m}^{3}$ seasonal 
storage with 140 boreholes of $30 \mathrm{~m}$ length storing the waste heat $\left(174 \mathrm{~kW}_{\text {th }}\right)$ generated in summer by a combined heat and power (CHP) plant. About $418 \mathrm{MWh} /$ year was charged into and $266 \mathrm{MWh} /$ year was discharged from the storage. The economic analysis shows that prices of specific energy with this system are almost the same as those of conventional energies like liquid-gas while $266 \mathrm{MWh} /$ year of useful energy are recovered. The minimum and maximum mean storage temperatures were $40^{\circ} \mathrm{C}$ and $72^{\circ} \mathrm{C}$, respectively. The storage efficiency was found to be $64 \%$.

Tarnawski and Leong $(1990,1993)$ developed a computer program to simulate the performance of an entire ground source heat pump system. A detailed numerical solution incorporates the following:

1. Simultaneous heat and moisture transfer in ground heat storage. The equations solved by the finite-element method.

2. A steady-state heat pump unit model.

3. The house, heating and cooling loads.

4. Detailed climatological data.

5. A profile of the initial temperature and soil moisture content.

A temperature change of fluid circulating in the closed-loop is calculated by the energy balance and heat transfer between the circulating fluid and surrounding soil. It is assumed that the ground heat storage around the borehole has symmetry along the vertical axis; thus, soil temperature and moisture pattern in ground heat storage are calculated only in the axial and radial directions and change the problem to a two-dimensional problem. The developed computer program can take into account a large number of issues, which are generally ignored for simpler analysis. Main processes which have been addressed in this program are highlighted as follows:

1. In ground, heat-storage coupled heat and moisture flow are considered.

2. During heat extraction and heat injection, soil freezing-thawing and drying-rewetting are regarded.

3. With the presence of the ground water table, different soil types and layers have been taken into the account.

4. Ground-surface effects, i.e., radiation, convection, advection, evapotranspiration and snow cover are considered. 
The following governing equations, describing simultaneous heat and moisture flow, have been used for the ground buried heat exchangers (Tarnawski and Leong 1990, 1993).

\section{$\underline{\text { Unfrozen soil }}$}

$\nabla\left(\lambda^{*} \nabla T\right)+\nabla\left(D_{\varepsilon} \nabla \theta_{l}\right)-c \frac{\partial T}{\partial t}+L \rho_{l} \frac{\partial}{\partial z}(\varepsilon K)=0$

$\nabla\left(\mathrm{D}_{\mathrm{T}} \nabla T\right)+\nabla\left(D_{\theta} \nabla \theta_{l}\right)-\frac{\partial \theta}{\partial t}+\frac{\partial}{\partial z}(K)=0$

where $\lambda^{*}=\lambda+\operatorname{L} \varepsilon \rho_{1} \mathrm{D}_{\mathrm{T}}(\mathrm{W} / \mathrm{mK})$ and $\mathrm{D}_{\varepsilon}=\mathrm{L} \varepsilon \rho_{1} \mathrm{D}_{\theta}$

Freezing soil

$c_{p f} \frac{\partial T}{\partial t}-\mathrm{L}_{f}=\nabla\left(\lambda_{p f}^{*} \nabla T\right)+\nabla\left(\mathrm{D}_{\varepsilon}^{*} \nabla \theta_{l}\right)+L \rho_{l} \frac{\partial}{\partial z}\left(\varepsilon K^{*}\right)$

$\frac{\partial \theta_{l}}{\partial t}+S=\nabla\left(\mathrm{D}_{\mathrm{T}}^{*} \nabla T\right)+\nabla\left(\mathrm{D}_{\theta}^{*} \nabla \theta_{l}\right)+\frac{\partial}{\partial z}\left(K^{*}\right)$

where $\mathrm{D}_{\varepsilon}{ }^{*}=\mathrm{L}_{\varepsilon} \rho_{1} \mathrm{D}_{\theta}{ }^{*}$ and $\mathrm{S}=\frac{\rho_{i}}{\rho_{l}} \frac{\partial \theta_{i}}{\partial t}$

Frozen soil

$c_{f} \frac{\partial T}{\partial t}=\nabla\left(\lambda_{f}^{*} \nabla T\right)$ and $\frac{\partial \theta_{l}}{\partial t}=0$

\section{Boundary condition}

Ground surface:

$\lambda \frac{\partial T}{\partial n}+q_{n}=0$ and $K \frac{\partial \phi}{\partial n}+D_{T} \frac{\partial T}{\partial n}+\frac{v_{n}}{\rho_{l}}=0$

$q_{n}=q_{s r}-q_{s i}+q_{l r}-q_{l i}+q_{e t}-q_{h}-q_{a d v}$ and $v_{n}=v_{e t}-v_{r}-v_{m}$

Ground heat exchanger's soil-pipe boundary (quasi-steady):

$T_{s p}=T_{f}-\left(T_{f}-T_{s}\right) \frac{R_{c o}+R_{p w}+R_{t c}}{R_{c o}+R_{p w}+R_{t c}+R_{s}}$

The soil moisture transport model is obtained from the Philip and De Vries (1957) and Thomas (1985). Field experimental data were provided by Clapp and Hornberger (1978) and Campbell (1985). The ground site condition and weather and climate data, such as solar radiation, ambient temperature, rainfall, wind speed, snow density, snow cover, and water vapor pressure, are used for the boundary conditions at the ground surface simulation. 
The equations (2-3) to (2-13) utilized in the program were created by Tarnawski and Leong $(1990,1993)$ which can model and simulate multiple year operations of a ground source heat pump system in the heating and cooling mode. The computer program is written in FORTRAN 77 and can be run on a broad range of computers.

The computer program has been modified and imported into TRNSYS 16 (Klein, 2004) software as a component Type 201a in 2009 (Leong and Tarnawski, 2010) and is used as a BTES component in a part of the modeling of the systems in this research.

For the thermal analysis of BTES, a number of tools have been developed so far. The main purpose of these tools is to design such complex systems optimally and cost-effectively. The available tools vary from simple design tools to advanced simulation modeling with hourly climate data and detailed load data. The model should consider the relatively large heat flow in the ground and the heat transfer in and adjacent to the boreholes to capture the relation between the temperature of the heat-transfer-fluid and the total storage heat transfer rate with a suitable time resolution (Nordell et al., 2000).

Eskilson and Claesson (1988) proposed a model using finite-difference, a superposition borehole model (SBM), which is a detailed model that can accept arbitrarily placed of vertical or horizontal boreholes. This model is validated and examined in several field experiments (Eskilson, 1987; Hellstrom, 1991). This model is used to calculate the thermal performance of the heat-pump-coupled system, in software such as EED (Hellstrom et al., 1997; Hellstrom and Sanner, 1997) and GLHEPRO (Manickam et al., 1997). This model calculates dimensionless thermal response functions in different borehole configurations.

Another simulation model by Hellstrom (1989) is duct ground heat storage model (DST). It is a simulation model for multiple boreholes with uniform borehole spacing. It has been used for both detailed design and field experiments evaluation extensively.

Both the SBM and DST models have been modified for use as TRNSYS components. The TRNSYS version of DST can also investigate problems within the stored volume, such as the radial stratification of the ground temperatures or the effect of the flow conditions in the borehole pipe on the thermal performance of the system (Pahud and Hellstrom, 1996). The accuracy of the DST has been verified with simulations of the heat transfer between a borehole storage unit and a solar collector field (Pahud, 1995). The DST model is named as Type 557 in TRNSYS, which is mainly employed throughout this work for the BTES modeling. 


\subsubsection{Field experiences with BTES}

As per Nordell et al. (2000), the first BTES experiments were built around 1976 in Sweden and France. The only high-temperature large scale BTES has been constructed in Lulea, Sweden, in 1982. Table 2-4 shows examples of borehole heat storage systems in Sweden.

Table 2-4 Examples of Swedish BTES (Nordell et al., 2000)

\begin{tabular}{|l|l|c|c|c|c|}
\hline \multirow{2}{*}{ Location } & \multicolumn{1}{|c|}{ Purpose } & Built & $\begin{array}{c}\text { Storage } \\
\text { Volume }\end{array}$ & \multicolumn{2}{c|}{ System Temperature $\left({ }^{\circ} \mathrm{C}\right)$} \\
\cline { 5 - 6 } & & & $\left(1000 \mathrm{~m}^{3}\right)$ & Warm & Cold \\
\hline Sigtuna & 1 Res. Unit & 1978 & 10 & 40 & 10 \\
\hline Lulea & Office & 1983 & 120 & 65 & 30 \\
\hline Finspang & Supermarket & 1984 & 42 & 30 & 15 \\
\hline Solna & Rec. Centre & 1984 & 30 & 35 & 10 \\
\hline Finspang & 750 Res. Units & 1985 & 220 & 35 & 10 \\
\hline Marsta & 40 Res. Units & 1985 & 32 & 14 & 4 \\
\hline Stockholm & Winter Garden & 1985 & 26 & 30 & 15 \\
\hline Kristinehamn & Office & 1988 & 30 & 35 & 10 \\
\hline Stockholm & Office & 1989 & 110 & 35 & 10 \\
\hline Jarfalla & Office & 1990 & 35 & 35 & 10 \\
\hline Storforsen & Hotel & 1995 & 100 & 20 & -10 \\
\hline
\end{tabular}

Pal et al. in 1997 investigated the world's largest BTES $\left(1,080,000 \mathrm{~m}^{3}\right)$ in operation, which was located at Stockton State College, Pomona, NJ, USA, with 400 boreholes at the depth of $135 \mathrm{~m}$ which used for part of the college heating and cooling demand since 1995.

Table 2-5 shows the technical characteristics of some demonstration plants with solar thermal collectors and BTES. They are all large-scale pilot plants in Germany, Sweden (built in 2010) and Canada.

- Neckarsulm BTES in Germany has 528 boreholes in the depth of $30 \mathrm{~m}$ with maximum design storage temperature of $85^{\circ} \mathrm{C}$. It was built in 1997 , and the BTES was expanded in 1998 and 2001. The monitoring data from 2003 to 2007 showed the maximum solar fraction of $44.8 \%$ had achieved in 2007 . The design solar fraction was $50 \%$ which the system did not reach that point yet. Bauer et al. (2010) found that it was because of the $10 \%$ smaller solar 
collector size, and higher net temperatures return from the loads. In the first five years, there was no discharge from the storage for letting the BTES heat up to a usable temperature.

Table 2-5 Central heating plant with BTES (Pavlov et. al., 2011)

\begin{tabular}{|l|c|c|c|c|c|c|}
\hline $\begin{array}{l}\text { Solar Plant } \\
\text { with BTES }\end{array}$ & $\begin{array}{c}\text { Heated Living } \\
\text { Area }\end{array}$ & $\begin{array}{c}\text { Total Heat } \\
\text { Demand } \\
(\mathrm{GJ} / \text { Year })\end{array}$ & $\begin{array}{c}\text { Solar } \\
\text { Collector } \\
\text { Area } \\
\left(\mathrm{m}^{2}\right)\end{array}$ & $\begin{array}{c}\text { Storage } \\
\text { Volume } \\
\left(\mathrm{m}^{3}\right)\end{array}$ & $\begin{array}{c}\text { Design } \\
\text { Solar } \\
\text { Fraction } \\
(\%)\end{array}$ & $\begin{array}{c}\text { Design } \\
\text { Maximum } \\
\text { Storage } \\
\text { Temperature } \\
\left({ }^{\circ} \mathrm{C}\right)\end{array}$ \\
\hline $\begin{array}{l}\text { Neckarsulm, } \\
\text { Germany }\end{array}$ & $\begin{array}{c}300 \text { Apartments, } \\
20,000 \mathrm{~m}^{2}\end{array}$ & 1,663 & 5,000 & 63,400 & 50 & 85 \\
\hline $\begin{array}{l}\text { Crailsheim, } \\
\text { Germany }\end{array}$ & $\begin{array}{c}260 \text { Houses } \\
\text { School \& Gym }\end{array}$ & 14,760 & 7,300 & 37,500 & 50 & 85 \\
\hline $\begin{array}{l}\text { Attenkirchen, } \\
\text { Germany }\end{array}$ & $\begin{array}{c}30 \text { Houses } \\
6,200 \mathrm{~m}^{2}\end{array}$ & 1,753 & 800 & 10,000 & 55 & 85 \\
\hline $\begin{array}{l}\text { Anneberg, } \\
\text { Sweden }\end{array}$ & $\begin{array}{c}90 \text { Houses } \\
9,000 \mathrm{~m}^{2}\end{array}$ & 3,888 & 3,000 & 60,000 & 60 & 45 \\
\hline $\begin{array}{l}\text { Okotoks, } \\
\text { Canada }\end{array}$ & $\begin{array}{c}52 \mathrm{Houses}^{2} \\
7,000 \mathrm{~m}^{2}\end{array}$ & 1,900 & 2,293 & 35,000 & 90 & 80 \\
\hline
\end{tabular}

- Crailsheim BTES in Germany has 80 boreholes in the depth of $55 \mathrm{~m}$. The system partly started operation in 2004. The monitoring data from two years operation (2006 and 2007), shows the solar fraction of $20 \%$, which is far from designed solar fraction of $50 \%$. The buffer storage tank for this system is $480 \mathrm{~m}^{3}$, selected because the solar collectors during the summer have a high capacity rate. Due to the large buffer tank size, the heat captured from solar collectors cannot directly charge the BTES, and therefore, it takes a longer time to fully charge the BTES (Mangold, 2007).

- Attenkirchen BTES in Germany is a combined HWTES and BTES. Ninety boreholes in the depth of $30 \mathrm{~m}$ are installed around a central concrete tank with a volume of $500 \mathrm{~m}^{3}$. Based on the temperature level in each storage system; heat pumps either use the borehole or hotwater-tank itself as a heat source to provide heat to the living area (Schmidt et al., 2004). The system commissioned in 2002 and is considered as one of the smallest such systems in Germany. Based on two-year monitoring data the solar fraction for the system was reported to be $73 \%$.

- The BTES in Anneberg, Sweden has been in operation since late 2002. It has 99 boreholes in the depth of $65 \mathrm{~m}$. It is designed for maximum storage temperature of $45^{\circ} \mathrm{C}$ in contrast to the 
former three cases in Germany, where all were designed for maximum storage temperature of $85^{\circ} \mathrm{C}$. The heating system is designed for low-temperature $\left(32 / 27^{\circ} \mathrm{C}\right)$ and individual electric heater back up (Lundh, 2008). After three to four years of operation, the solar fraction for this system was reported to be $70 \%$.

The system was designed and evaluated with simulation models TRNSYS 16 (Klein, 2004; Mazzarella, 1989) and MINSUN (Mazzarella, 1990) as well as with ground storage module DST (Duct storage model).

- Okotoks BTES, built in 2006, in Alberta, Canada has 144 boreholes with the depth of $37 \mathrm{~m}$. It is the first solar heat storage in Canada. The computer simulation results for this project show that the system will achieve the $90 \%$ solar fraction after five years (McDowell \& Thornton, 2008). The maximum designed borehole temperature is $80^{\circ} \mathrm{C}$. Sibbitt et al. (2007) described that the high-temperature storage has two disadvantages; 1) during the charging time, the return fluid temperature to the solar collectors will be relatively high, which cause to reduce the solar collectors efficiencies and 2) the storage heat loss will be relatively high, which is calculated to be almost $60 \%$. The system shows that the solar fraction has reached to $97 \%$ after five years of operation and measured performance.

In order to minimize the heat storage heat losses, Chapuis and Bernier (2009), offered an alternative design approach for the Okotoks-like system, to keep the storage temperature relatively low. It was based on using heat pumps to raise the temperature as per space heating demands. Based on the simulation using TRNSYS with its DST module, it was concluded that by keeping the average storage temperature slightly above the annual average ambient temperature, the return water temperature to the solar collectors would be relatively low, which leads to achieving higher efficiencies from the solar collectors by relatively reduced collector areas. Considering heat-pump electricity usage, the system could achieve $78 \%$ solar fraction.

In general, solar fraction of a system does not reflect the system effectiveness. There are other metrics, such as system efficiency and cost, including initial and operating, that needed to be taken into account for comparing different installations.

\subsection{Solar communities with cooling systems}

Technically, there are many possible processes for using solar energy in cooling. Solar radiation can be converted to electrical energy by photovoltaic to run electric chillers for cooling through vapor compression cycle. Solar energy can also be captured through thermal collectors 
for cooling by the heat transformation or thermoelectric process. Figure 2-7 shows the different technologies to convert solar heat into cooling or air-conditioning proposed by Henning (2007).

Processes in dark gray are technologies which are available in the market and are used for solar assisted cooling.

Solar heat transformation process for cooling can be an open or closed cycle. The two main categories of the closed cycle are: 1) absorption type using liquid sorbent materials such as ammonia and lithium bromide, and 2) adsorption type with solid sorbent materials such as silica gel.

The maximum possible (thermodynamic limit) thermal coefficient of performance (COP) for thermally driven technologies is defined as: $C O P_{\text {ideal }}=\frac{T_{C}}{T_{H}} \times \frac{T_{H}-T_{M}}{T_{M}-T_{C}}$ (Henning, 2007) where $T_{C}$ is the cold source temperature, $T_{H}$ is the heat source temperature and $T_{M}$ is the intermediate temperature at which the heat is transferred to a heat sink. Figure 2-8, shows the $\mathrm{COP}_{\text {ideal }}$ and real COP of such chillers which are available in the market presented by Grossman (2002) and Henning (2007).

Absorption is the dominating technology for thermally driven chillers. The operation of such systems is well-documented (e.g., ASHRAE Refrigeration, 2010). Nowadays, absorption chillers are mostly used if an inexpensive heat source is available, namely, waste heat, district heat or heat from co-generation plants. Absorption chillers used for air conditioning normally uses the sorption pair water- $\mathrm{LiBr}$ where water is refrigerant and $\mathrm{LiBr}$ sorbent. These are known as single effect machines, in which for each unit mass of refrigerant which evaporates in the evaporator then in the generator, one unit mass of refrigerant has to be desorbed from the refrigerant-sorbent solution. Typically these equipments operate with temperatures of $80-100^{\circ} \mathrm{C}$ and can deliver a COP around 0.7 .

Another alternative to single effect chiller is the machines using a double effect cycle. Two generators work in series at different temperatures, where the condenser heat of the refrigerant desorbed from the first generator and is used to heat the second generator. As a result, a higher $\mathrm{COP}$ in the range of 1.1 to 1.2 can be achieved. However, working temperatures in the range of $140-160^{\circ} \mathrm{C}$ are usually needed to run those chillers. These systems are usually suitable for the large capacities like $100 \mathrm{~kW}$ and more (Grossman, 2002 and Henning, 2007). 


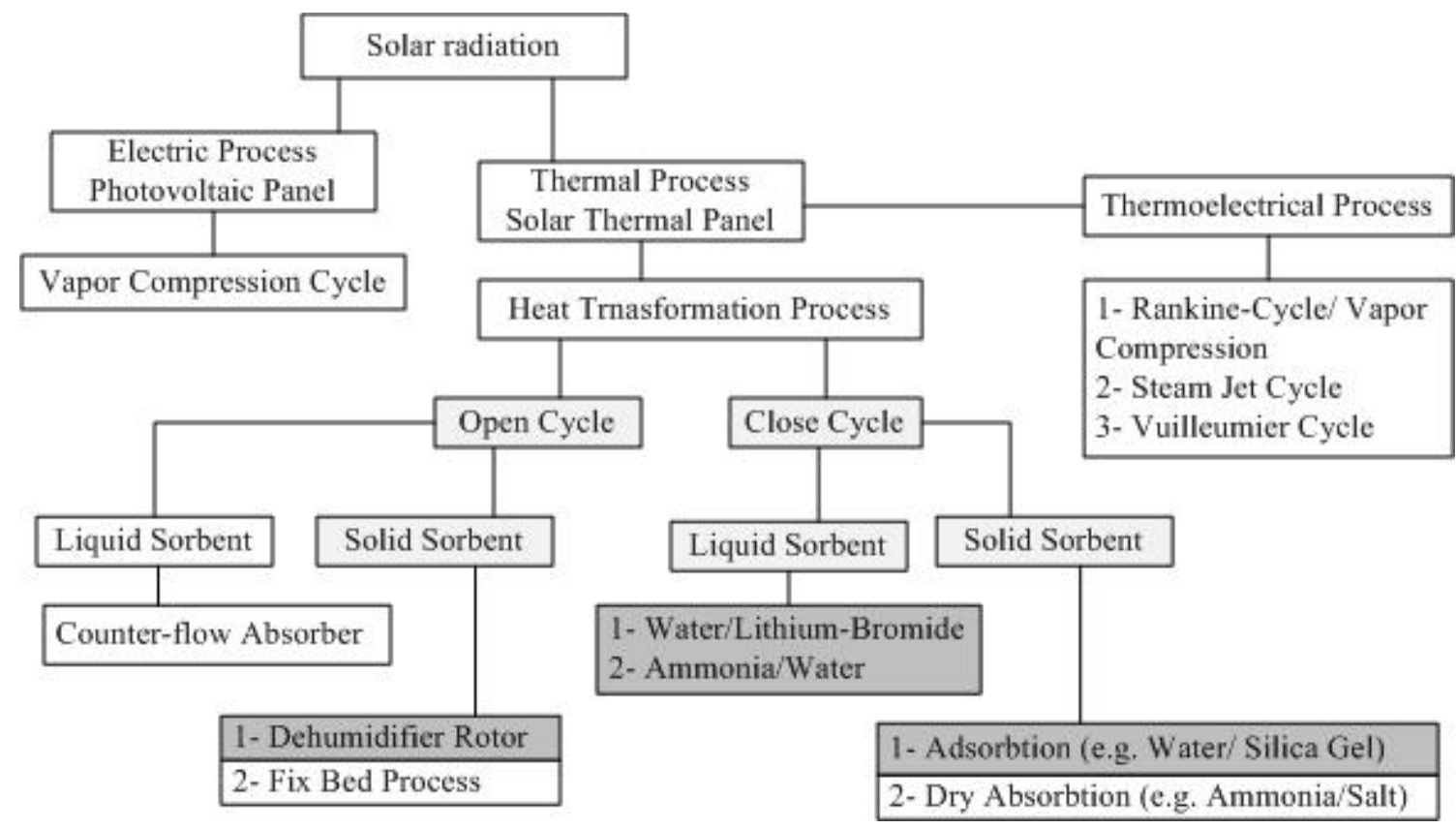

Figure 2-7 Physical ways to convert solar radiation into cooling (Henning, 2007)
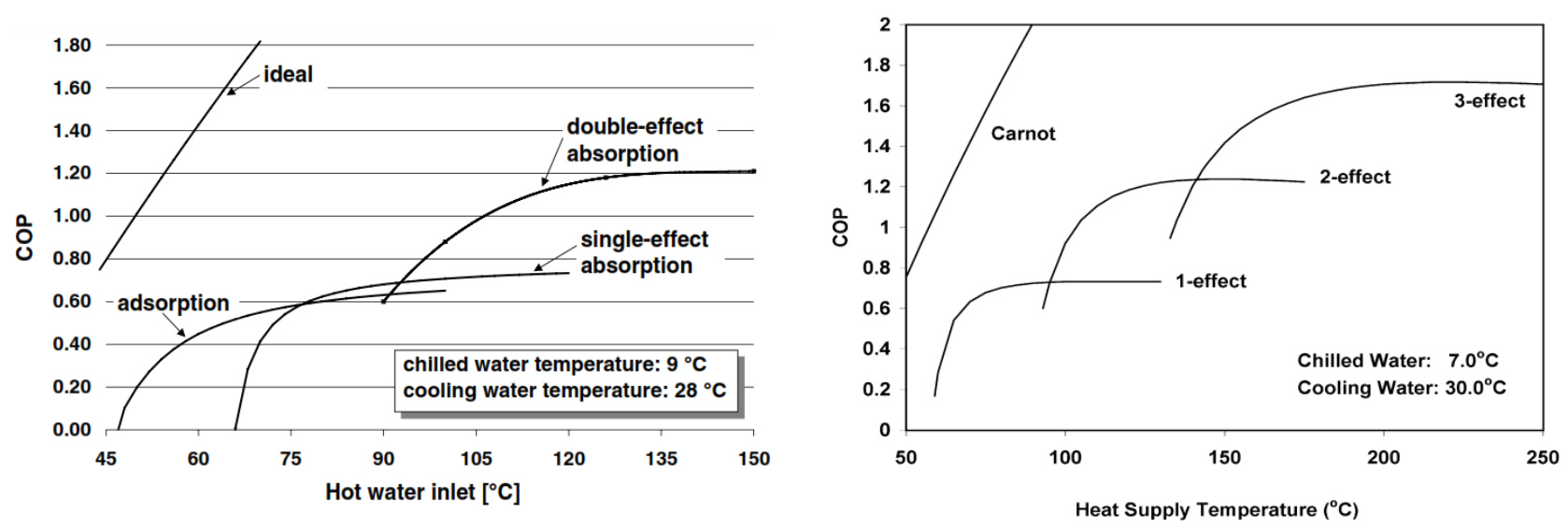

Figure 2-8 COP curves of sorption chillers (Henning, 2007 and Grossman, 2002)

In contrast to the liquid sorbent equipment, there are also machines working with solid sorption materials. In such systems, semi-continuous operation needs minimum two sections which contain the sorption material operating in parallel. Available systems on the market use water as refrigerant and silica gel as a sorbent. Usually, they are called adsorption chiller which as per Henning (2007), only two Japanese manufacturers making this kind of chillers. This equipment, under a typical operation conditions and heat source of about $80^{\circ} \mathrm{C}$, the systems can achieve a COP of about 0.6. Grossman (2002) described the open-cycle absorption and desiccant system as a suitable choice for the low-temperature heat source and introduced a system that 
makes it possible to use the solar heat with relatively low temperature for production of chilled water in variable quantities as required by the load.

Solar air conditioning and cooling technology are not fully established yet. More development is expected with increased competitiveness of this technology in the future. One main condition for a successful solar assisted cooling project is a good design with the adequate solar collector and thermal storage size. In order to make this kind of the systems economically viable, other systems should be integrated or supplemented; such as heating system or domestic hot water generating system. Henning (2007) reports only about seventy solar assisted cooling systems in Europe, which he concluded that these systems are in the early steps of growth. No standard design procedures or common practices for design still exist. Delorme et al. (2004) report fifty-three commercial buildings operated by solar cooling plants in seven European countries.

The operation of the eleven solar assisted air conditioning plants in six countries was investigated by IEA Task 25. Some important outcome of these investigation results was summarized by Henning (2007). The main problem with most of the plants was in hydraulic and control design and inappropriate commissioning process.

\subsubsection{Examples of installation of solar assisted cooling system}

Table 2-6 shows examples of realized solar cooling in Europe, presented by Delorme et al. (2004). The system components in different projects are quite distinct from each other, and there is no generalized established solution in design available yet.

Following a four-year monitoring of operation data and optimization in controls in the university hospital in Freiburg, Germany, it was found that the chiller operated with an acceptable COP (i.e., 0.42) but the cooling tower consumes relatively high amount of electricity. Average COP decreased through part-load operation during summer nights with low cooling demand. The annual specific collector yield was $365 \mathrm{kWh} / \mathrm{m}^{2}$ (Wiemken, 2009).

In Canada, a few solar cooling systems have been put into practice recently. In 2010, one project was commissioned in one retirement home in Woodstock, Ontario (Baldwin et al., 2012). The system has 162 solar collectors with a total of 3,240 evacuated tubes, which could produce up to $364 \mathrm{~kW}$ of thermal power. Other system components were a $105 \mathrm{~kW}$ absorption chiller and a 13,600 L thermal storage tank. Additional heater and chiller have also been installed as the backup of the system. 
The system provides heating and cooling to $9,900 \mathrm{~m}^{2}$ area. After two years of operation, the system generated $740 \mathrm{GJ}$ heating and $420 \mathrm{GJ}$ cooling. As such, this system greatly reduces the operating cost and $\mathrm{CO}_{2}$ emission.

Another system was installed in 2011 in a hospital in Thornhill, Ontario. The system consists of 131 evacuated tubes solar thermal collectors and ten $10 \mathrm{~kW}$ small size adsorption chiller plus 4,364 L of thermal storage tank. The initial calculation and system modeling estimated that the system would be able to offset $36 \%$ of the cooling loads and $44 \%$ of the heating loads as well as $91 \%$ of domestic hot-water use, which resulted in a solar fraction of $56 \%$.

Table 2-6 Examples of solar cooling commercial projects in Europe (Delorme at al., 2004)

\begin{tabular}{|c|c|c|c|c|c|c|c|}
\hline Country & Location & Building & $\begin{array}{c}\text { Cooling } \\
\text { Capacity } \\
\text { (kWc) }\end{array}$ & Technology & $\begin{array}{c}\text { Collector } \\
\text { Type }\end{array}$ & $\begin{array}{c}\text { Gross } \\
\text { Collector Area } \\
\left(\mathbf{m}^{2}\right)\end{array}$ & $\begin{array}{c}\text { In } \\
\text { Operation } \\
\text { Since }\end{array}$ \\
\hline Germany & Langenau & Offices & 35 & $\begin{array}{c}\text { Absorption } \\
\text { Chiller }\end{array}$ & $\begin{array}{c}\text { Evacuated } \\
\text { Tube }\end{array}$ & 45 & 1997 \\
\hline Germany & Freiburg & Laboratories & 70 & $\begin{array}{l}\text { Adsorption } \\
\text { Chiller }\end{array}$ & $\begin{array}{c}\text { Evacuated } \\
\text { Tube }\end{array}$ & 230 & 1999 \\
\hline Germany & Freiburg & Offices & 60 & $\begin{array}{l}\text { Desiccant } \\
\text { Cooling }\end{array}$ & $\begin{array}{l}\text { Flat Plate } \\
\text { Air } \\
\text { collector }\end{array}$ & 100 & 2001 \\
\hline Greece & Oinofyta & Warehouse & 700 & $\begin{array}{c}\text { Adsorption } \\
\text { Chiller }\end{array}$ & Flat Plate & 2700 & 1999 \\
\hline Greece & Crete & Hotel & 105 & $\begin{array}{c}\text { Absorption } \\
\text { Chiller }\end{array}$ & Flat Plate & 448 & 2000 \\
\hline Spain & Arteixo & $\begin{array}{l}\text { Offices and } \\
\text { Store }\end{array}$ & 170 & $\begin{array}{c}\text { Absorption } \\
\text { Chiller }\end{array}$ & Flat Plate & 1626 & 2003 \\
\hline Portugal & Lisbon & Offices & 36 & $\begin{array}{c}\text { Desiccant } \\
\text { Cooling and } \\
\text { Heat Pump }\end{array}$ & $\begin{array}{c}\text { Compound } \\
\text { Parabolic } \\
\text { Collector }\end{array}$ & 48 & 1999 \\
\hline Italy & $\begin{array}{c}\text { Pergine } \\
\text { Valsugana }\end{array}$ & $\begin{array}{l}\text { Business } \\
\text { Innovation } \\
\text { Centre }\end{array}$ & 108 & $\begin{array}{l}\text { Absorption } \\
\text { Chiller }\end{array}$ & Flat Plate & 265 & 2004 \\
\hline Austria & Hartberg & $\begin{array}{c}\text { Research } \\
\text { House }\end{array}$ & 30 & $\begin{array}{l}\text { Desiccant } \\
\text { Cooling }\end{array}$ & $\begin{array}{c}\text { Evacuated } \\
\text { Tube }\end{array}$ & 12 & 2000 \\
\hline France & Banyuls & Wine Cellar & 52 & $\begin{array}{l}\text { Absorption } \\
\text { Chiller }\end{array}$ & $\begin{array}{c}\text { Evacuated } \\
\text { Tube }\end{array}$ & 215 & 1991 \\
\hline
\end{tabular}

The system operation data are under fully monitoring system and is still to be examined. A newly developed triple-state adsorption chiller was also tested in a single residential home as a pilot project in Vaughan, Ontario, Canada (Hasib et al., 2012), although it was not a solar thermal driven system. 
In Europe, the university hospital in Freiburg, Germany operates a solar cooling and airconditioning system for a laboratory. The system has $170 \mathrm{~m}^{2}$ of evacuated solar tubes and a 70 $\mathrm{kW}$ adsorption chiller. Following to a four-year monitoring the operation data and optimization in controls, it was found that the chiller operates with an acceptable COP, but the cooling tower consumes too much electricity. Figure 2-9 shows the efficiencies (COPs) and solar fraction of the system for a typical summer day.

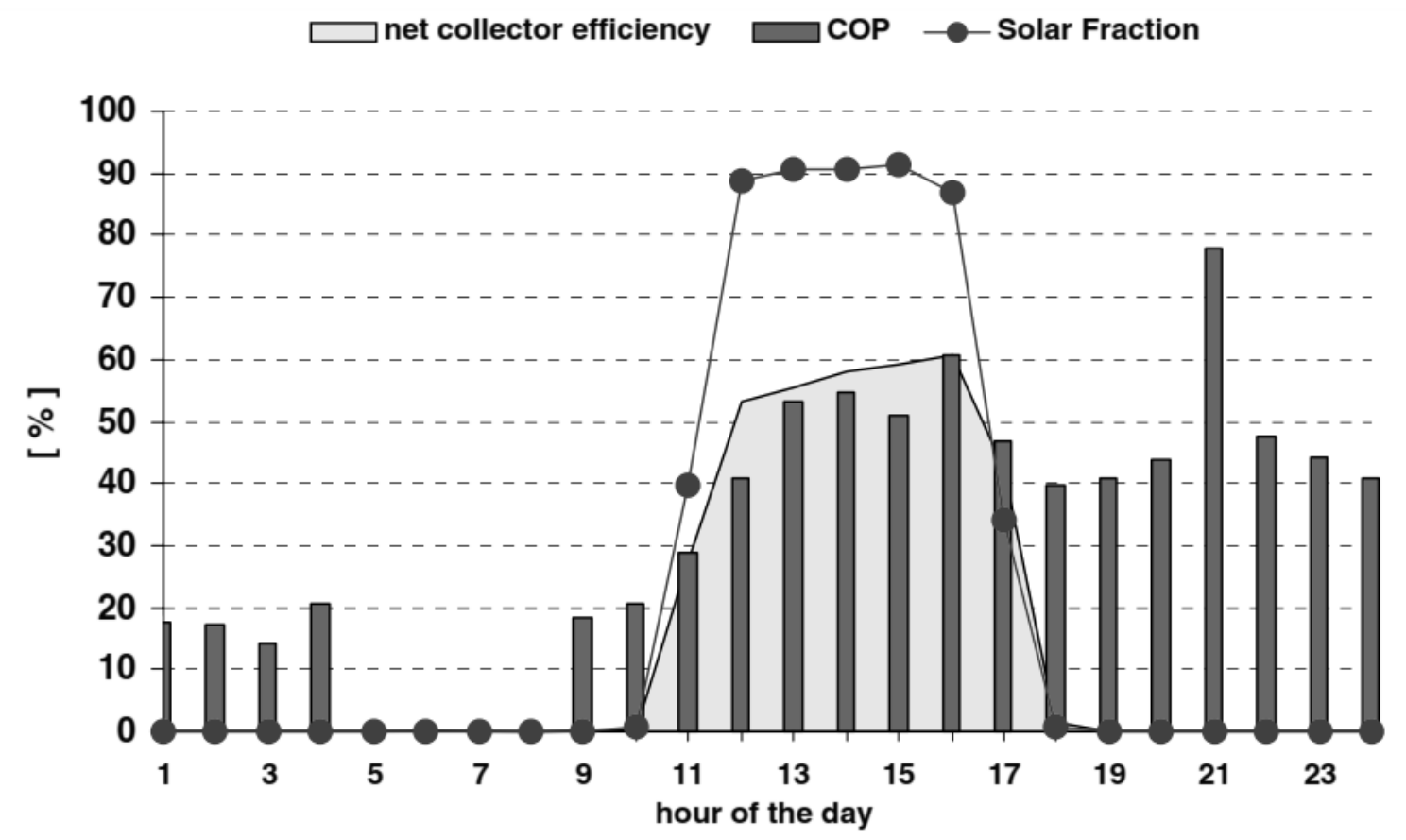

Figure 2-9 Operation of the solar cooling system installed at the University Hospital in Freiburg during a typical summer day (Henning, 2007)

Hesaraki et al. (2015) conducted a comparative review of different types of seasonal energy storage systems integrated with the heat pumps for heating and to some extent cooling applications. The paper presented the systems with low temperatures suitable for running heat pumps to satisfy heating rather than cooling loads mostly. In their study, the implications of storing excess heat generated by the heat pumps in cooling season and the storage of solar heat at the same time, have not been investigated. On the other hand, the study of such systems with distribution systems other than heat pumps, e.g., fan-coil, for both heating and cooling has not been presented yet. 


\subsection{Literature Review Summary}

Based on the comprehensive literature review, the following conclusions are summarized as follows:

- The majority of the existing solar communities are based on heating only. There are numerous successful projects (e.g., Okotoks) around this topic, which will be a lead to investigate further for the modifications and enhancement of the existing system.

- There is no research around solar communities with combined heating and cooling. The necessity of such a system will be based on the geographic location where cooling and heating are required in the course of the year, e.g., Southern Ontario, Canada.

- Compared to the existing community-scale thermal storage, borehole thermal energy storage (BTES), has the most favorable condition for long-term energy storage. This is because the large amounts of energy involvement and a relatively low cost of energy storage media.

- In the existing solar communities for cooling, the ground energy storage systems are designed for storing unused heat from solar collectors only. In these systems, there are no strategies and design for capturing the excess heat from thermally driven cooling equipment, i.e., absorption chillers. As such a new BTES for storing the low-grade heat could be a solution.

- The heating distribution systems in the existing solar communities are mostly based on medium-temperature $\left(\sim 40^{\circ} \mathrm{C}\right)$ fan-coil distribution system. The technical and economic viability of a low-temperature heat source, suitable for a centralized or distributed heat pump, has not been investigated yet.

- Community solar heating and cooling can produce low-carbon energy emission due to the widespread solar resources. 


\section{Chapter 3 : Solar Community Heating System with Borehole Thermal Energy Storage}

In Canada, Drake Landing Solar Community (DLSC) in Okotoks, Alberta, is the first large-scale BTES designed as a part of a solar community. Built in 2006, DLSC has achieved a 97 percent solar fraction after five years of operation (Sibbitt et al., 2007). The primary objective of the DLSC project was to demonstrate that substantial energy cost savings are possible compared to conventional systems by storing solar heat from summer for winter uses.

DLSC consists of 52 detached houses having a total annual simulated heating demand of 2,280 GJ (SAIC Canada, 2012). From the central energy center, hot water is distributed through a two-pipe system to each of the 52 houses. Each house is equipped with an individual air handler with a water-to-air fan coil. All the houses, having an efficient building envelope, were built and certified based on the R-2000 standard developed by Natural Resources Canada (NRCan, 2012). A total of 2,293 $\mathrm{m}^{2}$ of flat plate solar collectors was installed on the roof of the connected garages of the houses, facing south at an angle of $45^{\circ}$. The community energy center contains two short-term storage tanks (STSTs) with a total $240 \mathrm{~m}^{3}$ volumetric capacity, pumps, heat exchangers, and controls. A borehole thermal energy storage (BTES), located next to the energy center, containing 144 boreholes of $37 \mathrm{~m}$ depth installed in 24 parallel circuits, is used as a seasonal thermal storage. Figure 3-1 depicts the DLSC simplified system schematic (Sibbitt et al., 2007).

The DLSC's technical feasibility and system performance have been shown to be successful in terms of reducing energy costs (Sibbitt et al., 2012). However, the system's capital cost is substantially higher than conventional heating systems and does not offer any payback over the lifetime of the project.

The objective of this chapter is to use DLSC system as a base case, and then propose a new design with a similar, but more efficient, configuration.. The DLSC model has been validated against its measured system performance ( Sibbitt et al., 2012). The proposed model can have different components and possibly smaller sizes, to achieve lower initial costs and a better payback. The new design is constrained to produce the same solar fraction (SF) as the DLSC and simulated with an integrated model using TRNSYS software (Klein et al., 2010). 


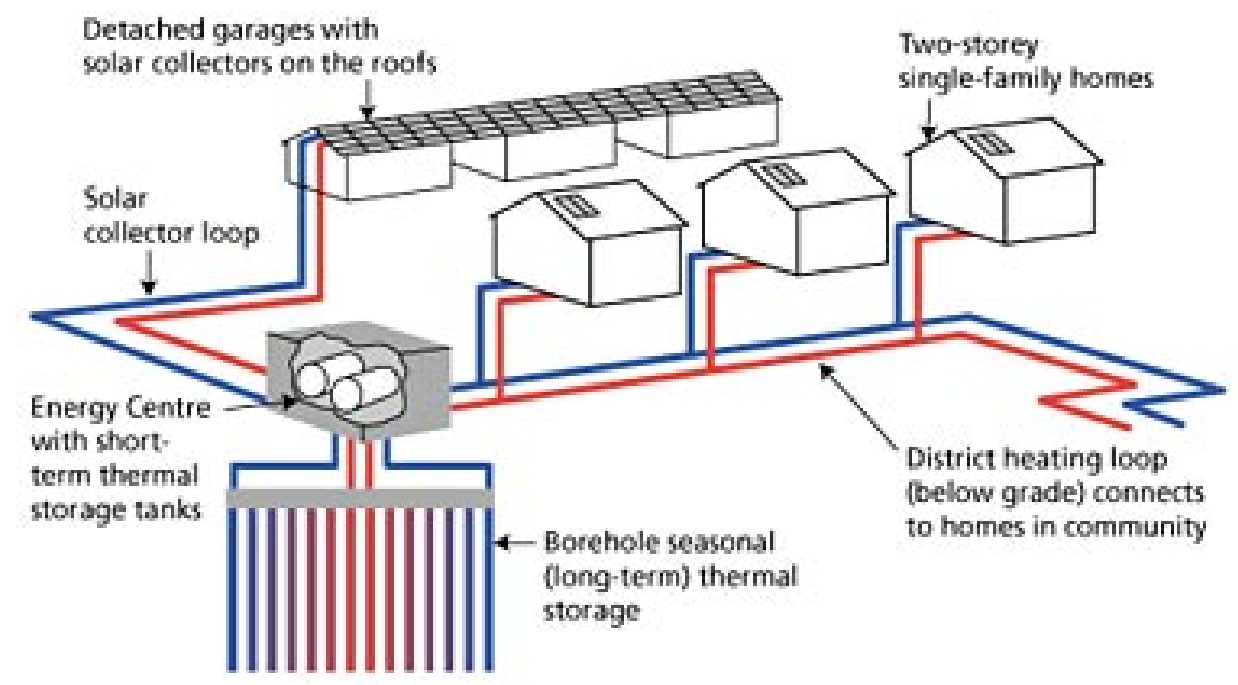

Figure 3-1 Drake Landing Solar Community (DLSC) simplified system schematic (Sibbitt et al., 2007)

\subsection{System configuration and community thermal load}

Figure 3-2 shows the system setup and equipment. The solar collectors transfer the harvested solar energy to a short term storage tank (STST) through a heat exchanger all year around. In the mid-spring and summer when there is no space heating demand from the community, the stored thermal energy is transferred to the ground for seasonal storage. The ground storage type is vertical borehole thermal energy storage (BTES). During the heating season, the stored heat in the Earth is extracted and transferred to the STST when the solar collectors cannot maintain the required temperature needed in the tank to meet the community heating load.

DLSC comprises 52 houses with a total heated area of about $7000 \mathrm{~m}^{2}$ which is approximately $135 \mathrm{~m}^{2}$ for each house. The houses are energy efficient and are constructed according to the R-2000 Standard (NRCan, 2012). Each house is 30\% more efficient than the conventionally built home. Table 3-1 shows the building envelope features. The DLSC simulated heating load is $416 \mathrm{~kW}$ with $2530 \mathrm{GJ}$ annual community (district) heating load, which consists of 2280 GJ annual space heating load and 250 GJ district loop losses (Sibbitt et al., 2007; 2012). 


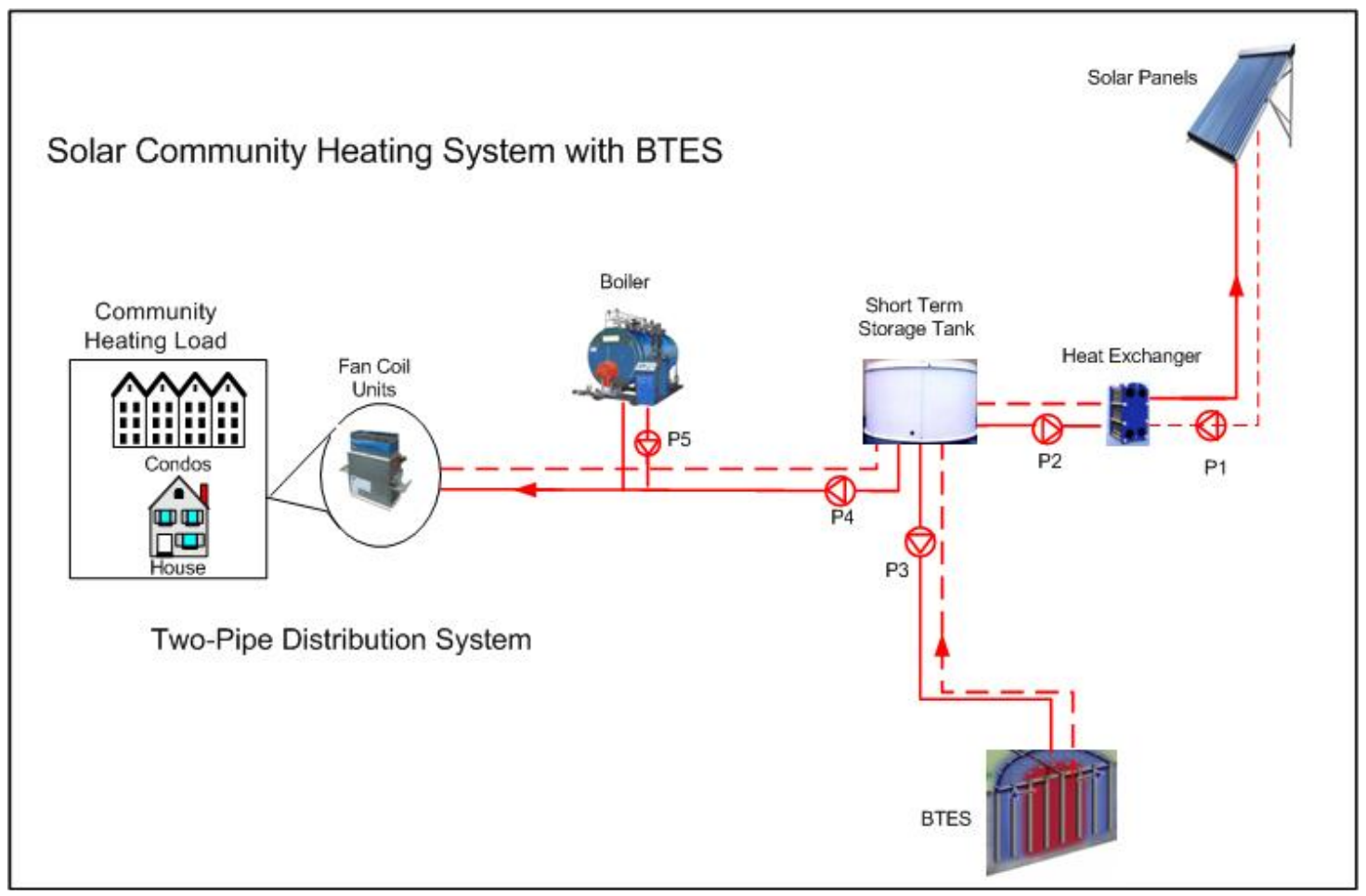

Figure 3-2 Solar community heating system with BTES - simplified system schematic

By using all available DLSC houses' data, a similar community was modeled and simulated by using eQuest software (James \& Associates, 2015). The calculated hourly thermal load profile is shown in Figure 3-3. The replicated community peak heating load is $457 \mathrm{~kW}$, and the total annual heating demand is $2350 \mathrm{GJ}$, which is about $10 \%$ higher than DLSC peak heating load and 7\% less than simulated annual DLSC heating load.

Figure 3-4 depicts monthly heating demand. The maximum monthly heating demand is 568 GJ, which corresponds to the month of January. Figure 3-5 shows the hourly heating load for the month of January which includes the hourly loads correspond to the highest, lowest and average loads.

Heat is supplied to the community through the distributed fan-coils connected to the hotwater distribution loop fed from the STST. The community water loop temperature is maintained on average at $40^{\circ} \mathrm{C}$. An auxiliary boiler is connected to the district water loop in the case the STST temperature falls below the set community loop temperature. 
Table 3-1 DLSC building envelope features

\begin{tabular}{|l|l|}
\hline Location & $\begin{array}{l}\text { Latitude: } 50.73^{\circ} \mathrm{N} \\
\text { Orientation: Streets are oriented east-west; most } \\
\text { window face north and south; garage roofs face } \\
\text { due south } \\
\text { Heating Degree Days (HDD): } 5,015^{\circ} \mathrm{C}-\text { days }\end{array}$ \\
\hline Walls & $\begin{array}{l}\text { Overall RSI-value: } 3.52(\mathrm{R}-20) \\
\text { Glazing percentage: } 8 \%\end{array}$ \\
\hline Windows & Effective U-factor for assembly: 0.76 RSI (R-4.3) \\
\hline Basement & Basement Wall Insulation RSI-value: 3.52 (R-20) \\
\hline Roof & Overall RSI-value: 8.8 (R-50) \\
\hline
\end{tabular}

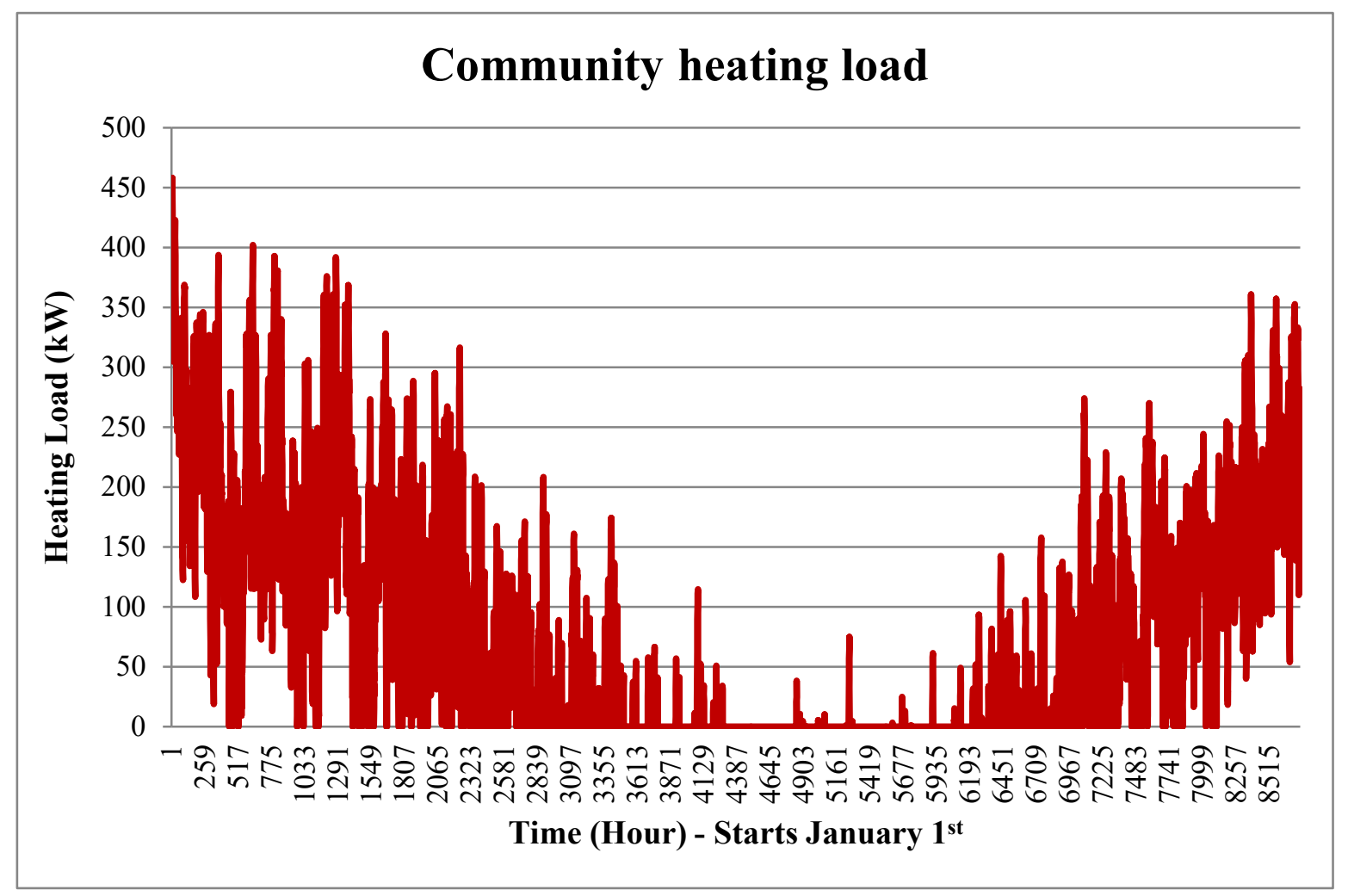

Figure 3-3 Simulated community hourly heating load - DLSC replicate 


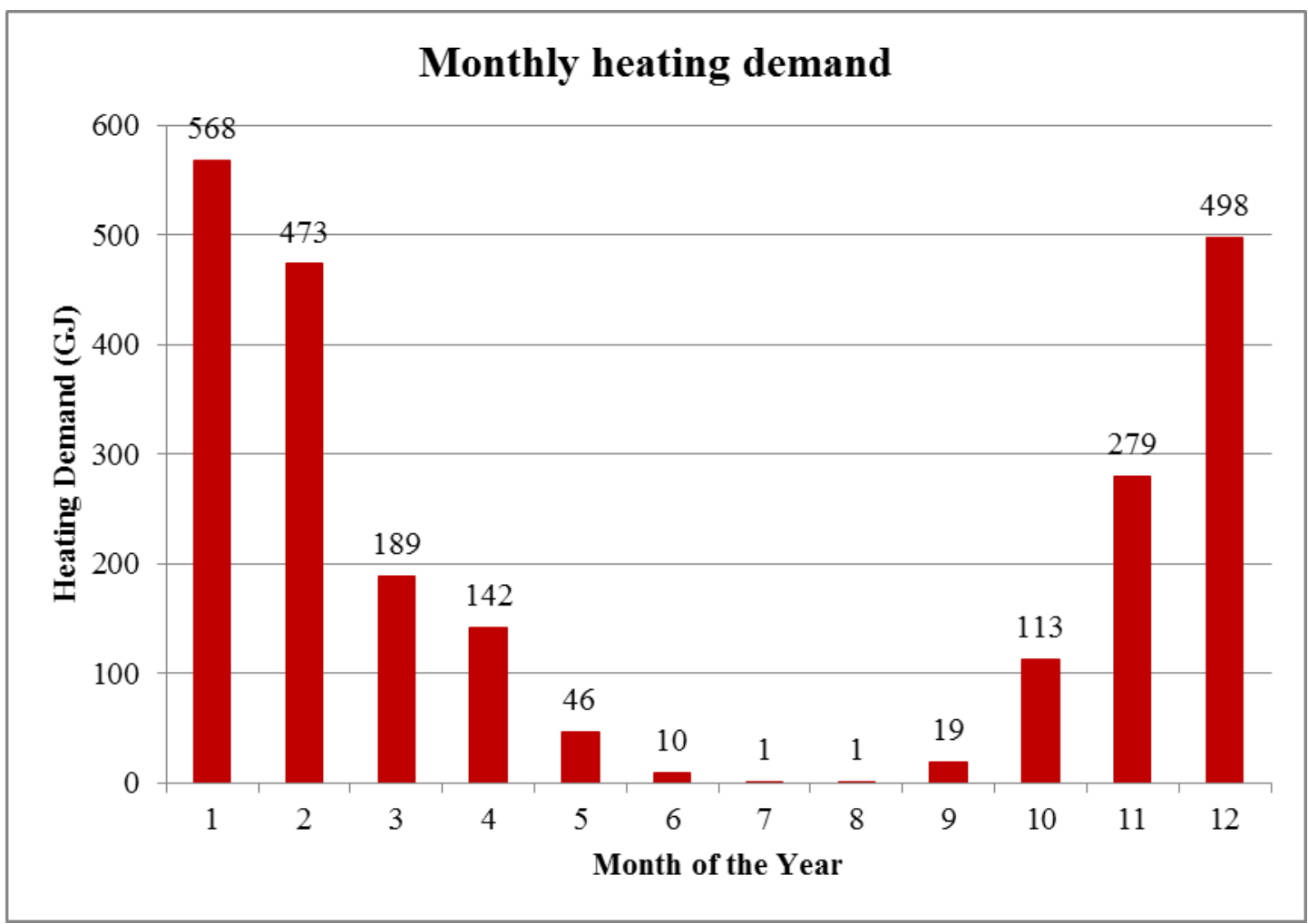

Figure 3-4 Simulated community monthly heating demand - DLC replicate

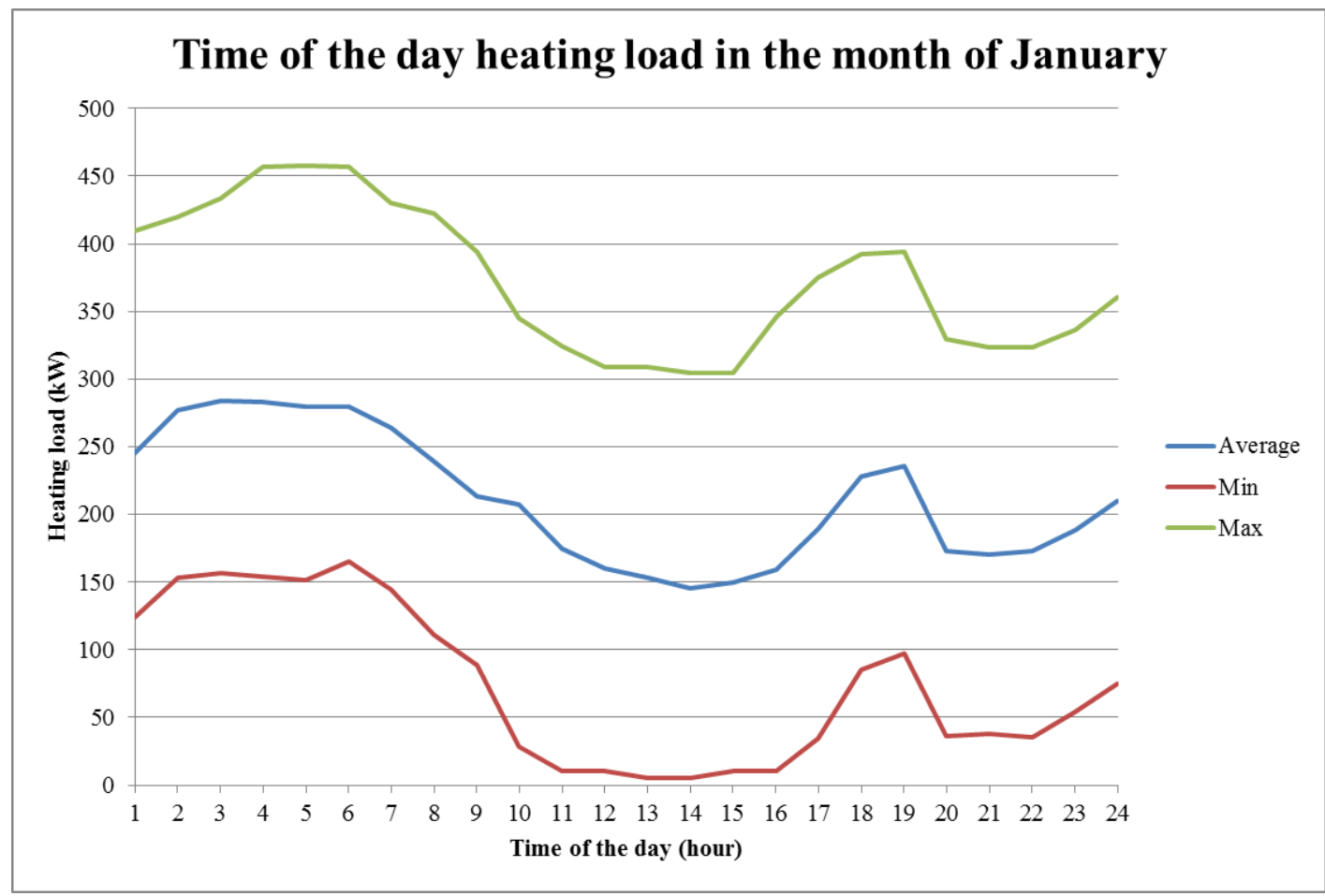

Figure 3-5 Time of the day heating load in the month of January (simulated) 
The STST and the pumps plus controls are all located in one location called the Energy Centre. For efficient use of pump electricity, the pumps in all loops, i.e., solar, BTES, and community loop, are equipped with variable flow devices to maintain the required flow in each loop.

\subsection{System major equipment configuration and model}

An integrated system is modeled using TRNSYS 17 software. Figure 3-6 shows the TRNSYS model layout. One focal point of the system is the short term storage tank (STST), where all three of the system's main loops, i.e., community, solar and BTES, meet and interact. The liquid flow through the solar collectors transfers the solar heat gain to the solar loop connected to the STST through a heat exchanger. The model receives the community hourly heating load from a spreadsheet resulting from eQuest community load calculations. The heating load is always satisfied by the proposed system. A boiler is connected to the community supply flow to maintain the desired temperature needed for the fan-coils in the community. Sections 3.2.1 to 3.2.5 describe the system's major components.

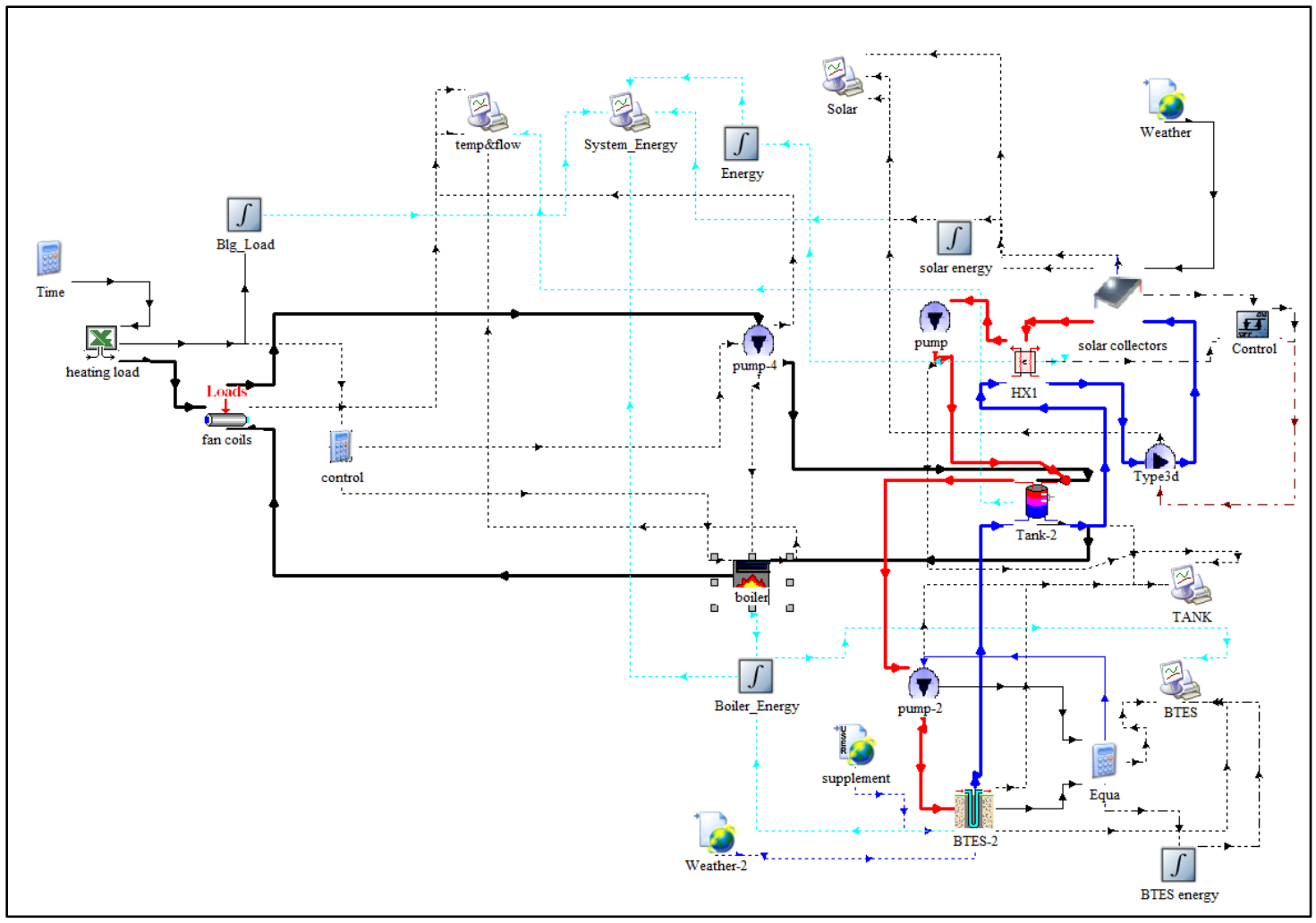

Figure 3-6 Solar community heating system with BTES - TRNSYS model schematic 


\subsubsection{Solar collectors}

The selected solar collectors are of a flat-plate type. The total collector area is $1722 \mathrm{~m}^{2}$, which includes 600 solar collectors in three parallel arrays with 200 collectors connected in series. The solar collectors face south and have a $45^{\circ}$ surface inclination. The efficiency of the collectors as per the manufacturer's "Solar Rating and Certification Corporation" evaluation, $\mathrm{SRCC}^{\mathrm{TM}}$ (Enerworks, 2015), is calculated as follows:

$$
\eta=0.762-3.2787\left(\frac{T_{i}-T_{a}}{G}\right)-0.0129\left(\frac{\left(T_{i}-T_{a}\right)^{2}}{G}\right)
$$

Here, $T_{i}$ and $T_{a}$ are the solar collector inlet and ambient air temperature in ${ }^{\circ} \mathrm{C}$ and $G$ is the global (total) radiation incident on the tilted-surface of the solar collector. The collector's incident angle modifier (IAM) is also selected from the manufacturer's SRCC ${ }^{\mathrm{TM}}$ certified data.

The selected solar collectors are similar to the solar collectors used in DLSC, and their specifications are presented in Appendix A.

In the proposed TRNSYS model, Type 1 for the flat-plate solar collectors is chosen. The number of collectors in series and the characteristics of each collector determine the thermal performance of the collector array. In this instance of Type 1, a second order quadratic function is used to compute the incident angle modifier. The coefficients of the function are supplied by the ASHRAE or an equivalent test (Klein et al., 2010). The manufacturer (Enerworks) provided the results from standard tests of collector efficiency versus a ratio of fluid temperature minus the ambient temperature to solar radiation. In Type 1, there are five possibilities for considering the effects of off-normal solar incidence. In this instance, a second order quadratic function is used to compute the incidence angle modifier. The coefficients of the function are supplied by ASHRAE Standard 93 (2010).

The origin of the Equation (3-1) is from the general equation for solar thermal collector efficiency which is obtained from the Hottel-Whillier Equation (Duffie and Beckman, 1991) as:

$$
\eta=a_{0}-a_{1} \frac{\Delta T}{l_{T}}-a_{2} \frac{(\Delta T)^{2}}{l_{T}}
$$

where $\mathrm{l}_{\mathrm{T}}\left(\mathrm{kJ} / \mathrm{h}-\mathrm{m}^{2}\right)$ is the global (total) radiation incident on the solar collector (tilted surface). It is the same parameter $G$ in the Equation (3-1) which is used in the SRCC documents. $\Delta \mathrm{T}$ is the difference between the inlet and ambient temperature. 
The thermal efficiency is defined by three parameters: $\mathrm{a}_{0}, \mathrm{a}_{1}$ and $\mathrm{a}_{2}$. These parameters are available for collectors tested according to ASHRAE 93 (2010). Table 3-2 shows the parameters considered for the Type 1 module.

Table 3-2 Solar collector parameters

\begin{tabular}{|l|c|l|}
\hline Number in series & 200 & \\
\hline Total collector area & 1722 & $\mathrm{~m}^{2}$ \\
\hline Fluid specific heat & 3.6 & $\mathrm{~kJ} / \mathrm{kgK}$ \\
\hline Tested flow rate & 1.104 & $\mathrm{~kJ} / \mathrm{hrm}^{2}$ \\
\hline Intercept efficiency $\left(\mathrm{a}_{0}\right)$ & 0.762 & \\
\hline Efficiency slope $\left(\mathrm{a}_{1}\right)$ & 3.2787 & $\mathrm{~kJ} / \mathrm{hrm}^{2} \mathrm{~K}$ \\
\hline Efficiency curvature $\left(\mathrm{a}_{2}\right)$ & 0.0129 & $\mathrm{~kJ} / \mathrm{hrm}^{2} \mathrm{~K}^{2}$ \\
\hline Optical mode 2 & 2 & \\
\hline $1^{\text {st }}$ order IAM* & 0.2 & \\
\hline $2^{\text {nd }}$ order IAM* & 0 & \\
\hline
\end{tabular}

* Incident angle modifier

The efficiency parameters provided by the manufacturer are a function of the inlet temperature and, therefore, the efficiency mode is set to one. The total area of the solar collector array is taken from the supplied efficiency parameters (typically gross area and not net area), and the flow rate is per unit collector area at which the collector was tested in order to determine the collector efficiency parameters. Intercept efficiency, efficiency slope, and efficiency curvature are $\mathrm{a}_{0}, \mathrm{a}_{1}$ and $\mathrm{a}_{2}$ in the efficiency Equation (3-2), and are obtained from ASHRAE collector test. Optical mode 2 is a parameter that specifies the second-order ASHRAE incident angle modifiers. Collector tests are performed on clear days at normal incidence so that the transmittanceabsorbance product is nearly the normal incidence value for the beam radiation. The intercept efficiency is corrected for non-normal solar incidence using a modifying factor of the form:

Incident Angle Modifier $($ IAM $)=1-\mathrm{b}_{0} \times \mathrm{S}-\mathrm{b}_{1} \times \mathrm{S}^{2}$

where $S=\left(\frac{1}{\cos \text { (incident angle) }}-1\right)$, " $1^{\text {st }}$-order IAM" parameter is $\mathrm{b}_{0}$, and " $2^{\text {nd }}$-order IAM" is $\mathrm{b}_{1}$ in the above equation for incident angle modifier (IAM). 


\subsubsection{Borehole thermal storage (BTES) system}

The BTES incorporated into the system has 90 boreholes each of $59 \mathrm{~m}$ depth. The boreholes are configured in a circular field with an average of $3 \mathrm{~m}$ borehole separation.

Comparing to the DLSC, which has the BTES of 144 boreholes each of $37 \mathrm{~m}$ depth with $3 \mathrm{~m}$ borehole separation, the proposed community has almost the same total borehole length, but 54 fewer boreholes (90 boreholes) and $22 \mathrm{~m}$ longer depth $(59 \mathrm{~m})$ with the same separation ( $3 \mathrm{~m})$. The selected number of boreholes for the proposed community (i.e., 90) has come out as a result of trial and error method by repeated attempts in reducing the borehole numbers in the system's model from 144 boreholes until the system fails to perform similarly to the DSLC experimental performance results.

The cylindrical shape storage that contains the boreholes has a volume of $34,017 \mathrm{~m}^{3}$ with a coverage of $580 \mathrm{~m}^{2}$ ground surface area. The nominal HDPE pipe size comprising the U-tube ground heat exchanger is $32 \mathrm{~mm}$ in diameter. To achieve a relatively high thermal conductivity between the pipes and the ground, a thermally enhanced grout with graphite base which is commercially available is selected. The thermal conductivity of the borehole grout chosen is 1.5 $\mathrm{W} / \mathrm{mK}$ (McClain and Collins, 2010). The ground comprising the storage volume is composed of the wet shale and sandstone selected from the drilling records in the Okotoks area. Based on the selected soil properties, the thermal conductivity of the ground is estimated to be $2 \mathrm{~W} / \mathrm{mK}$ (Kavanaugh and Rafferty, 1997).

Figure 3-7 depicts each circuit, which consists of nine boreholes connected in series in reverse return arrangement. Figure 3-8 shows the borehole layout and piping, which consists of 10 circuits connected in parallel to the main header. 


\section{Borehole Circuit Piping \\ 9 Boreholes in 10 Circuits}

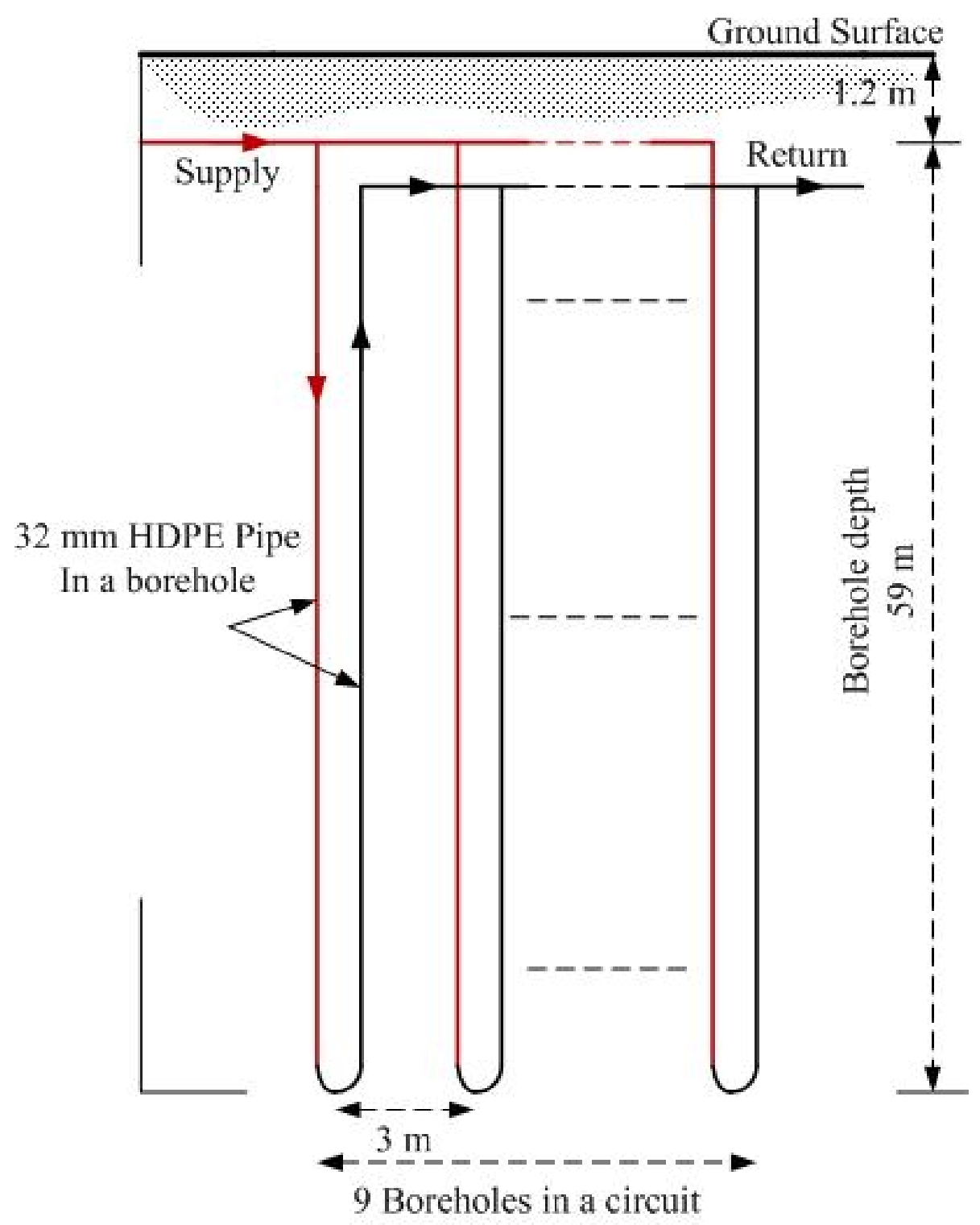

Figure 3-7 Borehole circuit piping schematic 


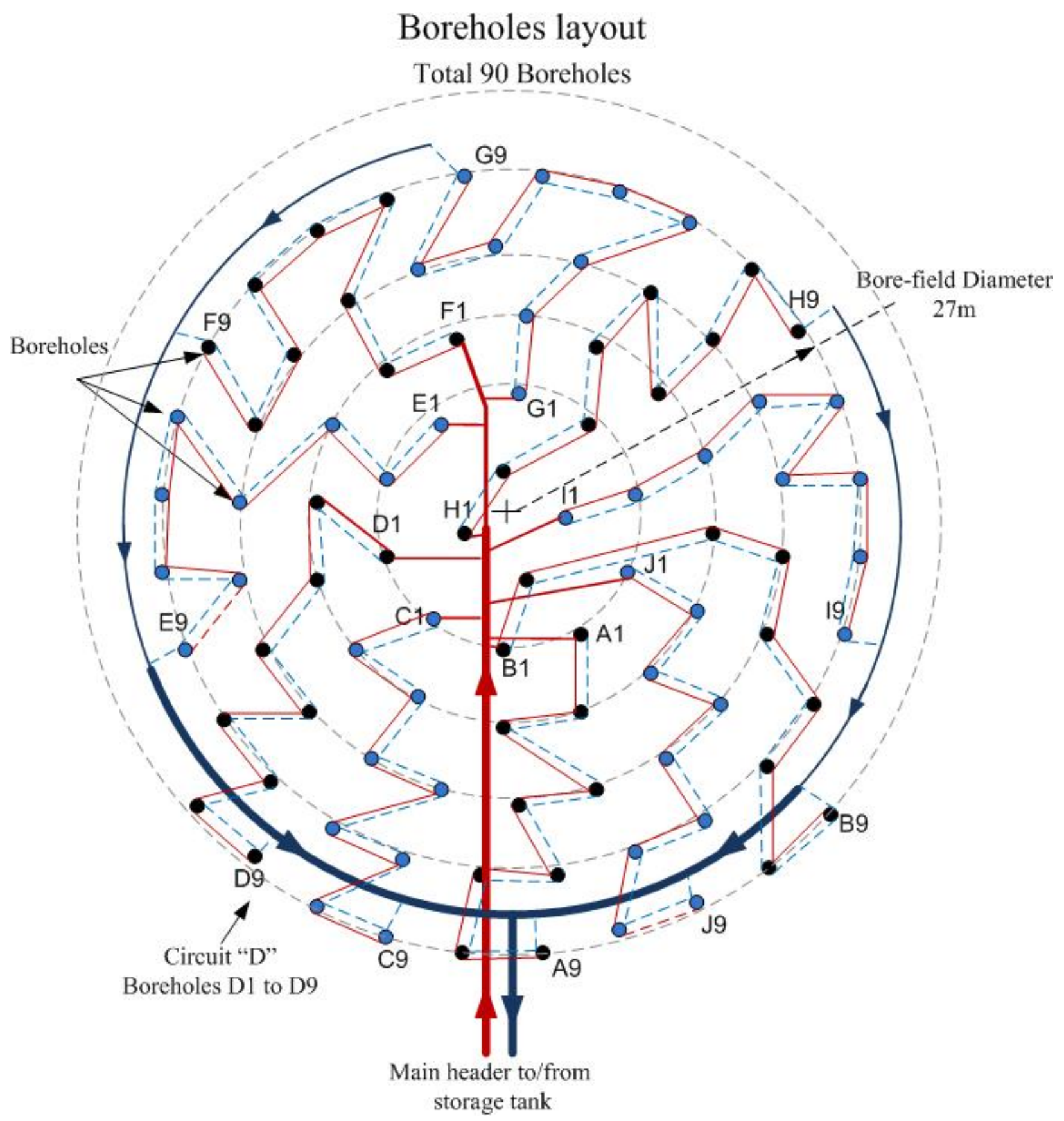

Figure 3-8 Borehole field layout and piping 
Ground Heat Exchanger Analysis Design and Simulation (GHEADS), developed by Tarnawski and Leong (1993), was initially used for the BTES design (Leong et al., 2010, Tarnawski et al., 1990, Rad et al., 2014). GHEADS is a detailed modeling program for ground heat exchangers and is flexible in terms of borehole layout design. GHEADS can produce more favorable results than the existing TRNSYS built-in duct-ground-storage (DST) model. However, the simulation running time in GHEADS is substantially longer.

GHEADS has the following advantages over the DST model (Rad et al., 2014):

1- Incorporates coupled heat and moisture flow in the ground heat storage The performance of a BTES depends strongly on the moisture content and soil type (mineralogical composition).

A light dry soil can deliver the highest storage efficiency because of the small storage losses through the BTES. However, the same soil also significantly limits the ability of the BTES to receive and deliver heat effectively (Sibbitt et al., 2015).

2- Provides flexibility in the design of the borehole layout by considering the heat and moisture interactions between the boreholes.

The TRNSYS default BTES model (DST) has the limitation on the borehole layout design. In this model, boreholes need to have same separation distances which restrict the optimum use of available real estate for the borefield.

3- Accounts for soil freezing-thawing and drying-rewetting due to heat extraction and heat deposition.

4- Can consider the presence of a groundwater table.

5- Accounts for dynamic ground-surface effects (radiation, convection, advection, evapotranspiration, snow cover, etc.).

GHEADS model requires comprehensive weather data that is not found in the existing TRNSYS weather data files. As a result, weather from Environment Canada needs to be used to supplement existing TRNSYS weather data.

Type 201a is the defined component for the GHEADS in TRNSYS. More details on the GHEADS software have been covered in Section 2.1.2. Simulation modes in Type 201a are defined as follows: 
1. Mode " 0 " considers heat transfer only (no moisture transfer) with constant thermal properties and without freezing/thawing process (values for storage thermal conductivity and heat capacity must be specified).

Based on the study by Rad et al. (2014), in this mode, comparing Type 201a to the default TRNSYS Type 557, shallow borehole fields in opposed to the deep borehole field can result a better performance. Type 201a uses insulated boundary condition around the borehole field volume in opposes to the Type 557.

The shallow borehole field or BTES-shape corresponds to the BTESs with the shape aspect ratio of less than one (depth/diameter), and the deep borehole field corresponds to the BTESs with the shape aspect ratio of greater than one (Sibbitt et al., 2015).

2. Mode "1" considers heat transfer only (no moisture transfer) with variable thermal properties and freezing/thawing process.

3. Mode " 2 " considers heat and moisture transfer (simultaneous heat and moisture transfer) with variable soil properties and freezing/thawing process.

Rad et al. (2014) compared the simulation time of Type 201a with Type 557 for a smaller system. The computer used for running the simulations had Intel Core i7 processor with 16 GB memory and ran with the following simulation time:

1. The simulation time for the system with Type 557 was 1 minutes and 19 seconds.

2. The simulation time for the system with Type 201a in mode " 0 " was 2 minutes and 23 seconds.

3. The simulation time for mode "1" and "2" were both in 2 hours and 35 minutes range. In this study, for the proposed system, mode " 0 " was initially selected. Due to the running time issues and the advantage of Type 557 over Type 201a for the deeper boreholes, TYPE 557 is chosen for the proposed model.

Sibbitt et al. (2015) have concluded that for a solar community similar to the DLSC, the BTES with deeper boreholes will provide a better BTES efficiency and higher solar fraction ultimately. In addition, by choosing deeper boreholes comparing to the DLSC's boreholes, the land surface area required for the BTES will also be reduced.

The ground loop heat exchanger's input parameters selected for this model are presented in Table 3-3. 
Table 3-3 Ground loop heat exchanger parameters

\begin{tabular}{|l|l|l|}
\hline Storage volume & 34017 & $\mathrm{~m}^{3}$ \\
\hline Borehole depth & 59 & $\mathrm{~m}$ \\
\hline Header depth & 1.2 & $\mathrm{~m}$ \\
\hline Number of boreholes & 90 & \\
\hline Borehole radius & 100 & $\mathrm{~mm}$ \\
\hline No. of borehole in series & 1 & \\
\hline Storage thermal conductivity & 2 & $\mathrm{~W} / \mathrm{mK}$ \\
\hline Storage heat capacity & 2016 & $\mathrm{~kJ} / \mathrm{m}^{3} \mathrm{~K}$ \\
\hline Inner radius of U-tube & 25.5 & $\mathrm{~mm}$ \\
\hline Outer radius of U-tube & 31.6 & $\mathrm{~mm}$ \\
\hline Center to center half distance & 76 & $\mathrm{~mm}$ \\
\hline Fill thermal conductivity & 1.5 & $\mathrm{~W} / \mathrm{mK}$ \\
\hline Pipe thermal conductivity & 0.2423 & $\mathrm{~W} / \mathrm{mK}$ \\
\hline Total borehole flow rate & 40000 & $\mathrm{~kg} / \mathrm{hr}$ \\
\hline Reference temperature & 10 & ${ }^{\circ} \mathrm{C}$ \\
\hline Pipe to pipe heat transfer & Considered & \\
\hline Fluid specific heat & 3.85 & $\mathrm{~kJ} / \mathrm{kgK}$ \\
\hline Fluid density & 968 & $\mathrm{~kg} / \mathrm{m}^{3}$ \\
\hline Number of simulation years & 20 & \\
\hline Maximum storage temperature & 100 & ${ }^{\circ} \mathrm{C}$ \\
\hline
\end{tabular}

The ground heat exchanger working fluid is $20 \%$ ethanol-in-water solution with the freezing point of $-10^{\circ} \mathrm{C}$. The header depth is the depth below the ground surface of the horizontal header pipe which feeds the ground heat exchangers. 


\subsubsection{Short term storage tank (STST)}

In addition to the stratified tank with multiple inlet and outlet, which is used in the DLSC's model, a more advanced tank type is selected. The new tank model allows for a heat exchanger within the reservoir and also allows unmatched inlet and outlet flows. The tank model used in TRNSYS is Type 60 which is a vertical tank with two inlet and two outlet streams and an internal heat exchanger. By introducing an internal heat exchanger, the glycol-water in the community loop of the tank is not mixed with the tank's water.

The tank is thermally stratified and is modelled by assuming fully-mixed equal volume segments. The number of segments, which is defined by the user, are the tank's temperature levels (nodes). The energy balance for the $i_{t h}$ node is shown in Figure 3-9.

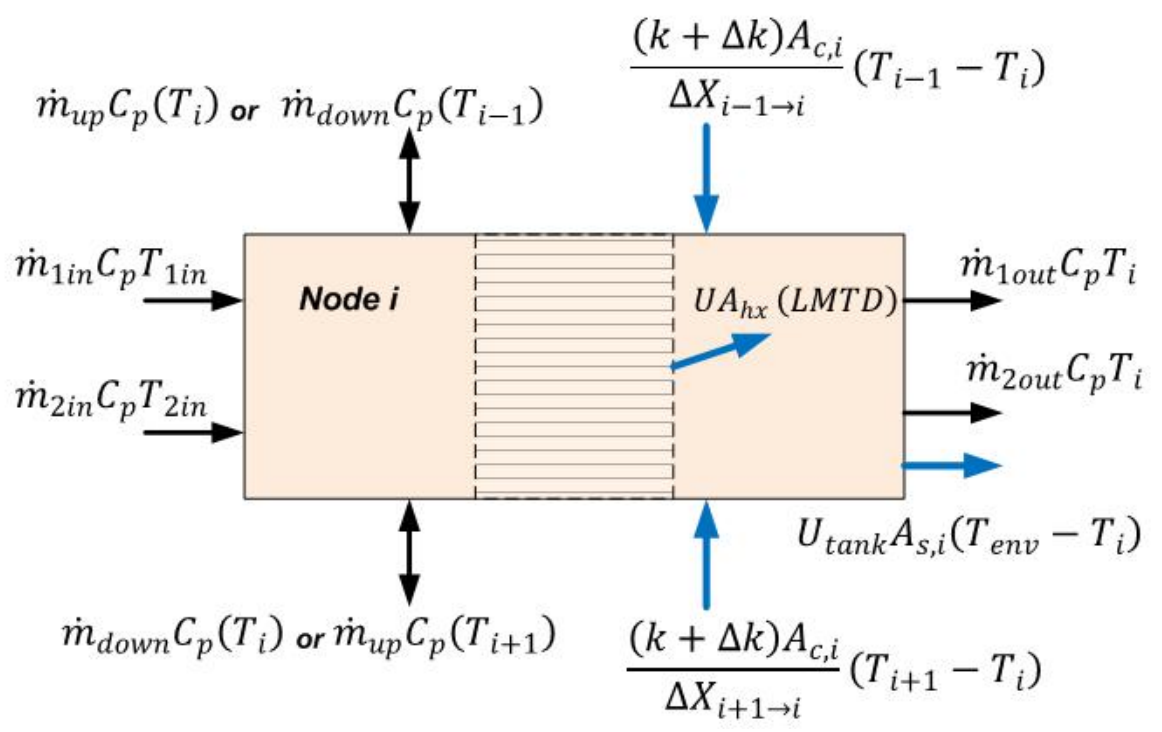

Figure 3-9 Representation of energy flows into a tank's node

The tank is uniformly insulated, and the total tank loss coefficient for each node is the loss coefficient (per unit of area) of the tank $\left(U_{\text {tank }}\right)$. There is de-stratification in the tank due to the mixing at node interfaces and conduction along the tank wall. To model de-stratification, an additional conductivity term $(\Delta k)$ is added to the conductivity of the tank fluid and is applied to the all nodes. The following equation is offered for a rough calculation of the $\Delta k$ (Klein et al., 2010).

$$
\Delta k=k_{\text {tank wall }} \frac{A_{c, \text { tank wall }}}{A_{c, \text { water }}}
$$

where $k_{\text {tank wall }}$ is the thermal conductivity of the tank wall and $A_{c}$ is the cross section area. 
The differential equation for the temperature of the $i_{t h}$ node is expressed as:

$$
\begin{aligned}
\left(M_{i} C_{p}\right) \frac{d T_{i}}{d t}= & \frac{(k+\Delta k) A_{c, i}}{\Delta X_{i+1 \rightarrow i}}\left(T_{i+1}-T_{i}\right)+\frac{(k+\Delta k) A_{c, i}}{\Delta X_{i-1 \rightarrow i}}\left(T_{i-1}-T_{i}\right) \\
& +U_{\text {tank }} A_{s, i}\left(T_{e n v}-T_{i}\right)+U_{h x} A_{h x}(L M T D) \\
& +\dot{m}_{\text {down }} C_{p}\left(T_{i-1}\right)-\dot{m}_{u p} C_{p}\left(T_{i}\right)+\dot{m}_{\text {down }} C_{p}\left(T_{i}\right)-\dot{m}_{u p} C_{p}\left(T_{i+1}\right) \\
& +\dot{m}_{1 \text { in }} C_{p} T_{1 \text { in }}-\dot{m}_{1 \text { out }} C_{p} T_{i}+\dot{m}_{2 \text { in }} C_{p} T_{2 \text { in }}-\dot{m}_{2 o u t} C_{p} T_{i}
\end{aligned}
$$

where $\frac{1}{U_{h x}}=\frac{1}{h_{0}}+\frac{\text { Pipe thichness }}{K_{\text {pipe }}}+\frac{1}{h_{i}}$

Each segment of the tank's temperatures are calculated by the integration of their time derivatives expressed in the Equation (3-5). At the end of each time step, temperature inversions are eliminated by mixing appropriate adjacent nodes.

The internal heat exchanger overall heat transfer coefficient $\left(U_{h x}\right)$ and logarithmic mean temperature differnce (LMTD) are determined iteratively by Type 60 . The outside natural convection coefficient of the internal heat exchanger $\left(h_{0}\right)$ is determined from:

$$
h_{0}=\frac{N u_{D} \times k}{D}, \text { where } N u_{D}=C R a^{n}
$$

where $C$ is constant in Nusselt number correlation, $R a$ is Rayleigh number, $n$ is exponent in Nusselt number correlation, $k$ is the tank fluid thermal conductivity, and $D$ is the outside diameter of the heat exchanger tube. Based on the geometry selected for the heat exchanger, the value for $C$ and $n$ are 0.5 and 0.25 , respectively (Klein at al., 2010). Due to the relatively small size of internal heat exchanger, compared with the tank volume, the relatively low average velocity of the water in the tank justifies the use of natural convection correlations in the analysis.

The internal convection heat transfer coefficient of the heat exchanger pipe are calculated based on the pipe dimensions plus inside fluid flow rate, temperature, and thermal properties.

Figure 3-10 shows a simple schematic of the STST. The selected STST volume is 171 $\mathrm{m}^{3}$ with a height of $4.5 \mathrm{~m}$. The two inlets and outlets of the tank are connected to the solar and BTES loops respectively. The maximum flow rates to the reservoir from the solar, BTES, and community loops are $90 \mathrm{~m}^{3} / \mathrm{hr}, 40 \mathrm{~m}^{3} / \mathrm{hr}$, and $20 \mathrm{~m}^{3} / \mathrm{hr}$ respectively.

The heat exchanger in the tank has the height of $2.1 \mathrm{~m}$. The pipe of the heat exchanger is made of copper with the outer diameter of $16 \mathrm{~mm}$ and thermal conductivity of $400 \mathrm{~W} / \mathrm{mK}$. The 
internal heat exchanger comprises of 40 parallel pipes with $20 \mathrm{~m}$ length each. The Reynolds number, corresponds to the internal flow is calculated to be 15,800 . Table 3-4 shows the parameters used for the STST's model.

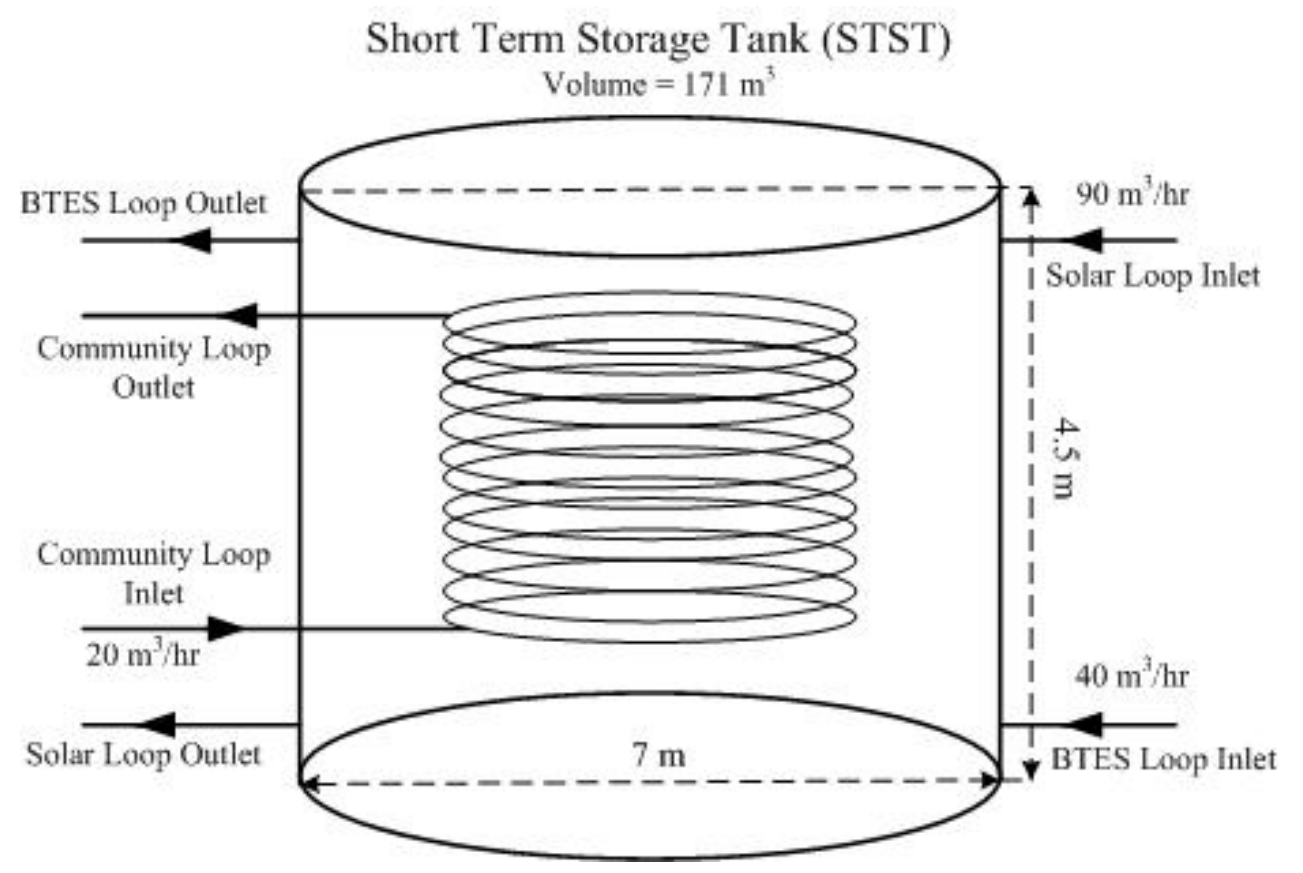

Figure 3-10 Simplified schematic of short term storage tank

Table 3-4 Short Term Storage Tank (STST) parameters

\begin{tabular}{|l|l|l|}
\hline Tank type (Cylindrical) & Vertical & - \\
\hline Tank volume & 171 & $\mathrm{~m}^{3}$ \\
\hline Tank height & 4.5 & $\mathrm{~m}$ \\
\hline Height* of inlet flow - BTES loop & 3.7 & $\mathrm{~m}$ \\
\hline Height* of outlet flow - BTES loop & 0.3 & $\mathrm{~m}$ \\
\hline Height* of inlet flow - solar loop & 0.3 & $\mathrm{~m}$ \\
\hline Height* of outlet flow - solar loop & 3.7 & $\mathrm{~m}$ \\
\hline Number of stratified segments (nodes) & 10 & \\
\hline Tank loss coefficient - average & 3 & $\mathrm{~kJ} / \mathrm{hr} \cdot \mathrm{m}^{2} \mathrm{~K}$ \\
\hline Internal heat exchanger pipe size & 15.87 & $\mathrm{~mm}$ \\
\hline $\begin{array}{l}\text { Total internal heat exchanger pipe length } \\
\text { (40 parallel pipes, 20 m each) }\end{array}$ & 800 & $\mathrm{~m}$ \\
\hline Total surface area of heat exchanger & 40 & $\mathrm{~m}$ \\
\hline Heat exchanger material conductivity & 400 & $\mathrm{~W} / \mathrm{mK}$ \\
\hline Height* of heat exchanger inlet & 3.3 & $\mathrm{~m}$ \\
\hline Height* of heat exchanger outlet & 1.2 & $\mathrm{~m}$ \\
\hline
\end{tabular}

*All heights are measured from the bottom of the tank 


\subsubsection{Heat exchangers and pumps}

Variable flow pumps with dedicated controls are used for the three most important hydronic loops, i.e., the solar, BTES and community loops. For transferring heat harvested from the solar collectors to the tank, a plate-and-frame heat exchanger is selected. The maximum flow rate of the solar loop heat exchanger on the load side (tank) is $90 \mathrm{~m}^{3} / \mathrm{hr}$ selected based on the tank output flow rate required to meet the community load. The maximum flow rate of the source side (solar collectors) is $60 \mathrm{~m}^{3} / \mathrm{hr}$ calculated as per the flow rates required by the solar collector system based on the manufacturer's recommended flow rates.

\subsubsection{Backup boiler and climate data}

The community supplemental heat source selected is a $500 \mathrm{~kW}$ natural gas boiler. The boiler is mostly in operation for the first few years of system operation, before the BTES becomes fully charged and will be redundant then after. The boiler set-point temperature is $41^{\circ} \mathrm{C}$.

The community thermal load and solar heat are calculated based on the Canadian Weather Year for Energy Calculation (CWEC) hourly data for the City of Calgary, 46 km north of Okotoks. It is the closest city next to the Calgary which the weather data is available in the CWED library. Type 201a in BTES model, mentioned in Section 3.2.2, uses extended weather data with climate parameters such as ground surface albedo, snow cover depth, snow depth density and rainfall ( $\mathrm{Rad}$ et al., 2014). These parameters are extracted from Environment Canada and defined in an additional weather data file. The supplementary hourly weather data was used as a separate input file for the BTES model.

\subsection{System simulation results}

\subsubsection{BTES performance}

Figure 3-11 demonstrates the five-year simulation results for the BTES system. It shows the annual BTES energy losses plus energy injected to and extracted from the ground, which is renewed each year starting January $1^{\text {st }}$. The average ground temperature (AGT) at the beginning of year one is $10^{\circ} \mathrm{C}$, which is the initial ground temperature. After two years, the average ground temperatures start exhibiting almost the same annual fluctuations for the subsequent years. From year three, at the beginning of January, the AGT is $57^{\circ} \mathrm{C}$. Moving forward a year, as heat is extracted from the ground, the AGT drops to the minimum $50^{\circ} \mathrm{C}$ until around the end of March. Then the AGT starts to rise and reaches a maximum temperature of $76^{\circ} \mathrm{C}$ around mid-October. 
Figure 3-12 also shows the accumulated energy injected to and extracted from the BTES. During heat extraction from the ground, the stored energy starts to decrease until the system reaches to the point where it does not require any heat from the ground, and subsequently the solar heat is injected into the ground. The heat extraction period is from mid-October to the end of March. The solar heat injection is mainly from the rest of the year, i.e., the beginning of April to the middle of October, which includes the entire summer and the shoulder seasons.

During the first year of operation, the ground is mainly becoming charged via heat from the boiler and solar-energy injection. In the fifth year, the total annual solar heat injection into the ground is calculated to be around $3900 \mathrm{GJ}$. Of which, $1800 \mathrm{GJ}$ is extracted during the heating season. The difference is due to the BTES heat losses as shown in Figure 3-11; the BTES overall thermal efficiency is calculated to be $46 \%$.

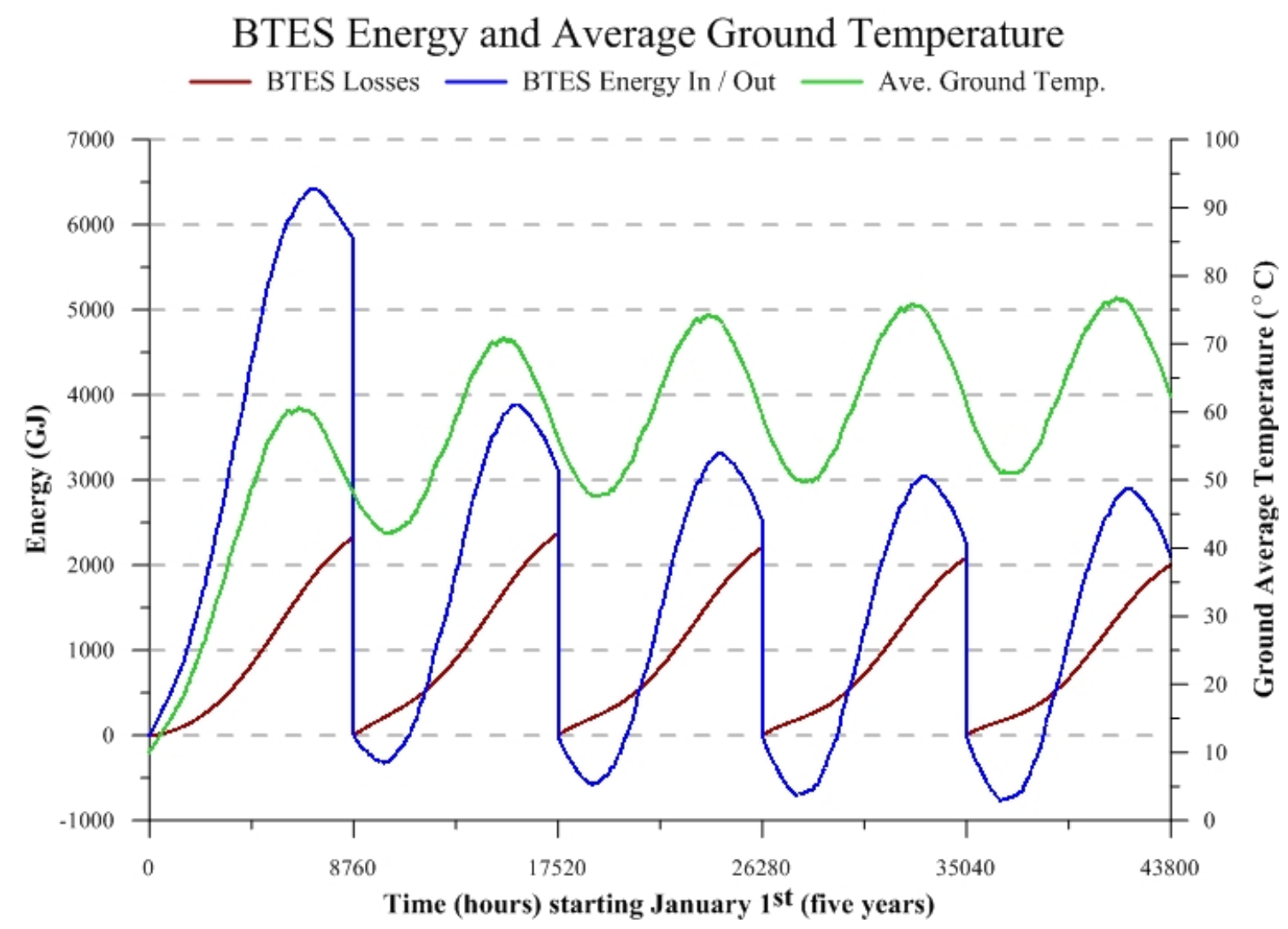

Figure 3-11Annual BTES system accumulated energy and average temperature 


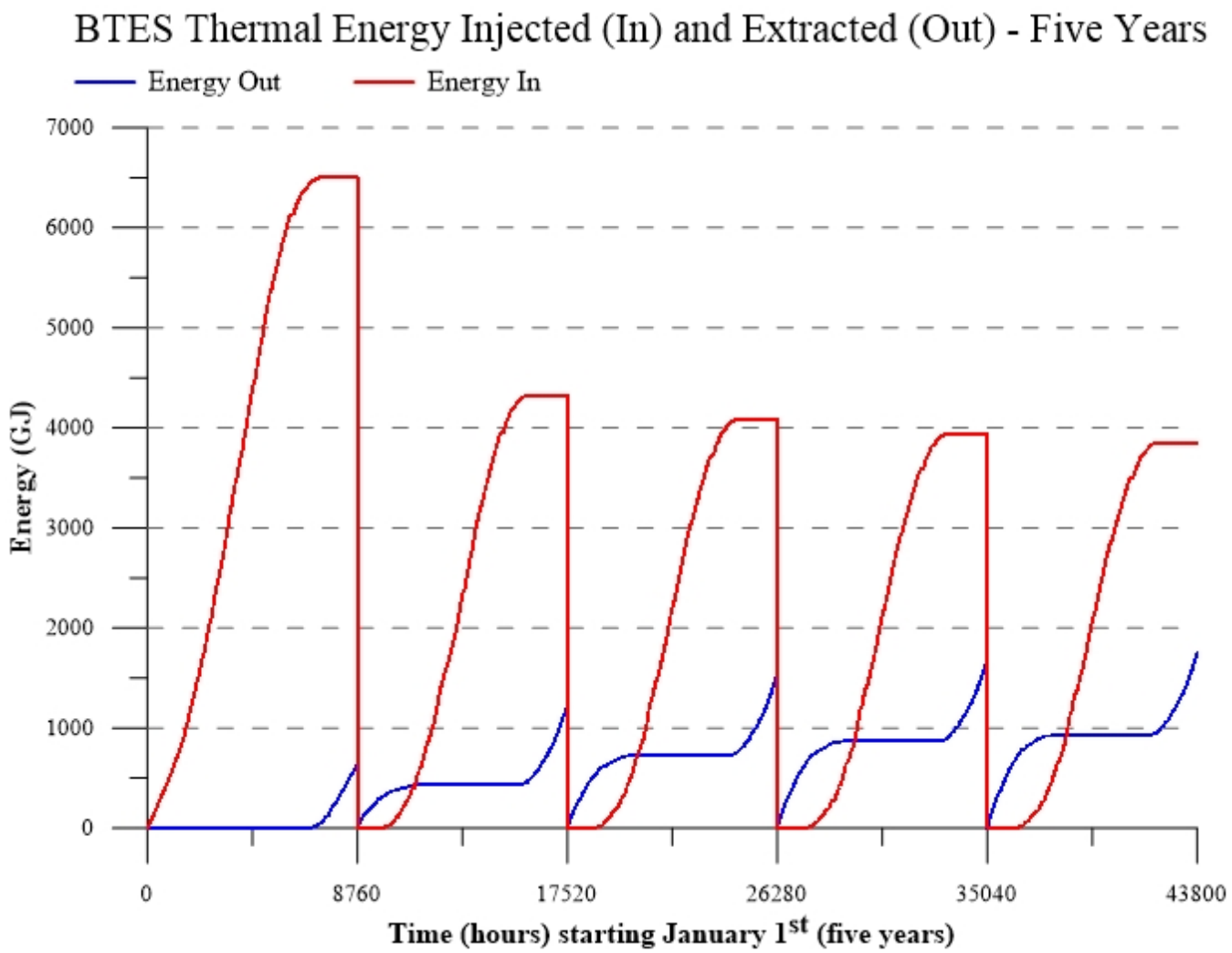

Figure 3-12 Annual accumulated thermal energy injected into and extracted from the BTES

\subsubsection{System energy and performance}

Figure 3-13 and Figure 3-14 show the system annual accumulated energy in five years.

The curves represent 1) community heating load, 2) BTES energy injection and extraction, 3) solar thermal collectors' energy collection, and 4) boiler auxiliary heat.

In year five, $4700 \mathrm{GJ}$ of energy is collected by the solar collectors, and about $4000 \mathrm{GJ}$ of that amount is directed into the ground to the seasonal storage. As it can be observed, the total annual community thermal load of $2350 \mathrm{GJ}$ is mostly met by the solar thermal collectors via BTES. In this year, the heat supplied by the auxiliary boiler is only 103 GJ. The solar fraction $\mathrm{SF}$ ) of the community at the end of the year five is $96 \%$. In other words, almost all the space heating demand by the proposed community is met by the solar thermal system with BTES. 


\section{System Energy}

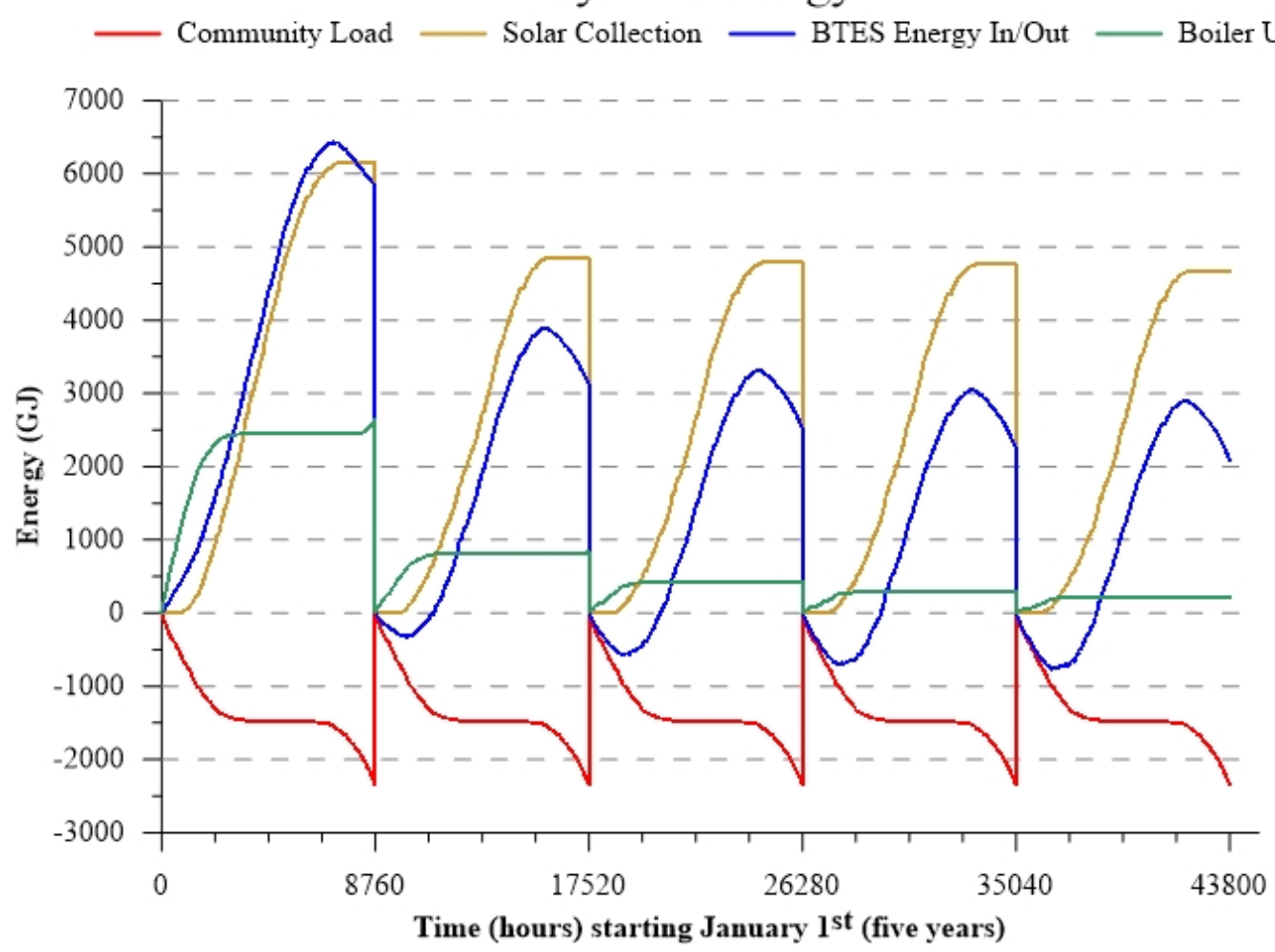

Figure 3-13 Five-year annual accumulated system energy

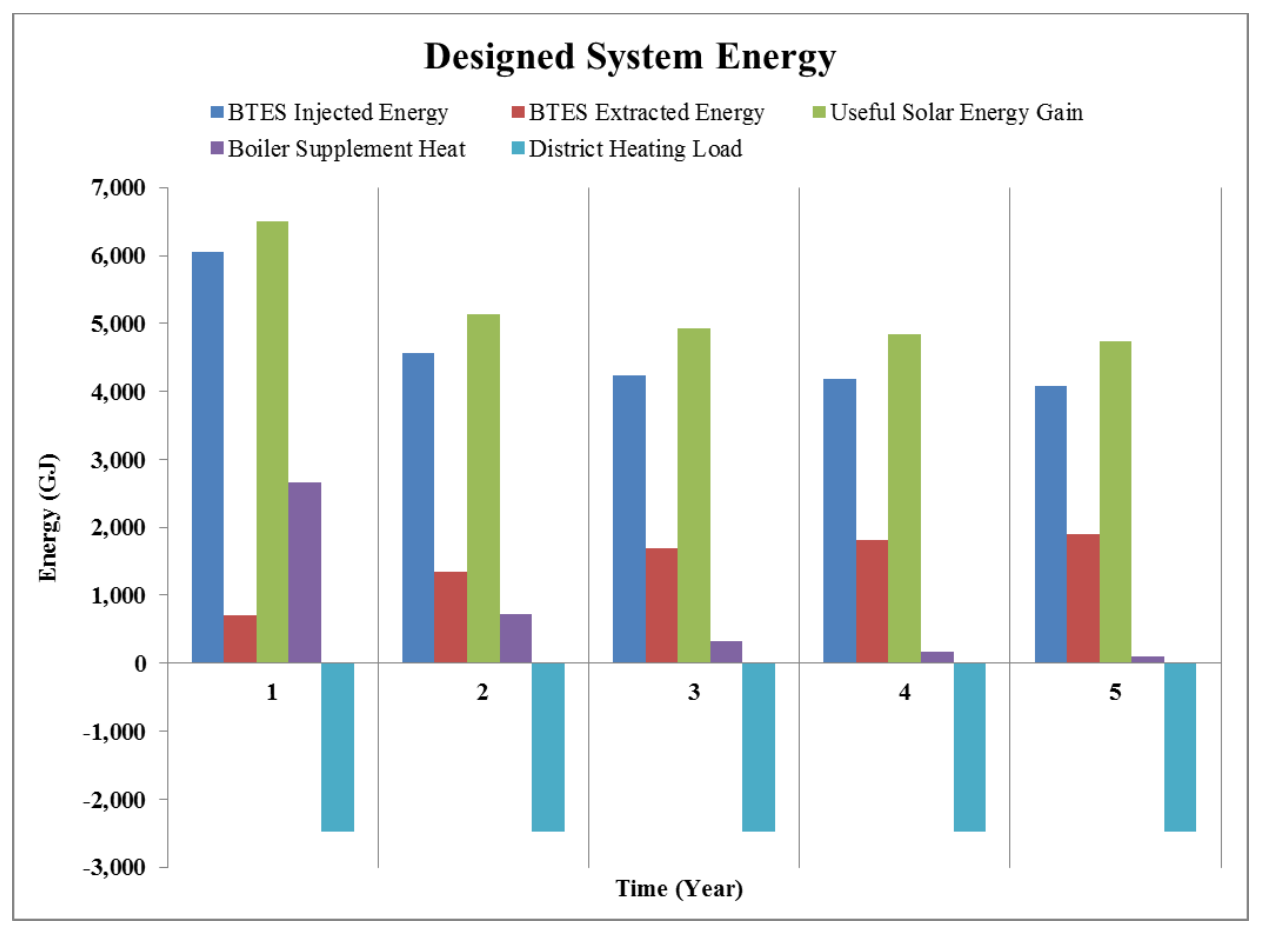

Figure 3-14 Annual system energy 


\subsubsection{Results comparison}

The annual simulation results, for five years, are tabulated in Table 3-5 and Table 3-6. For comparison of the results, published DLSC calculated performance parameters are also included in Table 3-5 and Table 3-6 (SAIC Canada, 2002). The annual community thermal demands are shown with the negative number as it is served by the main system.

Table 3-5 Year one and year two simulation summary

\begin{tabular}{|l|c|c|c|c|}
\cline { 2 - 5 } \multicolumn{1}{c|}{} & \multicolumn{2}{|c|}{ Year 1 } & \multicolumn{2}{c|}{ Year 2 } \\
\cline { 2 - 5 } \multicolumn{1}{c|}{} & DLSC & Proposed & DLSC & Proposed \\
\hline Community Thermal Demand (GJ) & $-2,530$ & $-2,349$ & $-2,530$ & $-2,349$ \\
\hline Solar Energy Gain (GJ) & 4,480 & 6,511 & 3,830 & 5,133 \\
\hline Boiler Supplement Heat (GJ) (eff=0.85) & 860 & 2,655 & 600 & 729 \\
\hline Solar Energy Into the BTES (GJ) & 3,030 & 6,044 & 2,390 & 4,563 \\
\hline Solar Energy Extracted from the BTES (GJ) & 273 & 705 & 550 & 1,339 \\
\hline BTES Losses (GJ) & NA* & 2,538 & NA* & 2,478 \\
\hline BTES Average Temperature $\left({ }^{\circ} \mathrm{C}\right)$ at yr end & 40 & 49.0 & 41.4 & 57.0 \\
\hline BTES Efficiency & $9 \%$ & $12 \%$ & $23 \%$ & $29 \%$ \\
\hline Solar Fraction (SF) & $66 \%$ & $0 \%$ & $76 \%$ & $69 \%$ \\
\hline
\end{tabular}

*Not Available

Table 3-6 Year three to year five simulation summary

\begin{tabular}{|l|c|c|c|c|c|c|}
\cline { 2 - 7 } \multicolumn{1}{c|}{} & \multicolumn{2}{c|}{ Year 3 } & \multicolumn{2}{c|}{ Year 4 } & \multicolumn{2}{c|}{ Year 5 } \\
\cline { 2 - 7 } \multicolumn{1}{c|}{} & DLSC & Proposed & DLSC & Proposed & DLSC & Proposed \\
\hline Community Thermal Demand (GJ) & $-2,530$ & $-2,349$ & $-2,530$ & $-2,349$ & $-2,530$ & $-2,349$ \\
\hline Solar Energy Gain (GJ) & 3,630 & 4,926 & 3,550 & 4,843 & 3,520 & 4,746 \\
\hline Boiler Supplement Heat (GJ) (eff=0.85) & 390 & 327 & 300 & 171 & 290 & 103 \\
\hline Solar Energy Into the BTES (GJ) & 2,200 & 4,239 & 2,110 & 4,185 & 2,080 & 4,087 \\
\hline Solar Energy Extracted from the BTES (GJ) & 770 & 1,692 & 844 & 1,818 & 853 & 1,892 \\
\hline BTES Losses (GJ) & NA* & 2,268 & NA* & 2,172 & NA* & 2,089 \\
\hline BTES Average Temperature $\left({ }^{\circ} \mathrm{C}\right)$ at yr end & 44.3 & 60.0 & 51.9 & 62.0 & 55.6 & 64.0 \\
\hline BTES Efficiency & $35 \%$ & $40 \%$ & $40 \%$ & $43 \%$ & $41 \%$ & $46 \%$ \\
\hline Solar Fraction (SF) & $85 \%$ & $86 \%$ & $88 \%$ & $93 \%$ & $89 \%$ & $96 \%$ \\
\hline
\end{tabular}

*Not Available

The proposed system specifications versus the DLSC system are shown in Table 3-7. The proposed system's results, compared to the DLSC's calculated results, show that with both systems having almost the same community heating load, the proposed configuration performs better. In year five, one important observation is the ratio of the useful solar energy gain that 
goes to the BTES. This ratio in the DLSC is $60 \%$ whereas for the proposed system it is $85 \%$. Therefore, in the proposed system, more heat is injected into the ground. In the same year, the average ground temperature (AGT) in the proposed system is $64^{\circ} \mathrm{C}$ and in DLSC is $55.6^{\circ} \mathrm{C}$. In the proposed system, in year one as the ground is not charged, the inlet fluid temperatures to the solar collectors are lower compared to the later years. Therefore, more solar energy is collected due to the higher fluid temperature differences between solar collectors' inlet and outlet flow (i.e., 4926 GJ in the year one versus 4087 GJ).

Figure 3-15 compares the solar fractions (SFs) of the DLSC and the proposed system for five years. It is seen that, after three years, the SFs of the proposed system are higher than for the DLSC.

Table 3-7 System specifications summary

\begin{tabular}{|l|c|c|c|}
\hline \multicolumn{4}{|c|}{ Sys te m specifications } \\
\hline Number of Boreholes & & 144 & 90 \\
\hline Borehole Depth & $\mathrm{m}$ & 37 & 59 \\
\hline Borehole Spacing & $\mathrm{m}$ & 3 & 3 \\
\hline BTES Volume & $\mathrm{m}^{3}$ & 34,133 & 34,017 \\
\hline Total Borehole Length & $\mathrm{m}$ & 5,328 & 5,310 \\
\hline Number of Solar Panels & & 800 & 600 \\
\hline Total Solar Panel Area & $\mathrm{m}^{2}$ & 2,293 & 1,722 \\
\hline Short Term Storage Tank & $\mathrm{m}^{3}$ & 240 & 171 \\
\hline
\end{tabular}

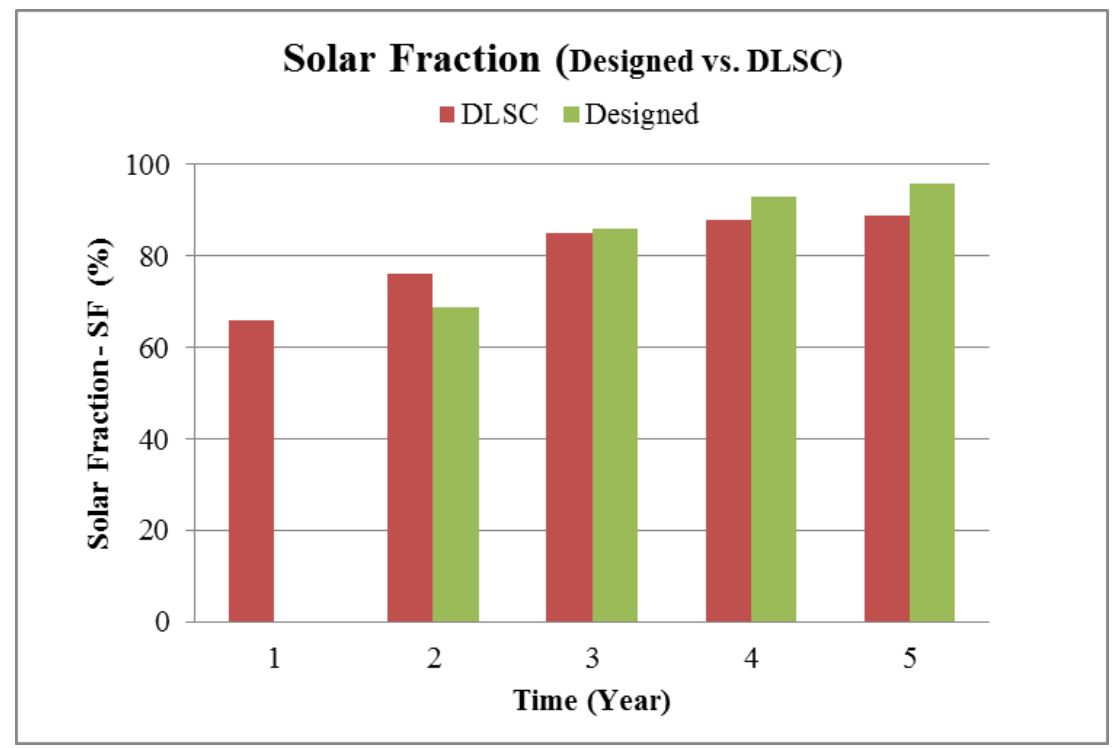

Figure 3-15 Solar fraction comparison, DLSC vs. proposed system 


\subsection{System cost comparisons}

By using the same cost index which was used for the DLSC in 2005-2006 (Hellstrom and Sanner, 1997), the initial cost of the proposed system is estimated to be $\$ 1.9$ million, which is $19 \%$ less from the initial cost of the DLSC. Based on the natural-gas price of $\$ 6.17$ per GJ (Enbridge Gas, 2016), the simple payback for the proposed systems is approximately 38 years. More detailed cost investigation is required in future studies.

Table 3-8 shows the costs for the main system components and provides comparisons. Other than the initial cost, by eliminating $25 \%$ of solar thermal collector area and $38 \%$ of the boreholes footprint area, more flexibility in layout planning is available. With possibly more unoccupied roof area with high solar radiation levels, solar PV collectors could be installed for offsetting the system electrical demand, i.e., pumps, controls and air handlers.

Table 3-8 Comparison of costs for the DLSC and proposed systems

\begin{tabular}{|l|c|c|c|}
\hline \multicolumn{4}{|c|}{ System Initial Cost (Incre me ntal) } \\
\hline \multicolumn{2}{|c|}{ DLSC Cost Index } & DLSC & Proposed \\
\hline Number of Boreholes & & 144 & 90 \\
\hline Borehole Depth & & 37 & 59 \\
\hline Number of Solar Panels & & 800 & 600 \\
\hline Cost of BTES & $116(\$ / \mathrm{m})$ & $\$ 618,048$ & $\$ 615,960$ \\
\hline Cost of Solar Panels & $497\left(\$ / \mathrm{m}^{2}\right)$ & $\$ 1,139,621$ & $\$ 855,834$ \\
\hline $\begin{array}{l}\text { Short term Storage Tank } \\
\text { Including the Energy Center }\end{array}$ & $2500\left(\$ / \mathrm{m}^{3}\right)$ & $\$ 600,000$ & $\$ 427,500$ \\
\hline Total Initial Cost & & $\$ 2,357,669$ & $\$ 1,899,294$ \\
\hline Initial Cost Saving & & Base & $19 \%$ \\
\hline BTES Land Area Saving & & Base & $38 \%$ \\
\hline Solar Area Saving & & Base & $25 \%$ \\
\hline
\end{tabular}

\subsection{Conclusion}

An integrated model for heating a solar community similar to the DLSC with 52 homes is developed and simulated. It is shown that by using almost the same system configuration as in DLSC and an advanced integrated simulation model, a smaller system with the same or better performance can be designed, which ultimately leads to a less expensive system.

The main improvements in the proposed system compared to the DLSC system are summarized as follows: 
1) Efficient BTES design with less heat losses, by proposing a new borehole field configuration and the deeper boreholes. The new model achieves a $38 \%$ reduction of the BTES footprint.

2) By selecting a more detailed STST module with an internal heat exchanger for the community loop, in contrast to the simple stratified tank, the STST efficiency and the size requirement compare to the DLSC was reduced. A new STST combined with the BTES designs leads reductions in total solar collector area and STST volumetric size of $25 \%$ and $29 \%$ respectively.

3) Active hourly integration of the thermal loads with all of the system components for five years simulation period. The optimum hourly interactions of the community thermal load with all system equipment and controls eliminates the unnecessary full-capacity operation in the sub-systems, i.e., BTES, solar and community loops. The proposed system shows better results comparing to the five years actual operation of the DLSC. During the first five years of DLSC operation, both model and physical system went through the changes and modifications to improve the system performance.

4) Lower initial system cost. The new system requires approximately $19 \%$ less capital cost to build. In addition to the initial cost, the reduced footprints and real estate requirements are significant added benefits. 


\section{Chapter 4 : Combined Heating and Cooling System for a Solar Community with Borehole Thermal Storage}

The majority of existing solar communities are for heating only, and solar cooling has received less attention. Henning (2007) reported about seventy solar assisted cooling systems in Europe. For making a solar cooling system economically viable, other systems such as space heating or domestic hot water generating system should be integrated or supplemented. IEA Task 25 investigated eleven solar assisted cooling plants in six countries. Two main problems with most of the plants were control design and inappropriate commissioning process. More development is expected with increased competitiveness of solar cooling technology in future.

In Chapter 3, the heating only modeling of a solar community similar to the DLSC located in Okotoks, Alberta, was presented and compared with the DLSC's published result performance. This chapter presents a unique design for a solar heating and cooling plant for a hypothetical community located in Toronto, Canada. This community is also similar to the community modeled in Chapter 3 but with the Toronto climate data which needs cooling in summer. The solar thermal collectors provide $100 \%$ of community heating demand in the heating season as well as assisting the absorption chiller in providing cooling for the community in the summer time. The system has two sets of BTES with two different storage temperatures. One is for storing solar heat and the other for storing rejected waste heat from the chiller at a slightly lower temperature than the solar BTES and higher than the ambient temperature.

\subsection{System layout}

Figure 4-1 depicts the system configuration and equipment. The community hydronic loop operates in either space heating or cooling mode based on the heating and cooling demands (Figure 4-2 and Figure 4-3). In both heating and cooling season, the short-term storage tank (STST) receives the harvested solar thermal energy through a solar hydronic loop.

In the cooling season (Figure 4-3) a high-temperature BTES receives and stores the excess heat in the STST. Part of the heat in the STST is transferred to the chiller hot water loop. A boiler regulates and maintains the input temperature of the chiller hot water for the optimum chiller operation. The rejected heat from the chiller is directed to the medium temperature BTES. 
The community fan coils receive the chilled water from chillers' chilled water loop. In the cooling mode, the high and medium temperature borehole systems operate independently.

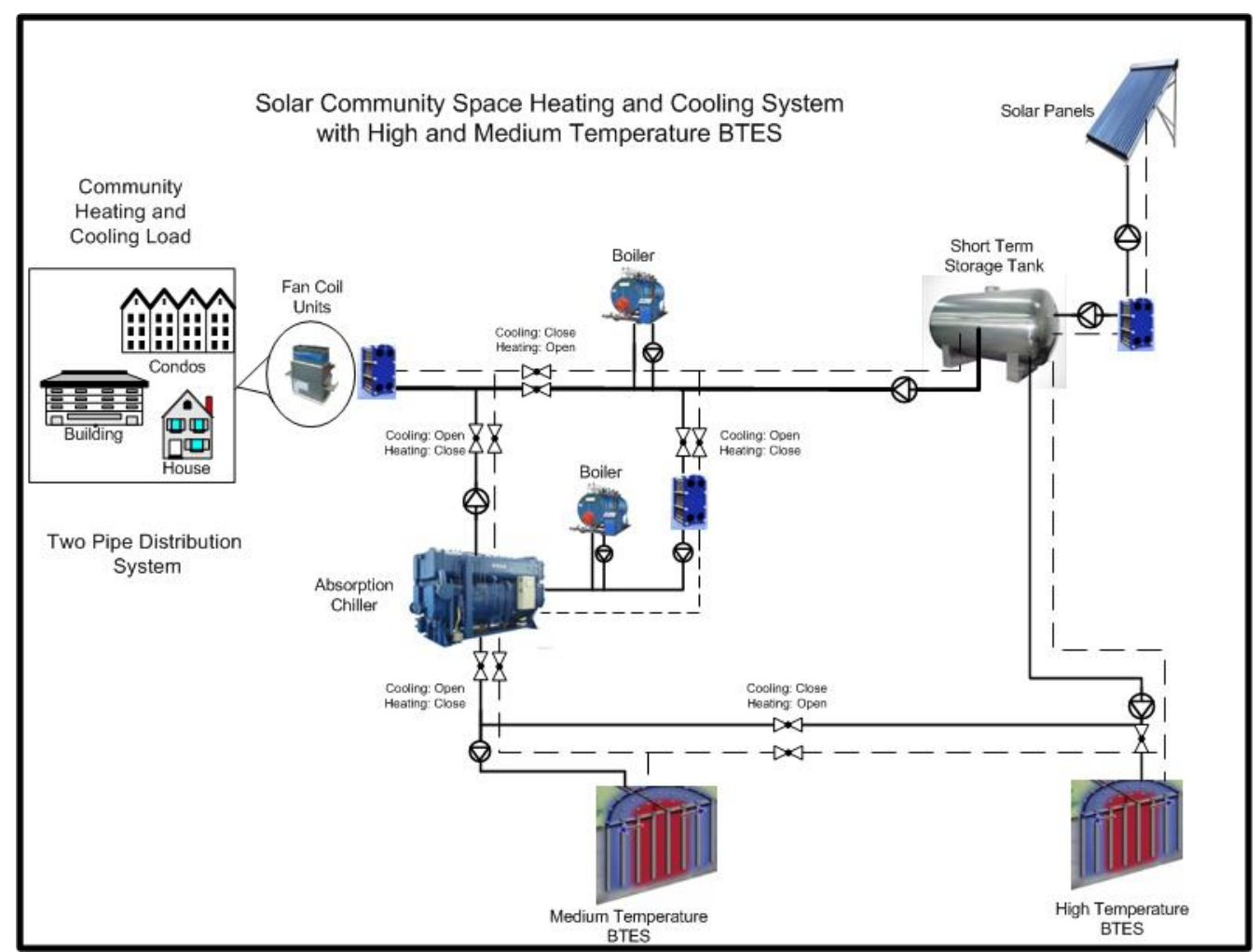

Figure 4-1 Overall system schematic - Solar community space heating and cooling system with high and medium temperature BTES

In the heating mode (Figure 4-2) the two borehole systems are connected in the heat extraction process. Water from the STST tank first passes through the medium-temperature BTES to collect the low-grade heat and then pass through the high-temperature BTES for the extraction of higher grade heat. Community fan coils receive hot water from hot water loop connected to the STST. The boiler in this loop operates when the temperature of the community loop falls below its set point (i.e., $40^{\circ} \mathrm{C}$ ). 


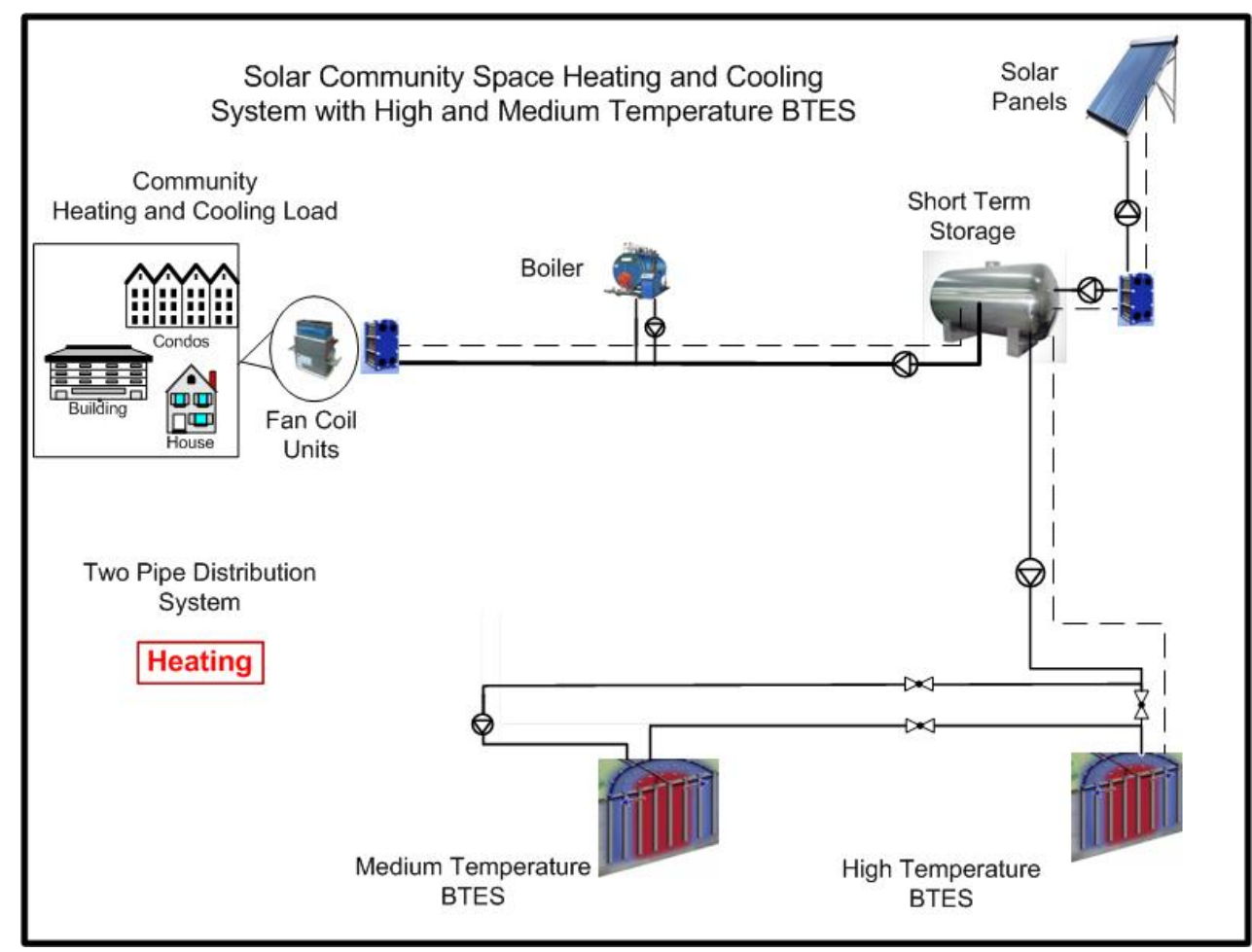

Figure 4-2 System schematic- Solar community space heating and cooling system with high and medium temperature BTES - Heating mode

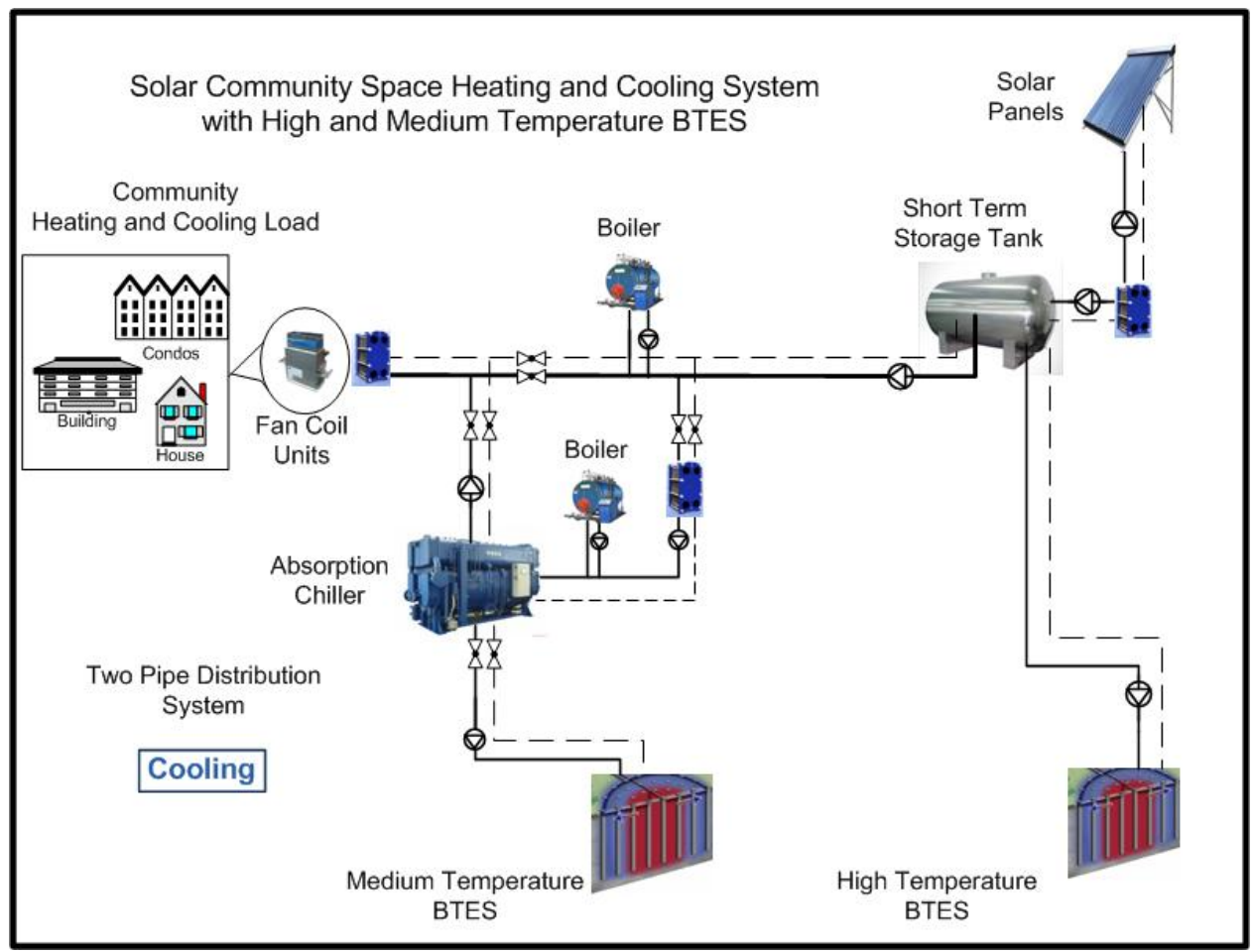

Figure 4-3 System schematic- Solar community space heating and cooling system with high and medium temperature BTES - Cooling mode 


\subsection{The community heating and cooling load}

The selected community is similar to the community chosen in Section 3.1. It comprises a combination of single and multifamily residential houses located in Toronto, Ontario with a considerable amount of cooling load. The annual community heating and cooling load are 2350 GJ and 1181 GJ with the peak heating and cooling load of $457 \mathrm{~kW}$ and $369 \mathrm{~kW}$, respectively. The heating and cooling loads are calculated by eQuest software (eQuest, 2010).

Figure 4-4 depicts the hourly community heating and cooling load profile, and Figure 4-5 shows the monthly heating and cooling demand. The maximum monthly heating and cooling demands are $568 \mathrm{GJ}$ and $455 \mathrm{GJ}$ which corresponds to the months of January and July respectively.

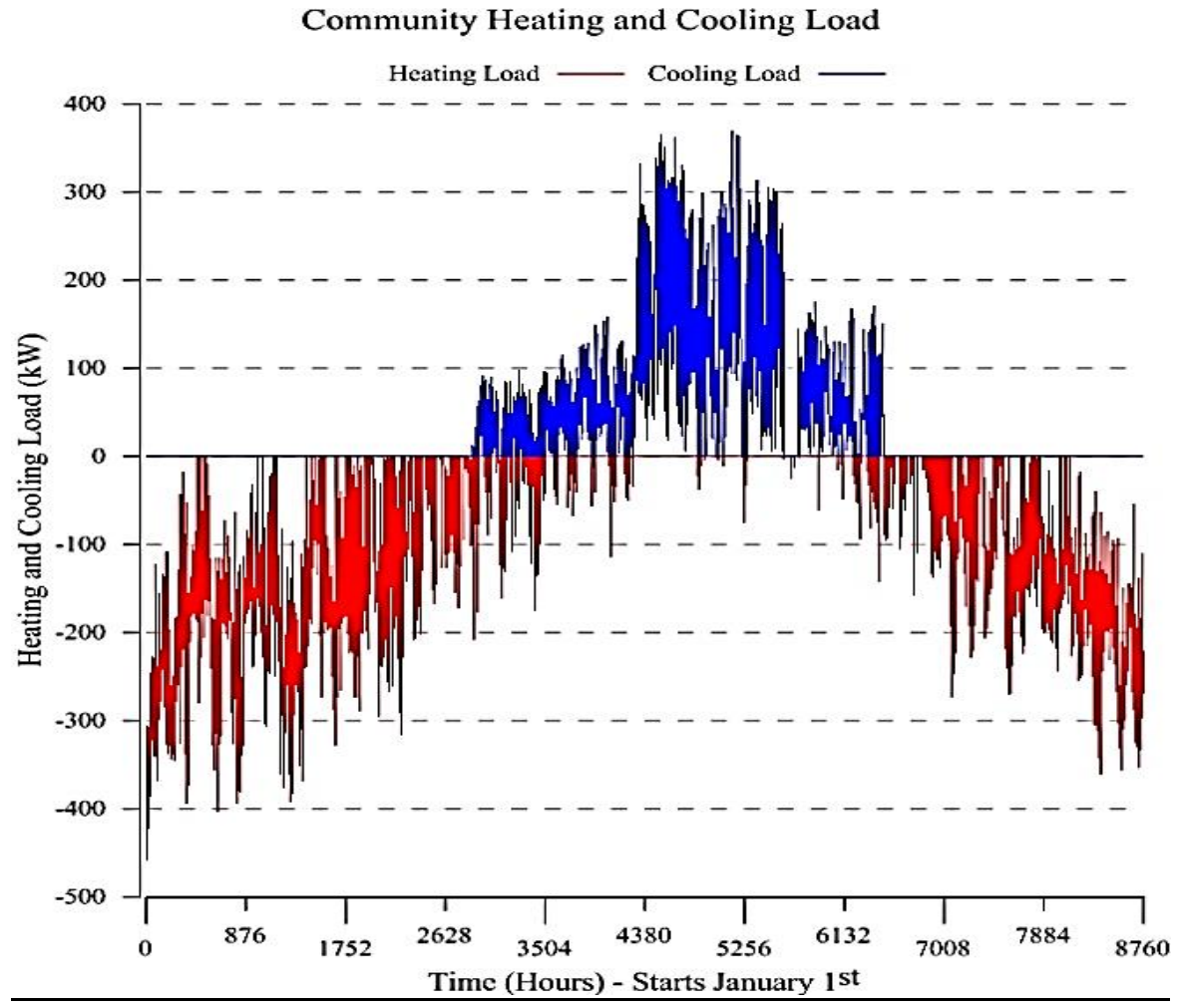

Figure 4-4 Community hourly heating and cooling load

The houses in the selected community, similar to DLSC, are built as per R2000 standards (NRCan, 2012) and are equipped with an air handler with a water-to-air fan coil. The fan coils, 
depending on the season, receive either hot or chilled water from a central energy center through a two-pipe distribution system. The house envelope details are provided in Table 3-1, Chapter 3.

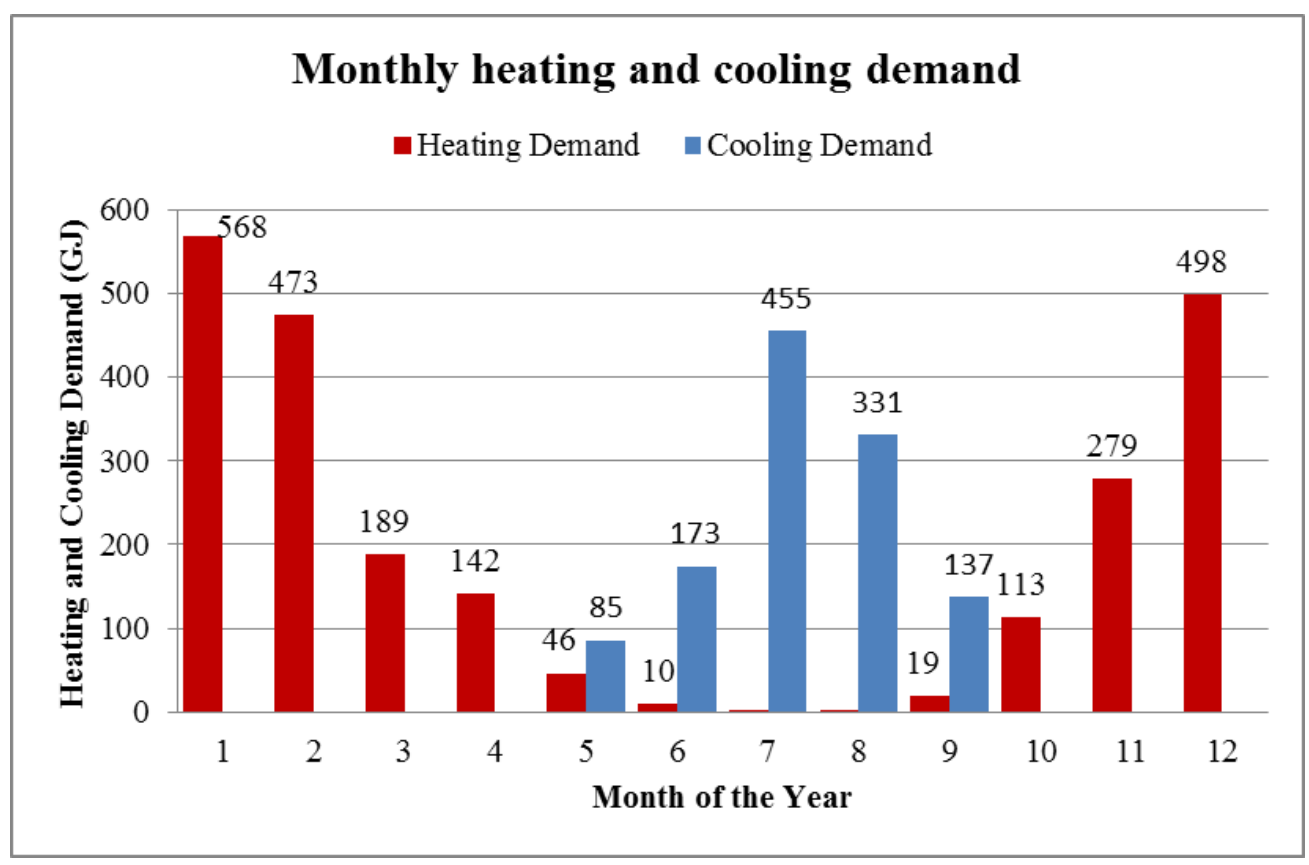

Figure 4-5 Community monthly heating and cooling demand

\subsection{System major equipment and methodology}

An integrated heating and cooling system are modeled using TRNSYS 17 software (Klein et al., 2010). Figure 4-6 depicts the TRNSYS model layout.

The system contains four hydronic loops that are connected to the STST, 1) solar loop, 2) high-temperature BTES loop, 3) chiller hot water loop, and 4) community hot water loop. There are also three other main loops connected to the chiller, 1) hot water loop to the STST, 2) cooling water loop to the medium-temperature BTES, and 3) community cold water loop.

The liquid flow through the solar collectors transfers the solar heat gain to the solar loop connected the STST through a heat exchanger. The model receives the hourly community heating and cooling loads from the spreadsheets resulting from eQuest community load calculations.

A boiler is connected to the community hot water loop to maintain the desired temperature needed for the fan coils in the community in the heating season. The same boiler also serves to maintain the hot water temperature required by the chillers through the hot water loop. 


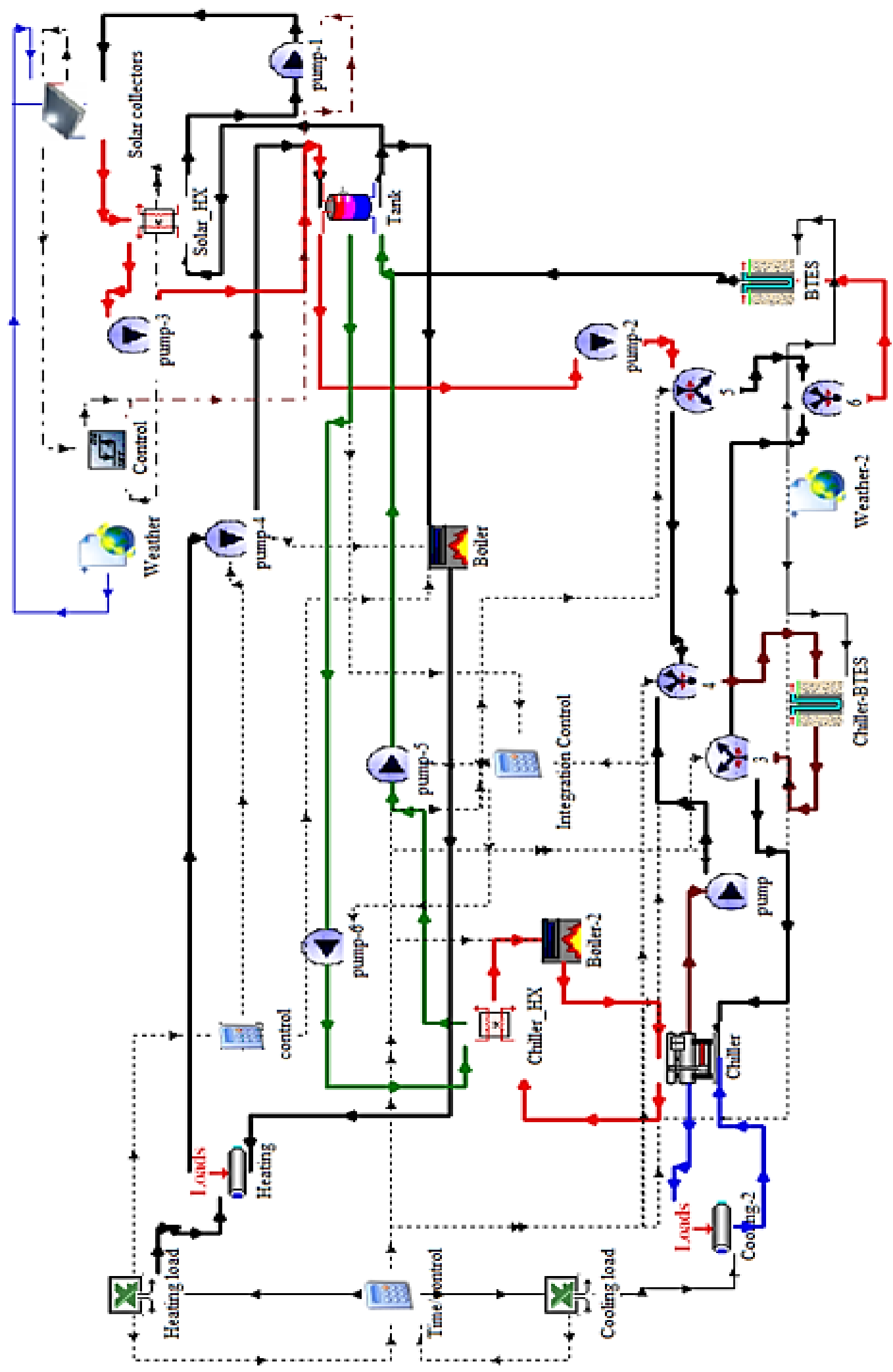

Figure 4-6 TRNSYS heating and cooling model schematic 


\subsubsection{Solar collectors}

The selected solar collectors are of a flat-plate type with the same specifications presented in the Section 3.2.1. The solar collectors, similar to the model presented in Chapter 3, have the total area of $1722 \mathrm{~m}^{2}$, which includes 600 solar collectors in three parallel arrays with 200 collectors connected in series. The solar collectors face south and have a $45^{\circ}$ surface inclination.

\subsubsection{High-temperature BTES}

The high-temperature BTES (solar-BTES) incorporated into the model is identical in shape, and size to the BTES presented in Section 3.2.2. As the system model uses two BTESs (solar-BTES and chiller-BTES), for consistency in the performance of the two boreholes and accurate comparisons, both boreholes are modeled using Type 557. The solar-BTES has 90 boreholes each of $59 \mathrm{~m}$ depth. The boreholes are configured in a circular field with an average $3 \mathrm{~m}$ borehole separation. The cylindrical shape storage that contains the boreholes has a volume of $34,017 \mathrm{~m}^{3}$ with coverage of $580 \mathrm{~m}^{2}$ ground surface area. The nominal HDPE pipe size comprising the U-tube ground heat exchanger is $32 \mathrm{~mm}$ in diameter. The thermal conductivities of the borehole grout and the ground comprising the storage volume are $1.5 \mathrm{~W} / \mathrm{mK}$ and $2 \mathrm{~W} / \mathrm{mK}$ respectively.

The borehole layout, which consists of 10 circuits connected in parallel to the main header. Each circuit consists of nine boreholes connected in parallel (Figure 3-7 and Figure 3-8).

\subsubsection{Medium temperature BTES}

The medium-temperature BTES (chiller-BTES) is installed in a location without having any direct thermal interaction with the solar-BTES. Type 557 is used for the chiller-BTES. The configuration and the borehole's characteristics of the chiller BTES are tabulated in Table 4-1.

The volume of the cylindrical shaped storage region which contains the boreholes is set to $93,470 \mathrm{~m}^{3}$, with the boreholes, placed uniformly within the storage volume. The properties of the ground within the storage volume are considered uniform while the properties of the ground outside the storage volume are described with several vertical layers. By considering the spacing between the boreholes to be $3 \mathrm{~m}$, the storage volume is calculated from the relationship suggested in TRNSYS manual (Klein et al., 2010) as shown in Equation (4-1). 
Storage Volume $=\pi \times$ Number of Boreholes $\times$ Borehole Depth $\times(0.525 \times$ Borehole

Spacing $)^{2}$

Storage Volume $=\pi \times 80 \times 150 \times(0.525 \times 3)^{2}=93,470 \mathrm{~m}^{3}$

Table 4-1 Chiller ground loop heat exchanger parameters - Type 557

\begin{tabular}{|l|l|l|}
\hline Storage volume & 93470 & $\mathrm{~m}^{3}$ \\
\hline Borehole depth & 150 & $\mathrm{~m}$ \\
\hline Header depth & 1.2 & $\mathrm{~m}$ \\
\hline Number of boreholes & 80 & \\
\hline Borehole radius & 100 & $\mathrm{~mm}$ \\
\hline No. of borehole in series & None & \\
\hline Storage thermal conductivity & 2 & $\mathrm{~W} / \mathrm{mK}$ \\
\hline Storage heat capacity & 2016 & $\mathrm{~kJ} / \mathrm{m}^{3} \mathrm{~K}$ \\
\hline Inner radius of U-tube & 25.5 & $\mathrm{~mm}$ \\
\hline Outer radius of U-tube & 31.6 & $\mathrm{~mm}$ \\
\hline Center to center half distance & 76 & $\mathrm{~mm}$ \\
\hline Fill thermal conductivity & 1.5 & $\mathrm{~W} / \mathrm{mK}$ \\
\hline Pipe thermal conductivity & 0.2423 & $\mathrm{~W} / \mathrm{mK}$ \\
\hline Total borehole flow rate & 154000 & $\mathrm{~kg} / \mathrm{hr}$ \\
\hline Reference temperature & 10 & ${ }^{\circ} \mathrm{C}$ \\
\hline Pipe to pipe heat transfer & Considered & \\
\hline Fluid specific heat & 3.85 & $\mathrm{~kJ} / \mathrm{kgK}$ \\
\hline Fluid density & 968 & $\mathrm{~kg} / \mathrm{m}^{3}$ \\
\hline Number of simulation years & 20 & \\
\hline Maximum storage temperature & 100 & ${ }^{\circ} \mathrm{C}$ \\
\hline
\end{tabular}

The depth of each borehole (from the surface) is $150 \mathrm{~m}$. The selected depth is based on typical drilling depth possible in Toronto area that will reduce the footprint of the borehole field. The number of boreholes is obtained by trial-and-error, and its initial value is calculated from the total borehole length which was approximated from the relation between equipment capacity 
(i.e., Chiller) and value of borehole length per kilowatt of the equipment capacity (i.e., 40 $\mathrm{m} / \mathrm{kW}$ ) (GSHP, 2011).

The borehole depth is the height of the storage volume. This value is also the length of one of the U-tube heat exchangers from the ground surface to the bottom of the U-tube bend.

Header depth is the depth below the surface of the top of the U-tube. This value is also typically the depth below the surface of the horizontal header pipe which feeds the ground heat exchanger.

The total number of boreholes within the storage volume is 80 . The radius of each borehole is $100 \mathrm{~mm}$. Each borehole's circuit has eight boreholes connected in series, and ten circuits are connected in parallel.

The thermal conductivity of the ground comprising the storage volume is considered 2 $\mathrm{W} / \mathrm{mK}$. The properties of the ground are assumed uniform within the storage volume but can be specified for different ground layers beyond the storage volume boundary. The heat capacity of the ground comprising the storage volume is $2016 \mathrm{~kJ} / \mathrm{m}^{3} \mathrm{~K}$. The properties of the soil within the storage volume are considered uniform. The heat exchanger fluid is modelled as an aqueous solution of $20 \%$ ethanol with a specific heat of $3.85 \mathrm{~kJ} / \mathrm{kgK}$ and density of $968 \mathrm{~kg} / \mathrm{m}^{3}$.

\subsubsection{Short term storage tank}

The STST is a stratified liquid storage tank with the same size and specification described in Section 3.2.3. The selected tank model allows for a heat exchanger within the reservoir and also allows unmatched inlet and outlet flows. The model type used in TRNSYS (Type 4) is a vertical tank with two inlet and two outlet streams and an internal heat exchanger.

Figure 4-7 shows a simple schematic of the STST. The selected STST volume is $171 \mathrm{~m}^{3}$ with a height of $4.5 \mathrm{~m}$. The two inlets and outlets of the tank are connected to the solar and BTES loops respectively. The maximum flow rates to the reservoir from the solar and BTES are $90 \mathrm{~m}^{3} / \mathrm{hr}, 40 \mathrm{~m}^{3} / \mathrm{hr}$ respectively. The internal heat exchanger is connected to the community loop with the flow of $20 \mathrm{~m}^{3} / \mathrm{hr}$ in the heating season. In the cooling season, the internal heat exchanger switches its connection to the chiller hot water loop with the same flow rate.

The internal heat exchanger in the STST has $2.1 \mathrm{~m}$ height. The pipe of the heat exchangers is made of copper with the outer diameter of $16 \mathrm{~mm}$ and thermal conductivity of 400 $\mathrm{W} / \mathrm{mK}$. 


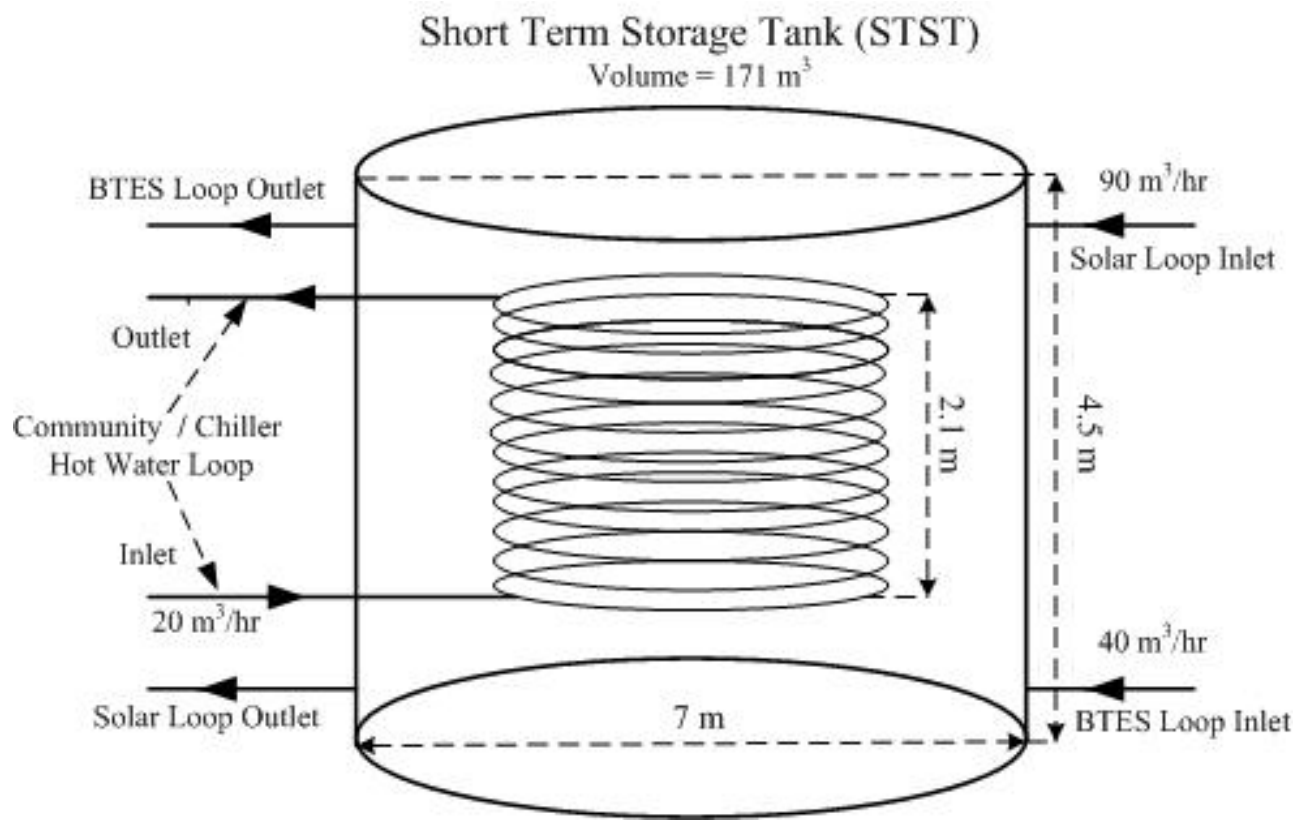

Figure 4-7 Short Term Storage Tank - simplified schematic

\subsubsection{Heat exchangers and pumps}

Variable flow pumps with dedicated controls are used for the main hydronic loops, i.e., the solar, solar-BTES, chiller-BTES, chiller and community loops. For transferring the heat harvested from the solar collectors to the tank, a plate-and-frame heat exchanger is selected. The maximum flow rate of the solar loop heat exchanger on the load-side (tank) is $90 \mathrm{~m}^{3} / \mathrm{hr}$ and on the source-side (solar collectors) is $60 \mathrm{~m}^{3} / \mathrm{hr}$.

\subsubsection{Backup boiler and climate data}

The supplemental heat source selected for the community heating demand as well as the chiller is a $500 \mathrm{~kW}$ natural gas boiler. In the heating season, the boiler is mostly in operation for the first few years of the system operation, before the BTESs becomes fully charged. In the cooling season, the same boiler is mostly running to maintain the minimum desired hot water loop temperature for the chiller (i.e., $90^{\circ} \mathrm{C}$ ).

The community thermal load and solar heat are calculated based on the Canadian Weather Year for Energy Calculation (CWEC) hourly data for the City of Toronto. 


\subsubsection{Absorption chiller}

The chiller selected is a single stage absorption chiller type as it can operate in lower hot water temperature comparing to the double stage absorption chillers. The energy balance for the single effect absorption chiller is calculated from Equation (4-2).

$$
\dot{Q}_{c w}=\dot{Q}_{c h w}+\dot{Q}_{h w}+\dot{Q}_{a u x}
$$

$\dot{Q}_{h w}$ and $\dot{Q}_{c w}$ are the energy removed from the hot and added to cold water (chillerBTES) stream respectively.

$\dot{Q}_{c h w}$ is the energy removed from the chilled water loop (community loop), and $\dot{Q}_{a u x}$ accounts for the energy consumed by various electrical equipment such as solution pumps, fluid stream pumps and controls.

The chiller COP is defined as shown in Equation (4-3), and the maximum theoretical chiller COP can be calculated from Equation (4-4) (Henning, 2007).

$$
\begin{aligned}
& C O P=\frac{\dot{Q}_{c h w}}{\dot{Q}_{a u x}+\dot{Q}_{h w}} \\
& C O P_{\text {max }}=\left(1-\frac{T_{c}}{T_{h}}\right)\left(\frac{T_{c h}}{T_{c}-T_{c h}}\right)
\end{aligned}
$$

where $T_{c}, T_{h}$ and $T_{c h}$ are cooling water, hot water and chilled water temperatures respectively.

The selected chiller rated capacity is $512 \mathrm{~kW}$ with the rated COP of 0.76 . Based on the entering hot water temperature (i.e., $90^{\circ} \mathrm{C}$ ) the nominal capacity of this chiller is $460 \mathrm{~kW}$. Table 4-2 shows the characteristic and performance data for the selected chiller (Broad, 2015). More specific details on the chiller specifications are presented in Appendix B.

In the proposed model in TRNSYS, Type 107, single effect hot water fired absorption chiller, is selected. Type 107 uses a normalized catalog data lookup approach to predict the performance of the chiller. In this model, the heat required for desorbing the refrigerant is provided by the stream or hot water. The energy of the refrigerant absorption process is rejected to the cooling water stream and the machine chills the third fluid stream to the designated set point temperature. The performance of the chiller is predicted and interpolated within the range of data provided. One beneficial feature of this model is that the data, taken directly from manufacturer catalogs is normalized so that once the data file is created, it can also be used to model the chiller other than the specific size for which the data was intended. The data file required by Type 107 is created based on the manufacturer performance data. 
Table 4-2 Chiller performance data

\begin{tabular}{|l|c|c|}
\hline \multicolumn{3}{|c|}{ Chiller Performance Data } \\
\hline Rated capacity & 512 & $\mathrm{~kW}$ \\
\hline Nominal capacity & 460 & $\mathrm{~kW}$ \\
\hline Rated COP & 0.76 & \\
\hline Rated hot water inlet temperature & 90 & ${ }^{\circ} \mathrm{C}$ \\
\hline Hot water flow rate & 57.9 & $\mathrm{~m}^{3} / \mathrm{h}$ \\
\hline Rated cooling water inlet temperature & 30 & ${ }^{\circ} \mathrm{C}$ \\
\hline Cooling water flow rate & 154 & $\mathrm{~m}^{3} / \mathrm{h}$ \\
\hline Rated chilled water inlet temperature & 12 & ${ }^{\circ} \mathrm{C}$ \\
\hline Chilled water flow rate & 62.7 & $\mathrm{~m}^{3} / \mathrm{h}$ \\
\hline Adjustable chilled water flowrate & $50-120$ & $\%$ \\
\hline Adjustable load & $5-115$ & $\%$ \\
\hline LiBr solution concentration & 52 & $\%$ \\
\hline
\end{tabular}

The file contains values of normalized fraction of full load capacity and fraction of design energy input for various values of fraction of design load, chilled water set point temperature, entering cooling water temperature and entering hot water temperature. The file contents are presented in Appendix C.

\subsubsection{Pumps}

Variable flow pumps with dedicated controls are used for the main hydronic loops. Table 4-3 shows the pump power for each loop selected based on the equipment's flow requirements.

Table 4-3 Pumps' specification summary

\begin{tabular}{|c|c|c|c|c|}
\cline { 3 - 5 } \multicolumn{2}{c|}{} & Flow & Head & $\begin{array}{c}\text { Shaft Power } \\
\text { Capacity }\end{array}$ \\
\hline \multicolumn{2}{r|c|}{ pump } & $\mathrm{m}^{3} / \mathrm{hr}$ & $\mathrm{m}$ & $\mathrm{kW}$ \\
\hline 1 & Solar loop & 57 & 30 & 11 \\
\hline 2 & Solar-STST loop & 91 & 8 & 5 \\
\hline 3 & Solar-BTES loop & 40 & 25 & 6 \\
\hline 4 & Community-STST loop- Heating & 20 & 6 & 2 \\
\hline 5,6 & Community-STST loop- Cooling & 20 & 6 & 2 \\
\hline 7 & Chiller-BTES loop & 154 & 35 & 24 \\
\hline 8 & Chiller hot side loop & 58 & 9 & 3 \\
\hline 9 & Chiller-community side loop & 63 & 9 & 4 \\
\hline
\end{tabular}




\subsection{System specifications summary}

The overview of the system design specifications for the major components is summarized in Table 4-4.

Table 4-4 System major components summary

\begin{tabular}{|l|c|c|}
\hline \multicolumn{3}{|c|}{ System Specifications Summary } \\
\hline Number of solar collectors & 600 & \\
\hline Total solar collector area & 1,722 & $\mathrm{~m}^{2}$ \\
\hline Fluid flow- solar & 90,000 & $\mathrm{~kg} / \mathrm{hr}$ \\
\hline Short term storage tank volume & 171 & $\mathrm{~m}^{3}$ \\
\hline Solar- BTES & & \\
\hline Number of boreholes & 90 & \\
\hline Borehole depth & 59 & $\mathrm{~m}$ \\
\hline Borehole spacing & 3 & $\mathrm{~m}$ \\
\hline BTES volume & 34,017 & $\mathrm{~m}^{3}$ \\
\hline Total borehole length & 5,310 & $\mathrm{~m}$ \\
\hline Max fluid flow-BTES & 40,000 & $\mathrm{~kg} / \mathrm{hr}$ \\
\hline Chiller (Table 4-2) & & \\
\hline Chiller- BTES & & \\
\hline Number of boreholes & 80 & \\
\hline Borehole depth & 150 & $\mathrm{~m}$ \\
\hline Borehole spacing & 3 & $\mathrm{~m}$ \\
\hline BTES volume & 93,470 & $\mathrm{~m}$ \\
\hline Total borehole length & 12,000 & $\mathrm{~m}$ \\
\hline Max fluid flow-BTES & 154,000 & $\mathrm{~kg} / \mathrm{hr}$ \\
\hline
\end{tabular}

\subsection{Simulation results}

Figure 4-8 depicts the simulation results for the accumulated chiller energy sources and sinks for five years. The hot water energy sources are from the boiler and the stored solar thermal energy out of the STST. During the first year, solar thermal energy along with the boiler energy are used for charging the solar-BTES, and then after, the stored solar thermal energy will assist the boiler to supply desired heat to the chiller.

Table 4-5 and Figure 4-9 represent the chiller energy breakdowns for the year one, five, ten, fifteen and twenty. In twenty-year simulation time, the chiller provides $1120 \mathrm{GJ}$ cooling to 
the community loop, and from the second year onward the chiller rejects $2701 \mathrm{GJ}$ heat to the chiller-BTES loop annually.

Chiller Source/Sink Energy (yearly accumulation)

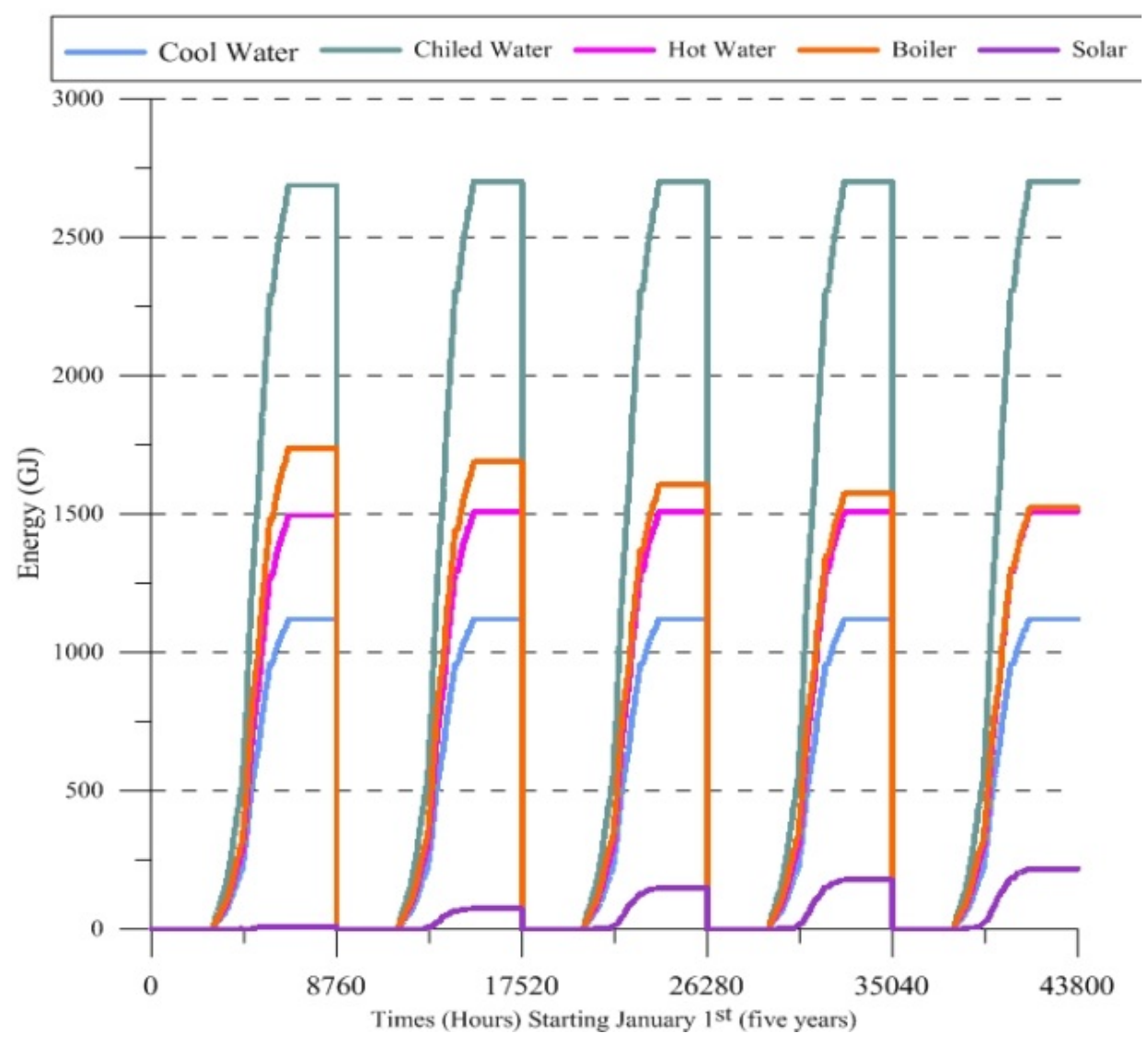

Figure 4-8 Chiller source and sink energy - five years

Table 4-5 Annual chiller source and sink energy

\begin{tabular}{|l|r|r|c|c|c|}
\hline Year & \multicolumn{1}{|c|}{} & \multicolumn{1}{c|}{$\mathbf{5}$} & \multicolumn{1}{c|}{$\mathbf{1 0}$} & \multicolumn{1}{c|}{$\mathbf{1 5}$} & \multicolumn{1}{c|}{$\mathbf{1 0}$} \\
\hline Chilled water energy (GJ) - chiller sink & 1,120 & 1,120 & 1,120 & 1,120 & 1,120 \\
\hline Cooling water energy (GJ) - chiller sink & 2,687 & 2,701 & 2,701 & 2,701 & 2,701 \\
\hline Hot water energy (GJ) - chiller source & 1,495 & 1,509 & 1,509 & 1,509 & 1,509 \\
\hline Boiler input energy (GJ) & 1,737 & 1,523 & 1,430 & 1,388 & 1,356 \\
\hline Solar energy used for cooling (GJ) & 8 & 217 & 304 & 341 & 365 \\
\hline
\end{tabular}

The total energy delivered to the chiller hot water loop is 1509 GJ annually, which is supplied from the boiler and the solar source. In the year one, the chillers' energy source is mainly provided by the boiler (i.e., $1737 \mathrm{GJ}$ ) and in the subsequent years, the solar energy source starts contributing to the chiller hot water loop. In the year five, the total heat delivered to the 
chiller (1740 GJ) is comprised of 217 GJ from the solar energy source, and 1523 GJ from the boiler source. Eventually, in the year twenty, the solar energy contribution to the chiller reaches to $365 \mathrm{GJ}$, which is $21 \%$ of the total energy delivered to the chiller. In year five and beyond, on average, the solar energy contribution to the chiller hot water source is $18 \%$, and the rest of the heat is supplied by the boiler.

During the cooling season, the chiller-BTES receives the chillers' rejected heat from the chiller cooling water loop.

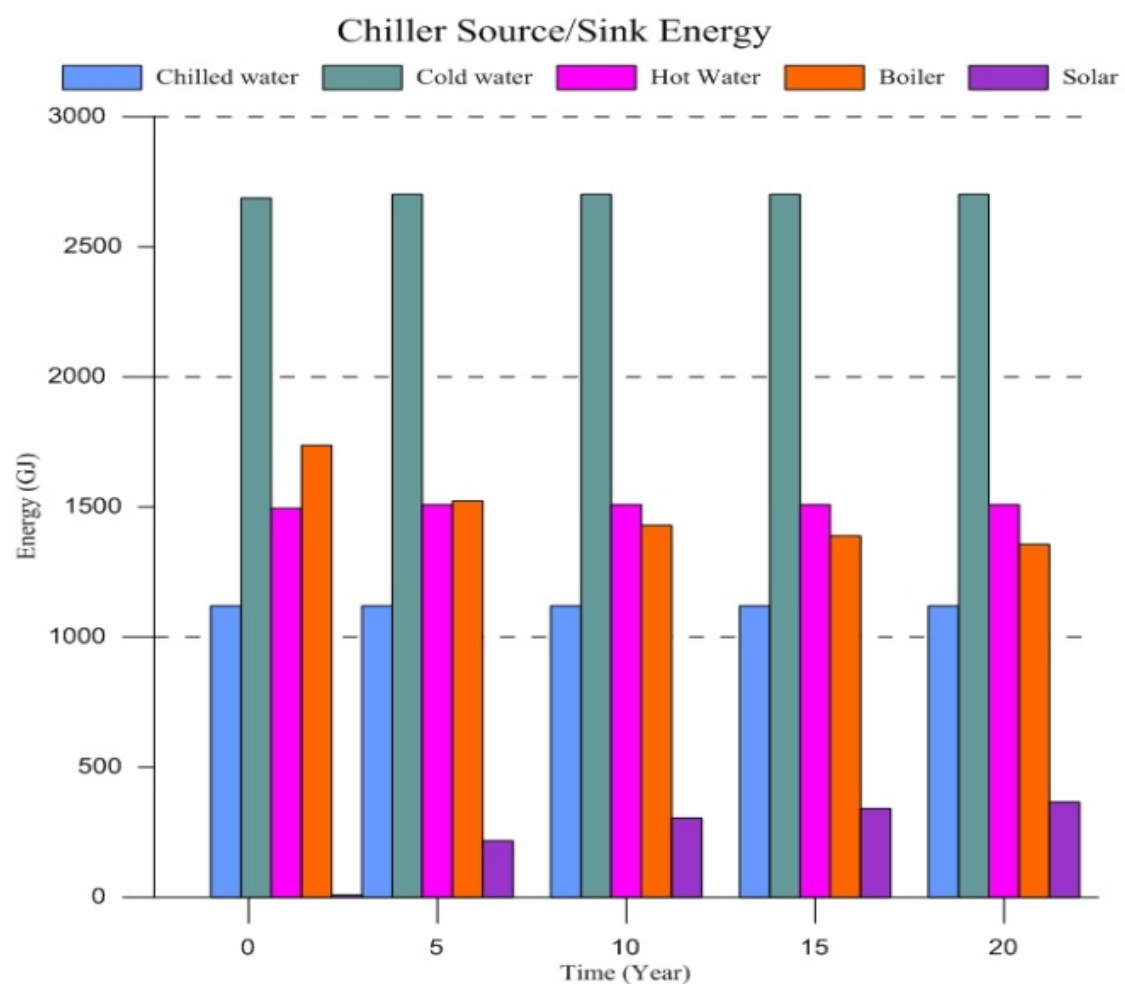

Figure 4-9 Chiller energy - year 1, 5, 10, 15 and 20

Figure 4-10 presents the solar and chiller BTES average hourly ground temperatures. In the year twenty, the ground temperature of the solar-BTES will reach to the maximum of $80.3^{\circ} \mathrm{C}$ and minimum $59.6^{\circ} \mathrm{C}$ and the chiller-BTES will reach to the maximum of $69.2^{\circ} \mathrm{C}$ and minimum of $59.3^{\circ} \mathrm{C}$. 
BTES average hourly ground temperature

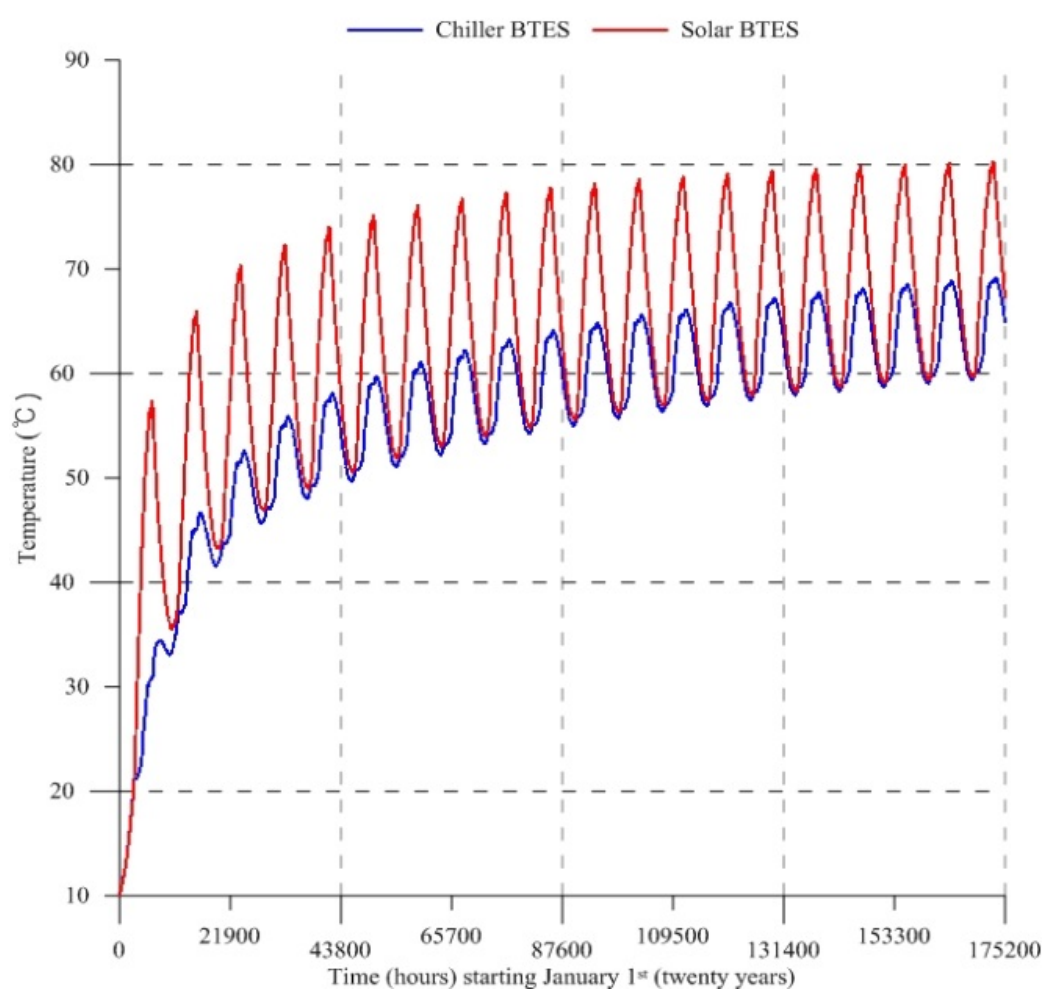

Figure 4-10 Solar and chiller BTES average hourly ground temperature - twenty years

Table 4-6 shows the annual maximum and minimum temperatures of the ground for solar-BTES and chiller-BTES for twenty years recorded in five years intervals. The ground temperature swing in the year twenty is about $21^{\circ} \mathrm{C}$ and $10^{\circ} \mathrm{C}$ for the solar and the chiller BTES respectively.

Table 4-6 Annual maximum and minimum ground temperatures

\begin{tabular}{|c|c|c|c|c|c|c|}
\cline { 2 - 7 } \multicolumn{1}{c|}{} & \multicolumn{2}{c|}{ Solar BTES Temperature $\left({ }^{\circ} \mathrm{C}\right)$} & \multicolumn{3}{c|}{ Chiller BTES Temperature $\left({ }^{\circ} \mathrm{C}\right)$} \\
\hline Year & Max & Min & Delta & Max & Min & Delta \\
\hline 1 & 57.4 & 10.0 & 47.4 & 34.4 & 10.0 & 24.4 \\
\hline 5 & 74.0 & 49.0 & 25.0 & 58.1 & 48.0 & 10.1 \\
\hline 10 & 77.8 & 54.8 & 23.0 & 64.1 & 54.2 & 9.9 \\
\hline 15 & 79.4 & 57.9 & 21.5 & 67.2 & 57.4 & 9.8 \\
\hline 20 & 80.3 & 59.6 & 20.7 & 69.2 & 59.3 & 9.9 \\
\hline
\end{tabular}

In the heating mode, the STST's flow temperature to the chiller-BTES should be maintained less than the chiller-BTES store media, to recover the stored heat in the chillerBTES. Therefore, the chiller-BTES ground temperature after charging (year three onwards) 
reaches to as high as 50 to $60^{\circ} \mathrm{C}$. This temperature range substantially influences the chillers' heat rejection temperature which is not favorable to the chiller operation.

In this condition, the nominal capacity of the chiller drops to the minimum of $370 \mathrm{~kW}$. By setting the chilled water and hot water temperature to $10^{\circ} \mathrm{C}$ and $90^{\circ} \mathrm{C}$, the maximum $\mathrm{COP}$ of the chiller is calculated to 0.91 (Equation (4-4)). The simulated overall seasonal chiller COPs, including the total chillers' pumping energy, in the year five and the year fifteen are 0.56 and 0.54 respectively in contrast to the rated chiller COP of 0.76 .

The amount of the injected and extracted heat plus heat loss of the solar-BTES and chiller-BTES are presented in Table 4-7.In the first year of the system operation, the injected heat into the ground for solar and chiller BTESs are 5704 GJ and 6380 GJ respectively. These amounts compare to the subsequent years are higher as the ground is in the charging process. In this year, the boiler provides all the heat needed for the chillers' hot-water loop when all the rejected heat from the chiller cooling water loop (i.e., 2678 GJ from Table 4-5) is directed into the ground. In the first year, the chiller-BTES also receives heat from the solar-BTES loop in the heating season. It means from $6380 \mathrm{GJ}$ annual heat injection into the chiller-BTES, $3702 \mathrm{GJ}$ is from the STST. From year five and onwards, both BTESs achieve the designed operation goals. From year five to year twenty, the average annual heat retrieved from the solar-BTES and chiller-BTES are 1307 GJ and 918 GJ which are $41 \%$ and $25 \%$ of the average annual injected heat respectively. The heat losses from the solar-BTES and chiller-BTES are 1776 GJ and 2528 GJ which are $56 \%$ and $70 \%$ of the average annual injected heat respectively.

Although the solar-BTES are operating at a higher temperature, compared to the chillerBTES, the losses from the solar-BTES are less which is because the size difference of two BTESs (the chiller BTES is three times larger) and a more efficient operation of the solar-BTES. For the year one, five, ten, fifteen and twenty, Figure 4-11 shows the annual injected and extracted heat plus the heat losses for the two borehole sets, side by side.

Figure 4-12 depicts the annual accumulated energy for major heating related components in five years. The curve bundle for each year represents 1) community heating load, 2) solar thermal collectors' energy generation, 3) solar-BTES energy injection and extraction, 4) boiler auxiliary heat, and 5) chiller-BTES energy injection and extraction. As it is seen, in the course of five years, the total energy corresponds to each curve is declining toward the system balancing, 
which is the year that the changes of the energy magnitudes in subsequent years, for each component, become relatively negligible, i.e., the year four and the year five.

Figure 4-13 and Table 4-8 represents the heating system energy for twenty years, which is recorded in five years interval.

Table 4-7 Solar-BTES and chiller-BTES annual energy

\begin{tabular}{|l|r|r|r|r|r|}
\hline \multicolumn{7}{|c|}{ Year } & \multicolumn{1}{c|}{$\mathbf{1}$} & \multicolumn{1}{c|}{$\mathbf{5}$} & \multicolumn{1}{c|}{$\mathbf{1 0}$} & \multicolumn{1}{c|}{$\mathbf{1 5}$} & \multicolumn{1}{c|}{$\mathbf{2 0}$} \\
\hline \multicolumn{7}{|c|}{ Solar-BTES } \\
\hline Injected heat (GJ) & 5,704 & 3,486 & 3,194 & 3,032 & 2,936 \\
\hline Extracted heat (GJ) & $-1,093$ & $-1,427$ & $-1,353$ & $-1,254$ & $-1,192$ \\
\hline Heat Loss (GJ) & 1,858 & 1,873 & 1,775 & 1,739 & 1,718 \\
\hline \multicolumn{6}{|c}{ Chiller-BTES } \\
\hline Injected heat (GJ) & 6,380 & 3,874 & 3,613 & 3,525 & 3,478 \\
\hline Extracted heat (GJ) & 0 & -732 & -924 & -985 & $-1,029$ \\
\hline Heat Loss (GJ) & 1,883 & 2,736 & 2,536 & 2,450 & 2,388 \\
\hline
\end{tabular}

Solar and Chiller BTES Energy

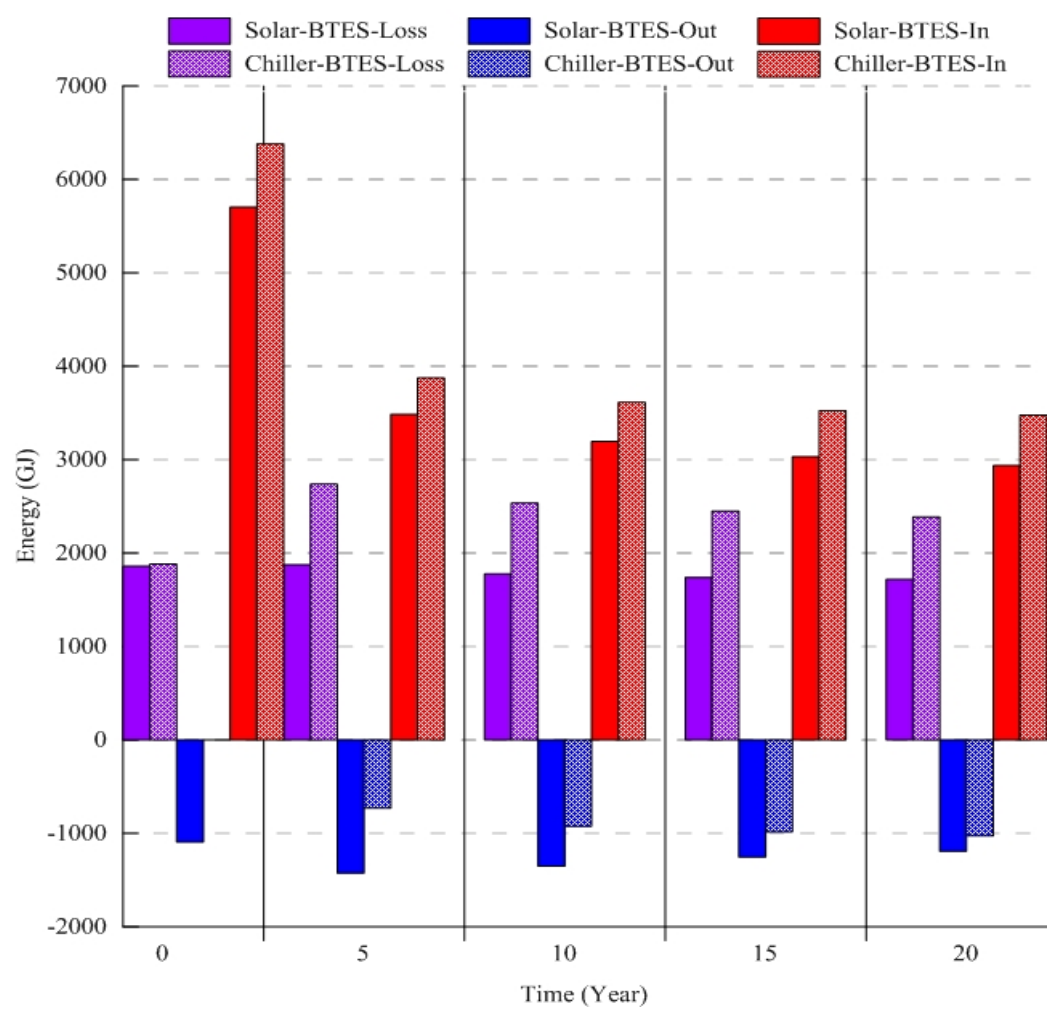

Figure 4-11 Solar-BTES and chiller-BTES annual energy comparison 


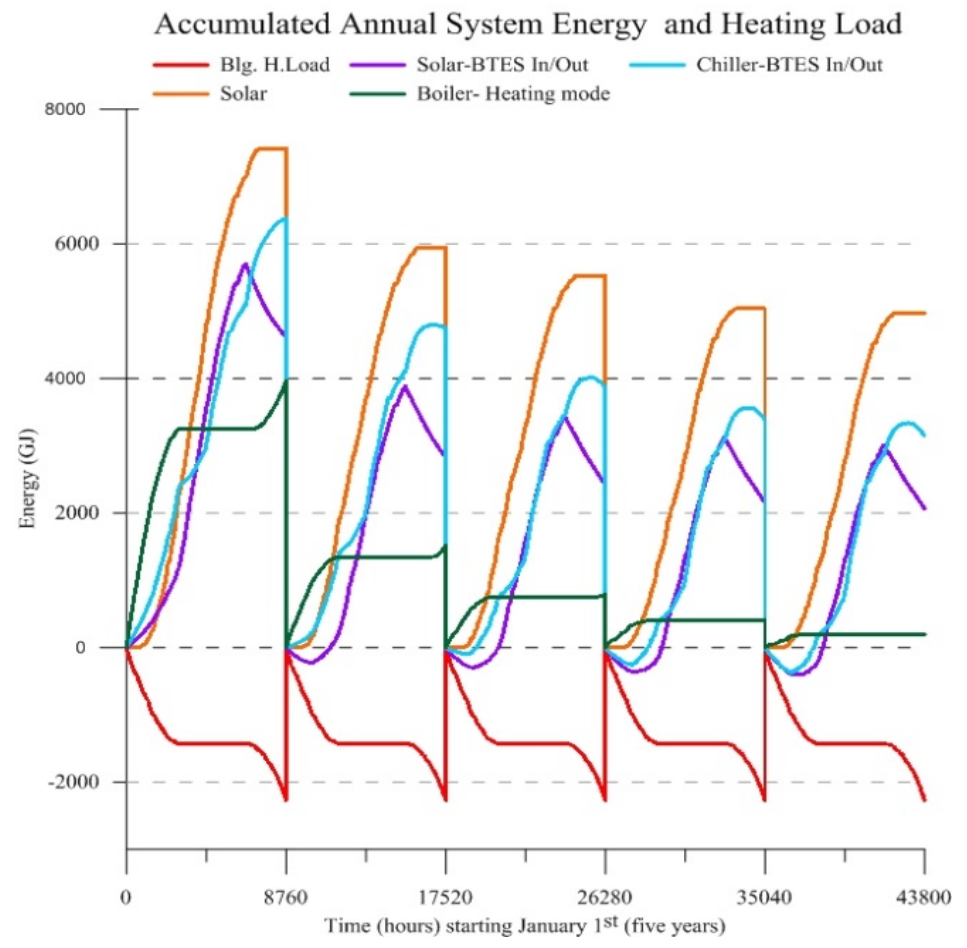

Figure 4-12 Annual system accumulated energy, heating - five years

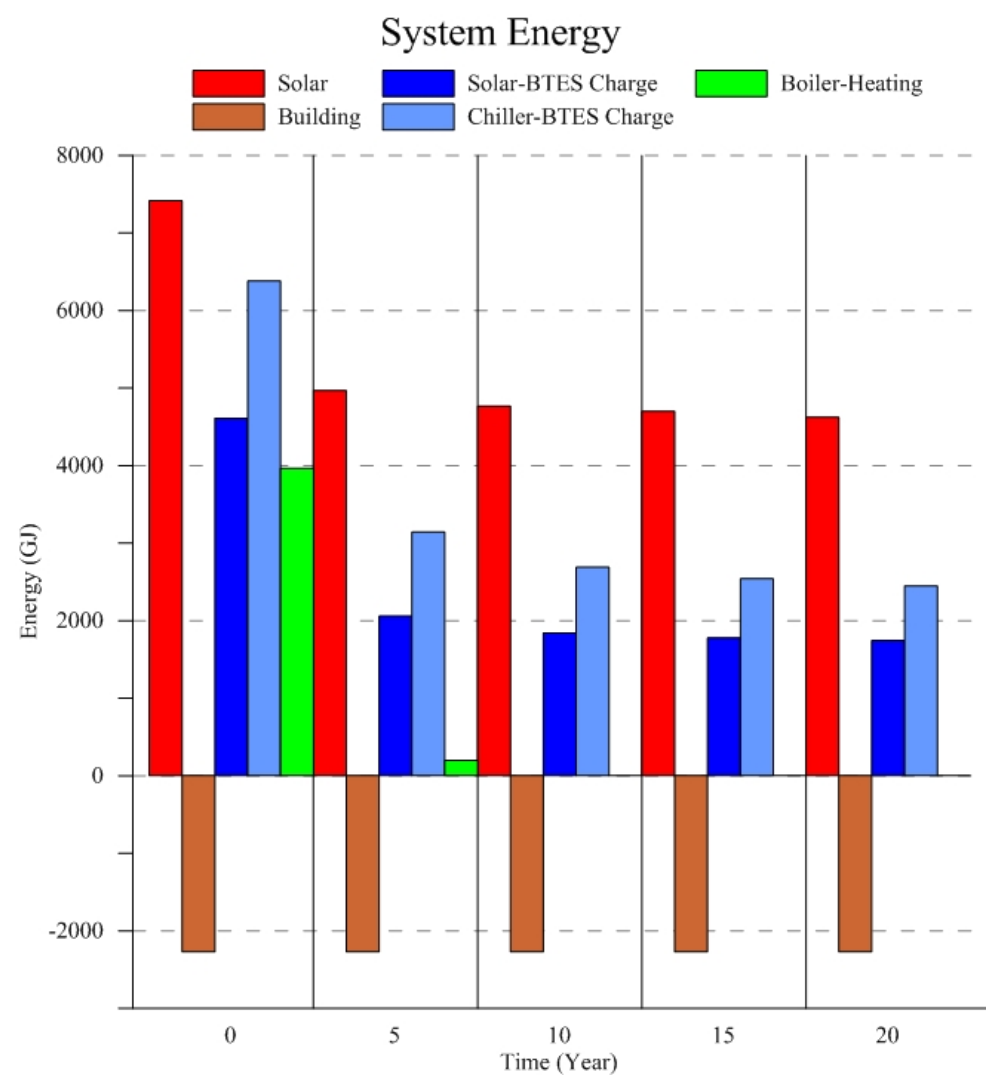

Figure 4-13 System energy comparison related to heating mode 
Table 4-8 System energy related to the heating mode

\begin{tabular}{|l|r|r|r|r|r|}
\hline Year & \multicolumn{1}{|c|}{$\mathbf{1}$} & \multicolumn{1}{c|}{$\mathbf{5}$} & \multicolumn{1}{c|}{$\mathbf{1 0}$} & \multicolumn{1}{c|}{$\mathbf{1 5}$} & \multicolumn{1}{c|}{$\mathbf{2 0}$} \\
\hline Useful solar Energy (GJ) & 7,415 & 4,969 & 4,765 & 4,699 & 4,622 \\
\hline Building (Community) Heating Load (GJ) & $-2,350$ & $-2,350$ & $-2,350$ & $-2,350$ & $-2,350$ \\
\hline Solar-BTES Charge (GJ) & 4,611 & 2,059 & 1,841 & 1,777 & 1,744 \\
\hline Chiller-BTES Charge (GJ) & 6,380 & 3,143 & 2,689 & 2,540 & 2,449 \\
\hline Boiler Energy Use in Heating Mode (GJ) & 3,966 & 197 & 4 & 0 & 0 \\
\hline
\end{tabular}

In the first year of the operation, as the ground is not charged, the solar energy and boiler energy use are 7415 GJ and 3966 GJ respectively, which are higher compared to the subsequent years. The boiler and solar energy use by the end of the year five are 197 GJ and 4969 GJ, respectively. This corresponds to the reduction of $95 \%$ boiler energy consumption and $33 \%$ solar energy use. From year five onward, on average, the solar annual energy use is 4764 GJ where the boiler energy consumption is zero.

The BTES charges are the total amount of stored energy in the ground at each year-end, which is the difference between annual heat injected into and the sum of heat extracted from the ground plus losses. From the year five to the year twenty, the average year-end charge of the solar-BTES and chiller-BTES are 1855 GJ and 2700 GJ respectively.

In the year ten, the average annual solar harvested energy is $4765 \mathrm{GJ}$, which is enough to supply all energy needed to meet the annual heating load. The boiler load in the year five is 197 GJ that it will reach to zero in subsequent years. In other words, the solar fraction (SF) of the community for heating at the end of the year five is $91 \%$. The SF is the ratio of the difference in boiler energy use and the community heating load, which is solar energy use to the community heating load (i.e., $\mathrm{SF}=100 \times(2350-197) / 2350)$. The solar fraction reaches to the $100 \%$ beyond the year five.

The solar fraction (SF) of the community for heating in the first five years plus year ten, fifteen and twenty are shown in Figure 4-14. In this figure, the solar fractions in cooling mode are also included. On average from the year five and beyond the SF in heating is $100 \%$ while the $\mathrm{SF}$ in cooling is $18 \%$. This means for a community which is designed for $100 \% \mathrm{SF}$ for space heating (similar to the design presented in Chapter 3), the same size solar thermal system can also deliver $18 \%$ of thermal energy needs in the cooling mode. 


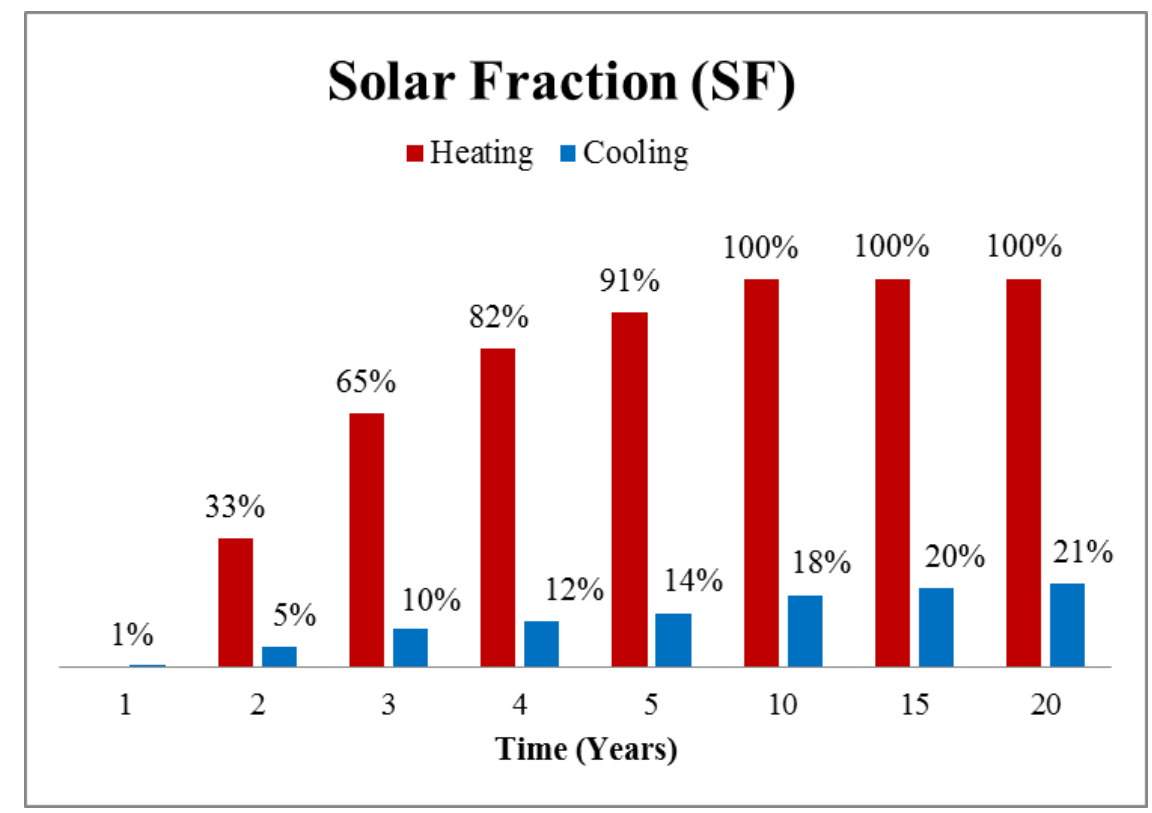

Figure 4-14 Community Solar Fraction (SF) in heating and cooling mode

The annual pumping energy consumptions for the major pumps specified in Table 4-3 are shown in Figure 4-15 and Table 4-9. The total annual pumping electricity requirement for the solar and solar-BTES (pump 1, 2 and 3) in the year-one is $471 \mathrm{GJ}$ (131 MWh) which is 21\% higher than the year-five (370 GJ) due to the first-year ground charging. The pumping electricity consumptions for the chillers' pumps (pump 7,8 and 9) are almost constant for the year-one and the year-five. The total electricity requirement for the chillers' pumps is $223 \mathrm{GJ}$ (62 MWh).

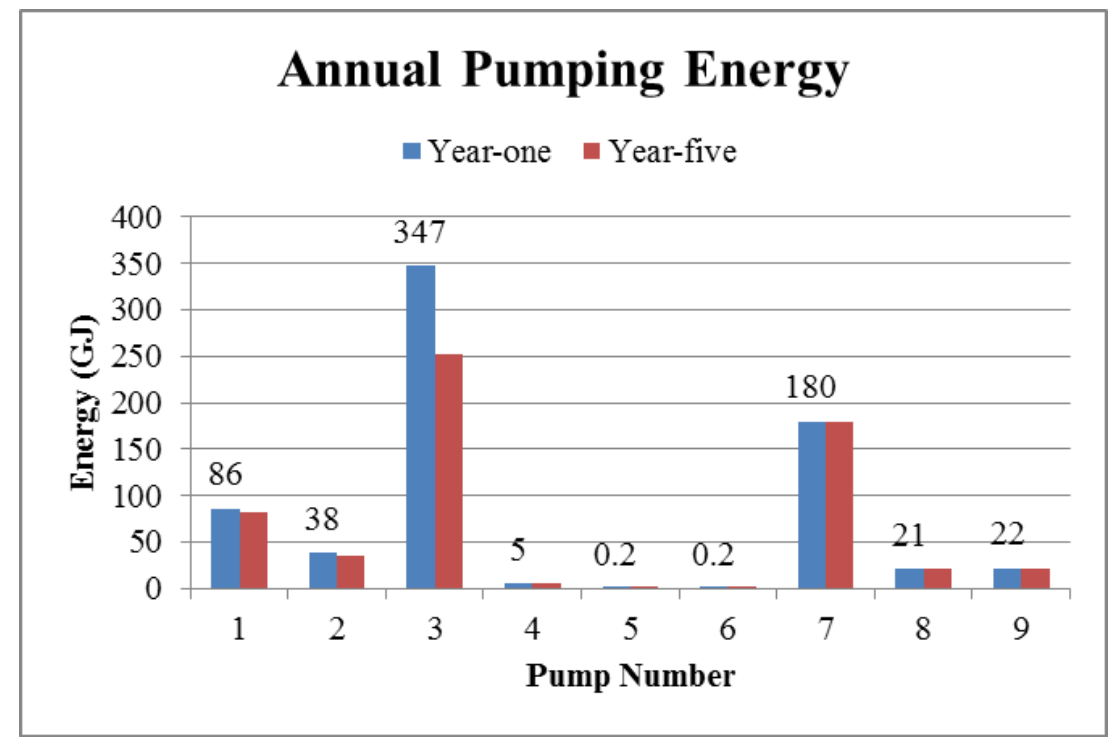

Figure 4-15 Annual pumping energy comparisons for the year-one and the year-five 
Table 4-9 Annual pumping energy consumptions for the year-one and the year-five

\begin{tabular}{|c|l|c|c|c|c|}
\cline { 3 - 6 } \multicolumn{2}{c|}{} & \multicolumn{2}{c|}{ Energy (Year 1) } & \multicolumn{2}{c|}{ Energy (Year 5) } \\
\hline \multicolumn{2}{|c|}{ pump } & GJ & MWh & GJ & MWh \\
\hline 2 & Solar loop & 86 & 24 & 82 & 23 \\
\hline 3 & Solar-STST loop & 38 & 11 & 36 & 10 \\
\hline 4 & Colar-BTES loop & 347 & 96 & 252 & 70 \\
\hline 5,6 & Community-STST loop- Heating & 5 & 1 & 5 & 1 \\
\hline 7 & Chiller-BTES loop & 0.4 & 0.1 & 0.4 & 0.1 \\
\hline 8 & Chiller hot side loop & 180 & 50 & 180 & 50 \\
\hline 9 & Chiller-community side loop & 21 & 6 & 21 & 6 \\
\hline
\end{tabular}

The chillers' hot and chilled water loop compared to the chiller-BTES water loop consumes higher pumping energy (21 GJ and 22 GJ vs.180 GJ). The total chillers 'pumping energy is equal to the $25 \%$ of the input energy to the chiller (1509 GJ). The overall seasonal chiller COPs by considering the pumping energy are calculated to be 0.56 and 0.54 for the year five and the year fifteen respectively.

\subsection{System cost comparison}

Similar to the Section 3.4, the proposed system incremental cost is compared to the systems costings tabulated in Table 3-8 for the DLSC and the modified similar systems.

Table 4-10 presents the system cost comparisons between solar-thermal-chiller (STC) system and the two heating -only solar thermal systems which all serve the same community heating and cooling loads. The STC system does not offer any payback over the lifetime of the project due to the high initial system cost.

The total costs are incremental for the major system components which the similar components between the systems are excluded. The cost index sources are the same as the Chapter 3 Section 3.4 and from the RSMeans (2013) handbook for the absorption chiller. 
Table 4-10 Solar-thermal-chiller (STC) system cost comparison with the DLSC and modified DLSC system

\begin{tabular}{|l|c|c|c|c|}
\hline \multicolumn{5}{|c|}{ Sys tem Initial Cos ting (Incre mental)- Ins talled } \\
\hline & Index & \multicolumn{2}{c|}{ Heating Only } & Heating and Cooling \\
\hline System & & DLSC & Mod.-DLSC & Abs. Chiller \\
\hline Number of Boreholes & & 144 & 90 & 90 and 80 \\
\hline Borehole Depth $(\mathrm{m})$ & & 37 & 59 & 59 and 150 \\
\hline Number of Solar Thermal Panels & $2.87\left(\mathrm{~m}^{2} /\right.$ panel) & 800 & 600 & 600 \\
\hline Cost of BTES & $116(\$ / \mathrm{m})$ & $\$ 618,048$ & $\$ 615,960$ & $\$ 2,007,960$ \\
\hline Cost of Solar Thermal Panels & $497\left(\$ / \mathrm{m}^{2}\right)$ & $\$ 1,139,621$ & $\$ 855,834$ & $\$ 855,834$ \\
\hline $\begin{array}{l}\text { Short Term Storage Tank } \\
\text { Including the Energy Center }\end{array}$ & $2500\left(\$ / \mathrm{m}^{3}\right)$ & $\$ 600,000$ & $\$ 427,500$ & $\$ 427,500$ \\
\hline Cost of absorption Chiller & $715 / 570(\$ / \mathrm{kW})$ & $\$ 0$ & $\$ 0$ & $\$ 291,840$ \\
\hline Total Initial Cost & & $\$ 2,357,669$ & $\$ 1,899,294$ & $\$ 3,583,134$ \\
\hline Solar Area Saving & & Base & $25 \%$ & $25 \%$ \\
\hline
\end{tabular}

\subsection{Conclusion}

In this chapter, the integration of a cooling system to the heating system in a solar community with a medium and high-temperature borehole thermal storages were modeled, and it was shown that such a system is technically viable.

The selected community is a heating dominated community that has $50 \%$ more annual heating demand than the annual cooling demand. The winter peak heating load is $19 \%$ higher than peak cooling load.

The simulation results show that the system will reach a favorable operation in year five and after. From year five onwards, in the heating season, the community operates with $100 \%$ of the solar energy and the stored energy in the two BTES systems. In the cooling season, the chiller receives $18 \%$ of its the required energy from the solar energy source.

It is also concluded that, from year five, in the heating season, the total extracted energy from the two BTESs comprised 31\% from the chiller-BTES and 69\% from the solar-BTES extracted energy.

Due to the relatively high waste heat amount from the chillers' cooling water loop, the size of the chiller-BTES designed is fairly large. The chiller-BTES size is almost three times bigger than the size of the solar-BTES, which was obtained by trial-and-error. The average efficiencies of the solar-BTES and chiller-BTES are $44 \%$ and $30 \%$ respectively. In order to reduce the chiller-BTES size and subsequently its initial capital cost, integrating a cooling tower for rejecting part of the chillers' heat can be considered for the future studies. 
In the proposed system, the chiller does not operate optimally, because of the high chiller rejecting heat storage media (i.e., chiller-BTES). On average, the chiller functions on almost $72 \%$ of its rated capacity ( $512 \mathrm{~kW}$ vs. $370 \mathrm{~kW})$, and $74 \%$ of its rated efficiency ( 0.76 vs. 0.56$)$.

Based on the availability of more rooftop space for the solar thermal collectors in the community, the heat supply to chiller can be designed in a way to have more contribution from solar heat rather than the boiler heat.

There is substantial initial system costs associated with the proposed system compared to the conventional boiler-chiller system. However, due to the relatively small system operation cost, future study and investigation on the economy of the system are required.

Finally, in such systems, several major hydronic loops need electricity for running their associated pumps and controls. The amount of the electricity required for the pumps operation should also be considered in the economics of the system. Integration of solar photovoltaic (PV) system can offset part or all of the system electrical demand. 


\section{Chapter 5 : Community Heating and Cooling with the Central Heat Pump and Borehole Thermal Energy Storage System}

In this chapter, the heating and cooling of the same community that was described and modeled in Chapter 4 are investigated with a central heat pump, BTES, and photovoltaic system. The result of this investigation by modeling the system in TRNSYS will be used as the base case for evaluating a newly proposed system which has a similar configuration with the addition of a solar thermal and a new high-temperature BTES system. The goal is to increase the system performance by introducing relatively higher temperature to the heat pump system during the heating season from the solar thermal and a new BTES source. The proposed system will be presented in Chapter 6.

In this base case scenario, the existing space on the roofs will be used to install solar photovoltaic (PV) to generate electricity for the heat pumps' operation.

\subsection{System layout}

Figure 5-1 depicts the system configuration and main equipment for the community heating and cooling system with central heat pumps, BTES and PV, called HPPV system. The community hydronic loop operates in either heating or cooling mode based on the community heating and cooling demands.

The heat pump units located at the central mechanical room (energy center) provided hot or chilled water via a storage tank to the community's fan-coil system. In the cooling season, the heat pump condensers reject heat to the BTES and during the heating season heat is extracted from the BTES to the heat pump evaporators.

The PV panels offset heat pumps electricity requirements. The power generation and consumptions are assumed to be able to be net-metered via the utility company. This will allow sending the electricity during the day to the grid and use the required electricity from the grid at any time. In the net-metering program, the annual utility charges will be based on the difference between the sending and receiving of the total kilowatt-hours of electricity to and from the grid system. 


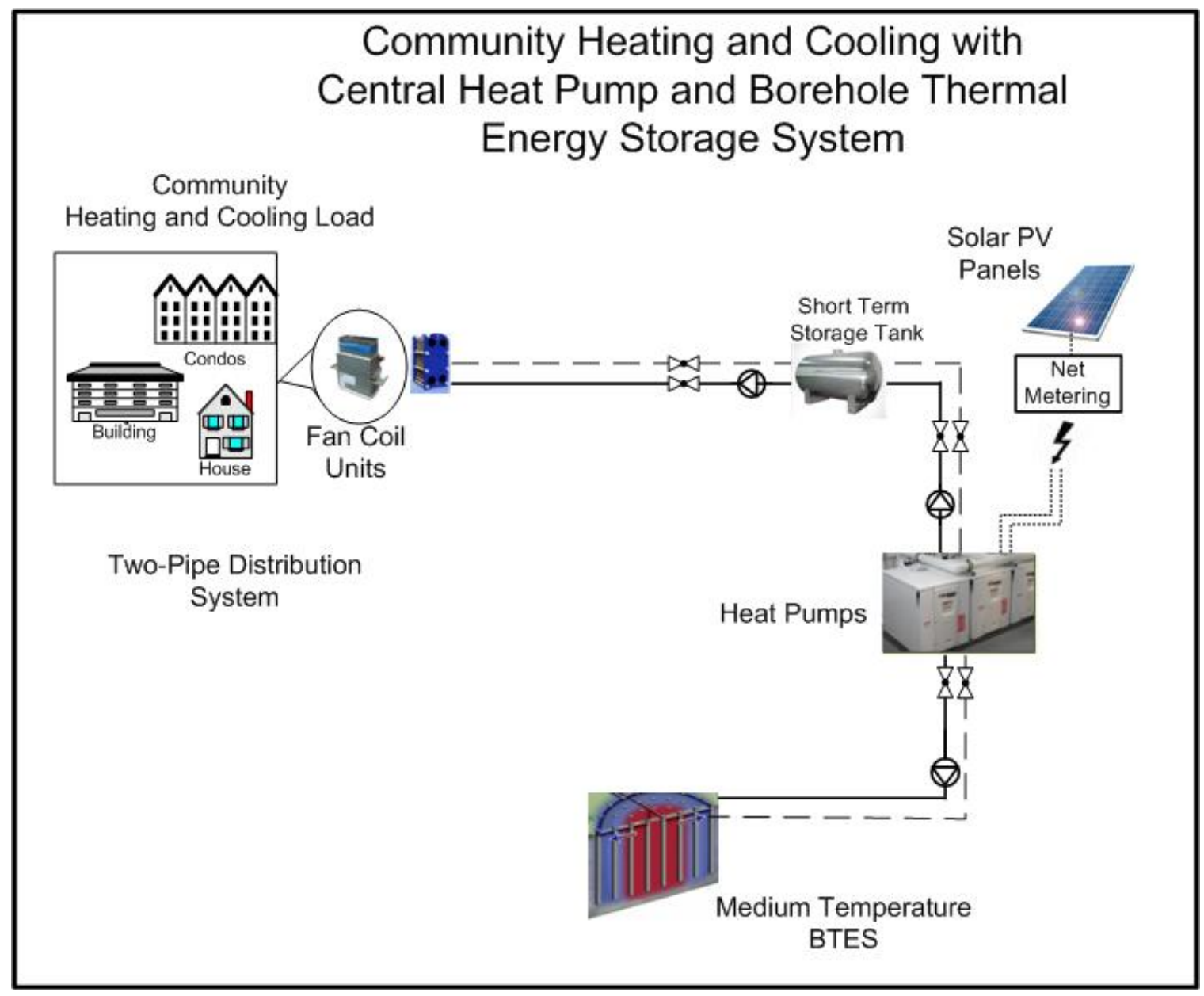

Figure 5-1 Overall system schematic - HPPV system

\subsection{The community heating and cooling load}

The selected community heating and cooling loads are similar to the community chosen in Chapters 4 Section 4.2. It comprises a combination of single and multifamily residential houses located in Toronto, Ontario with a considerable amount of cooling load. The annual community heating and cooling load are $2350 \mathrm{GJ}$ and $1181 \mathrm{GJ}$ with the peak heating and cooling load of $457 \mathrm{~kW}$ and $369 \mathrm{~kW}$ respectively.

The houses in the community, as described in Chapter 3 Section 3, are built based on R2000 standards (NRCan, 2012) and are equipped with an air handler with a water-to-air fan coil. The fan coils, depending on the season, receive either hot or chilled water from a central energy center through a two-pipe distribution system. 


\subsection{System major equipment and methodology}

The system is modeled using TRNSYS 17 software (Klein et al., 2010). Figure 5-2 depicts the TRNSYS model layout.

The system contains three hydronic loops; 1) heat pumps-STST loop, 2) heat pumpsBTES loop and 3) community loop. The model receives the hourly community heating and cooling loads from two spreadsheets, which are created from the eQuest software load calculations results.

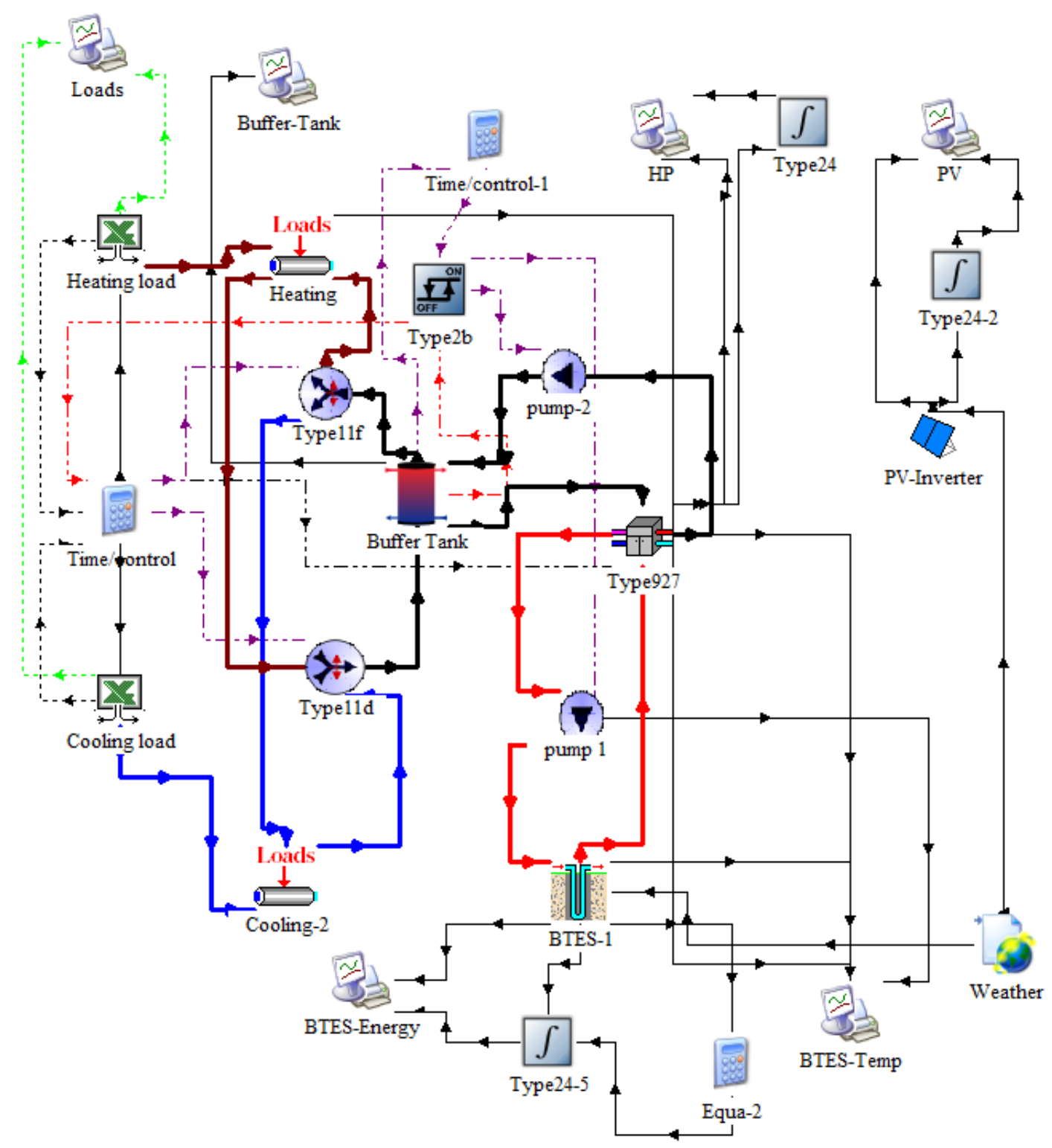

Figure 5-2 TRNSYS heat pump heating and cooling model schematic - HPPV system 


\subsubsection{Heat pumps}

The heat pump selected for this model is the water-to-water ground loop type having high efficiency and direct digital control. Four individual heat pumps connected in parallel are used in this design. The rated capacities of each heat pump in heating and cooling mode are $117 \mathrm{~kW}$ and $93 \mathrm{~kW}$ respectively. In the cooling mode, the rated heat pump's EER is $5.4(\mathrm{~W} / \mathrm{W})$ and in the heating mode, the heat pump has the COP of 3.4 (ClimateMaster Inc., 2016). The total rated capacity of the four heat pumps in heating and cooling mode are $468 \mathrm{~kW}$ and $372 \mathrm{~kW}$ respectively. Table 5-1 shows the overall performance and specifications of each heat pump. More details are presented in Appendix D.

Table 5-1 Individual heat pump specifications by the manufacturer

\begin{tabular}{|l|l|l|}
\hline \multicolumn{3}{|c|}{ Ground Loop Heat Pump* } \\
\hline \multicolumn{3}{|c|}{ Specifications Summary } \\
\hline Heating capacity & 93 & $\mathrm{~kW}$ \\
\hline COP heating & 3.4 & - \\
\hline Cooling capacity & 117 & $\mathrm{~kW}$ \\
\hline EER cooling & 5.4 & $\mathrm{~W} / \mathrm{W}$ \\
\hline Load side water flow range & 2.84 to 5.68 & $1 / \mathrm{s}$ \\
\hline Source side water flow range & 2.84 to 5.68 & $1 / \mathrm{s}$ \\
\hline Load leaving temperature range & -4.4 to 60 & ${ }^{\circ} \mathrm{C}$ \\
\hline Source leaving temperature range & -6.7 to 54.4 & ${ }^{\circ} \mathrm{C}$ \\
\hline Refrigerant & HFC- $410 \mathrm{~A}$ & \\
\hline & * ClimateMaster, Tranquility, TMW-360 \\
\hline
\end{tabular}

In TRNSYS, Type 927 is water-to-water heat pump component that models the heat pump, designed by Mitchell and Braun (1997). The heat pumps condition the load side liquid stream by rejecting heat to (cooling mode) or absorbing heat from (heating mode) source side liquid stream. This model is based on the user-supplied data file containing catalog data for the capacity and power draw, depending on the entering load and source fluid temperatures. Following the data file required syntax by the Type 927, the two performance data file were created for the cooling and heating mode. The data files contents are presented in Appendix E.

The heat pump COP at the current condition and the amount of energy absorbed from the source fluid stream $\left(\dot{Q}_{\text {absorbed }}\right)$ in heating mode are calculated using Equations (5-1) and (5-2). 


$$
\begin{aligned}
& \text { COP }=\frac{\text { Cap }_{\text {heating }}}{\dot{P}_{\text {heating }}} \\
& \dot{Q}_{\text {absorbed }}=\text { Cap heating } \\
& -\dot{P}_{\text {heating }}
\end{aligned}
$$

Cap heating is heat pump heating capacity at current condition and $\dot{P}_{\text {heating }}$ is power drawn by the heat pump in heating mode.

The outlet temperatures of the source and load liquid streams (in ${ }^{\circ} \mathrm{C}$ ) can then be calculated using Equations (5-3) and (5-4).

$$
\begin{aligned}
& T_{\text {source,out }}=T_{\text {source,in }}-\frac{\left|\dot{Q}_{\text {absorbed }}\right|}{\dot{m}_{\text {source }} \times C p_{\text {source }}} \\
& T_{\text {load,out }}=T_{\text {load,in }}+\frac{\text { Cap } p_{\text {heating }}}{\dot{m}_{\text {load }} \times C p_{\text {load }}}
\end{aligned}
$$

where $\dot{m}_{\text {load }}$ and $\dot{m}_{\text {source }}$ are mass flow rates of the liquids on the load side and source side respectively in $\mathrm{kg} / \mathrm{hr}$. $C p_{\text {load }}$ and $C p_{\text {source }}$ are specific heats of the liquid on the load and source side of the heat pump in $\mathrm{kJ} / \mathrm{kg} . \mathrm{K}$.

Similarly in cooling mode Equations (5-5), (5-6), (5-7) and (5-8) are used to obtain the $\mathrm{COP}$ at the current condition, from the energy rejected by the source fluid stream in $\mathrm{kJ} / \mathrm{hr}$ and outlet temperatures of the source and the load liquid streams.

$$
\begin{aligned}
& \text { COP }=\frac{\text { Cap }_{\text {cooling }}}{\dot{P}_{\text {cooling }}} \\
& \dot{Q}_{\text {rejected }}=\text { Cap } p_{\text {cooling }}+\dot{P}_{\text {cooling }} \\
& T_{\text {source,out }}=T_{\text {source, } \text { in }}+\frac{\left|\dot{Q}_{\text {rejected }}\right|}{\dot{m}_{\text {source }} \times C p_{\text {source }}} \\
& T_{\text {load,out }}=T_{\text {load, in }}-\frac{\text { Cap }}{\dot{m}_{\text {cooling }} \times C p_{\text {load }}}
\end{aligned}
$$

The main parameters and input data used in Type 927 are tabulated in Table 5-2. The heat pumps' source side fluid connected to the BTES is $20 \%$ in volume ethanol-in-water solution with the freezing point of $-10^{\circ} \mathrm{C}$.

\subsubsection{Short term storage tank (STST)}

The STST is a stratified liquid storage tank with the same size and specifications demonstrated in Chapter 3 Section 3.2.3 but without an internal heat exchanger. The tank volume is $171 \mathrm{~m}^{3}$ has a vertical cylindrical shape with the height of $4.5 \mathrm{~m}$. The maximum flow rates to 
Table 5-2 Heat pump parameters - Type 927

\begin{tabular}{|l|l|l|}
\hline Number of identical heat pumps & 4 & - \\
\hline Rated cooling capacity per heat pump & 93 & $\mathrm{~kW}$ \\
\hline Rated cooling power per heat pump & 27 & $\mathrm{~kW}$ \\
\hline Rated heating capacity per heat pump & 117 & $\mathrm{~kW}$ \\
\hline Rated heating power per heat pump & 22 & $\mathrm{~kW}$ \\
\hline Rated source flow rate per heat pump & 4.25 & $\mathrm{1} / \mathrm{s}$ \\
\hline Rated load flow rate per heat pump & 4.25 & $1 / \mathrm{s}$ \\
\hline Source fluid specific heat & 3.85 & $\mathrm{~kJ} / \mathrm{kgK}$ \\
\hline Source fluid density & 968 & $\mathrm{~kg} / \mathrm{m}^{3}$ \\
\hline Load fluid specific heat & 4.19 & $\mathrm{~kJ} / \mathrm{kgK}$ \\
\hline Load fluid density & 1000 & $\mathrm{~kg} / \mathrm{m}^{3}$ \\
\hline
\end{tabular}

the load (community) and from the source (heat pump) are $61.2 \mathrm{~m}^{3} / \mathrm{hr}$ each which is based on the heat pumps' flow rate requirement.

Type 4, in TRNSYS, is selected for the STST. It is a stratified storage tank with two optional auxiliary heaters. The thermal performance of a fluid-filled sensible energy storage tank, subject to thermal stratification, is modeled by assuming that the tank consists of $\mathrm{N}(\mathrm{N}<100)$ fully-mixed equal volume segments. The value of $\mathrm{N}$ determines the degree of stratification. If $\mathrm{N}$ is equal to 1 , the storage tank is modeled as a fully-mixed tank, and no stratification effects are possible. Options of fixed or variable inlets, unequal size nodes, temperature dead band on heater thermostats, incremental loss coefficients, and losses to the flue gas of the auxiliary heater are all available in this model. In this instance, two fixed inlets, equal nodes, and no auxiliary heaters are used. Table 5-3 shows the selected main parameters of the storage tank.

Table 5-3 Storage tank parameters - Type 4

\begin{tabular}{|l|l|l|}
\hline Tank volume & 171 & $\mathrm{~m}^{3}$ \\
\hline Fluid specific heat & 4.18 & $\mathrm{~kJ} / \mathrm{kgK}$ \\
\hline Fluid density & 1000 & $\mathrm{~kg} / \mathrm{m}^{3}$ \\
\hline Tank loss coefficient & 3 & $\mathrm{~kJ} / \mathrm{hrm}^{2} \mathrm{~K}$ \\
\hline Tank temperature levels (nodes) & 9 & - \\
\hline Height of each node & 0.5 & $\mathrm{~m}$ \\
\hline Set point temperature - heating/cooling & $40 / 10$ & ${ }^{\circ} \mathrm{C}$ \\
\hline
\end{tabular}




\subsubsection{Medium-temperature BTES}

In this chapter, in order to model the base case heat-pump system, default TRNSYS BTES model (Type 557) is selected. The configuration and the borehole's characteristics are similar to the Chiller-BTES design in Chapter 4, Section 4.3.2.

The volume of the cylindrical shaped storage region which contains the boreholes is set to $93,470 \mathrm{~m}^{3}$, with the boreholes, placed uniformly within the storage volume. The total number

of boreholes in the storage volume is 80 , and the depth of each borehole (from the surface) is 150 $\mathrm{m}$ with $3 \mathrm{~m}$ separation. The selected depth is based on typical drilling depth possible in Toronto area and will also reduce the footprint of the borehole field because the fairly deep boreholes are employed.

The radius of each borehole is $100 \mathrm{~mm}$. Each borehole's circuit has eight boreholes connected in parallel in ten parallel circuits.

The thermal conductivity of the ground comprising the storage volume is considered 2 $\mathrm{W} / \mathrm{mK}$. The properties of the ground are assumed uniform within the storage volume. The heat exchanger fluid is modeled as an aqueous solution of $20 \%$ ethanol with a specific heat of 3.85 $\mathrm{kJ} / \mathrm{kgK}$ and density of $968 \mathrm{~kg} / \mathrm{m}^{3}$. More details can be found in Table 4-1.

\subsubsection{Pumps}

Variable flow pumps with dedicated controls are used for the main hydronic loops, i.e., heat pumps' source and load loops and the community loop. As per heat pump's manufacturer recommendations, the pumps selected (for both source and load side) have a maximum flow rate of $61.2 \mathrm{~m}^{3} / \mathrm{hr}$ with $9 \mathrm{~kW}$ shaft power capacity and an assumed head of $35 \mathrm{~m}$.

\subsubsection{Climate data}

The community thermal load and solar heat are calculated based on the Canadian Weather Year for Energy Calculation (CWEC) hourly data for the City of Toronto.

\subsubsection{Solar photovoltaic (PV) panel}

To offset the community electricity requirements, PV panels are laid on the top of the garage's rooftops. The total available rooftop area for the community is $2,293 \mathrm{~m}^{2}$ (Table 3-7).

The PV panels selected are high performance $320 \mathrm{~W}$ panels with an average efficiency of 19.9\%. Table 5-4 shows the key data of the PV panels and detail specifications are presented in Appendix F. 
Table 5-4 Photovoltaic panels parameters

\begin{tabular}{|l|c|c|}
\hline \multicolumn{3}{|c|}{ Photovoltaic Panel* } \\
\hline \multicolumn{3}{|c|}{ Specifications Summary } \\
\hline Nominal power & 320 & $\mathrm{~W}$ \\
\hline Average PV panel efficiency & 19.9 & $\%$ \\
\hline Rated voltage & 54.7 & $\mathrm{~V}$ \\
\hline Rated current & 5.9 & $\mathrm{~A}$ \\
\hline Operating temperature & -40 to +85 & ${ }^{\circ} \mathrm{C}$ \\
\hline Power temperature coefficient & -0.38 & $\% /{ }^{\circ} \mathrm{C}$ \\
\hline Panel area & 1.6 & $\mathrm{~m}^{2}$ \\
\hline Power degradation after year 5 to 25 & -0.4 & $\% /$ Year \\
\hline & * SUNPOWER Solar panel E20-327 &
\end{tabular}

The available rooftop area can accommodate 1,400 of the above PV panels with the total power capacity of $448 \mathrm{~kW}$.

Type 194 in TRNSYS is used to model and estimate the power generation of the PV system. The results of the PV performance and electricity generation from TRNSYS are also compared with the RETScreen software which is used for the economic analysis (RETScreen, 2016).

In TRNSYS, the photovoltaic array (Type 194), determines the electrical performance of the system using a five-parameter model (Duffie and Beckman, 1991). The model is based on the calculation method presented by DeSoto et al. (2007). Type 194 may be used in simulations involving electrical storage batteries, direct load coupling, and utility grid connections. The model determines the current and power of the array at a specified voltage. Other outputs include current and voltage at the maximum power point. It includes a mode that allows an inverter to be modeled with the PV. This coupling allows the limitations of the inverter to affect the performance of the PV array directly. These limitations include the minimum and maximum allowable input voltage and maximum allowable input power. Based on the manufacturer data, Table 5-5 presents the parameters used in Type 194. 
Table 5-5 Photovoltaic array parameters - Type 194

\begin{tabular}{|l|l|l|}
\hline Module short-circuit current & 6.24 & $\mathrm{~A}$ \\
\hline Module open-circuit voltage & 64.8 & $\mathrm{~V}$ \\
\hline Module voltage at max power point & 54.7 & $\mathrm{~V}$ \\
\hline Module current at max power point & 5.86 & $\mathrm{~A}$ \\
\hline Current Temperature coefficient & 3.5 & $\mathrm{~mA} /{ }^{\circ} \mathrm{C}$ \\
\hline Voltage Temperature coefficient & -176.6 & $\mathrm{mV} /{ }^{\circ} \mathrm{C}$ \\
\hline Number of modules in series & 10 & - \\
\hline Number of modules in parallel & 140 & - \\
\hline Maximum inverter power & 450 & $\mathrm{~kW}$ \\
\hline Maximum inverter voltage & 650 & $\mathrm{~V}$ \\
\hline Minimum inverter voltage & 500 & $\mathrm{~V}$ \\
\hline Inverter efficiency & $95 \%$ & - \\
\hline
\end{tabular}

\subsection{Overall system specifications}

The overview of the system design specifications for the major components is summarized in Table 5-6.

Table 5-6 System major components summary

\begin{tabular}{|l|l|l|}
\hline \multicolumn{3}{|c|}{ System Specifications Summary } \\
\hline Photovoltaic Panels & 1400 & \\
\hline Number of PV panels & 2,240 & $\mathrm{~m}^{2}$ \\
\hline Total solar panel area & 320 & $\mathrm{~W}$ \\
\hline Rated power for each panel & & \\
\hline Heat Pumps - water to water & 4 & \\
\hline Number of heat pumps & 372 & $\mathrm{~kW}$ \\
\hline Total cooling capacity & 468 & $\mathrm{~kW}$ \\
\hline Total heating capacity & 3.4 & - \\
\hline COP heating & 5.4 & $\mathrm{~W} / \mathrm{W}$ \\
\hline EER cooling & 61.2 & $\mathrm{~m} / \mathrm{hr}$ \\
\hline Rated source and load side flow rate & & \\
\hline BTES / Geo-exchanger & 80 & \\
\hline Number of boreholes & 150 & $\mathrm{~m}$ \\
\hline Borehole depth & 3 & $\mathrm{~m}$ \\
\hline Borehole spacing & 93,470 & $\mathrm{~m}^{3}$ \\
\hline BTES volume & 12,000 & $\mathrm{~m}$ \\
\hline Total borehole length & 61.2 & $\mathrm{~m}^{3} / \mathrm{hr}$ \\
\hline Max fluid flow-BTES & 171 & $\mathrm{~m}$ \\
\hline STST volume & & \\
\hline
\end{tabular}




\subsection{Simulation results}

Figure 5-3 depicts the simulation results for the annual accumulated heat pumps' energy source and sink plus the electricity for five years. The load and source side energy amount are the heat that is transferred to or received from the STST and the BTES respectively.

Based on the 20-years simulation time, Table 5-7, Figure 5-4, and Figure 5-5 show the heat pumps' energy and performance in five-year intervals (i.e., 1, 5, 10, 15 and 20). In the year five, in the heating mode, the total heat transferred to the STST is $2442 \mathrm{GJ}$, which is the sum of the total heat extracted from the BTES (1706 GJ) and electricity delivered to the heat pumps (736 GJ).

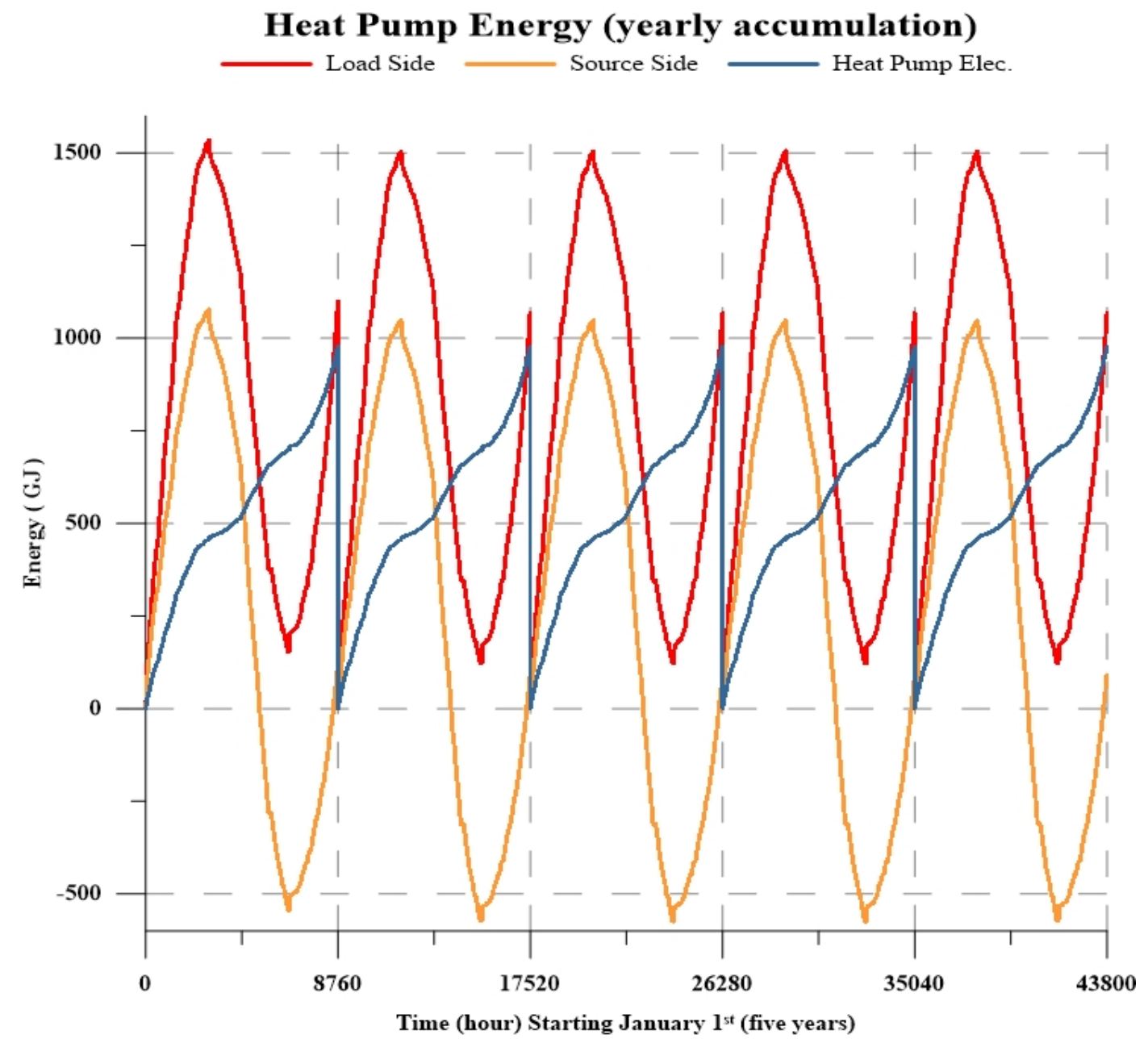

Figure 5-3 Heat pump accumulated annual energy - five years 
Table 5-7 Annual heat pumps energy and performance

\begin{tabular}{|l|c|c|c|c|c|}
\cline { 2 - 7 } \multicolumn{1}{c|}{} & \multicolumn{5}{c|}{ Heating } \\
\hline Year & $\mathbf{1}$ & $\mathbf{5}$ & $\mathbf{1 0}$ & $\mathbf{1 5}$ & $\mathbf{2 0}$ \\
\hline Heat transferred to the load (GJ) & 2,472 & 2,442 & 2,442 & 2,443 & 2,441 \\
\hline Heat transferred from the source (GJ) & 1,738 & 1,706 & 1,704 & 1,703 & 1,700 \\
\hline Electric energy (GJ) & 735 & 736 & 738 & 740 & 740 \\
\hline COP (seasonal) & 3.4 & 3.3 & 3.3 & 3.3 & 3.3 \\
\hline & \multicolumn{5}{|c|}{ Cooling } \\
\hline Year & $\mathbf{1}$ & $\mathbf{5}$ & $\mathbf{1 0}$ & $\mathbf{1 5}$ & $\mathbf{2 0}$ \\
\hline Heat transferred from the load (GJ) & 1,379 & 1,381 & 1,382 & 1,384 & 1,385 \\
\hline Heat transferred to the source (GJ) & 1,621 & 1,619 & 1,618 & 1,619 & 1,618 \\
\hline Electric energy (GJ) & 241 & 238 & 236 & 234 & 233 \\
\hline COP (seasonal) & 5.7 & 5.8 & 5.9 & 5.9 & 5.9 \\
\hline
\end{tabular}

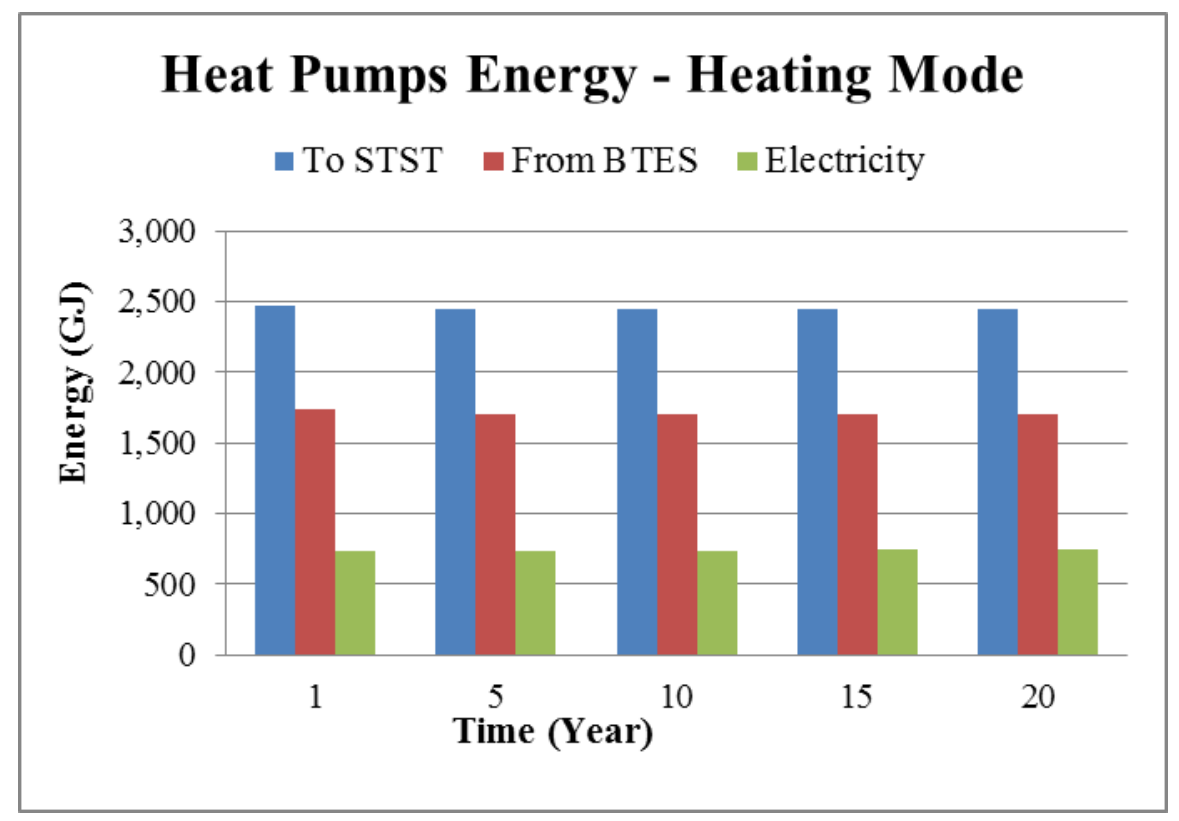

Figure 5-4 Heat pumps' energy in heating mode - year 1, 5, 10, 15 and 20 


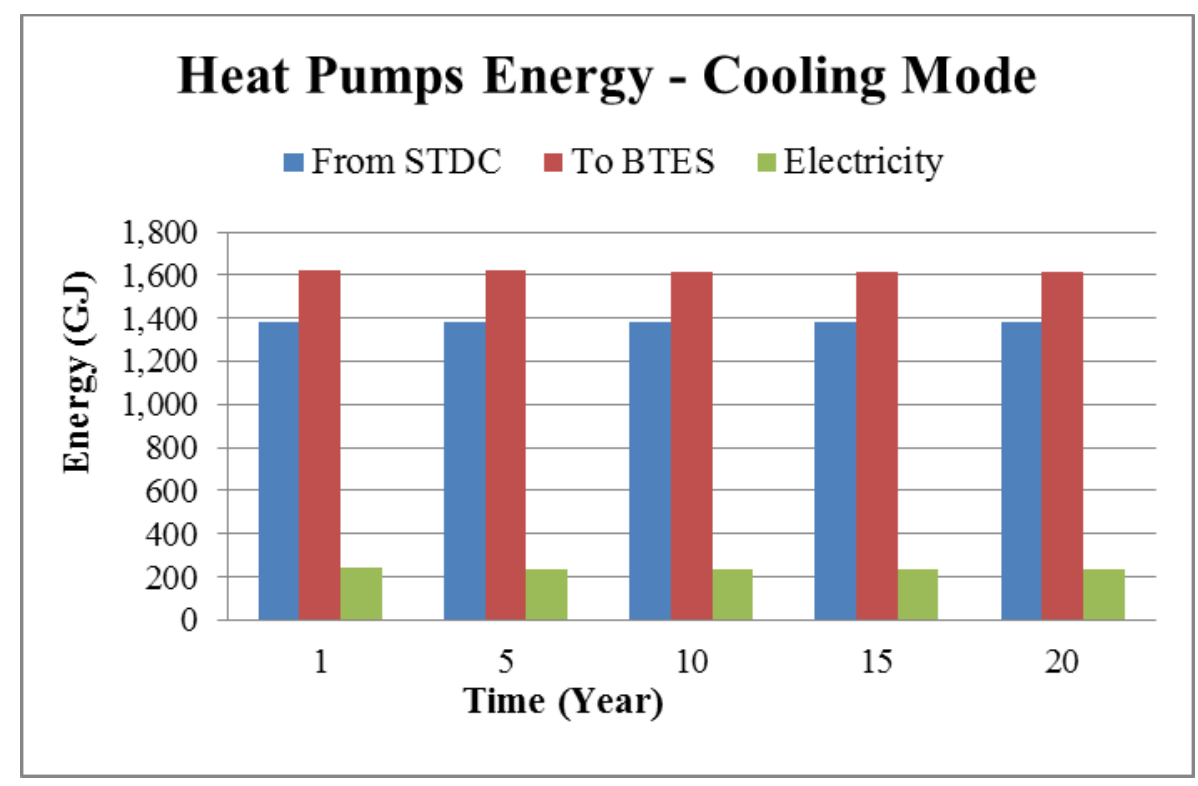

Figure 5-5 Heat pumps' energy in cooling mode - year 1, 5, 10, 15 and 20

In the year five, in the cooling mode, the heat transferred to the BTES is 1619 GJ, which is the sum of the heat extracted from the STST $(1381 \mathrm{GJ})$ and the electricity delivered to the heat pumps (238 GJ).

After year one, the performance of the heat pumps is almost stable during the whole simulation time (i.e., 20 years). The heat pump seasonal COPs are 3.3 and 5.9 in heating and cooling mode respectively. The simulated heat pumps' seasonal COPs compared to the rated heat pump's COPs are very close in heating mode and better in cooling mode. This demonstrates a relatively optimum heat pump operation in a year. The rated COP of the heat pump, provided by the manufacturer, in the cooling mode, is 5.4, measured at the source and load temperatures of $25{ }^{\circ} \mathrm{C}$ and $12{ }^{\circ} \mathrm{C}$ respectively. The rated heat pump's COP in the heating mode is 3.4 , measured at the source and load temperatures of $0{ }^{\circ} \mathrm{C}$ and $40{ }^{\circ} \mathrm{C}$ respectively.

The pumping energy requirement for the two hydronic loops of the heat pumps is estimated to be $161 \mathrm{GJ}$ (44.7 MWh) annually. Figure 5-6 shows the annual accumulated pumping energy for both load-side (STST) and source-side (BTES) of the heat pumps' hydronic loops. 


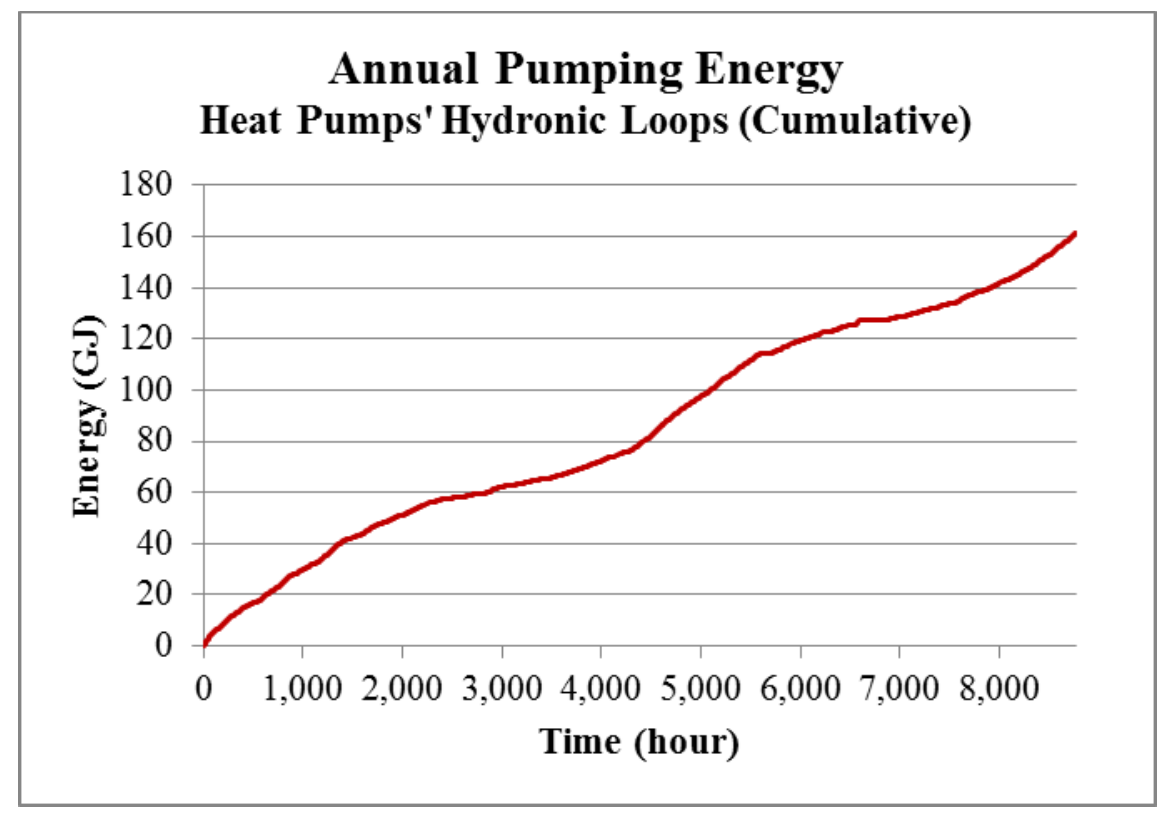

Figure 5-6 Annual accumulated pumping energy of the heat pumps' hydronic loops

By including the pumping energy to the system supplied energy, the overall system COP in heating and cooling seasons are calculated to be 2.8 and 4.1, respectively. The overall annual system COP is estimated to be 3.1, which is calculated by dividing the total annual system's useful delivered energy (heating and cooling) by the total annual input electricity.

Figure 5-7 depicts the average hourly ground temperature simulated in twenty years. The annual ground temperature swing, the difference between peak cooling and heating, is $3.8^{\circ} \mathrm{C}$. In year twenty the ground temperature is $1.4{ }^{\circ} \mathrm{C}$ less than the year one. The ground temperature drop is due to the imbalance community heating and cooling load which in this case the community heating demand is about 50\% higher than its cooling demand. Table 5-8 and Figure 5-8 show the average ground temperatures in the year 1, 5, 10, 15 and 20.

Table 5-8 Minimum, maximum and average ground temperatures and temperature swing

\begin{tabular}{|l|c|c|c|c|c|}
\hline Year & $\mathbf{1}$ & $\mathbf{5}$ & $\mathbf{1 0}$ & $\mathbf{1 5}$ & $\mathbf{2 0}$ \\
\hline Minimum Temperature $\left({ }^{\circ} \mathrm{C}\right)$ & 7.6 & 7.1 & 6.7 & 6.4 & 6.2 \\
\hline Maximum Temperature $\left({ }^{\circ} \mathrm{C}\right)$ & 11.4 & 11.0 & 10.6 & 10.3 & 10.1 \\
\hline Average Temperature $\left({ }^{\circ} \mathrm{C}\right)$ & 9.5 & 9.1 & 8.7 & 8.4 & 8.2 \\
\hline Annual Temperature swing $\left({ }^{\circ} \mathrm{C}\right)$ & 3.8 & 3.8 & 3.8 & 3.8 & 3.8 \\
\hline
\end{tabular}


Average Ground Temperature in Twenty Years

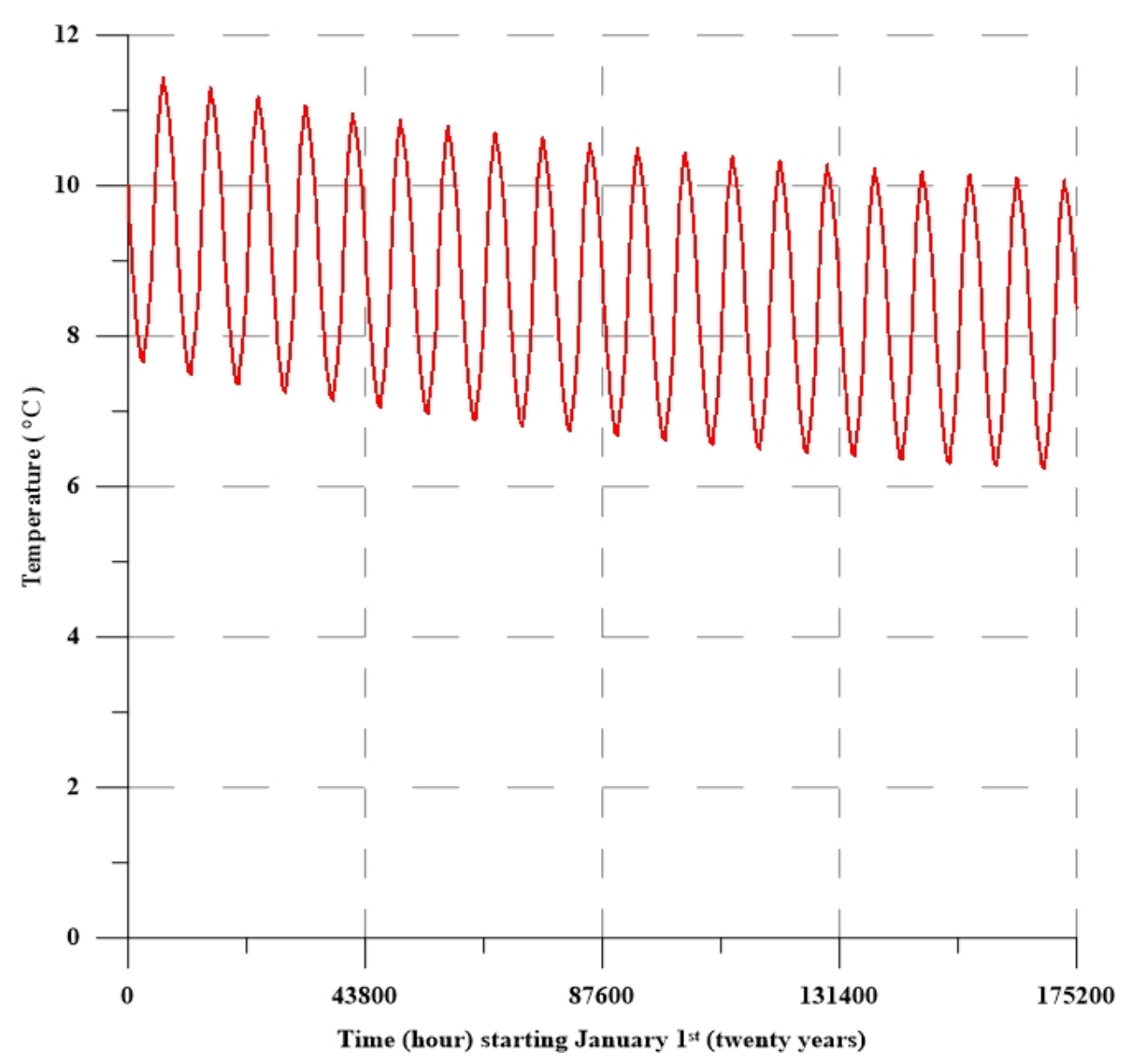

Figure 5-7 BTES hourly average ground temperature - twenty years

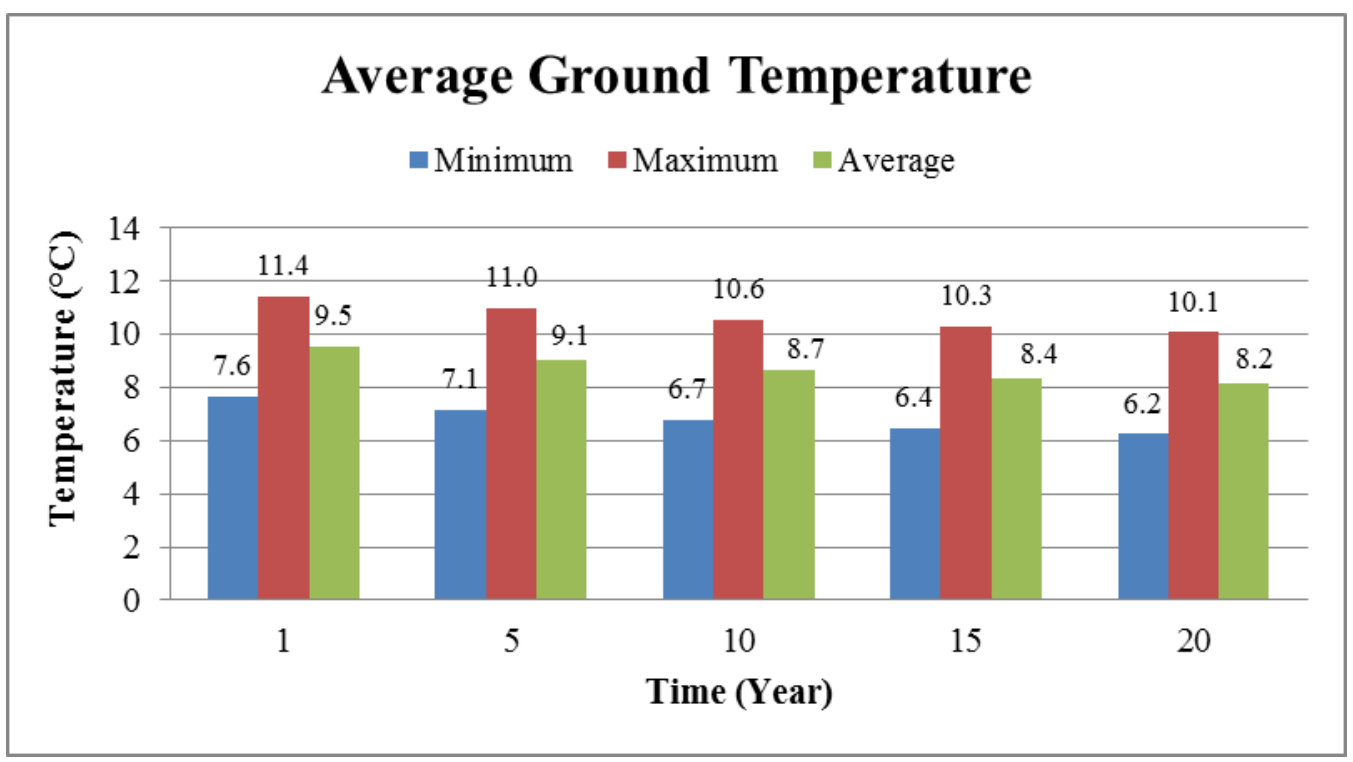

Figure 5-8 Minimum, maximum and average ground temperature - twenty years 
The ground-loop inlet and outlet temperature difference do not change significantly during twenty years. Therefore, the heat pumps' performance will not change drastically despite the small variations in the average ground temperature. Figure 5-9 shows the hourly ground inlet and outlet fluid temperatures in the first five years. As it shows, in all years in the heating mode, the minimum fluid outlet temperature from the ground is around $0^{\circ} \mathrm{C}$, which is the same as fluid inlet temperatures (EFT) to heat pumps. In the cooling mode, the maximum ground fluid outlet temperature is $27^{\circ} \mathrm{C}$. The minimum and maximum outlet fluid temperature from the ground (i.e., $0^{\circ} \mathrm{C}$ and $27^{\circ} \mathrm{C}$ ) happen in few hours of the year and are in the acceptable heat pump EFTs. More detail on the minimum heat pump's EFTs can be seen in the heat pump manufacturer's data shown in Appendix D.

\section{BTES - In/Out and Average Tempreture}

Into the Ground

Out of the Ground

Average Ground

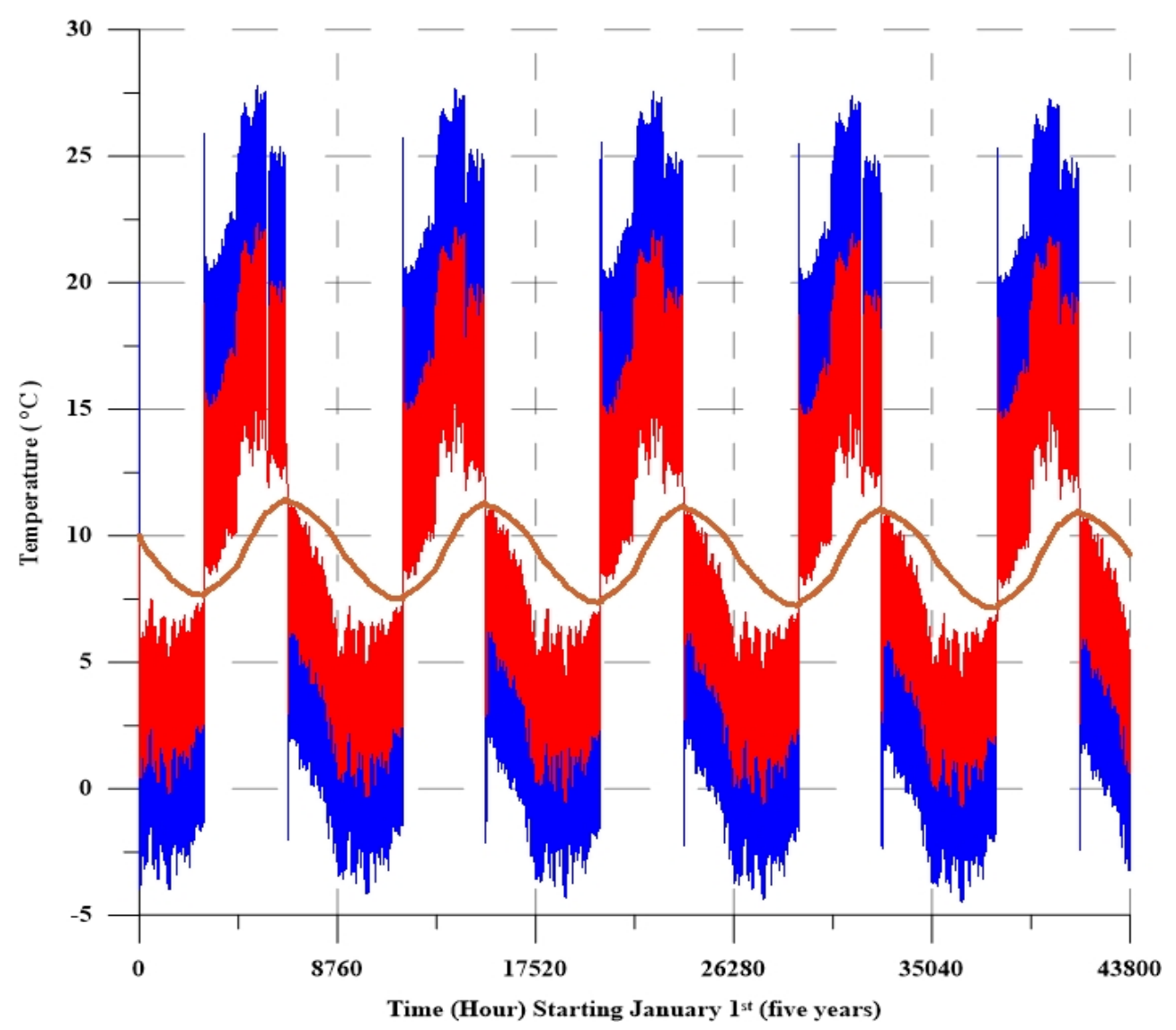

Figure 5-9 BTES hourly inlet and outlet fluid temperature and average ground temperature

- five years 
The $448 \mathrm{~kW}$ photovoltaic system generates $570 \mathrm{MWh}$ (2,052 GJ) electricity, which based on the net-metering program all will be transferred to the local grid system. The PV and the inverter efficiencies are $19.6 \%$ and 95\% respectively. Figure 5-10 shows the annual PV system's hourly and cumulative electricity generation.

The annual heat pumps electricity demands, in the year five, are 736 GJ and 238 GJ in the heating and the cooling mode respectively with the total of 974 GJ (Table 5-7). This amount is equivalent to the $271 \mathrm{MWh}$. By including the heat pumps hydronic annual pumping energy ( 44.7 MWh), the total electricity requirement for the heat pump system will be $315.7 \mathrm{MWh}$, which is $55 \%$ of the total PV power generation capacity. The balance of the generated power (254.3 MWh) can be used for the rest of the system and in the community.

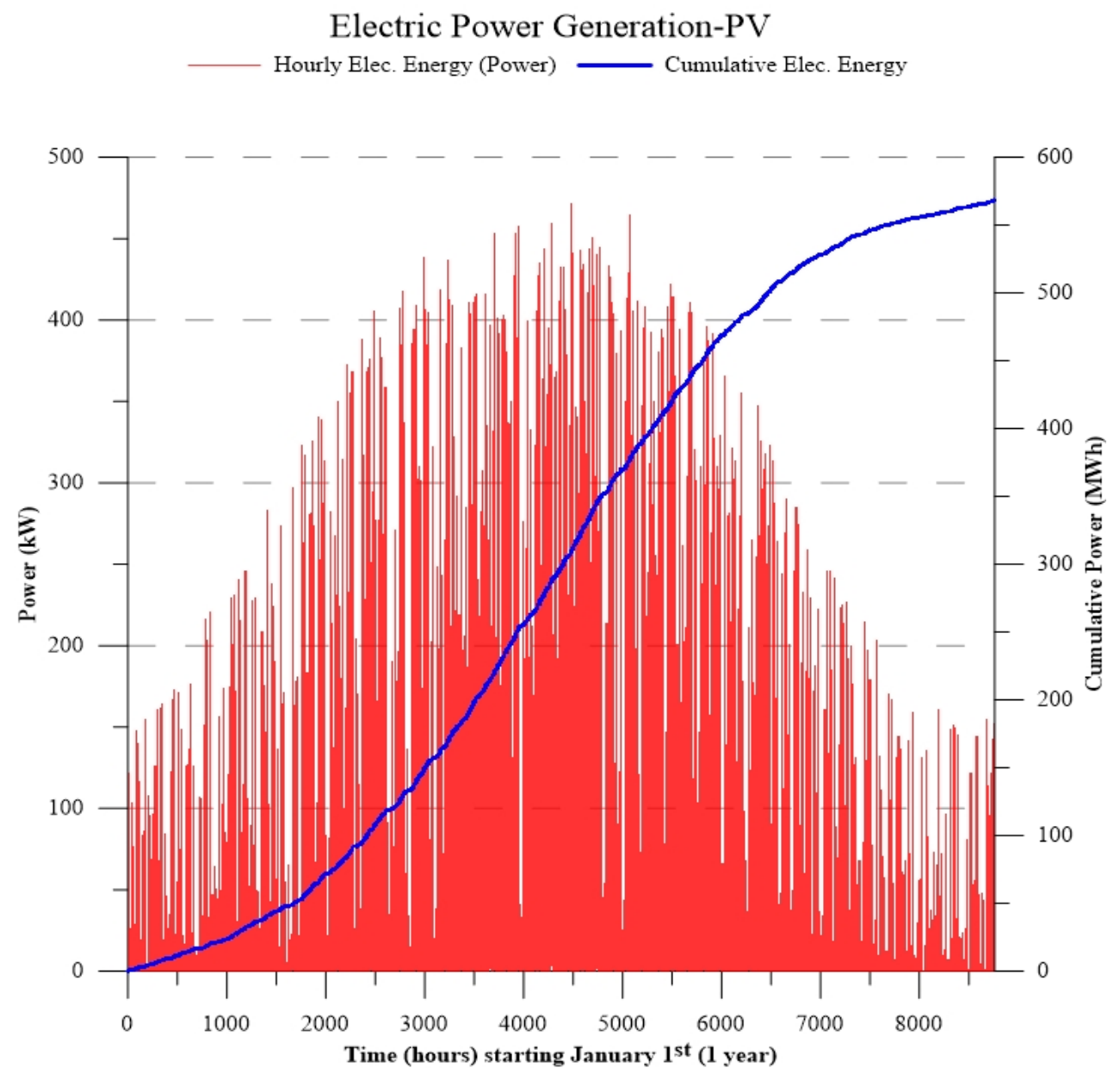

Figure 5-10 Annual PV system hourly and cumulative electricity generation 


\subsection{System cost comparison}

Similar to the Section 3.4, the proposed system incremental cost is compared to the systems costings tabulated in Table 3-8 for the DLSC and the modified similar systems.

Table 5-9 presents the system cost comparisons between heat-pump-PV (HPPV) system and solar-thermal-chiller (STC) system and the two heating-only solar thermal systems which all serve the same community heating and cooling loads. The HPPV system does not offer any payback over the lifetime of the project due to the high initial system cost. Based on the blended electrify rate of $\$ 0.21$ per $\mathrm{kWh}$ (OEB, 2016), the simple payback of the HPPV system is estimated to be 44 years.

Table 5-9 Heat pump system cost of the DLSC and modified DLSC systems

\begin{tabular}{|l|c|c|c|c|c|}
\hline \multicolumn{5}{|c|}{ Sys tem Initial Costing (Incre mental)- Ins talled } \\
\hline & Index & Heating Only & \multicolumn{2}{c|}{ Heating and Cooling } \\
\hline System & & DLSC & Mod.-DLSC & Abs. Chiller & Heat Pump-PV \\
\hline Number of Boreholes & & 144 & 90 & 90 and 80 & 80 \\
\hline Borehole Depth $(\mathrm{m})$ & & 37 & 59 & 59 and 150 & 150 \\
\hline Number of Solar Thermal Panels & $2.87\left(\mathrm{~m}^{2} / \mathrm{panel}\right)$ & 800 & 600 & 600 & 0 \\
\hline Number of Solar PV panels * & $1.6\left(\mathrm{~m}^{2} / \mathrm{panel}\right)$ & 0 & 0 & 0 & 780 \\
\hline Cost of BTES & $116(\$ / \mathrm{m})$ & $\$ 618,048$ & $\$ 615,960$ & $\$ 2,007,960$ & $\$ 1,392,000$ \\
\hline Cost of Solar Thermal Panels & $497\left(\$ / \mathrm{m}^{2}\right)$ & $\$ 1,139,621$ & $\$ 855,834$ & $\$ 855,834$ & $\$ 0$ \\
\hline Cost of Solar PV Panels with Inverter & $3(\$ / \mathrm{W})$ & $\$ 0$ & $\$ 0$ & $\$ 0$ & $\$ 748,800$ \\
\hline $\begin{array}{l}\text { Short Term Storage Tank } \\
\text { Including the Energy Center }\end{array}$ & $2500\left(\$ / \mathrm{m}^{3}\right)$ & $\$ 600,000$ & $\$ 427,500$ & $\$ 427,500$ & $\$ 427,500$ \\
\hline Cost of Heat Pumps / Absorption Chiller & $715 / 570(\$ / \mathrm{kW})$ & $\$ 0$ & $\$ 0$ & $\$ 291,840$ & $\$ 334,620$ \\
\hline Total Initial Cost & & $\$ 2,357,669$ & $\$ 1,899,294$ & $\$ 3,583,134$ & $\$ 2,902,920$ \\
\hline Solar Area Saving & & Base & $25 \%$ & $25 \%$ & $49 \%$ \\
\hline
\end{tabular}

* the number of the PV panels corresponds to the heat pumps power and their hydronic pumping energy

The total costs are incremental for the major system components, i.e. the similar components between the systems are excluded. The cost index sources are the same as the Chapter 3 Section 3.4 and from the RSMeans (2013) handbook for the heat pumps, absorption chiller, and solar PV panels.

The HPPV system, which provides both heating and cooling, costs 19\% less than STC system and requires $24 \%$ less area for the solar panels. On the other hand, the STC system as described in Chapter 4, had the solar fraction of $18 \%$ in cooling which means the absorption chiller needs to use the boiler for its $82 \%$ of energy needs. This brings about $\$ 7,204$ annual 
operating (incremental) cost to the STC system compared to the HPPV incremental operating cost of zero. The chillers' annual operating cost associated with the boiler's natural gas (NG) consumption is estimated from the boiler NG use (Table 4-5) multiplied by the delivered NG price per GJ, which is $\$ 6.17$ (Enbridge Gas, 2016).

\subsection{Conclusion}

In this chapter, heat pumps with BTES and photovoltaic system were modeled for a community in Toronto area. The selected community is a heating dominated community that has $50 \%$ higher annual heating demand than the annual cooling demand. The winter peak heating load is $19 \%$ greater than peak cooling load.

The simulation results show that the system operates favorably from the first year and does not have any significant performance degradation in 20 years.

Due to the imbalance community annual heating and cooling loads, the average ground temperature drops $1.4^{\circ} \mathrm{C}$ in twenty years. This change has been considered in the BTES sizing design in the way to show the minimal effect on the system performance.

On average, the heat pumps perform with the seasonal COP of 3.3 in the heating mode and 5.9 in the cooling mode. In the heating mode, heat pumps provide 2442 GJ heat to the STST consisting of $1704 \mathrm{GJ}$ from the BTES and $738 \mathrm{GJ}(205 \mathrm{MWh})$ from the electricity grid. In the cooling mode, the heat pumps use $236 \mathrm{GJ}$ ( $66 \mathrm{MWh}$ ) electricity to extract $1382 \mathrm{GJ}$ heat from the STST and inject 1,618 GJ heat to the BTES annually.

The total heat pumps' power load, including their pumping energy, is $315.7 \mathrm{MWh}$ annually, which can be net-metered by $780 \mathrm{PV}$ panel's production, installed on the rooftops. The total available rooftop area in the community is $2293 \mathrm{~m}^{2}$ which can accommodate $1433 \mathrm{PV}$ panels. The potential electricity generation capacity using all available rooftop area is $570 \mathrm{MWh}$ annually. The heat pumps' energy, including their hydronic-pumps, requires $55 \%$ of this total power generation capacity.

Based on the high-level costing analysis, the HPPV system capital incremental cost is $19 \%$ more economical than the solar-thermal-chiller (STC) system. The HPPV does not have any incremental operating cost compared to the STC system. 


\section{Chapter 6 : Solar Community Heating and Cooling System with Central Heat Pump and Borehole Thermal Energy Storage System}

In Chapter 5, a new system presented for heating and cooling the same community used in Chapter 4 . The community heating and cooling energy were provided through a storage tank connected to a central heat pump system exchanging heat with a borehole thermal energy system. In cold climates like Canada, where the heating requirements are relatively higher than cooling in a given year, such a system performance degrades in few years as the result of the imbalance heating and cooling loads. In the heating mode, after few years of operation, the ground temperature drops, and subsequently, the heat pump entering fluid temperature decreases. As the result, the heat pump operates less efficiently. Following the study made on the heat pump system (Chapter 5), in this chapter, a solar thermal system with borehole thermal energy storage is integrated into the same heat pump system (ST-HPPV).

The heat pump-PV system case (HPPV), presented in Chapter 5, will be used as a base case (BC) to compare how the newly introduced system will perform.

\subsection{System layout}

Figure 6-1 depicts the system configuration and main equipment of the proposed STHPPV system. The community hydronic loop operates in either heating or cooling mode based on the community energy demands.

The heat pump units (HPs) located at the central mechanical room (energy center) provided hot or chilled water via a storage tank (HP-STST) and a heat exchanger to the community's fan-coil system. In the cooling season, the heat pump condensers reject heat to the heat pump BTES (HP-BTES) and during the heating season heat is extracted from the solar short term storage tank (solar-STST) to the heat pump evaporators.

The solar-STST receives the harvested solar thermal energy through a solar hydronic loop all year around. Solar-BTES receives the heat stored in the solar-STST during the cooling season and provides the stored heat back to the solar-STST in the heating season. 


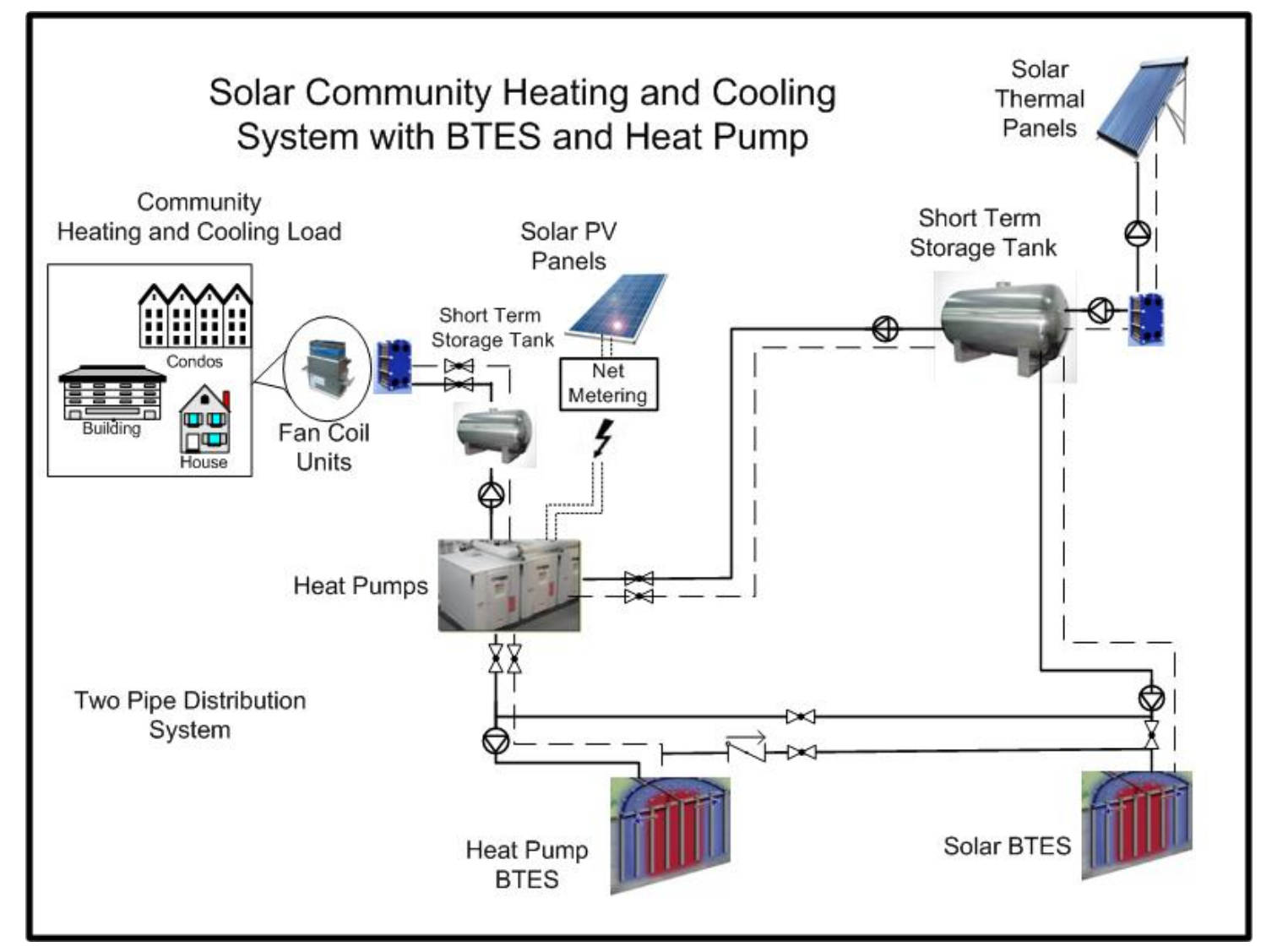

Figure 6-1 Overall ST-HPPV system schematic

In the cooling mode (Figure 6-2), the solar thermal system, including the solar-BTES and solar-STST, operates independently. Both the solar-BTES and the HP-BTES receive heat for the seasonal storage. HP-BTES receives the rejected heat from the heat pumps, and solar-BTES receives the harvested heat from the solar thermal system.

In the heating mode (Figure 6-3) the heat pumps' source-side hydronic loop is connected to the solar-STST to receive the required heat. A hydronic loop connects the solar-STST to the HP-BTES and the solar-BTES. The fluid flow passes through HP-BTES from the solar-STST first and then go through the solar-BTES and then back to the solar-STST. The HP-BTES operates at the lower temperature than the solar-BTES due to the heat pumps operation requirement. Therefore, the solar-BTES and HP-BTES are called high and medium temperature BTESs respectively. 


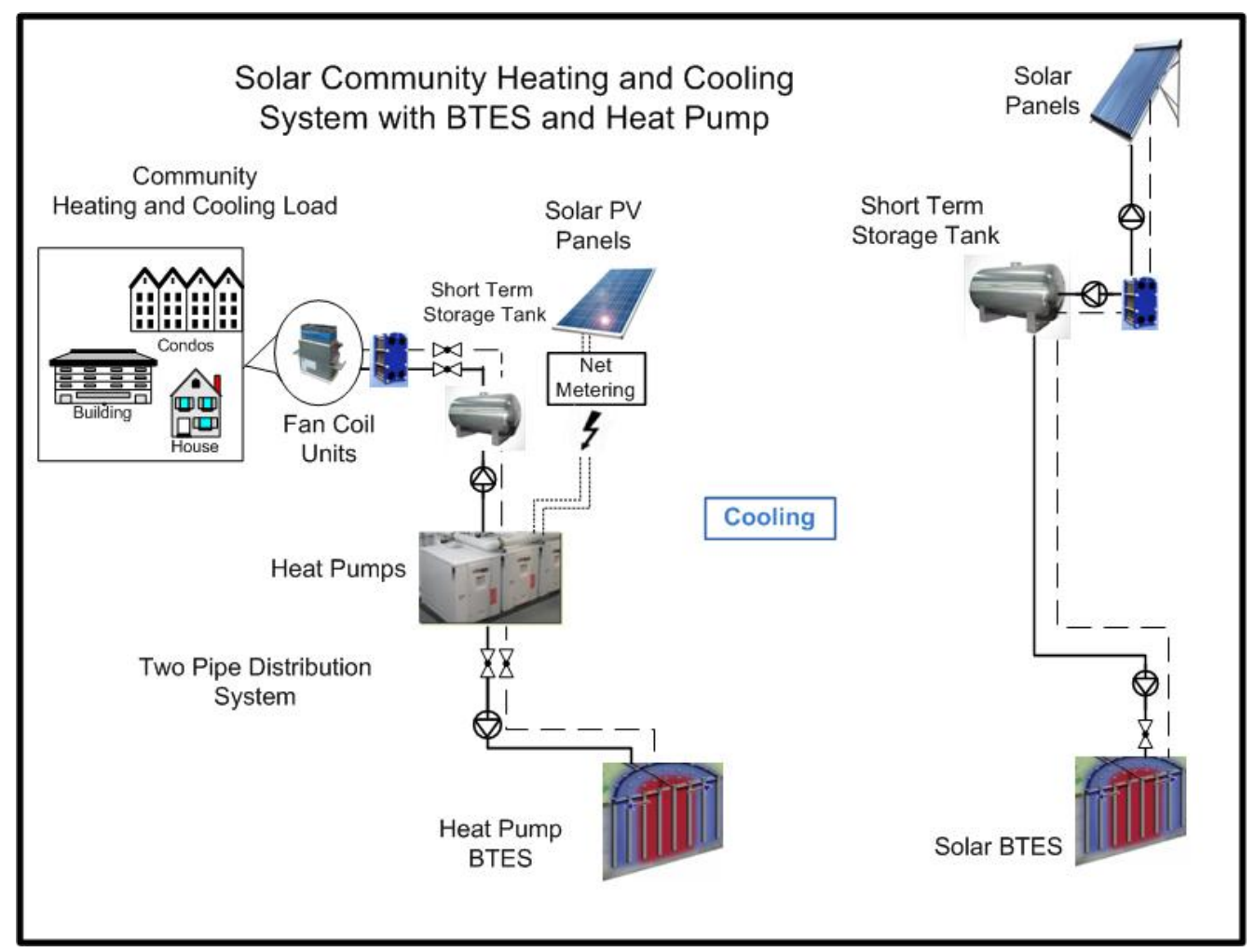

Figure 6-2 ST-HPPV system schematic in cooling mode

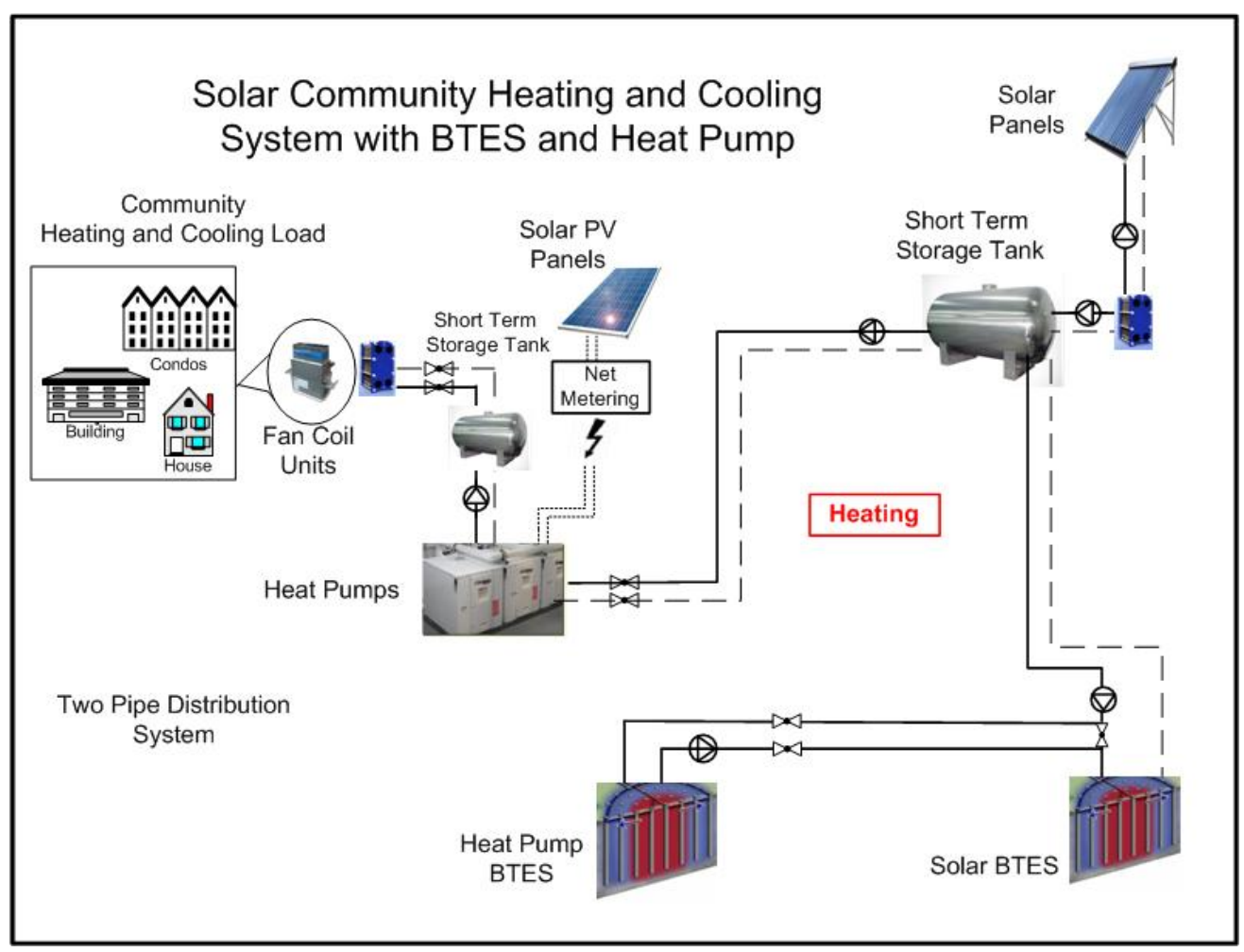

Figure 6-3 ST-HPPV system schematic in heating mode 


\subsection{The community heating and cooling load}

The selected community heating and cooling loads are similar to the community chosen in Section 5.2 and Section 4.2. It comprises a combination of single and multifamily residential houses located in Toronto, Ontario with a considerable amount of cooling load. The annual community heating and cooling load are $2350 \mathrm{GJ}$ and $1181 \mathrm{GJ}$ with the peak heating and cooling load of $457 \mathrm{~kW}$ and $369 \mathrm{~kW}$ respectively.

The houses in the community, as described in Chapter 3 Section 3, are built based on R2000 standards (NRCan, 2012) and are equipped with an air handler with a water-to-air fan coil. The fan coils, depending on the season, receive either hot or chilled water from a central energy center through a two-pipe distribution system.

\subsection{System major equipment and methodology}

The system is modeled using TRNSYS 17 software (Klein et al., 2010). Figure 6-4 depicts the TRNSYS model layout.

The system contains three hydronic loops connected to the solar-STST, 1) solar loop, 2) high-temperature solar-BTES loop and 3) heat pump source hot-water source loop. There are also three other main loops connected to the heat pumps, 1) hot or chilled water loop from heat pumps to the HP-STST, 2) heat rejecting water loop to the medium-temperature BTES, and 3) community chilled or hot-water loop from the HP-STST.

The liquid flow through the solar collectors transfers the solar heat gain to the solar loop connected the solar-STST through a heat exchanger. The model receives the hourly community heating and cooling loads from the spreadsheets resulting from eQuest community load calculations.

\subsubsection{Heat pumps}

The heat pumps selected for this model is similar to the heat pumps presented in Chapter 5 Section 5.3.1. There are four heat pumps with each having the rated capacities of $117 \mathrm{~kW}$ and $93 \mathrm{~kW}$ in heating and cooling mode respectively. The total rated capacity of the heat pumps in the heating and cooling mode are $468 \mathrm{~kW}$ and $372 \mathrm{~kW}$ respectively.

In TRNSYS, Type 927 is water-to-water heat pump component, which is selected for this model. Heat pump specification and Type 927 parameters are shown in Chapter 5 Table 5-1 and Table 5-2. 


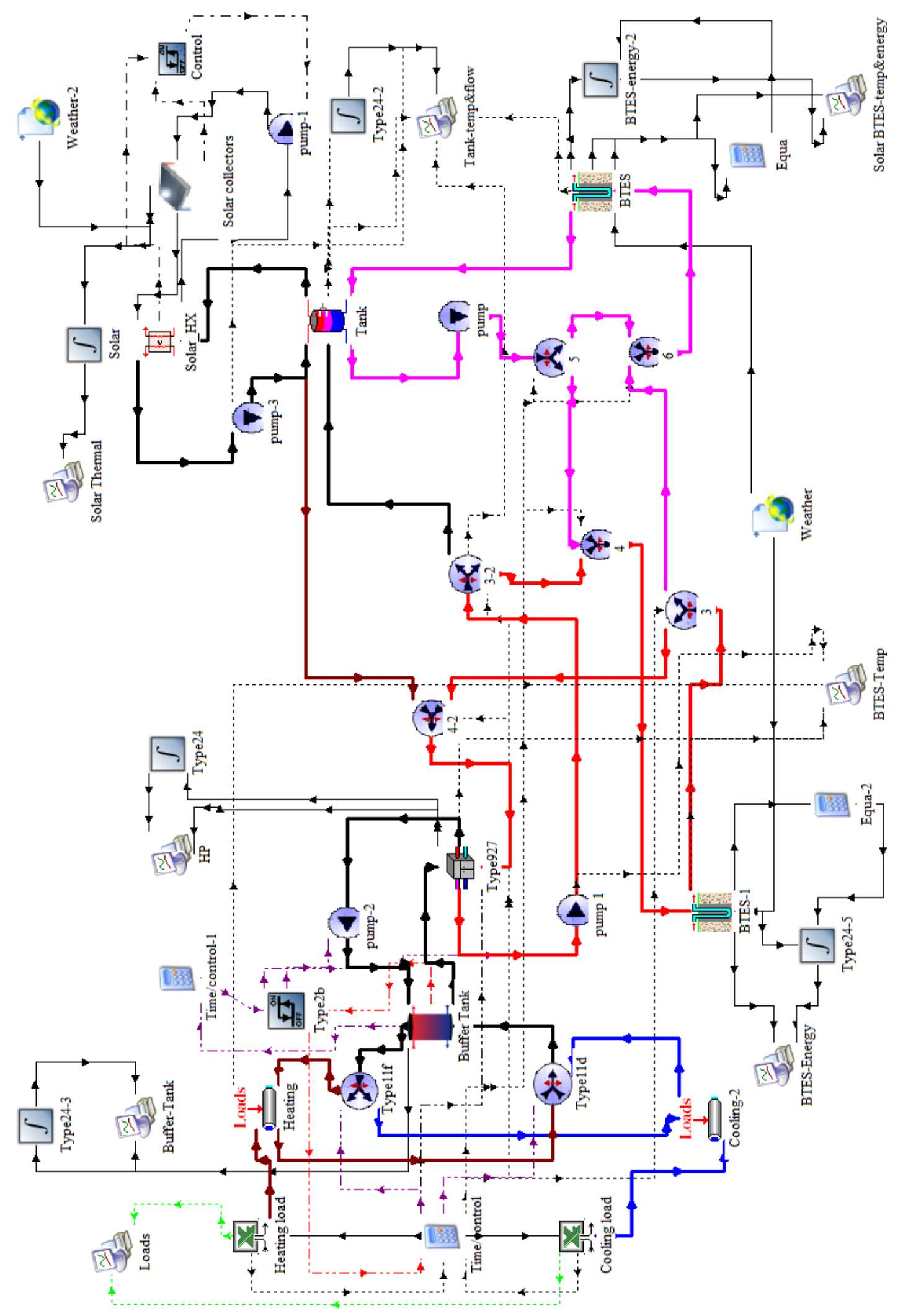

Figure 6-4 TRNSYS solar thermal-heat pump-PV (ST-HPPV) model schematic 


\subsubsection{Heat pump short term storage tank (HP-STST)}

The HP-STST is similar to the STST presented in Chapter 5 Section 5.3.2. It is a stratified liquid storage tank with the same size and specifications. The tank volume is $171 \mathrm{~m}^{3}$ has a vertical cylindrical shape with the height of $4.5 \mathrm{~m}$. The maximum flow rates to the load (community) and from the source (heat pumps) are $61.2 \mathrm{~m}^{3} / \mathrm{hr}$ each, which is sized based on the heat pumps' flow rate requirement. Type 4, in TRNSYS, is used to model this tank too.

\subsubsection{Solar short term storage tank (Solar-STST)}

The Solar-STST is also a stratified tank. The model type employed in TRNSYS (Type 4) is a vertical tank with two inlet and two outlet streams and an internal heat exchanger. Figure 6-5 shows a simple schematic of the solar-STST.

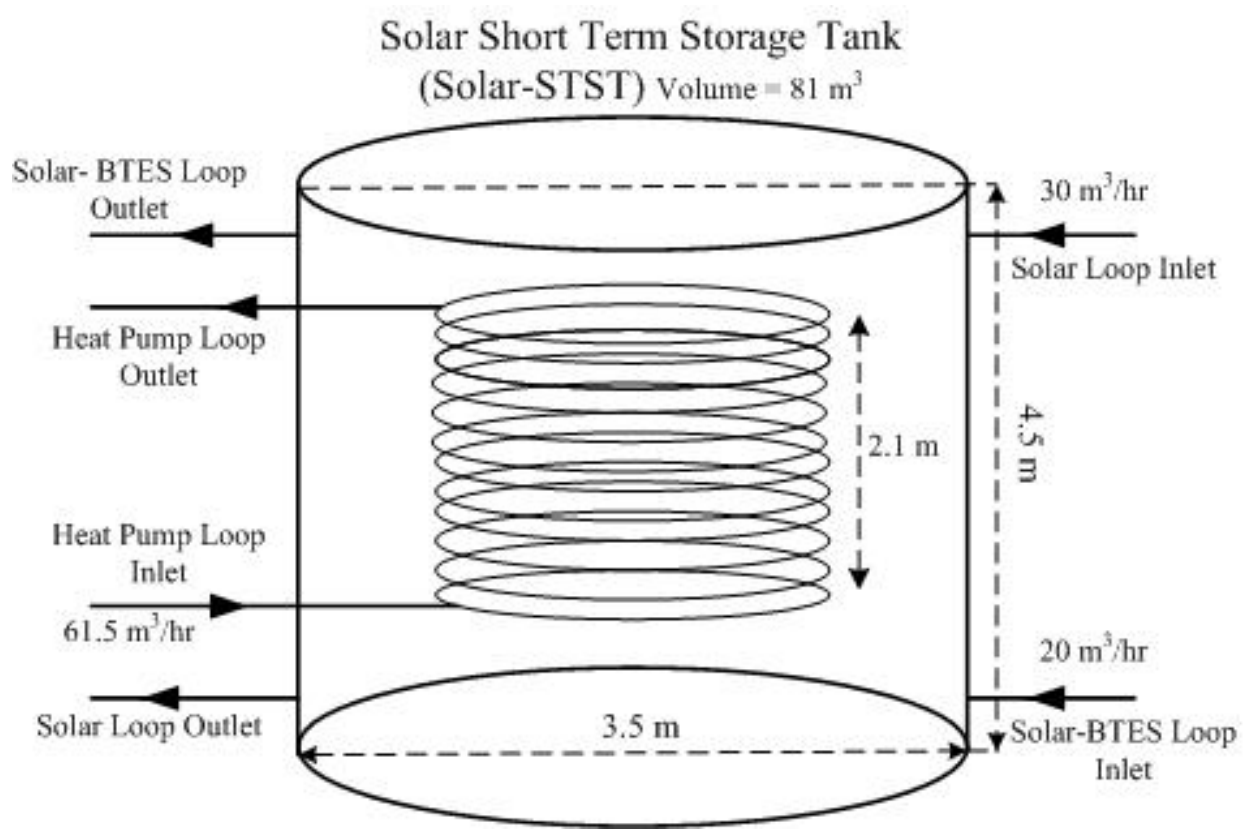

Figure 6-5 Solar Thermal Short Term Storage Tank (solar-STST) - simplified schematic

The selected solar-STST volume is $81 \mathrm{~m}^{3}$ with a height of $4.5 \mathrm{~m}$. The two inlets and outlets of the tank are connected to the solar and solar-BTES loops respectively. The maximum flow rates to the reservoir from the solar and solar-BTES are $30 \mathrm{~m}^{3} / \mathrm{hr}$ and $20 \mathrm{~m}^{3} / \mathrm{hr}$ respectively. The flow rates are calculated based on the solar collector and solar-BTES system requirements. The internal heat exchanger is connected to the heat pump source-side loop with the flow of 61.5 $\mathrm{m}^{3} / \mathrm{hr}$ in the heating season, calculated based on the heat pumps flow requirements. In the 
cooling season, the internal heat exchanger is disconnected, and the heat pump source-side loop is connected to the HP-BTES.

The internal heat exchanger in the solar-STST has $2.1 \mathrm{~m}$ height. The pipe of the heat exchangers is made of copper with the outer diameter of $16 \mathrm{~mm}$ and thermal conductivity of 400 $\mathrm{W} / \mathrm{mK}$.

\subsubsection{Medium-temperature BTES (HP-BTES)}

The HP-BTES size and configuration are similar to the medium-temperature BTES presented in Chapter 5 Section 5.3.3. The total number of boreholes in the storage volume is 80 , and the depth of each borehole (from the surface) is $150 \mathrm{~m}$ with $3 \mathrm{~m}$ separation.

\subsubsection{High-temperature BTES (solar-BTES)}

The high-temperature BTES (solar-BTES) incorporated into the model is similar to the BTES presented in Chapter 3 Section 3.2.2. The BTES has 45 boreholes each of $59 \mathrm{~m}$ depth. The boreholes are configured in a circular field with an average $3 \mathrm{~m}$ borehole separation. The bore field cylindrical shape storage that contains the boreholes has a volume of $17000 \mathrm{~m}^{3}$ with coverage of $290 \mathrm{~m}^{2}$ ground surface area. The nominal HDPE pipe size comprising the U-tube ground heat exchanger is $32 \mathrm{~mm}$ in diameter. The thermal conductivities of the borehole grout and the ground comprising the storage volume are $1.5 \mathrm{~W} / \mathrm{mK}$ and $2 \mathrm{~W} / \mathrm{mK}$ respectively.

The borehole layout, which consists of 5 circuits connected in parallel to the main header. Each circuit consists of nine boreholes connected in parallel too (similar layout to Chapter 3 Figure 3-8 and Figure 3-9).

\subsubsection{Solar thermal collectors}

The selected solar thermal collectors are of a flat-plate type with the same specifications presented in Chapter 3 Section 3-2-1. The solar collectors have the total area of $861 \mathrm{~m}^{2}$, which includes 300 solar collectors in three parallel arrays with 100 collectors connected in series. The solar collectors face south and have a $45^{\circ}$ surface inclination.

\subsubsection{Solar photovoltaic (PV) panels}

The total rooftop area available in the community is $2296 \mathrm{~m}^{2}$, which solar thermal collectors have used $861 \mathrm{~m}^{2}$ of this amount. The remaining area of $1435 \mathrm{~m}^{2}$ will be available for the PV panels. 
The PV panels and related inverters, selected for this model are similar to the PV panels and invertors used in Chapter 5 Section 5.3.6. They are high performance $320 \mathrm{~W}$ panels with an average efficiency of $19.9 \%$. Detail specifications of the PV panels are presented in Appendix F. In the TRNSYS model, Type 194 is used for the PV panels with invertors.

\subsubsection{Pumps and climate data}

Variable flow pumps with dedicated controls are utilized for the main hydronic loops, i.e., heat pumps' loops and the community loop plus the solar-BTES and solar thermal collectors. As per heat pump's manufacturer recommendations, the pumps selected (for both source and load side) have a maximum flow rate of $61.2 \mathrm{~m}^{3} / \mathrm{hr}$ with $9 \mathrm{~kW}$ shaft power capacity and an assumed head of $35 \mathrm{~m}$. The pumps serving the solar-BTES and solar panels' loop have $2 \mathrm{~kW}$ and $3 \mathrm{~kW}$ shaft power capacities each for the $20 \mathrm{~m}^{3} / \mathrm{hr}$ and $30 \mathrm{~m}^{3} / \mathrm{hr}$ flow, respectively. Table 61represents the pump powers based on the equipment's flow requirements.

Table 6-1 Pump specification summary

\begin{tabular}{|c|c|c|c|c|}
\hline & & Flow & Head & $\begin{array}{c}\text { Shaft Power } \\
\text { Capacity }\end{array}$ \\
\hline \multicolumn{2}{|r|}{ pump } & $\mathrm{m}^{3} / \mathrm{hr}$ & $\mathrm{m}$ & $\mathrm{kW}$ \\
\hline 1 & Solar loop & 30 & 15 & 3 \\
\hline 2 & Solar-STST loop & 90 & 8 & 4 \\
\hline 3 & Solar-BTES loop & 20 & 12 & 2 \\
\hline 4 & Heat Pump-Community loop & 61.5 & 6 & 3 \\
\hline 5 & Heat Pump-BTES loop & 61.5 & 25 & 7 \\
\hline
\end{tabular}

The community thermal load and solar heat are calculated based on the Canadian Weather Year for Energy Calculation (CWEC) hourly data for the City of Toronto.

\subsection{Overall system specifications}

The overview of the system design specifications for the major components is summarized in Table 6-2. 
Table 6-2 ST-HPPV system major components summary

\begin{tabular}{|l|l|l|}
\hline \multicolumn{3}{|c|}{ System Specifications Summary } \\
\hline Photovoltaic panel & 897 & \\
\hline Number of PV panels & 1,435 & $\mathrm{~m}^{2}$ \\
\hline Total solar panel area & 320 & $\mathrm{~W}$ \\
\hline Rated power for each panel & & \\
\hline Heat pump - water to water & 4 & \\
\hline Number of heat pumps & 372 & $\mathrm{~kW}$ \\
\hline Total cooling capacity & 468 & $\mathrm{~kW}$ \\
\hline Total heating capacity & 3.4 & - \\
\hline COP heating & 5.4 & $\mathrm{~W} / \mathrm{W}$ \\
\hline EER cooling & 61.2 & $\mathrm{~m}^{3} / \mathrm{hr}$ \\
\hline Rated source and load side flow rate & & \\
\hline Heat pump - BTES & 80 & \\
\hline Number of boreholes & 150 & $\mathrm{~m}$ \\
\hline Borehole depth & 3 & $\mathrm{~m}$ \\
\hline Borehole spacing & 93,470 & $\mathrm{~m}^{3}$ \\
\hline BTES volume & 12,000 & $\mathrm{~m}$ \\
\hline Total borehole length & 61.2 & $\mathrm{~m}^{3} / \mathrm{hr}$ \\
\hline Max fluid flow-BTES & 171 & $\mathrm{~m}^{3}$ \\
\hline Heat pump - STST volume & & \\
\hline Solar thermal collectors & 300 & \\
\hline Number of solar collectors & 862 & $\mathrm{~m}^{2}$ \\
\hline Total solar collector area & 30 & $\mathrm{~m}^{3} / \mathrm{hr}$ \\
\hline Fluid flow- solar & 81 & $\mathrm{~m}^{3}$ \\
\hline Solar-STST volume & 20,655 & $\mathrm{~m}$ \\
\hline Solar- BTES & 45 & $\mathrm{~m} 3 / \mathrm{hr}$ \\
\hline Number of boreholes & 59 & $\mathrm{~m}$ \\
\hline Borehole depth & 3 & $\mathrm{~m}$ \\
\hline Borehole spacing & 17,000 & $\mathrm{~m}{ }^{3}$ \\
\hline Solar-BTES volume & & \\
\hline Total borehole length & & \\
\hline Max fluid flow-solar-BTES & & \\
\hline
\end{tabular}




\subsection{Simulation results}

Based on the 20-years simulation time, Table 6-3 shows the heat pump annual energy and performance for the year 1, 5, 10, 15 and 20. Comparing the results to the base case (BC) system that developed in Chapter 5 and presented in Table 5-7, the following observations are made.

1. In the heating mode, the heat pumps, comparing to the base case system in the year ten:

a. the energy transferred to the load (HP-STST) are almost the same,

b. the energy transferred from the source (HP-BTES) has improved from 1704 GJ to $1791 \mathrm{GJ}(5 \%)$,

c. the total heat pumps' electricity consumption has reduced from $738 \mathrm{GJ}$ to 668 GJ (10\%), and

d. the heat pumps' seasonal COPs have been improved from 3.3 to $3.8(13 \%)$ after year ten.

2. In the cooling mode, the heat pumps, comparing to the base case system in the year ten:

a. the energy transferred from the load (HP-STST) are almost the same,

b. the energy transferred to the source (HP-BTES) has increased from $1618 \mathrm{GJ}$ to $1734 \mathrm{GJ}(7 \%)$,

c. the total heat pumps' electricity consumption increased from $236 \mathrm{GJ}$ to 383 GJ (38\%), and

d. the heat pumps' seasonal COPs have been dropped from 5.9 to $3.1(47 \%)$ after year ten.

The last two observations (2.c and 2.d) are undesirable due to the community load characteristics which will be discussed in later sections. 
Table 6-3 Annual heat pumps energy and performance of ST-HPPV system

\begin{tabular}{|l|c|c|c|c|c|}
\hline \multicolumn{7}{|c|}{} & \multicolumn{7}{|c|}{ Heating } \\
\hline Ending Year & $\mathbf{1}$ & $\mathbf{5}$ & $\mathbf{1 0}$ & $\mathbf{1 5}$ & $\mathbf{2 0}$ \\
\hline Heat transferred to the load (GJ) & 2,464 & 2,454 & 2,459 & 2,462 & 2,467 \\
\hline Heat transferred from the source (GJ) & 1,732 & 1,769 & 1,791 & 1,807 & 1,821 \\
\hline Electric energy (GJ) & 732 & 685 & 668 & 655 & 646 \\
\hline COP (seasonal) & 3.4 & 3.6 & 3.7 & 3.8 & 3.8 \\
\hline & \multicolumn{5}{|c|}{ Cooling } \\
\hline Ending Year & $\mathbf{1}$ & $\mathbf{5}$ & 10 & 15 & $\mathbf{2 0}$ \\
\hline Heat transferred from the load (GJ) & 1,379 & 1,357 & 1,351 & 1,348 & 1,348 \\
\hline Heat transferred to the source (GJ) & 1,621 & 1,693 & 1,734 & 1,759 & 1,779 \\
\hline Electric energy (GJ) & 242 & 336 & 383 & 411 & 431 \\
\hline COP (seasonal) & 5.7 & 4.0 & 3.5 & 3.3 & 3.1 \\
\hline
\end{tabular}

Figure 6-6 and Figure 6-7 depict the energy and COP's of the heat pumps in the solar thermal heat pump (ST-HPPV) system. The base case (BC) system heat pumps' energy and COPs are also included for the comparisons. Figure 6-8 shows the heat pumps' COPs in the heating and cooling mode for the ST-HPPV system and the base case.

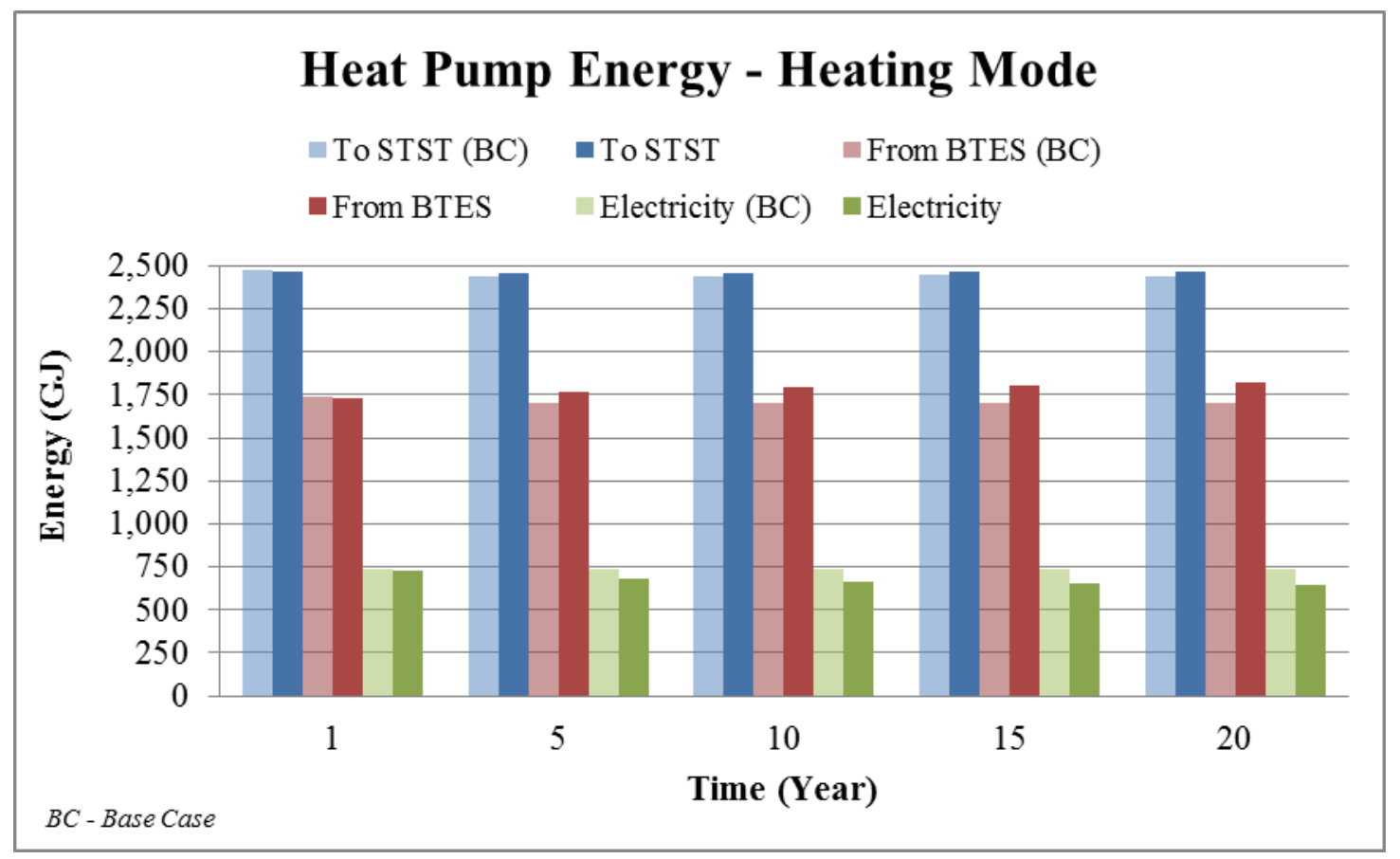

Figure 6-6 Heat pumps' energy - heating mode - ST-HPPV vs. HPPV (BC) 


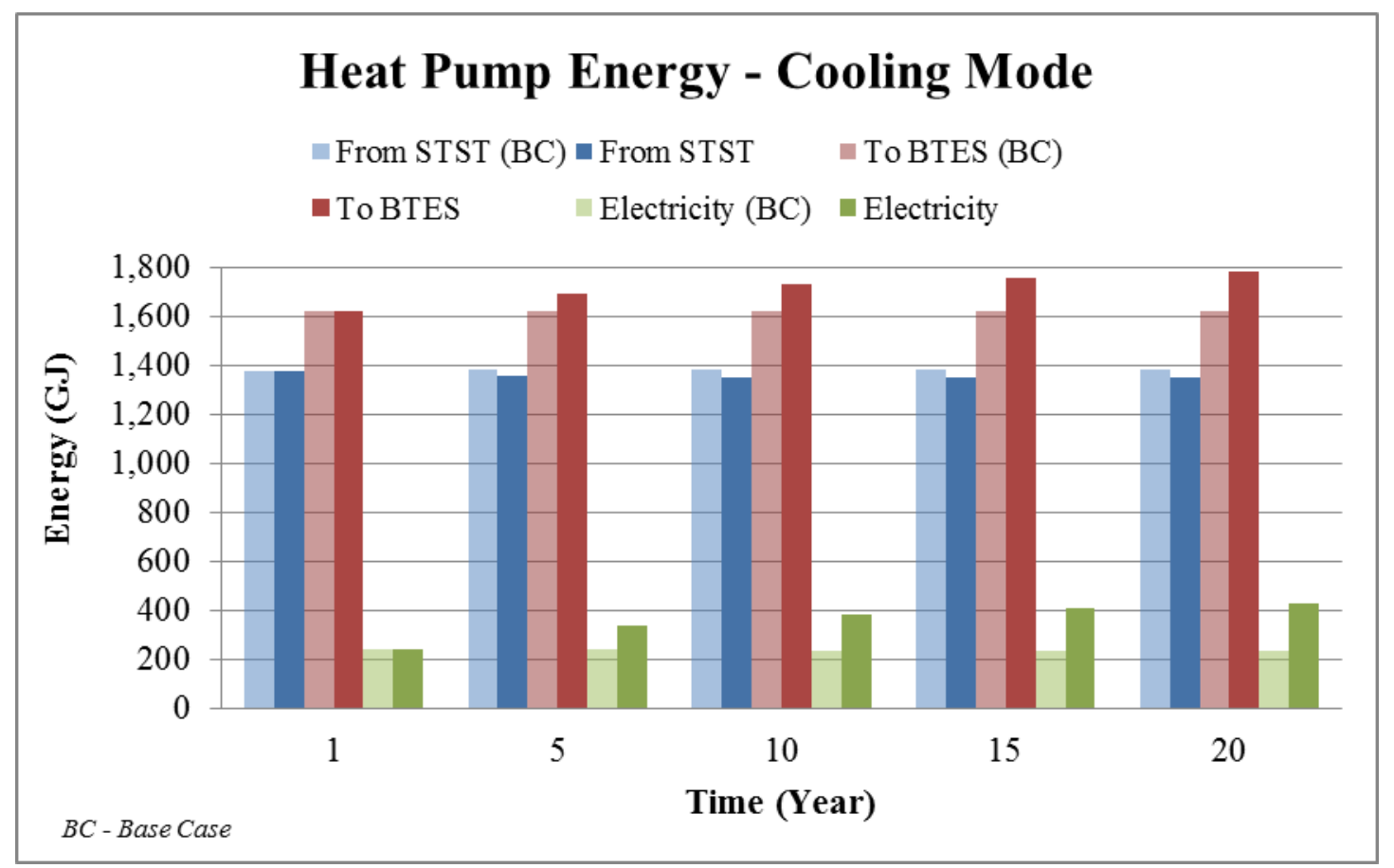

Figure 6-7 Heat pumps' energy - cooling mode - ST-HPPV vs. HPPV (BC)

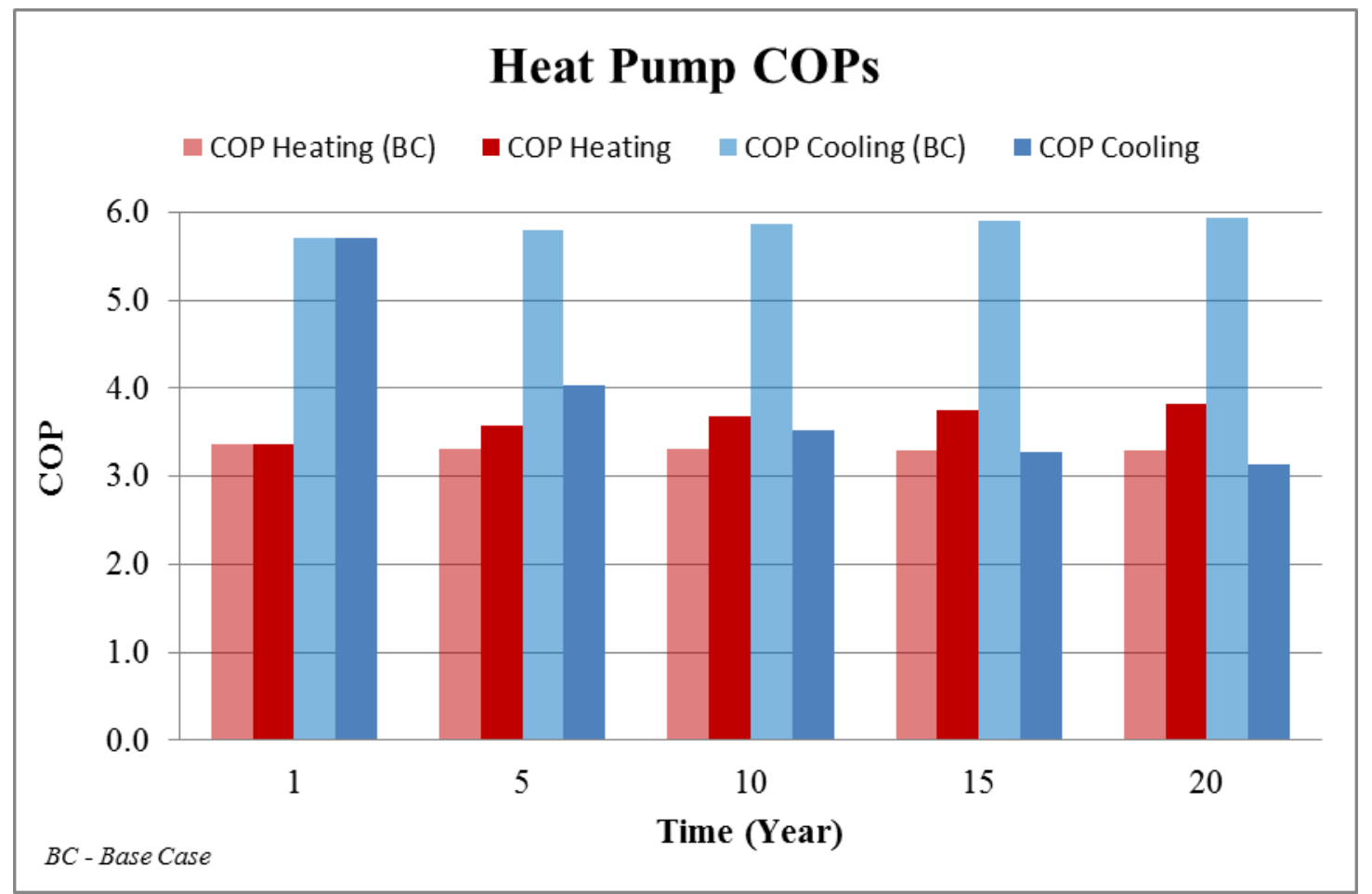

Figure 6-8 Heat pumps COPs - ST-HPPV vs. HPPV (BC) 
Figure 6-9 and Figure 6-10 show the hourly heat pump COPs for the ST-HPPV and base case (BC) system respectively for five years. By comparing the two figures, it is seen that the heat pumps' COPs in the heating mode is improving during the first five years whereas the heat pumps' COPs in the cooling mode is dropping accordingly.

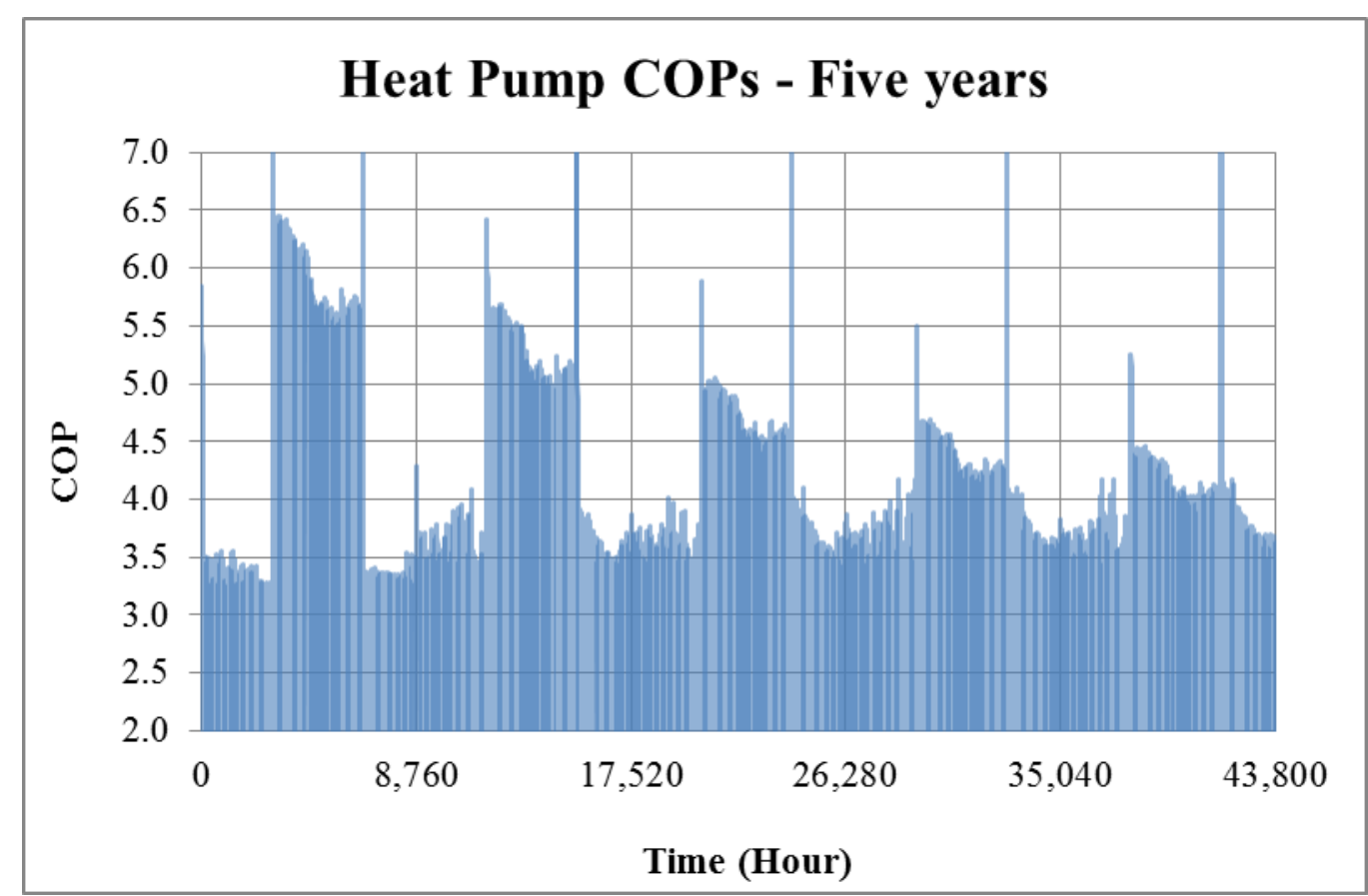

Figure 6-9 Heat pumps hourly COPs - ST-HPPV system - five years

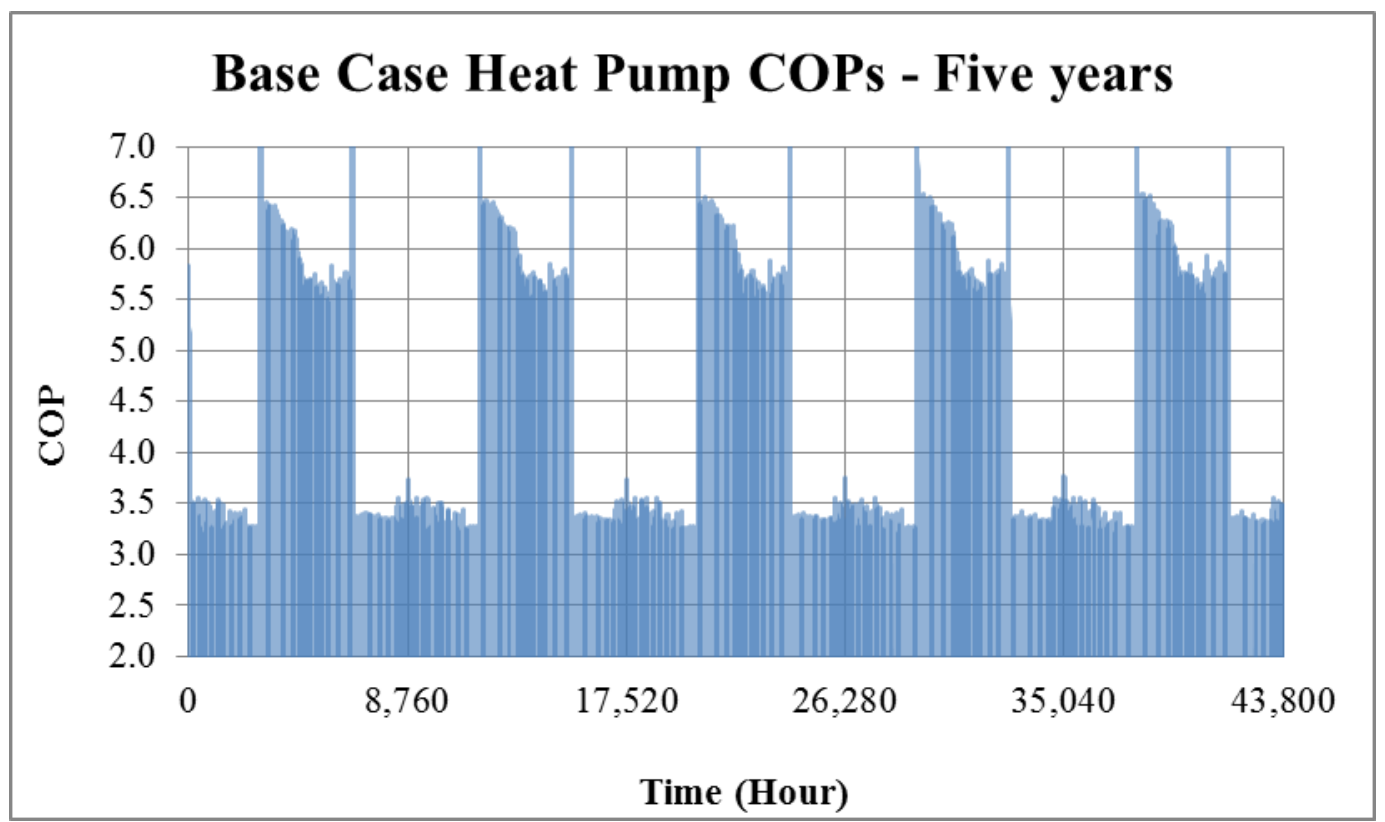

Figure 6-10 Heat pumps COPs - HPPV system as the Base Case (BC) - five years 
Figure 6-11 shows the hourly solar thermal collectors energy generation and solar thermal BTES (solar-BTES) energy injected into and energy extracted from, in twenty years. The annual harvested solar thermal energy in the year ten is 2495 GJ. In the same year, the annual energy injected into and extracted from the solar-BTES is $1810 \mathrm{GJ}$ and $1134 \mathrm{GJ}$ respectively. The efficiency of the solar-BTES is calculated to be $63 \%$.

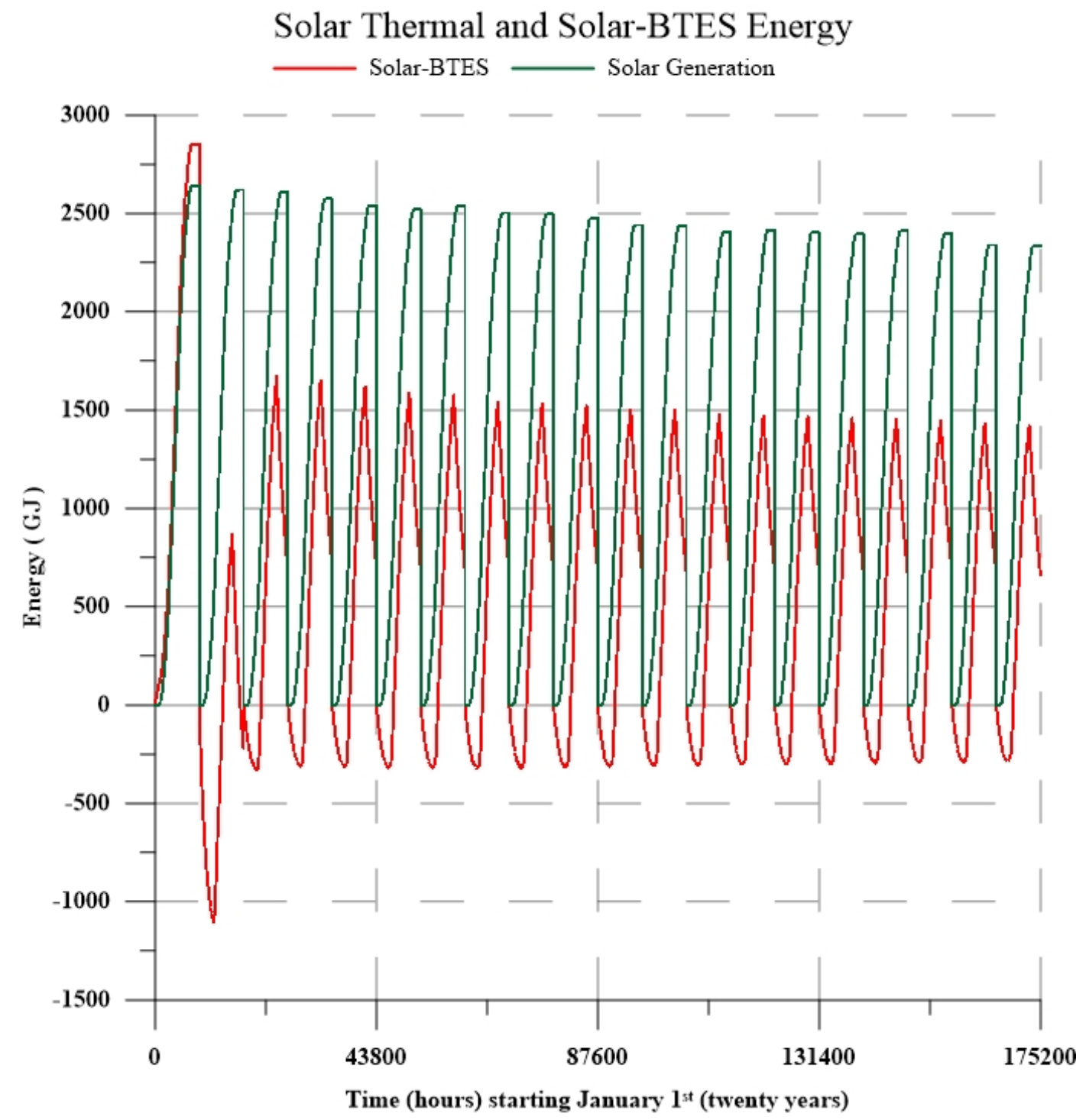

Figure 6-11 Solar energy generation and solar-BTES In/Out energy - twenty years

The average ground temperature of the solar BTES and HP-BTES are shown in Figure 612. The solar-BTES average ground temperature has almost $30^{\circ} \mathrm{C}$ temperature swing whereas 
the HP-BTES has less than $2.5^{\circ} \mathrm{C}$. After twenty years the solar-BTES and HP-BTES average ground temperature will reach to the maximum $56{ }^{\circ} \mathrm{C}$ and $33{ }^{\circ} \mathrm{C}$ respectively which is in the cooling mode and to the minimum of $30^{\circ} \mathrm{C}$ in the heating mode for both BTESs.

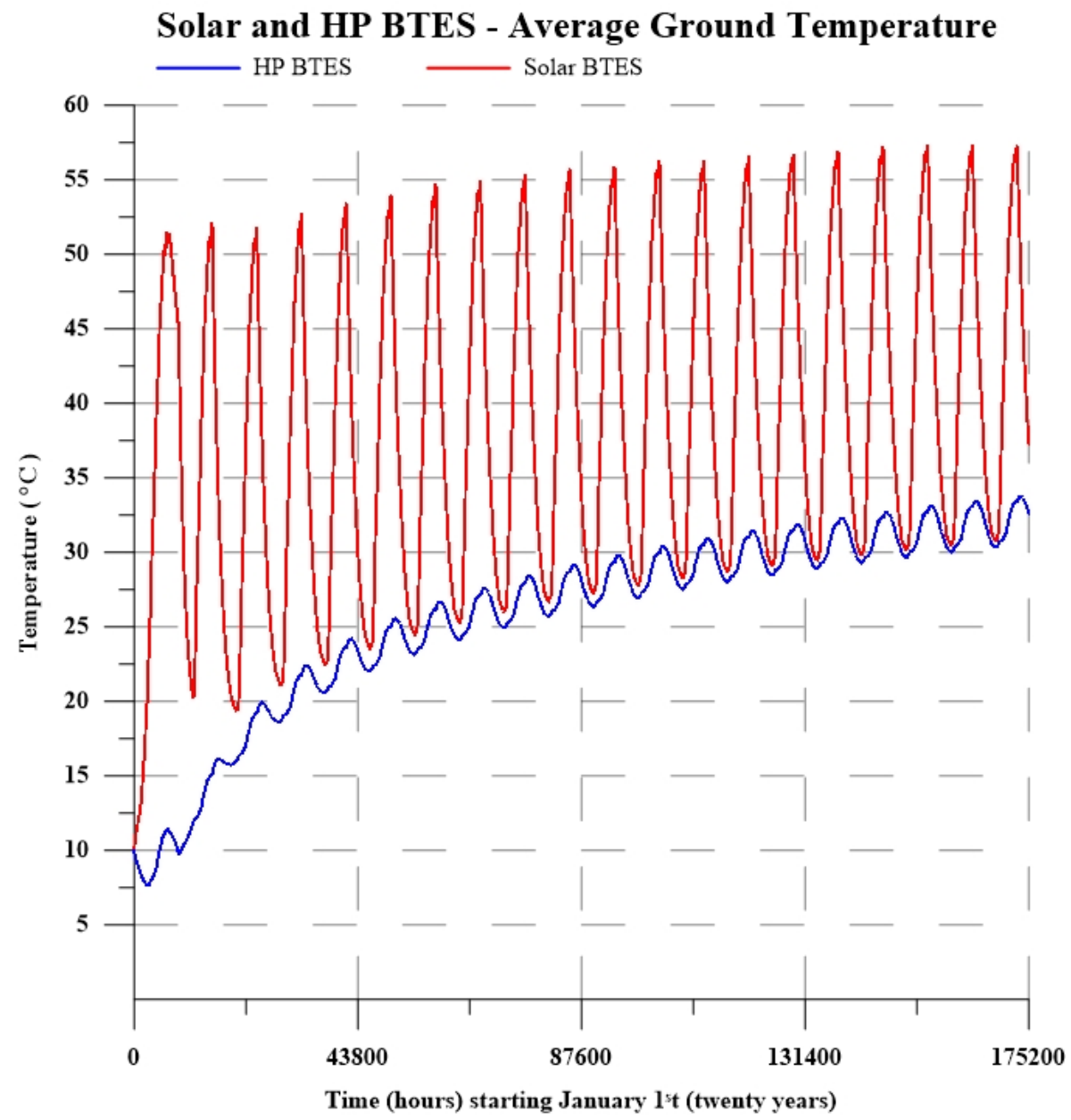

Figure 6-12 Solar and heat pump BTES average ground temperature - twenty years

Figure 6-13 depict the average ground temperature of the HP-BTES in twenty years for the both ST-HPPV and base case system. It is noted that in the ST-HPPV system the average ground temperature increases whereas in the heat pump only case $(\mathrm{BC})$ the ground temperature has a relatively small drop during the 20 -years simulation time. 


\section{HP BTES - Average Ground Temperature}

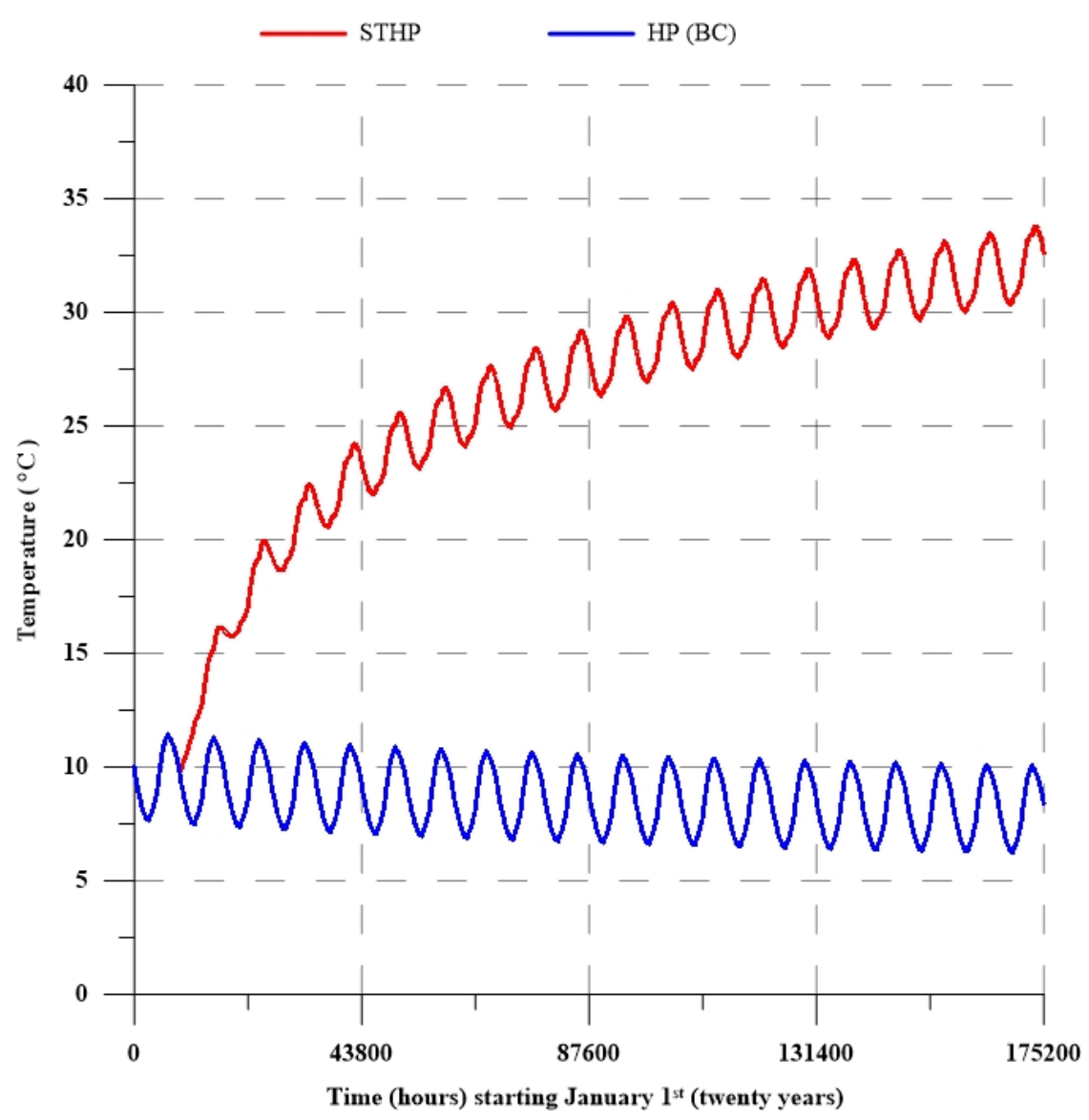

Figure 6-13 Heat pump BTES average ground temperature - solar thermal heat pump (ST-HPPV) vs. HPPV (BC) - twenty years

\subsection{Simulation results discussions}

From the simulation result, it is shown that by integrating a solar thermal system to the heat pump system the COP of the system increases in the heating mode and decreases in the cooling mode. In the ST-HPPV system, the entering fluid temperatures to the heat pumps will increase as the result of the temperature increase of the ground. This is in the favor of the heat pumps' performance in heating season and is not beneficial in the cooling season. Therefore, it can be concluded that this system would be more beneficial for the communities with lower cooling load comparing to the one in this study.

To investigate how reducing the community cooling load affects the total system performance, three ST-HPPV system scenarios are investigated. One with the half the cooling load (HCL - Scenario 2) and the other with the quarter cooling load (QCL - Scenario 3) of the 
community cooling load of this study ( FCL - Scenario 1). The system components and equipment in all scenarios are the same including the community heating load.

Table 6-4 shows the existing community heating and cooling load and the three proposed scenarios.

Table 6-4 Community heating and cooling load scenarios

\begin{tabular}{|c|c|c|c|c|}
\cline { 2 - 5 } \multicolumn{1}{c|}{} & Heating & \multicolumn{3}{c|}{ Cooling } \\
\hline Scenarios & All & $\mathbf{1}$ & $\mathbf{2}$ & $\mathbf{3}$ \\
\hline Peak Load (kW) & 457 & 369 & 185 & 92 \\
\hline Annual Load (GJ) & 2350 & 1181 & 591 & 295 \\
\hline
\end{tabular}

From the twenty years simulation, Table 6-5 shows the COPs of the heat pump for the year 1, 5, 10, 15, and 20 for the different scenarios. As it is seen the COPs in the heating mode, have slightly dropped (from 3.7 to 3.6 in year ten) with the reduction of the cooling load. On the other hand, the COPs of cooling improved (from 3.5 to 4.4 in the year ten). These changes are due to the reduced heat pumps heat injection into the ground as the result of the less community cooling load.

Table 6-5 COPs - Community heating and cooling load scenarios

\begin{tabular}{|l|c|c|c|c|c|}
\cline { 2 - 6 } \multicolumn{1}{c|}{} & \multicolumn{5}{c|}{ COP-Heating } \\
\hline Year & $\mathbf{1}$ & $\mathbf{5}$ & $\mathbf{1 0}$ & $\mathbf{1 5}$ & $\mathbf{2 0}$ \\
\hline FCL - Scenario 1 & 3.4 & 3.6 & 3.7 & 3.8 & 3.8 \\
\hline HCL - Scenario 2 & 3.4 & 3.6 & 3.6 & 3.6 & 3.7 \\
\hline QCL - Scenario 3 & 3.3 & 3.5 & 3.6 & 3.6 & 3.6 \\
\hline & \multicolumn{5}{|c|}{ COP-Cooling } \\
\hline Year & $\mathbf{1}$ & $\mathbf{5}$ & $\mathbf{1 0}$ & $\mathbf{1 5}$ & $\mathbf{2 0}$ \\
\hline FCL - Scenario 1 & 5.7 & 4.0 & 3.5 & 3.3 & 3.1 \\
\hline HCL - Scenario 2 & 6.0 & 4.5 & 4.0 & 3.9 & 3.8 \\
\hline QCL - Scenario 3 & 6.3 & 4.8 & 4.4 & 4.3 & 4.2 \\
\hline
\end{tabular}

Figure 6-14 and Figure 6-15 show the COP changes in the different scenario in twenty years. The COPs of the heat pump only case (BC) are also included in the graphs for the reference. 


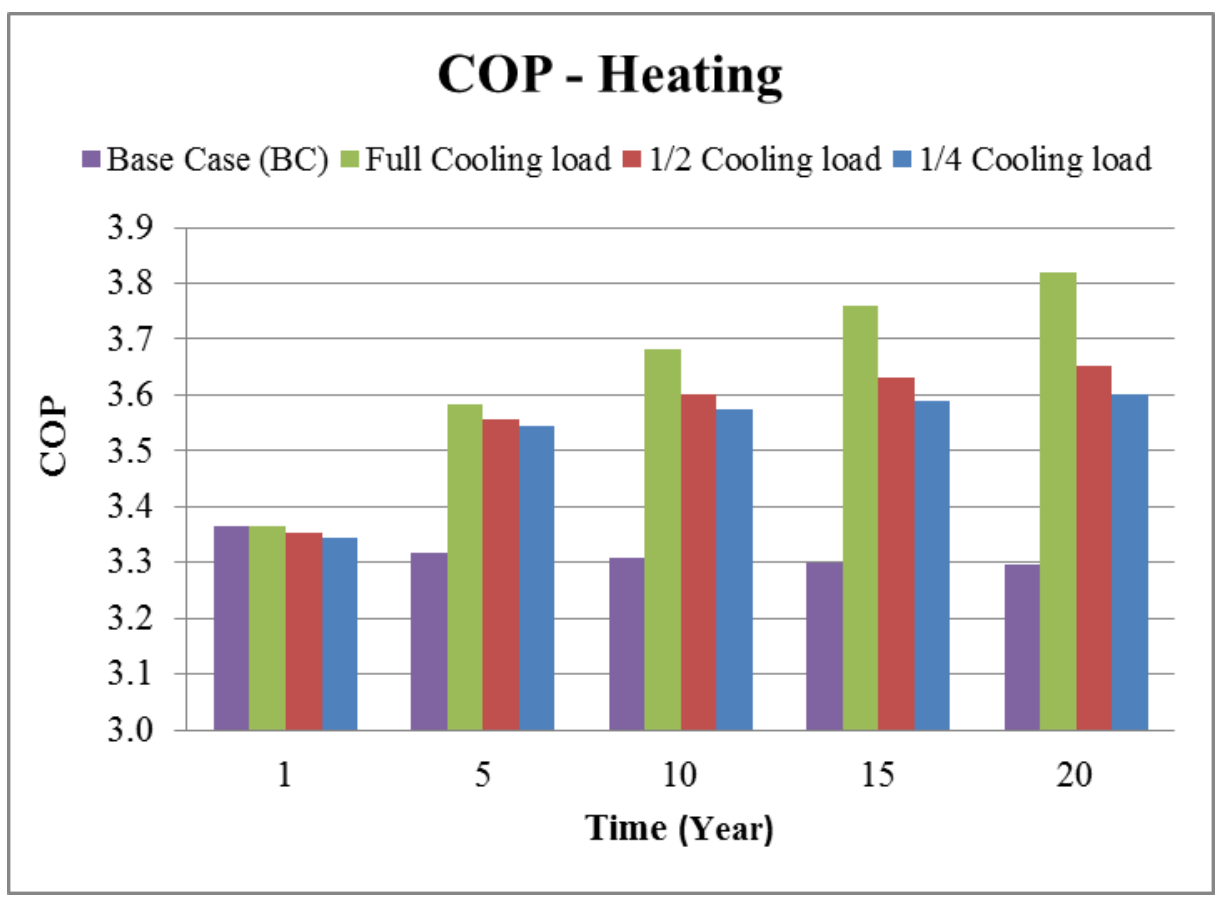

Figure 6-14 Heat pump COPs in reduced community cooling loads - heating mode

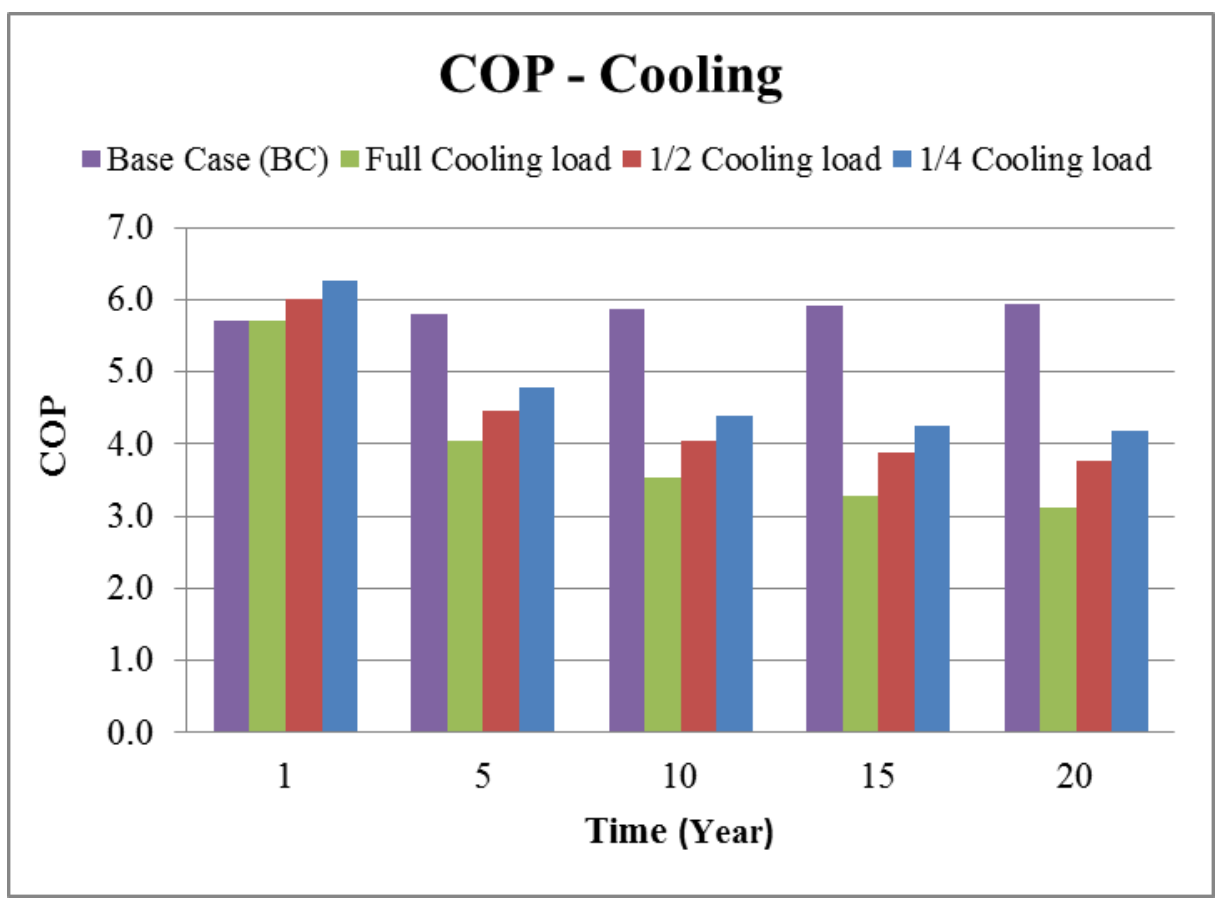

Figure 6-15 Heat pump COPs in reduced community cooling load - cooling mode 
The average annual pumping energy for the ST-HPPV system are shown in Table 6-6. Comparing $161 \mathrm{GJ}(44.7 \mathrm{MWh})$ pumping energy use in the base case (BC) system to the pumping energy consumption in the ST-HPPV system, ST-HPPV system uses 45 GJ (12.6 $\mathrm{MWh}$ ) more electricity than BC system. The total average annual pumping energy for ST-HPPV system is $206 \mathrm{GJ}(57.3 \mathrm{MWh})$.

Table 6-6 Annual pumping energy - ST-HPPV system

\begin{tabular}{|c|c|c|c|}
\hline & & \multicolumn{2}{|c|}{ Annual Energy } \\
\hline \multicolumn{2}{|r|}{ pump } & GJ & MWh \\
\hline 1 & Solar loop & 0.4 & 0.1 \\
\hline 2 & Solar-STST loop & 13 & 4 \\
\hline \multirow[t]{2}{*}{3} & Solar-BTES loop & 32 & 9 \\
\hline & Sub-total (solar thermal loops) & 45 & 12.6 \\
\hline 4 & Heat pump-community loop & 48 & 13 \\
\hline \multirow[t]{3}{*}{5} & Heat pump-BTES loop & 113 & 31.4 \\
\hline & Sub-total (heat pump loops) & 161 & 44.7 \\
\hline & Total pumping energy & 206 & 57.3 \\
\hline
\end{tabular}

In year ten, the annual heat pumps' electricity demands in the ST-HPPV system (Scenario 1), are $668 \mathrm{GJ}$ and $383 \mathrm{GJ}$ in the heating and the cooling mode, respectively (Table 67). The total annual heat pumps electricity use is $1051 \mathrm{GJ}$ (292 MWh). By including the heat pumps annual hydronic pumping energy (i.e., 57.3 MWh), the total electricity requirement for the whole system will be 349.5 MWh annually. Comparing 349.3 MWh system energy consumption to the base case system (heat pump only) which was $315.7 \mathrm{MWh}$, the total annual heat pump electricity requirement has increased by less than $10 \%$. The total PV panel area requirement, in this case, is $1384 \mathrm{~m}^{2}$ (865 panels).

The required total PV panel area, for different cooling-load scenarios, are also tabulated in Table 6-7.The annual pumping energy in the BC system is $14 \%$ of the total system input energy whereas in the ST-HPPV system the annual pumping energy is $16 \%$ of the total system input energy. This means by adding the solar thermal system to the heat pump system (base case) the pumping energy will increase by $2 \%$, which is almost negligible. 
By considering the pumping energy, the overall annual COP of the system is calculated by dividing the total annual energy provided by the system to the total electricity consumed by the system, which is shown in Table 6-8 for the different scenarios.

Table 6-7 Electricity and PV panel requirements for the different scenarios

\begin{tabular}{|c|c|c|c|c|c|c|c|c|}
\hline Scenarios & \multicolumn{2}{|c|}{ BC } & \multicolumn{2}{|c|}{1} & \multicolumn{2}{|c|}{2} & \multicolumn{2}{|c|}{3} \\
\hline & GJ & MWh & GJ & MWh & GJ & $\mathrm{MWh}$ & GJ & $\mathrm{MWh}$ \\
\hline HP electricity - heating & 738 & 205 & 668 & 186 & 682 & 190 & 686 & 191 \\
\hline HP electricity - cooling & 236 & 66 & 383 & 106 & 205 & 57 & 111 & 31 \\
\hline HP electricity - pumps & 161 & 44.7 & 206 & 57.3 & 206 & 57.3 & 206 & 57.3 \\
\hline Total system electricity & 1,135 & 315.5 & 1,257 & 349.5 & 1,093 & 303.9 & 1,003 & 278.9 \\
\hline Total PV panel area $\left(\mathrm{m}^{2}\right)$ & \multicolumn{2}{|c|}{1248} & \multicolumn{2}{|c|}{1384} & \multicolumn{2}{|c|}{1203} & \multicolumn{2}{|c|}{1104} \\
\hline Number of PV panels & \multicolumn{2}{|c|}{780} & \multicolumn{2}{|c|}{865} & \multicolumn{2}{|c|}{752} & \multicolumn{2}{|c|}{690} \\
\hline
\end{tabular}

Table 6-8 ST-HPPV system overall COPs

\begin{tabular}{|l|c|c|c|c|}
\hline Scenarios & BC & $\mathbf{1}$ & $\mathbf{2}$ & $\mathbf{3}$ \\
\hline Total energy delivered (GJ) & 3,531 & 3,531 & 2,941 & 2,645 \\
\hline Total electricity used (GJ) & 1,135 & 1,257 & 1,093 & 1,003 \\
\hline System overall COP & 3.1 & 2.8 & 2.8 & 2.8 \\
\hline
\end{tabular}

From Table 6-8, it can be concluded that for the cases of imbalance loads between ground heat injection and extraction, to avoid thermal degradation of the ground, similar system COP as of the balanced load can be achieved by integration of a solar thermal system to the heat pump system.

\subsection{System cost comparisons}

Table 6-9 presents the heating and cooling system cost comparisons among solarthermal-chiller (STC) system (Chapter 4) and heat-pump-PV (HPPV) system (Chapter 5) and solar thermal heat pump-PV system (ST-HPPV), which all serves the same community heating and cooling loads.

From this high-level cost comparison, the heat pump-PV only system (HPPV) is the most economically viable system for the selected community.

From the three scenario's results that were investigated for the solar thermal heat pumpPV (ST-HPPV) system, more favorable economic would be possible for the communities with 
lower heating and cooling load proportions. All proposed systems do not offer any payback over the lifetime of the project due to the high initial system capital cost. Based on the blended electrify rate of $\$ 0.21$ per $\mathrm{kWh}(\mathrm{OEB}, 2016)$ and natural-gas rate of $\$ 6.17$ per GJ (Enbridge Gas, 2016), the simple payback of HPPV system and ST-HPPV system is estimated to be, 44 and 52 years respectively.

Table 6-9 Cost comparisons of different proposed heating and cooling systems

\begin{tabular}{|l|c|c|c|c|}
\hline \multicolumn{5}{|c|}{ Sys te m Initial Costing (Incre me ntal)- Installed } \\
\hline & Index & \multicolumn{3}{|c|}{ Heating and Cooling } \\
\hline System & & Abs. Chiller & HPPV & ST-HPPV \\
\hline Number of Boreholes & & 90 and 80 & 80 & 45 and 75 \\
\hline Borehole Depth $(\mathrm{m})$ & & 59 and 150 & 150 & 59 and 150 \\
\hline Number of Solar Thermal Panels & $2.87\left(\mathrm{~m}^{2} /\right.$ panel) & 600 & 0 & 300 \\
\hline Number of Solar PV panels * & $1.6\left(\mathrm{~m}^{2} /\right.$ panel) & 0 & 780 & 834 \\
\hline Cost of BTES & $116(\$ / \mathrm{m})$ & $\$ 2,007,960$ & $\$ 1,392,000$ & $\$ 1,612,980$ \\
\hline Cost of Solar Thermal Panels & $497\left(\$ / \mathrm{m}^{2}\right)$ & $\$ 855,834$ & $\$ 0$ & $\$ 427,917$ \\
\hline Cost of Solar PV Panels with Inverter & $3(\$ / \mathrm{W})$ & $\$ 0$ & $\$ 748,800$ & $\$ 800,640$ \\
\hline $\begin{array}{l}\text { Short Term Storage Tank } \\
\text { Including the Energy Center }\end{array}$ & $2500\left(\$ / \mathrm{m}^{3}\right)$ & $\$ 427,500$ & $\$ 427,500$ & $\$ 202,500$ \\
\hline Cost of Heat Pumps / Absorption Chiller & $715 / 570(\$ / \mathrm{kW})$ & $\$ 291,840$ & $\$ 334,620$ & $\$ 427,500$ \\
\hline Total Initial Cost & & $\$ 3,583,134$ & $\$ 2,902,920$ & $\$ 3,806,157$ \\
\hline Solar PV Area $\left(\mathrm{m}^{2}\right)$ & & 0 & 1,248 & 1334 \\
\hline Solar Thermal Area $\left(\mathrm{m}^{2}\right)$ & & 1,772 & 0 & 861 \\
\hline
\end{tabular}

* the number of the PV panels corresponds to the heat pumps power and their related hydronic pumping energy

\subsection{Conclusion}

In this chapter, a solar community with central heat pump and BTES plus photovoltaic (ST-HPPV) systems were modeled for a community in Toronto area. The selected community, similar to the communities chosen in Chapter 4 and Chapter 5, is a heating dominated community that has $50 \%$ higher annual heating demand than the annual cooling demand. The winter peak heating load is $19 \%$ greater than peak cooling load.

The results from system simulation show that for a community having such heating and cooling load splits, adding a solar thermal to the HPPV system improve the heat pumps' performance in the heating mode but reduce the performance in cooling mode. As the result, the 
overall heat pumps electricity input of ST-HPPV system was higher than the HPPV system ( 10\%, from $1257 \mathrm{GJ}$ to $1135 \mathrm{GJ})$.

The effect of heat pumps' COP drops in the cooling mode on the overall system, was investigated with two other hypothetical community heating, and cooling loads. One with the half-cooling loads (HCL) and the other with the quarter-cooling loads (QCL) of the main community cooling loads with both communities having the same heating loads were selected. For the system with lesser cooling load (QCL), the overall system electricity consumption was decreased by 24\% (from 1,257 GJ to 955 GJ). In the QCL scenario, comparing to FCL scenario, the heat pump COP in the cooling mode improves from 3.5 to $4.4(26 \%)$ where the there is a small drop on the COP in the heating mode (3.7 to 3.6).

For the communities with the imbalance heat rejection to and extraction from the ground by the heat pump, the overall system COP improves by adding solar thermal system. For the case of balance load (Scenario 1), adding solar thermal system will reduce the overall system COP by $10 \%$ (from 3.1 to 2.8 )

The proposed ST-HPPV system high-level incremental cost was $24 \%$ and $6 \%$ higher than the HPPV and STC system respectively. Therefore, for the proposed community the HPPV is the most economical system $(\$ 2,902,902)$ in the case of the balanced HP-BTES loads (scenario 1).

A sensitivity analysis on the community cooling loads was presented. It can be concluded that for the communities with the annual heating and cooling loads difference of $75 \%$ or more, the ST-HPPV could be a viable solution, comparing to the HPPV system. Further future system optimization requires for such cases. 


\section{Chapter 7 : Conclusions and Future Work}

\subsection{Summary and conclusions}

The main purpose of this research is to investigate the viability of the combined heating and cooling systems for solar communities with borehole thermal energy storage, through energy analysis, modeling, and simulation.

Based on the literature review, the majority of the existing communities use solar thermal system for heating only. There is no research on solar communities with a combined heating and cooling system. The necessity of such a system relies on the geographic locations that are heating-dominated, and both heating and cooling are required.

From the existing community-scale thermal storage types, borehole thermal energy storage (BTES) is found to be the favorable mechanism for a significant amount of energy involvement and relatively low-cost energy storage. In the existing solar communities with cooling using BTES where thermally driven cooling equipment is used, there is not any strategy to capture equipment rejected heat. Therefore, storing the low-grade heat in a new BTES could be a solution.

Using a central heat pump system and employing a relatively higher temperature fluid source for boosting the heat pump COPs has not been investigated for solar communities in cold climate regions.

Drake Landing community in Okotoks, Alberta (DLSC) is the first solar community in Canada. It is chosen as the basis for generating an initial model and comparing the simulation results with the actual data. It is concluded that the proposed heating system model with the same configuration as DLSC, but relatively smaller in size, will perform similarly to the DLSC system. Ultimately, the proposed system would be a less-expensive system compared to the DLSC system.

The main improvements in the modified DLSC system are the reduced total solar thermal collector area (29\%), smaller STST size (25\%), and reduced BTES borehole footprint (38\%).

The modified DLSC design costs approximately 19\% less to build compared to the DSLC capital cost, with the additional benefit of a reduced footprint and real estate requirements. 
Using the developed model similar to the DLSC as the base case, a cooling system is added to the system by incorporating an absorption chiller and a medium-temperature BTES for storing the chiller's rejected heat. The proposed new design, called solar thermal chiller system (STC), is an integrated heating and cooling system for heating a hypothetical community similar to the DLSC. The community is located in Toronto, Ontario with the annual cooling load of 50\% less than the heating load.

The simulation results show that, in the heating season, the system achieved $100 \%$ solar fraction after five years of operation. For the cooling system, the chiller uses $18 \%$ of its required heating energy from the solar source and the rest from a boiler. This solar fraction percentage could be increased by adding more solar thermal collectors to the system. From the total chillers' rejected heat into the ground, $36 \%$ is recovered during the heating season.

The chiller in the proposed system is not operating optimally because of the hightemperature rejecting heat media (chiller-BTES) which is due to the chiller-BTES interaction with the solar-BTES. On average, the chiller functions at almost $72 \%$ of its rated capacity (370 $\mathrm{kW}$ vs. $512 \mathrm{~kW}$ ), and $74 \%$ of its rated efficiency ( 0.56 vs. 0.76$)$.

The capital cost for the cooling system integration in the STC system is estimated to be $89 \%$ more than the estimated incremental capital cost of the heating only system ( $\$ 3.6$ million for STC versus $\$ 1.9$ million for the heating only base case). In such systems, several major hydronic loops need electricity for running their associated pumps and controls. The amount of the annual electricity required for the pumps' operation is $166 \mathrm{MWh}$, which should also be considered in the economics of the system. Integration of the solar photovoltaic (PV) system can offset part or all the system's electric demand.

A combined heating and cooling system for the community with the central heat pump and PV system (HPPV) is explored as an alternative to the solar thermal chiller (STC) system. The electricity source for the heat pumps is the solar PV system. For the same community that currently uses the STC system, twenty-years simulation results show that the system would operate favorably beginning the first year and does not have any significant performance degradation in 20 years. The total heat pumps' power requirement, including circulation pumping energy, is $315.7 \mathrm{MWh}$ annually, which can be net-metered by $780 \mathrm{PV}$ panels' electricity production, installed on the rooftops. The total available rooftop area in the community is $2,293 \mathrm{~m}^{2}$, which can accommodate 1,433 solar PV panels. The potential electricity 
generation capacity using all available rooftop area with 1,433 solar PV panels is $570 \mathrm{MWh}$ annually. The total heat pumps' energy, including their circulation hydronic-pumps, requires only $55 \%$ of this total power generation capacity.

Based on the high-level cost analysis, the HPPV system capital incremental cost is $19 \%$ more economical than the solar-thermal-chiller (STC) system, in other words, the HPPV system's incremental cost is $19 \%$ less than the STC system. The HPPV does not have any incremental operating cost compared to the STC system. It means that in the HPPV system the total operating energy requirement is provided by the PV system at no cost, whereas in the STC system part of the chiller energy requirement is coming from the natural gas for the boiler and electricity for the pumps.

Lastly, integration of the solar thermal energy with a dedicated borehole thermal storage system attached to the heat pump-PV case (HPPV) is explored. The simulation results show that the proposed community currently has a balanced heat pumps' storage load. By adding the solar thermal system to the HPPV system (ST-HPPV), the heat pumps' performance in the heating mode improves but the performance in cooling mode declines. As a result, the overall heat pumps' electricity requirement of the ST-HPPV system is slightly higher than that of the HPPV system ( 10\% higher, 1257 GJ versus 1135 GJ).

The effect of heat pumps' COP drop in the cooling mode on the overall ST-HPPV system is investigated with two other hypothetical community heating, and cooling loads. One with the half-cooling loads (HCL), and the other with the quarter-cooling loads (QCL) of the main community cooling loads (FCL). Both scenarios have the same heating loads as the STC or HPPV community case heating loads. For the system with a lesser cooling load (QCL), the overall heat pumps' electricity consumption is improved by $24 \%$ (from 1,257 GJ to 955 GJ). In the QCL scenario, comparing to FCL scenario, the heat pump COP in the cooling mode improves from 3.5 to $4.4(26 \%)$ in year 10, where there is a small drop on the COP in the heating mode (3.7 to 3.6$)$.

For the communities with the imbalance heat rejection to and extraction from the ground by the heat pump, the overall system COP improves by adding solar thermal system. For the case of balance load (Scenario 1), adding solar thermal system will reduce the overall system COP by $10 \%$ (from 3.1 to 2.8 ) 
The proposed ST-HPPV system high-level incremental cost estimations were $24 \%$ and $6 \%$ higher than that of the HPPV and STC system respectively. Therefore, for the proposed community, with the balanced HP-BTES loads (Scenario 1), the HPPV is the most economical system.

The sensitivity analysis on the community cooling loads shows that for the communities that the annual heating loads to the annual cooling loads difference of $75 \%$ or less, the ST-HPPV could be a viable solution, as oppose to the HPPV system. Further system optimization is required for such cases.

\subsection{Dissertation contribution}

The main outcomes of this research work are outlined as follows:

- A new heating model in TRNSYS software for a solar community was developed. The new system had a relatively smaller system size compared to the existing heating-only community (DLSC). The proposed system offers $19 \%$ savings in the initial cost in addition to reductions of BTES area of $38 \%$ and the solar thermal collector area of $25 \%$.

- An advanced model in TRNSYS for an integrated heating and cooling system for a solar community with the borehole thermal storage and thermally driven chiller (STC system) was designed and developed. In this system, 18\% of the chillers' energy source is provided by the same size solar thermal collectors as the modified DLSC case. In the heating mode, $100 \%$ solar fraction would be achieved after five years.

- An advanced model in TRNSYS for an integrated heating and cooling system for a community with heat pumps and borehole thermal storage plus a PV system (HPPV system) was designed and developed. The designed system had a balanced heat pump BTES (HP-BTES) energy transfers (in/out) with a negligible ground temperature drop $\left(1.4^{\circ} \mathrm{C}\right)$ over twenty years. In this case, the system incremental cost is $19 \%$ less than that of STC system.

- An advanced model in TRNSYS for an integrated heating and cooling system for a solar community with the borehole thermal storage and central heat pump system plus a PV system (ST-HPPV system) was designed and developed. The proposed system initial cost is $24 \%$ higher than that of the HPPV system. This system is found to be 
more beneficial for the community with higher heating loads compared to the cooling loads.

- All the proposed systems/models can be used as a tool for designing emerging heating and cooling systems for solar communities with different configurations and types.

\subsection{Future work and recommendations}

The recommended continuity and supplementary work are as follows:

- The existing models implemented in TRNSYS require long computation time, and the chosen TRNSYS platform is not very flexible and efficient for large scale optimization simulation work. It is recommended that such solar community energy and storage systems be implemented in a more flexible and efficient platform, such as Matlab, for future advanced modeling and optimization studies.

- For all model simulation work, only simple trial and error (or brute force) methods for optimum equipment sizing were used. Meaning that various attempts with a variety of reasonable system configurations were made until the simulation of the whole model functions without any errors. This method of optimal sizing can be improved by introducing a more sophisticated optimization model in a future study.

- In this thesis, cost estimations for all systems were at very high-level analysis. More detailed cost estimates are recommended for the purpose of decisionmaking and selection of an optimal system configuration(s).

- One of the significant benefits of the solar communities, in general, is the reduction or elimination of fossil fuel usage for heating and cooling. Analysis of greenhouse gas (GHG) emission reduction potential for the proposed systems versus conventional systems would be ideal and should be included in the future work.

- In the proposed ST-HPPV system, exploration of a new control strategy is recommended in order to avoid overheating of the HP-BTES, specifically in the cases similar to Scenario 1. This could be achieved by limiting the interaction between the solar-BTES and HP-BTES in the heating season. The two BTES' 
interactions should be restricted in the way that the HP-BTES heat injection in summer becomes almost equal to the heat extraction in the winter time. In this case, the heat pump COP degradation in the cooling mode will not happen while the heat pump COPs will be improved during the heating season by the elevated heat pump entering fluid temperature. The idea can be expanded based the research done by Wang et al. (2012) on an office building in China by managing the BTES loads in a way to become balanced by introducing separate sets of the boreholes. 


\section{Appendix A: Solar thermal collector manufacturer data sheets}

\section{Appendix A: Solar thermal collector manufacturer data sheets}

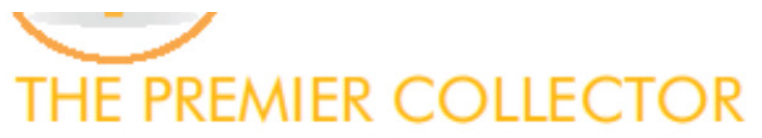

A North American assembled, reliable, high efficiency innovative collector
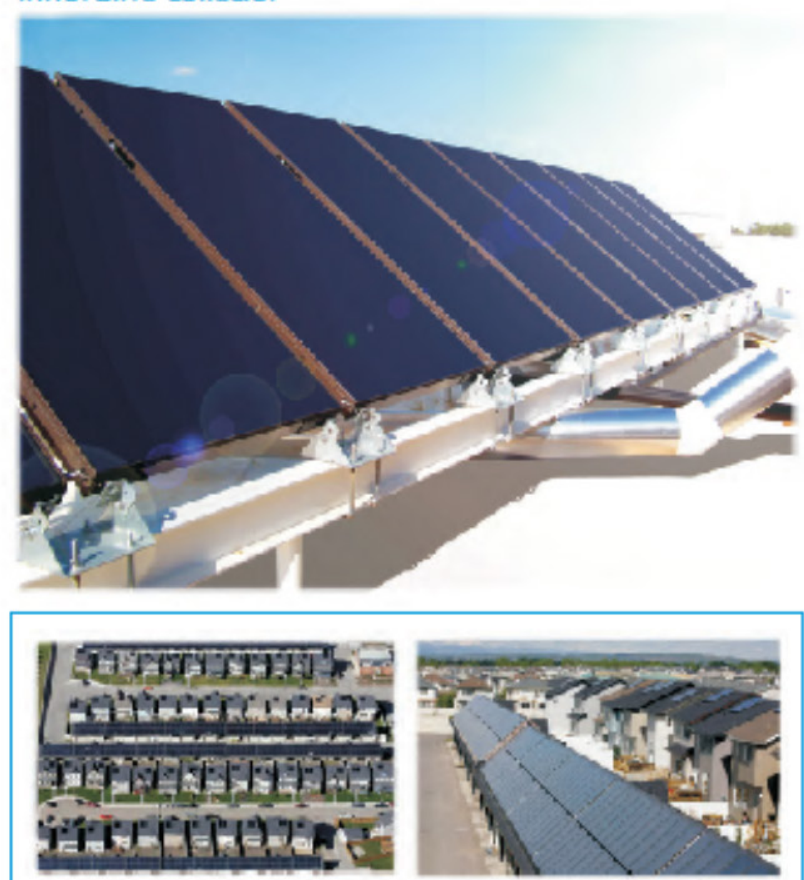

Oleotols, $\mathrm{Ab}$ Canada -Solar Community - 800 Collectors

\section{PRODUCT DESCRIPTION}

- Collectors operafing in hotels, hospitals, car washes, research and production facilifies, national parks, apartment buildings, military bases, residenfial communities, retirement homes, public schools, restaurants, laundry mats, dairy farms, etc.

- It resembles roof-top skylights when mounted on sloped roof. Flat roofracking, wall mount and ground rocking also available

- Collectors, pipeconnectors and mounting components designed for quickinstallation in modules of up to 10 colledtors

- Optimal solution for hot water and space he ating needs

\section{Harness the sun's energy to heat your water-a clean, cost-effective solution!}

FEATURES AND HIGHUIGHTS

- Reliable

- One of the highest efficiency collector rated by the SRCC nu

- Thousands of collectors installed in all climates

- Each collector is factory tested

- Greater than 20 years life expectancy

- Hail res istant for peace of mind

\section{- Energy savings}

- Cut conventional water-heating and space heafing energy requirements

- Reduce the impad of rising energy prices

- Designed for all climates

- All components are of the highest quality and durability

- Designed for freeze-protected dosed loop systems to nun year-round at temperatures down to $-50^{\circ} \mathrm{C}\left(-58^{\circ} \mathrm{F}\right)$
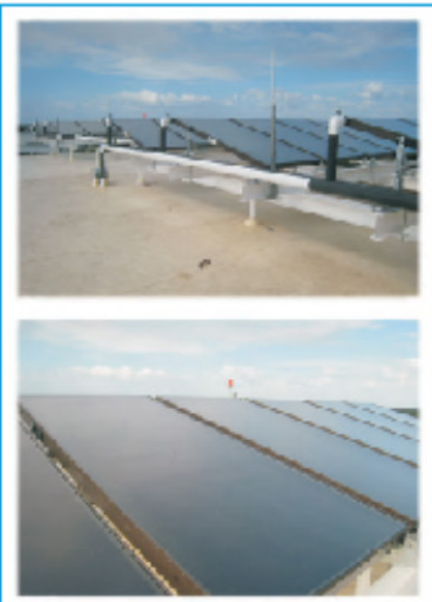

Sarasota, FL USA - Hospital 42 collectors

www.enerworks.com - 1-877-268-6502 - 470 Industrial Ave. Woodstock Ontario N4S 7L1 Canada 


\section{Appendix A: Solar thermal collector manufacturer data sheets}

\section{TECHNICAL SPECIFICATIONS}

\begin{tabular}{|c|c|}
\hline \multicolumn{2}{|c|}{ Premier Solar Collector } \\
\hline Dimensions $(\mathrm{W} \times \mathrm{H} \times \mathrm{D})$ & $\begin{array}{l}46.25^{\circ} \times 96.25^{\circ} \times 3.25^{\circ} \\
(1175 \mathrm{~mm} \times 2445 \mathrm{~mm} \times 83 \mathrm{~mm})\end{array}$ \\
\hline Weight & $110 \mathrm{lbs} .(50 \mathrm{~kg})$ \\
\hline Nosorber & $\begin{array}{l}\text { Copper sube laser welded to duminum } \\
\text { sheet - abeorplance } 95 \%\end{array}$ \\
\hline Giazing & Low-ison, potherned, sempered glass \\
\hline Aseembly & Al bonded conatrudion \\
\hline Configuration & Serpentine with heoders \\
\hline Mounting hardware & $\begin{array}{l}\text { Roof, rack or woll mourted with } \\
\text { proprietary brockets }\end{array}$ \\
\hline Connedions & $\begin{array}{l}-3 / 4^{4} \text { swect fftings b line-set } \\
\text { - flexible stainless stel bellow-type } \\
\text { between colledors }\end{array}$ \\
\hline $\begin{array}{l}\text { Maximum operating } \\
\text { pressure }\end{array}$ & $100 \mathrm{psi}(689 \mathrm{KPa})$ \\
\hline Fluid cortent & 0.5 us gollons (1.9 L) \\
\hline$S R C C$ cerification & $2006006 \mathrm{~A}$ \\
\hline FSEC cerification & $00447 N$ \\
\hline
\end{tabular}
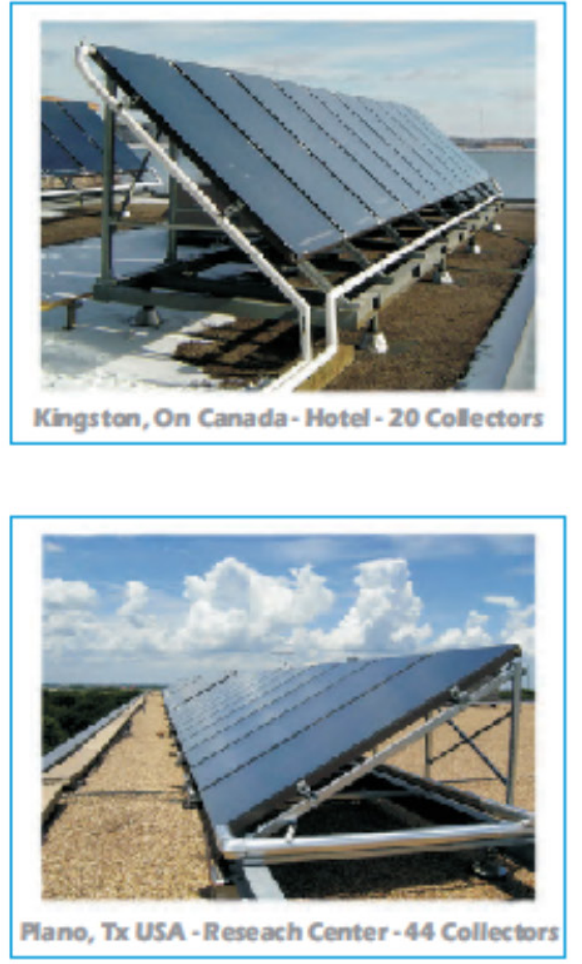

PRODUCT DETAILS

\section{SCHEMATIC}

Two colbdors shown; up to 10 can be instolod in a bank
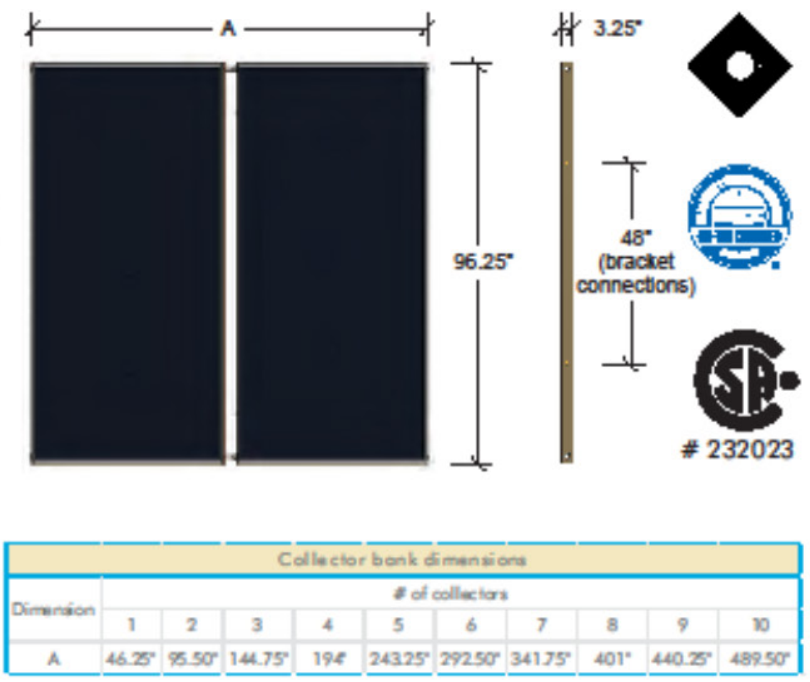

\section{CROSS SECTION VIEW}

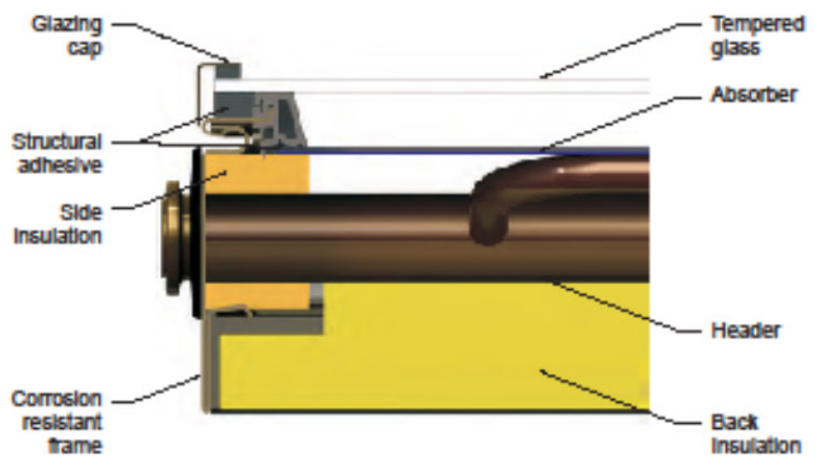

\section{COMPANY PROFILE}

Enerworks Inc. is a leading North American manufacturer of solar thermal products. Formore information about our products visit:

Commerdal Solar Thermal Products: Online Store:

Contact us:

www.enenworks.com/cammerdal wrwwsolar thermal.com wwww.enerworks.com/contact-us/ $1-877-268-6502$ Solar Pool Heaters: wrwwenersol.com 


\section{Appendix A: Solar thermal collector manufacturer data sheets}






\section{Appendix B: Chiller manufacturer data sheets}

\section{Appendix B: Chiller manufacturer data sheets}

packaged waste heat chiller(hot water chiller) Performance date and price jacket water from generator and industrial waste hot water (pump set, cooling tower, machine room's data and price as the same as DFA)

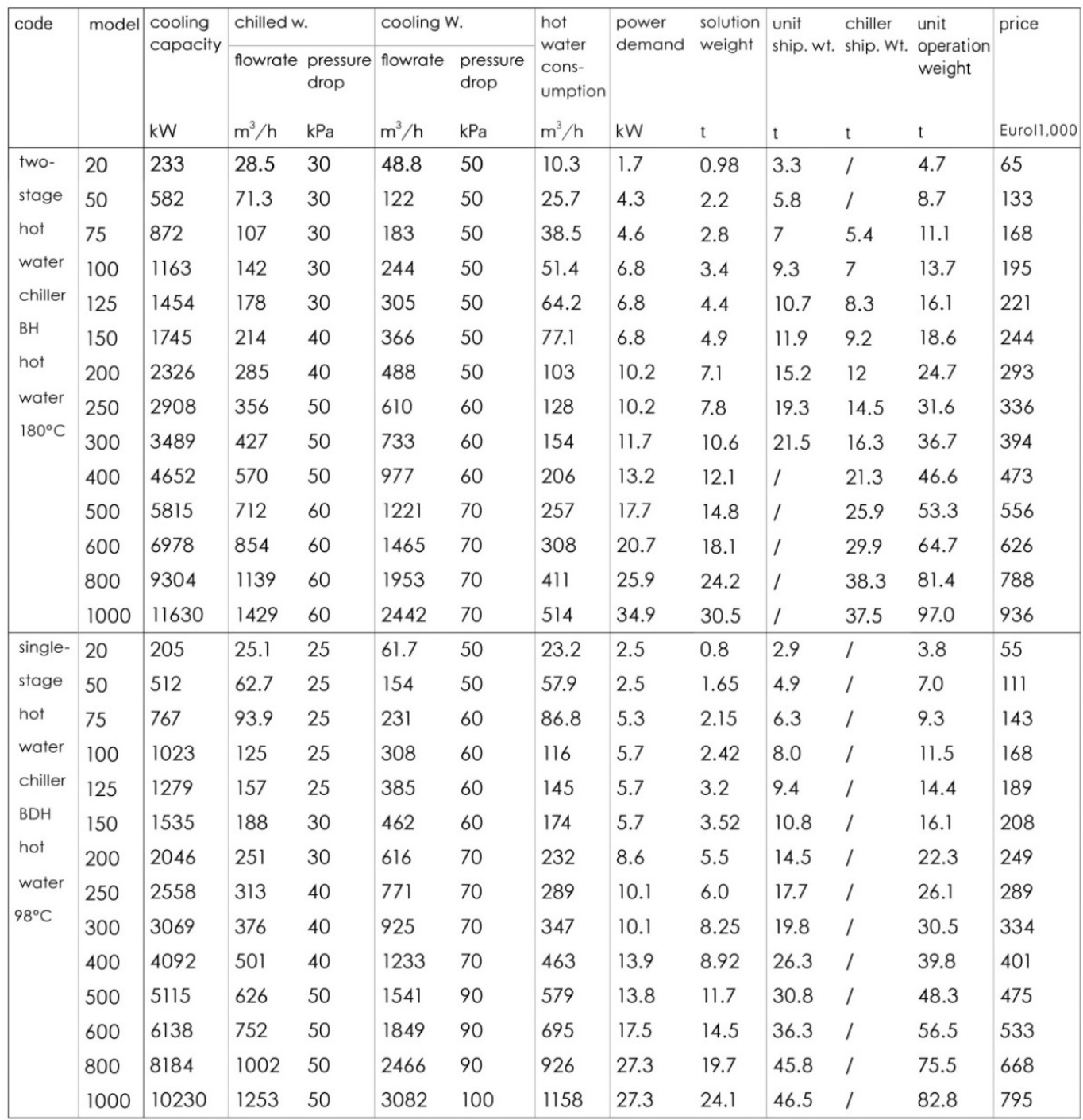

\section{General Conditions:}

1. Rated hot W. inlet/outlet temp.

Two-stage hot W. chiller: $180^{\circ} \mathrm{C} / 165^{\circ} \mathrm{C}$

Single-stage hot W. chiller: $98^{\circ} \mathrm{C} / 88^{\circ} \mathrm{C}$

2. Rated chilled W. outlet/inlet temp.: $7^{\circ} \mathrm{C} / 14^{\circ} \mathrm{C}$

3. Rated cooling W. outlet/inlet temp.: $37^{\circ} \mathrm{C} / 30^{\circ} \mathrm{C}$

4. Lowest permitted outlet temperature for chilled water: $5^{\circ} \mathrm{C}$ (except special order)

5. Lowest permitted inlet temperature for cooling water: $10^{\circ} \mathrm{C}$

6. Adjustable chilled water flowrate: $50 \%$ 120\%

7. pressure limit for chilled/cooling W.:0.8mpa
8. Adjustable load: $5 \% \sim 115 \%$

9. Fouling factor for chilled W., cooling W.,:0.086 $\mathrm{m} 2 \cdot \mathrm{K} / \mathrm{kW}$

10. LiBr Solution concentration: $52 \%$

11. Machine room temperature: $5 \sim 43^{\circ} \mathrm{C}$, humidity $\leq 85 \%$

12. Rated COP:two-stage hot W. chiller:1.41 single-stage hot W. chiller:0.76

13. Designed lifespan: 25 years

Note: 1.price are vilid from July 1, 2008-December 31,2008 (the price is $5 \%$ less before July 1) 2.pumpset price for packaged single-stage hot W. chiller is $28 \%$ 


\section{Appendix B: Chiller manufacturer data sheets}

Packaged Two-stage Waste Heat Chiller

(BS: steam chiller, BH: hot W. chiller, BE: exhaust chiller)

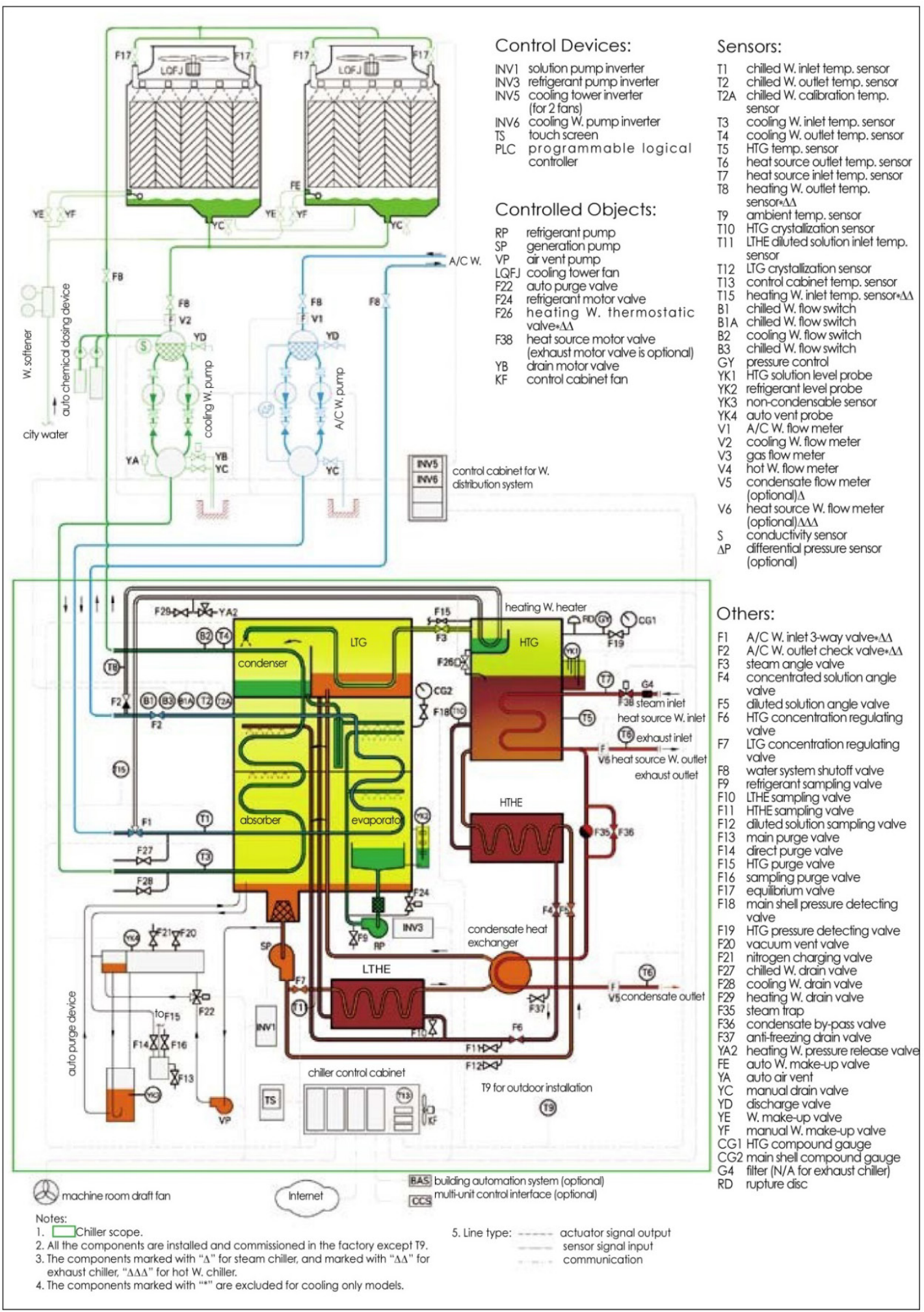




\section{Appendix C: Chiller performance data}

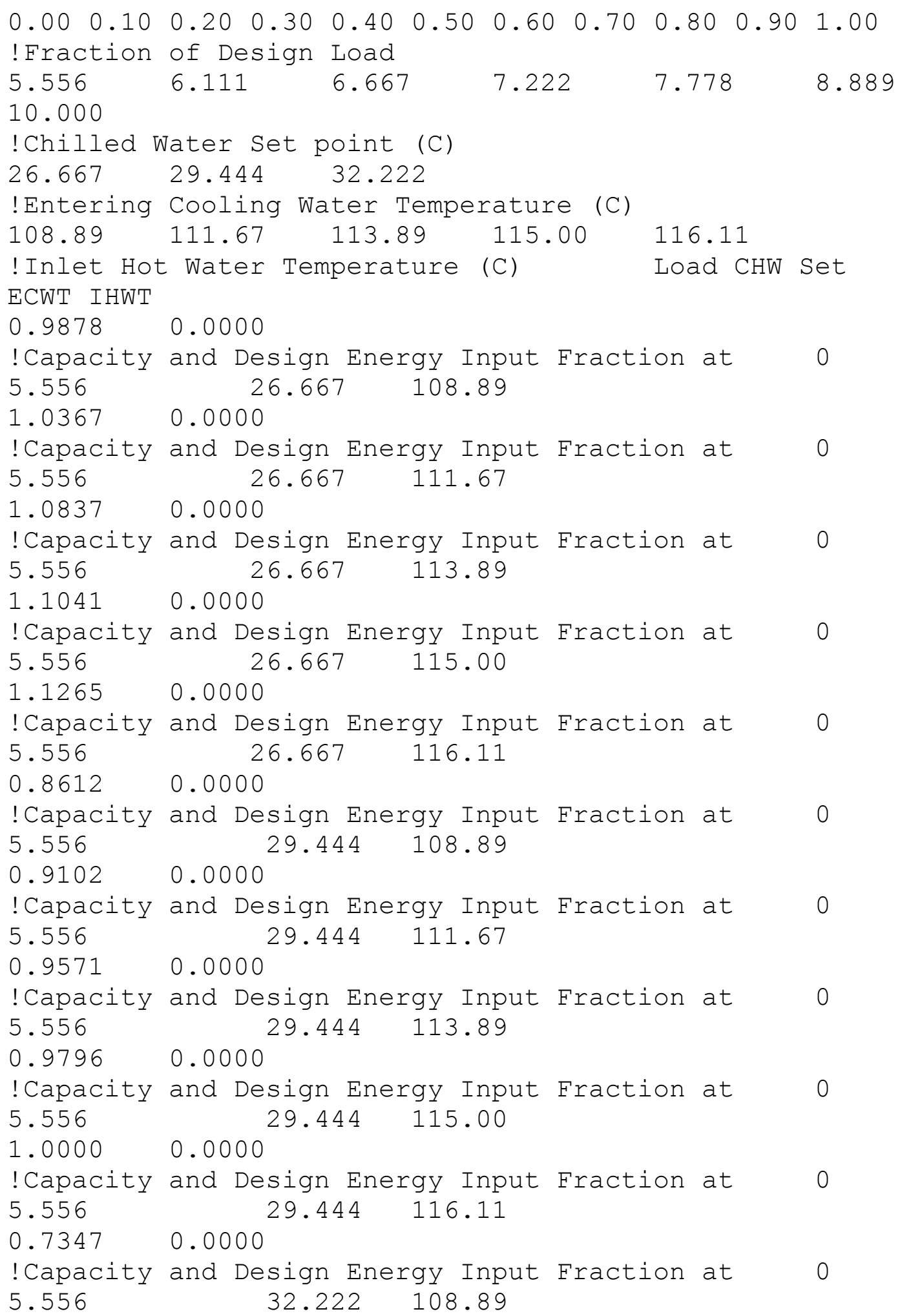




\section{Appendix C: Chiller performance data}

$0.7857 \quad 0.0000$

!Capacity and Design Energy Input Fraction at 0

$\begin{array}{lll}5.556 & 32.222 & 111.67\end{array}$

$0.8327 \quad 0.0000$

!Capacity and Design Energy Input Fraction at 0

$\begin{array}{lll}5.556 & 32.222 & 113.89\end{array}$

$0.8531 \quad 0.0000$

!Capacity and Design Energy Input Fraction at 0

$\begin{array}{lll}5.556 & 32.222 & 115.00\end{array}$

$0.8735 \quad 0.0000$

!Capacity and Design Energy Input Fraction at 0

$\begin{array}{lll}5.556 & 32.222 & 116.11\end{array}$

$1.0102 \quad 0.0000$

!Capacity and Design Energy Input Fraction at 0

$\begin{array}{lll}6.111 & 26.667 & 108.89\end{array}$

1.05920 .0000

!Capacity and Design Energy Input Fraction at 0

$\begin{array}{lll}6.111 & 26.667 & 111.67\end{array}$

$1.1061 \quad 0.0000$

!Capacity and Design Energy Input Fraction at 0

$\begin{array}{lll}6.111 & 26.667 & 113.89\end{array}$

$1.1286 \quad 0.0000$

!Capacity and Design Energy Input Fraction at 0

$\begin{array}{lll}6.111 & 26.667 & 115.00\end{array}$

$1.1490 \quad 0.0000$

!Capacity and Design Energy Input Fraction at 0

$\begin{array}{lll}6.111 & 26.667 & 116.11\end{array}$

$0.8837 \quad 0.0000$

!Capacity and Design Energy Input Fraction at 0

$\begin{array}{lll}6.111 \quad 29.444 & 108.89\end{array}$

$0.9327 \quad 0.0000$

!Capacity and Design Energy Input Fraction at 0

$6.111 \quad 29.444 \quad 111.67$

$0.9776 \quad 0.0000$

!Capacity and Design Energy Input Fraction at 0

$\begin{array}{lll}6.111 & 29.444 & 113.89\end{array}$

$1.0000 \quad 0.0000$

!Capacity and Design Energy Input Fraction at 0

$\begin{array}{lll}6.111 & 29.444 & 115.00\end{array}$

$1.0224 \quad 0.0000$

!Capacity and Design Energy Input Fraction at 0

$\begin{array}{lll}6.111 & 29.444 & 116.11\end{array}$

$0.7571 \quad 0.0000$

!Capacity and Design Energy Input Fraction at 0
6.111
$32.222 \quad 108.89$ 


\section{Appendix C: Chiller performance data}

$0.8061 \quad 0.0000$

!Capacity and Design Energy Input Fraction at 0

$\begin{array}{lll}6.111 & 32.222 & 111.67\end{array}$

$0.8531 \quad 0.0000$

!Capacity and Design Energy Input Fraction at 0

$\begin{array}{lll}6.111 & 32.222 & 113.89\end{array}$

$0.8735 \quad 0.0000$

!Capacity and Design Energy Input Fraction at 0

$\begin{array}{lll}6.111 & 32.222 & 115.00\end{array}$

$0.8959 \quad 0.0000$

!Capacity and Design Energy Input Fraction at 0

$\begin{array}{lll}6.111 & 32.222 & 116.11\end{array}$

$1.0306 \quad 0.0000$

!Capacity and Design Energy Input Fraction at 0

$\begin{array}{lll}6.667 & 26.667 & 108.89\end{array}$

1.08160 .0000

!Capacity and Design Energy Input Fraction at 0

$\begin{array}{lll}6.667 & 26.667 & 111.67\end{array}$

$1.1286 \quad 0.0000$

!Capacity and Design Energy Input Fraction at 0

$\begin{array}{lll}6.667 & 26.667 & 113.89\end{array}$

$1.1510 \quad 0.0000$

!Capacity and Design Energy Input Fraction at 0

$\begin{array}{lll}6.667 & 26.667 & 115.00\end{array}$

1.17140 .0000

!Capacity and Design Energy Input Fraction at 0

$6.667 \quad 26.667 \quad 116.11$

$0.9041 \quad 0.0000$

!Capacity and Design Energy Input Fraction at 0

$\begin{array}{lll}6.667 & 29.444 & 108.89\end{array}$

$0.9531 \quad 0.0000$

!Capacity and Design Energy Input Fraction at 0

$6.667 \quad 29.444 \quad 111.67$

$1.0000 \quad 0.0000$

!Capacity and Design Energy Input Fraction at 0

$6.667 \quad 29.444 \quad 113.89$

1.02240 .0000

!Capacity and Design Energy Input Fraction at 0

$6.667 \quad 29.444 \quad 115.00$

$1.0449 \quad 0.0000$

!Capacity and Design Energy Input Fraction at 0

$\begin{array}{lll}6.667 & 29.444 & 116.11\end{array}$

$0.7776 \quad 0.0000$

!Capacity and Design Energy Input Fraction at 0 $\begin{array}{lll}6.667 & 32.222 & 108.89\end{array}$ 


\section{Appendix C: Chiller performance data}

$0.8265 \quad 0.0000$

!Capacity and Design Energy Input Fraction at 0 $\begin{array}{lll}6.667 & 32.222 & 111.67\end{array}$

$0.8735 \quad 0.0000$

!Capacity and Design Energy Input Fraction at 0

$\begin{array}{lll}6.667 & 32.222 & 113.89\end{array}$

0.89590 .0000

!Capacity and Design Energy Input Fraction at 0

$\begin{array}{lll}6.667 & 32.222 & 115.00\end{array}$

$0.9163 \quad 0.0000$

!Capacity and Design Energy Input Fraction at 0

$\begin{array}{lll}6.667 & 32.222 & 116.11\end{array}$

1.05310 .0000

!Capacity and Design Energy Input Fraction at 0

$\begin{array}{lll}7.222 & 26.667 & 108.89\end{array}$

$1.1041 \quad 0.0000$

!Capacity and Design Energy Input Fraction at 0

$\begin{array}{lll}7.222 & 26.667 & 111.67\end{array}$

$1.1510 \quad 0.0000$

!Capacity and Design Energy Input Fraction at 0

$\begin{array}{lll}7.222 & 26.667 & 113.89\end{array}$

1.17350 .0000

!Capacity and Design Energy Input Fraction at 0

$\begin{array}{lll}7.222 & 26.667 & 115.00\end{array}$

1.19590 .0000

!Capacity and Design Energy Input Fraction at 0

$\begin{array}{lll}7.222 & 26.667 & 116.11\end{array}$

$0.9245 \quad 0.0000$

!Capacity and Design Energy Input Fraction at 0

$\begin{array}{lll}7.222 & 29.444 & 108.89\end{array}$

$0.9755 \quad 0.0000$

!Capacity and Design Energy Input Fraction at 0

$\begin{array}{lll}7.222 & 29.444 & 111.67\end{array}$

1.02240 .0000

!Capacity and Design Energy Input Fraction at 0

$\begin{array}{lll}7.222 & 29.444 & 113.89\end{array}$

$1.0449 \quad 0.0000$

!Capacity and Design Energy Input Fraction at 0

$\begin{array}{lll}7.222 & 29.444 & 115.00\end{array}$

$1.0673 \quad 0.0000$

!Capacity and Design Energy Input Fraction at 0

$\begin{array}{lll}7.222 & 29.444 & 116.11\end{array}$

$0.7980 \quad 0.0000$

!Capacity and Design Energy Input Fraction at 0 $\begin{array}{lll}7.222 & 32.222 & 108.89\end{array}$ 


\section{Appendix C: Chiller performance data}

$0.8469 \quad 0.0000$

!Capacity and Design Energy Input Fraction at 0

$\begin{array}{lll}7.222 & 32.222 & 111.67\end{array}$

0.89390 .0000

!Capacity and Design Energy Input Fraction at

7.222

$32.222 \quad 113.89$

0.9163

0.0000

!Capacity and Design Energy Input Fraction at

0

$\begin{array}{lll}7.222 & 32.222 & 115.00\end{array}$

$0.9388 \quad 0.0000$

!Capacity and Design Energy Input Fraction at

7.222

$32.222 \quad 116.11$

1.0755

0.0000

!Capacity and Design Energy Input Fraction at

7.778 $26.667 \quad 108.89$

1.1265

0.0000

!Capacity and Design Energy Input Fraction at

7.778

$26.667 \quad 111.67$

1.1755

0.0000

!Capacity and Design Energy Input Fraction at

7.778 $26.667 \quad 113.89$

1.1980 0.0000

!Capacity and Design Energy Input Fraction at

7.778 $26.667 \quad 115.00$

1.2184

0.0000

!Capacity and Design Energy Input Fraction at

7.778 $26.667 \quad 116.11$

0.9469 0.0000

!Capacity and Design Energy Input Fraction at

7.778 $29.444 \quad 108.89$

0.9980

0.0000

!Capacity and Design Energy Input Fraction at

7.778

$29.444 \quad 111.67$

1.0449

0.0000

!Capacity and Design Energy Input Fraction at

7.778

$29.444 \quad 113.89$

1.0673

0.0000

!Capacity and Design Energy Input Fraction at

7.778

$29.444 \quad 115.00$

1.0898

0.0000

!Capacity and Design Energy Input Fraction at

0

7.778 $29.444 \quad 116.11$

0.8184

0.0000

!Capacity and Design Energy Input Fraction at

$32.222 \quad 108.89$ 


\section{Appendix C: Chiller performance data}

$0.8694 \quad 0.0000$

!Capacity and Design Energy Input Fraction at 0

$\begin{array}{lll}7.778 & 32.222 & 111.67\end{array}$

$0.9163 \quad 0.0000$

!Capacity and Design Energy Input Fraction at

7.778

$32.222 \quad 113.89$

0.9388

0.0000

!Capacity and Design Energy Input Fraction at

0

$\begin{array}{lll}7.778 & 32.222 & 115.00\end{array}$

$0.9592 \quad 0.0000$

!Capacity and Design Energy Input Fraction at

7.778

$32.222 \quad 116.11$

1.1204

0.0000

!Capacity and Design Energy Input Fraction at

8.889 $26.667 \quad 108.89$

1.1735

0.0000

!Capacity and Design Energy Input Fraction at

8.889

$26.667 \quad 111.67$

1.2204

0.0000

!Capacity and Design Energy Input Fraction at

8.889

$26.667 \quad 113.89$

1.2449

0.0000

!Capacity and Design Energy Input Fraction at

8.889

$26.667 \quad 115.00$

1.2673

0.0000

!Capacity and Design Energy Input Fraction at

8.889

$26.667 \quad 116.11$

0.9898

0.0000

!Capacity and Design Energy Input Fraction at

8.889

$29.444 \quad 108.89$

1.0408

0.0000

!Capacity and Design Energy Input Fraction at

8.889

$29.444 \quad 111.67$

1.0898

0.0000

!Capacity and Design Energy Input Fraction at

8.889

$29.444 \quad 113.89$

1.1122

0.0000

!Capacity and Design Energy Input Fraction at

8.889

$29.444 \quad 115.00$

1.1347

0.0000

!Capacity and Design Energy Input Fraction at

0

8.889

$29.444 \quad 116.11$

0.8592

0.0000

!Capacity and Design Energy Input Fraction at

$32.222 \quad 108.89$ 


\section{Appendix C: Chiller performance data}

\begin{tabular}{|c|c|c|c|c|}
\hline $\begin{array}{l}0.9102 \\
\text { ! Capacity }\end{array}$ & $\begin{array}{l}0.0000 \\
\text { and Design Energy }\end{array}$ & Input & Fraction & at \\
\hline 8.889 & 32.222 & 1.67 & & \\
\hline 0.9592 & 0.0000 & & & \\
\hline ! Capacity & and Design Energy & Input & Fraction & at \\
\hline 8.889 & 32.222 & 3.89 & & \\
\hline 0.9816 & 0.0000 & & & \\
\hline ! Capacity & and Design Energy & Input & Fraction & at \\
\hline 8.889 & $32.222 \quad 11$ & 5.00 & & \\
\hline .0041 & 0.0000 & & & \\
\hline ! Capacity & and Design Energy & Input & Fraction & at \\
\hline 8.889 & $32.222 \quad 11$ & 6.11 & & \\
\hline .1673 & 0.0000 & & & \\
\hline ! Capacity & and Design Energy & Input & Fraction & at \\
\hline 10.000 & $26.667 \quad 108.89$ & & & \\
\hline .2204 & 0.0000 & & & \\
\hline ! Capacity & and Design Energy & Input & Fraction & at \\
\hline 10.000 & $26.667 \quad 111.67$ & & & \\
\hline 1.2694 & 0.0000 & & & \\
\hline ! Capacity & and Design Energy & Input & Fraction & at \\
\hline 10.000 & $26.667 \quad 113.89$ & & & \\
\hline 1.2898 & 0.0000 & & & \\
\hline ! Capacity & and Design Energy & Input & Fraction & at \\
\hline 10.000 & $26.667 \quad 115.00$ & & & \\
\hline 1.2898 & 0.0000 & & & \\
\hline ! Capacity & and Design Energy & Input & Fraction & at \\
\hline 10.000 & $26.667 \quad 116.11$ & & & \\
\hline 1.0347 & 0.0000 & & & \\
\hline ! Capacity & and Design Energy & Input & Fraction & at \\
\hline 10.000 & $29.444 \quad 108.89$ & & & \\
\hline 1.0857 & 0.0000 & & & \\
\hline ! Capacity & and Design Energy & Input & Fraction & at \\
\hline 10.000 & $29.444 \quad 111.67$ & & & \\
\hline 1.1347 & 0.0000 & & & \\
\hline ! Capacity & and Design Energy & Input & Fraction & at \\
\hline 10.000 & $29.444 \quad 113.89$ & & & \\
\hline 1.1592 & 0.0000 & & & \\
\hline ! Capacity & and Design Energy & Input & Fraction & at \\
\hline 10.000 & $29.444 \quad 115.00$ & & & \\
\hline 1.1796 & 0.0000 & & & \\
\hline ! Capacity & and Design Energy & Input & Fraction & at \\
\hline 10.000 & $29.444 \quad 116.11$ & & & \\
\hline 0.9020 & 0.0000 & & & \\
\hline $\begin{array}{l}\text { ! Capacity } \\
10.000\end{array}$ & $\begin{array}{c}\text { and Design Energy } \\
32.222108 .89\end{array}$ & Input & Fraction & at \\
\hline
\end{tabular}




\section{Appendix C: Chiller performance data}

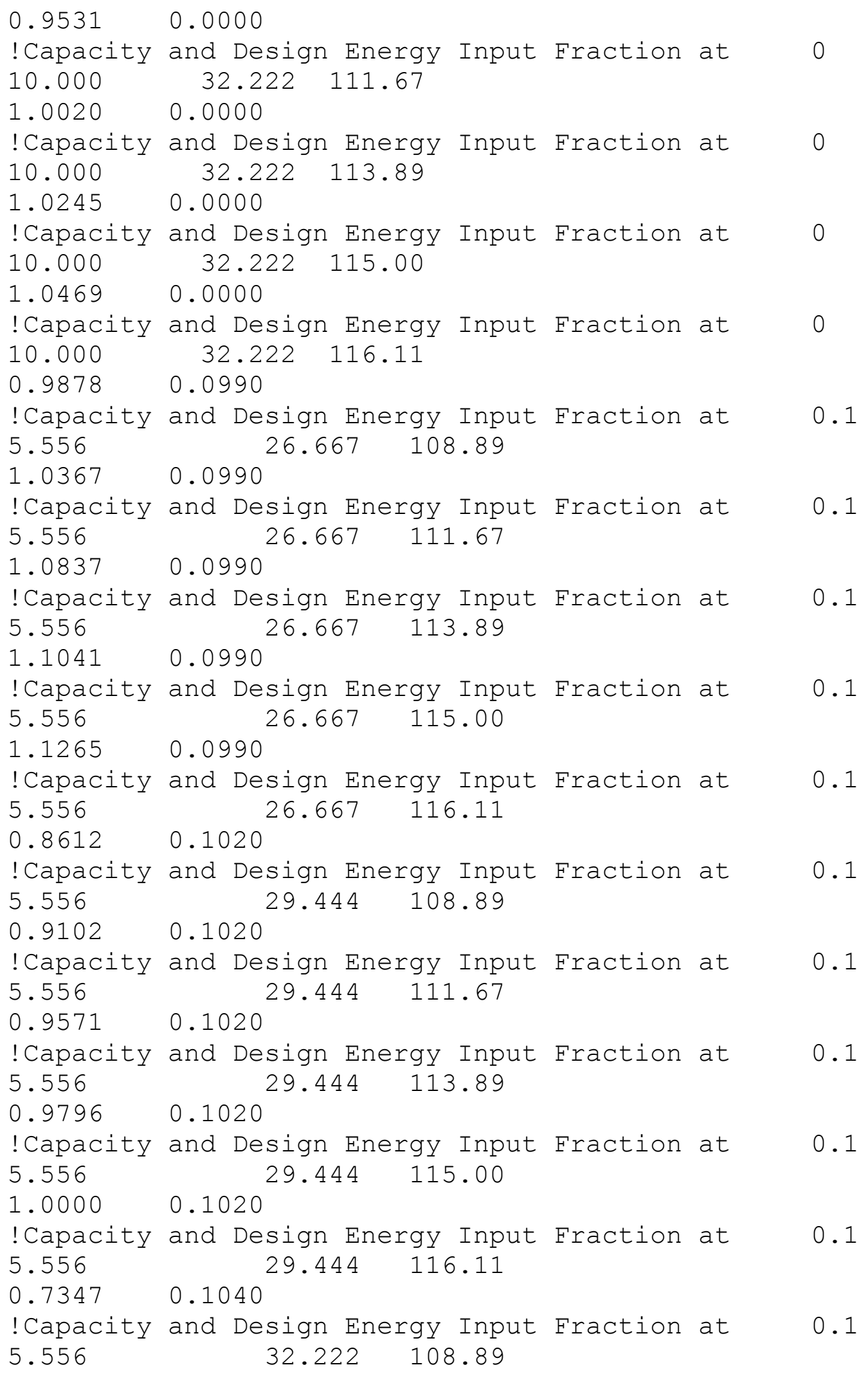




\section{Appendix C: Chiller performance data}

$0.7857 \quad 0.1040$

!Capacity and Design Energy Input Fraction at 0.1

$\begin{array}{lll}5.556 & 32.222 & 111.67\end{array}$

$0.8327 \quad 0.1040$

!Capacity and Design Energy Input Fraction at 0.1

$\begin{array}{lll}5.556 & 32.222 & 113.89\end{array}$

$0.8531 \quad 0.1040$

!Capacity and Design Energy Input Fraction at 0.1

$\begin{array}{lll}5.556 & 32.222 & 115.00\end{array}$

$0.8735 \quad 0.1040$

!Capacity and Design Energy Input Fraction at 0.1

$\begin{array}{lll}5.556 & 32.222 & 116.11\end{array}$

$1.0102 \quad 0.0980$

!Capacity and Design Energy Input Fraction at 0.1

$\begin{array}{lll}6.111 & 26.667 & 108.89\end{array}$

$1.0592 \quad 0.0980$

!Capacity and Design Energy Input Fraction at 0.1

$\begin{array}{lll}6.111 & 26.667 & 111.67\end{array}$

$1.1061 \quad 0.0980$

!Capacity and Design Energy Input Fraction at 0.1

$\begin{array}{lll}6.111 & 26.667 & 113.89\end{array}$

$\begin{array}{ll}1.1286 & 0.0980\end{array}$

!Capacity and Design Energy Input Fraction at 0.1

$\begin{array}{lll}6.111 & 26.667 & 115.00\end{array}$

$1.1490 \quad 0.0980$

!Capacity and Design Energy Input Fraction at 0.1

$\begin{array}{lll}6.111 & 26.667 & 116.11\end{array}$

$0.8837 \quad 0.1010$

!Capacity and Design Energy Input Fraction at 0.1

$\begin{array}{lll}6.111 & 29.444 & 108.89\end{array}$

$0.9327 \quad 0.1010$

!Capacity and Design Energy Input Fraction at 0.1

$\begin{array}{lll}6.111 & 29.444 & 111.67\end{array}$

$0.9776 \quad 0.1010$

!Capacity and Design Energy Input Fraction at 0.1

$\begin{array}{lll}6.111 \quad 29.444 & 113.89\end{array}$

$1.0000 \quad 0.1010$

!Capacity and Design Energy Input Fraction at 0.1

$\begin{array}{lll}6.111 & 29.444 & 115.00\end{array}$

1.02240 .1010

!Capacity and Design Energy Input Fraction at 0.1

$6.111 \quad 29.444 \quad 116.11$

$0.7571 \quad 0.1040$

!Capacity and Design Energy Input Fraction at 0.1

$\begin{array}{lll}6.111 & 32.222 & 108.89\end{array}$ 


\section{Appendix C: Chiller performance data}

$0.8061 \quad 0.1040$

!Capacity and Design Energy Input Fraction at 0.1

$\begin{array}{lll}6.111 & 32.222 & 111.67\end{array}$

$0.8531 \quad 0.1040$

!Capacity and Design Energy Input Fraction at 0.1

$\begin{array}{lll}6.111 & 32.222 & 113.89\end{array}$

$0.8735 \quad 0.1040$

!Capacity and Design Energy Input Fraction at 0.1

$\begin{array}{lll}6.111 & 32.222 & 115.00\end{array}$

$0.8959 \quad 0.1040$

!Capacity and Design Energy Input Fraction at 0.1

$\begin{array}{lll}6.111 & 32.222 & 116.11\end{array}$

$\begin{array}{ll}1.0306 & 0.0980\end{array}$

!Capacity and Design Energy Input Fraction at 0.1 $\begin{array}{lll}6.667 & 26.667 & 108.89\end{array}$

$\begin{array}{ll}1.0816 & 0.0980\end{array}$

!Capacity and Design Energy Input Fraction at 0.1 $\begin{array}{lll}6.667 & 26.667 & 111.67\end{array}$

$\begin{array}{ll}1.1286 & 0.0980\end{array}$

!Capacity and Design Energy Input Fraction at 0.1 $\begin{array}{lll}6.667 & 26.667 & 113.89\end{array}$

$\begin{array}{ll}1.1510 & 0.0980\end{array}$

!Capacity and Design Energy Input Fraction at 0.1 $\begin{array}{lll}6.667 & 26.667 & 115.00\end{array}$

1.17140 .0980

!Capacity and Design Energy Input Fraction at 0.1

$6.667 \quad 26.667 \quad 116.11$

$0.9041 \quad 0.1000$

!Capacity and Design Energy Input Fraction at 0.1

$6.667 \quad 29.444 \quad 108.89$

$0.9531 \quad 0.1000$

!Capacity and Design Energy Input Fraction at 0.1

$6.667 \quad 29.444 \quad 111.67$

$1.0000 \quad 0.1000$

!Capacity and Design Energy Input Fraction at 0.1

$6.667 \quad 29.444 \quad 113.89$

1.02240 .1000

!Capacity and Design Energy Input Fraction at 0.1

$6.667 \quad 29.444 \quad 115.00$

1.04490 .1000

!Capacity and Design Energy Input Fraction at 0.1

$\begin{array}{lll}6.667 & 29.444 & 116.11\end{array}$

$0.7776 \quad 0.1030$

!Capacity and Design Energy Input Fraction at 0.1
6.667
$32.222 \quad 108.89$ 


\section{Appendix C: Chiller performance data}

$0.8265 \quad 0.1030$

!Capacity and Design Energy Input Fraction at 0.1 $\begin{array}{lll}6.667 & 32.222 & 111.67\end{array}$

$0.8735 \quad 0.1030$

!Capacity and Design Energy Input Fraction at 0.1

$\begin{array}{lll}6.667 & 32.222 & 113.89\end{array}$

$0.8959 \quad 0.1030$

!Capacity and Design Energy Input Fraction at 0.1

$\begin{array}{lll}6.667 & 32.222 & 115.00\end{array}$

$0.9163 \quad 0.1030$

!Capacity and Design Energy Input Fraction at 0.1

$\begin{array}{lll}6.667 & 32.222 \quad 116.11\end{array}$

$1.0531 \quad 0.0970$

!Capacity and Design Energy Input Fraction at 0.1

$\begin{array}{lll}7.222 & 26.667 & 108.89\end{array}$

$\begin{array}{ll}1.1041 & 0.0970\end{array}$

!Capacity and Design Energy Input Fraction at 0.1

$\begin{array}{lll}7.222 & 26.667 & 111.67\end{array}$

$1.1510 \quad 0.0970$

!Capacity and Design Energy Input Fraction at 0.1

$\begin{array}{lll}7.222 & 26.667 & 113.89\end{array}$

$1.1735 \quad 0.0970$

!Capacity and Design Energy Input Fraction at 0.1

$\begin{array}{lll}7.222 & 26.667 & 115.00\end{array}$

1.19590 .0970

!Capacity and Design Energy Input Fraction at 0.1

$\begin{array}{lll}7.222 & 26.667 & 116.11\end{array}$

$0.9245 \quad 0.0990$

!Capacity and Design Energy Input Fraction at 0.1

$\begin{array}{lll}7.222 & 29.444 & 108.89\end{array}$

$0.9755 \quad 0.0990$

!Capacity and Design Energy Input Fraction at 0.1

$\begin{array}{lll}7.222 & 29.444 & 111.67\end{array}$

1.02240 .0990

!Capacity and Design Energy Input Fraction at 0.1

$\begin{array}{lll}7.222 & 29.444 & 113.89\end{array}$

$1.0449 \quad 0.0990$

!Capacity and Design Energy Input Fraction at 0.1

$\begin{array}{lll}7.222 & 29.444 & 115.00\end{array}$

$1.0673 \quad 0.0990$

!Capacity and Design Energy Input Fraction at 0.1

$\begin{array}{lll}7.222 & 29.444 & 116.11\end{array}$

$0.7980 \quad 0.1020$

!Capacity and Design Energy Input Fraction at 0.1

$\begin{array}{lll}7.222 & 32.222 & 108.89\end{array}$ 


\section{Appendix C: Chiller performance data}

$0.8469 \quad 0.1020$

!Capacity and Design Energy Input Fraction at 0.1

7.222

$32.222 \quad 111.67$

0.8939

0.1020

!Capacity and Design Energy Input Fraction at

0.1

7.222

$32.222 \quad 113.89$

0.9163

0.1020

!Capacity and Design Energy Input Fraction at

0.1

7.222

$32.222 \quad 115.00$

0.9388

0.1020

!Capacity and Design Energy Input Fraction at

0.1

7.222

$32.222 \quad 116.11$

1.0755

0.0960

!Capacity and Design Energy Input Fraction at

0.1

7.778 $26.667 \quad 108.89$

1.1265

0.0960

!Capacity and Design Energy Input Fraction at

7.778

$26.667 \quad 111.67$

1.1755

0.0960

!Capacity and Design Energy Input Fraction at

7.778

$26.667 \quad 113.89$

1.1980

0.0960

!Capacity and Design Energy Input Fraction at

7.778

$26.667 \quad 115.00$

1.2184

0.0960

!Capacity and Design Energy Input Fraction at

7.778

$26.667 \quad 116.11$

0.9469

0.0980

!Capacity and Design Energy Input Fraction at

7.778

$29.444 \quad 108.89$

0.9980

0.0980

!Capacity and Design Energy Input Fraction at

7.778

$29.444 \quad 111.67$

1.0449

0.0980

!Capacity and Design Energy Input Fraction at

7.778

$29.444 \quad 113.89$

1.0673

0.0980

!Capacity and Design Energy Input Fraction at

7.778

$29.444 \quad 115.00$

1.0898

0.0980

!Capacity and Design Energy Input Fraction at

0.1

7.778 $29.444 \quad 116.11$

0.8184

0.1010

!Capacity and Design Energy Input Fraction at

0.1

7.778

$32.222 \quad 108.89$

0.1

0.1

0.1

0.1

0.1

0.1

0.1

0.1 


\section{Appendix C: Chiller performance data}

$0.8694 \quad 0.1010$

!Capacity and Design Energy Input Fraction at 0.1

$\begin{array}{lll}7.778 & 32.222 & 111.67\end{array}$

$0.9163 \quad 0.1010$

!Capacity and Design Energy Input Fraction at 0.1

$\begin{array}{lll}7.778 & 32.222 & 113.89\end{array}$

$0.9388 \quad 0.1010$

!Capacity and Design Energy Input Fraction at 0.1

$\begin{array}{lll}7.778 & 32.222 & 115.00\end{array}$

$0.9592 \quad 0.1010$

!Capacity and Design Energy Input Fraction at 0.1

$\begin{array}{lll}7.778 & 32.222 & 116.11\end{array}$

$1.1204 \quad 0.0950$

!Capacity and Design Energy Input Fraction at 0.1

$8.889 \quad 26.667 \quad 108.89$

$1.1735 \quad 0.0950$

!Capacity and Design Energy Input Fraction at 0.1

$\begin{array}{lll}8.889 & 26.667 & 111.67\end{array}$

$1.2204 \quad 0.0950$

!Capacity and Design Energy Input Fraction at 0.1

$\begin{array}{lll}8.889 & 26.667 & 113.89\end{array}$

$1.2449 \quad 0.0950$

!Capacity and Design Energy Input Fraction at 0.1

$8.889 \quad 26.667 \quad 115.00$

$1.2673 \quad 0.0950$

!Capacity and Design Energy Input Fraction at 0.1

$8.889 \quad 26.667 \quad 116.11$

$0.9898 \quad 0.0970$

!Capacity and Design Energy Input Fraction at 0.1

$\begin{array}{lll}8.889 & 29.444 & 108.89\end{array}$

$1.0408 \quad 0.0970$

!Capacity and Design Energy Input Fraction at 0.1

$\begin{array}{lll}8.889 & 29.444 & 111.67\end{array}$

$1.0898 \quad 0.0970$

!Capacity and Design Energy Input Fraction at 0.1

$\begin{array}{lll}8.889 & 29.444 & 113.89\end{array}$

$\begin{array}{ll}1.1122 & 0.0970\end{array}$

!Capacity and Design Energy Input Fraction at 0.1

$\begin{array}{lll}8.889 & 29.444 & 115.00\end{array}$

$1.1347 \quad 0.0970$

!Capacity and Design Energy Input Fraction at 0.1

$8.889 \quad 29.444 \quad 116.11$

$0.8592 \quad 0.1000$

!Capacity and Design Energy Input Fraction at 0.1

$\begin{array}{lll}8.889 & 32.222 & 108.89\end{array}$ 


\section{Appendix C: Chiller performance data}

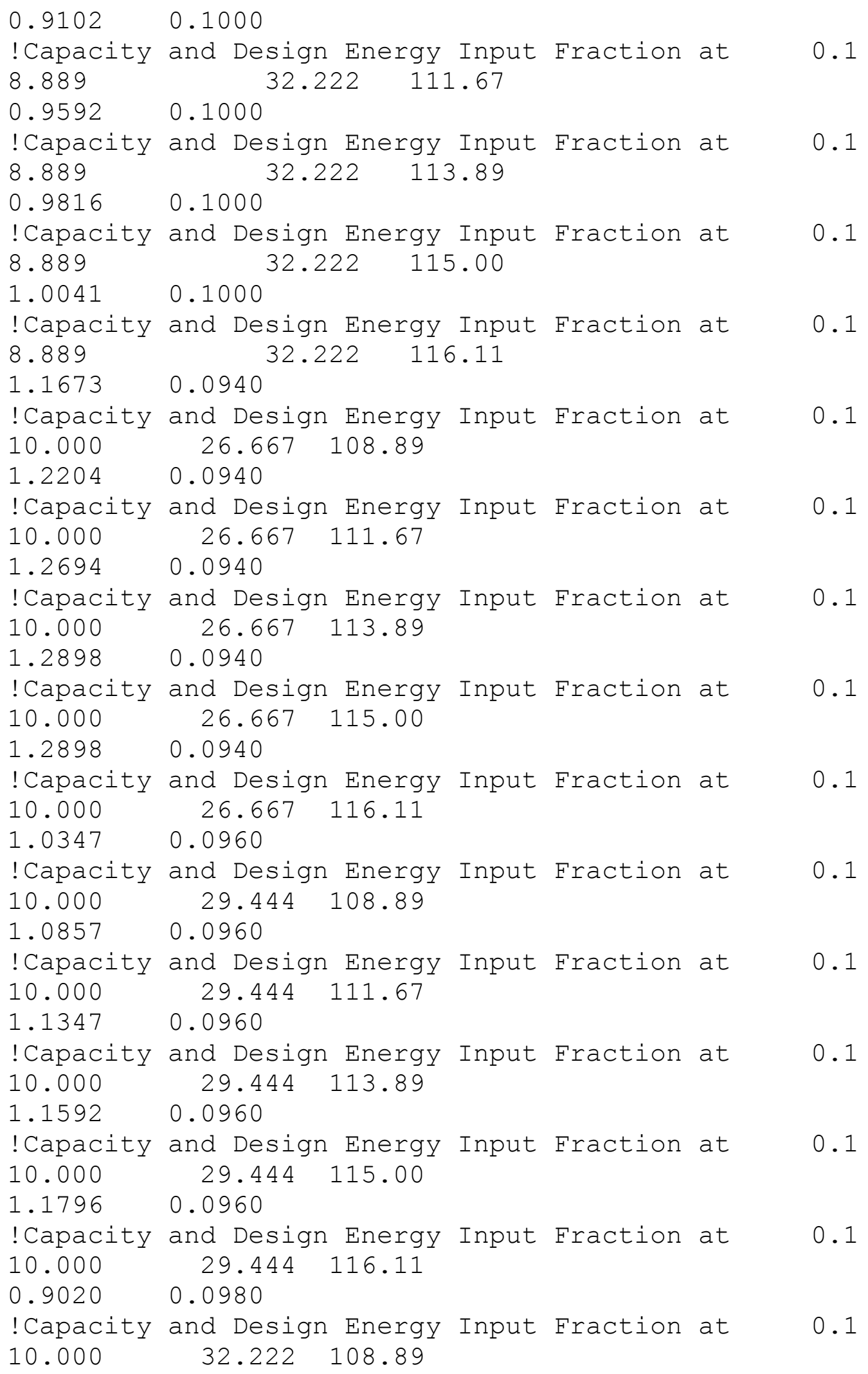




\section{Appendix C: Chiller performance data}

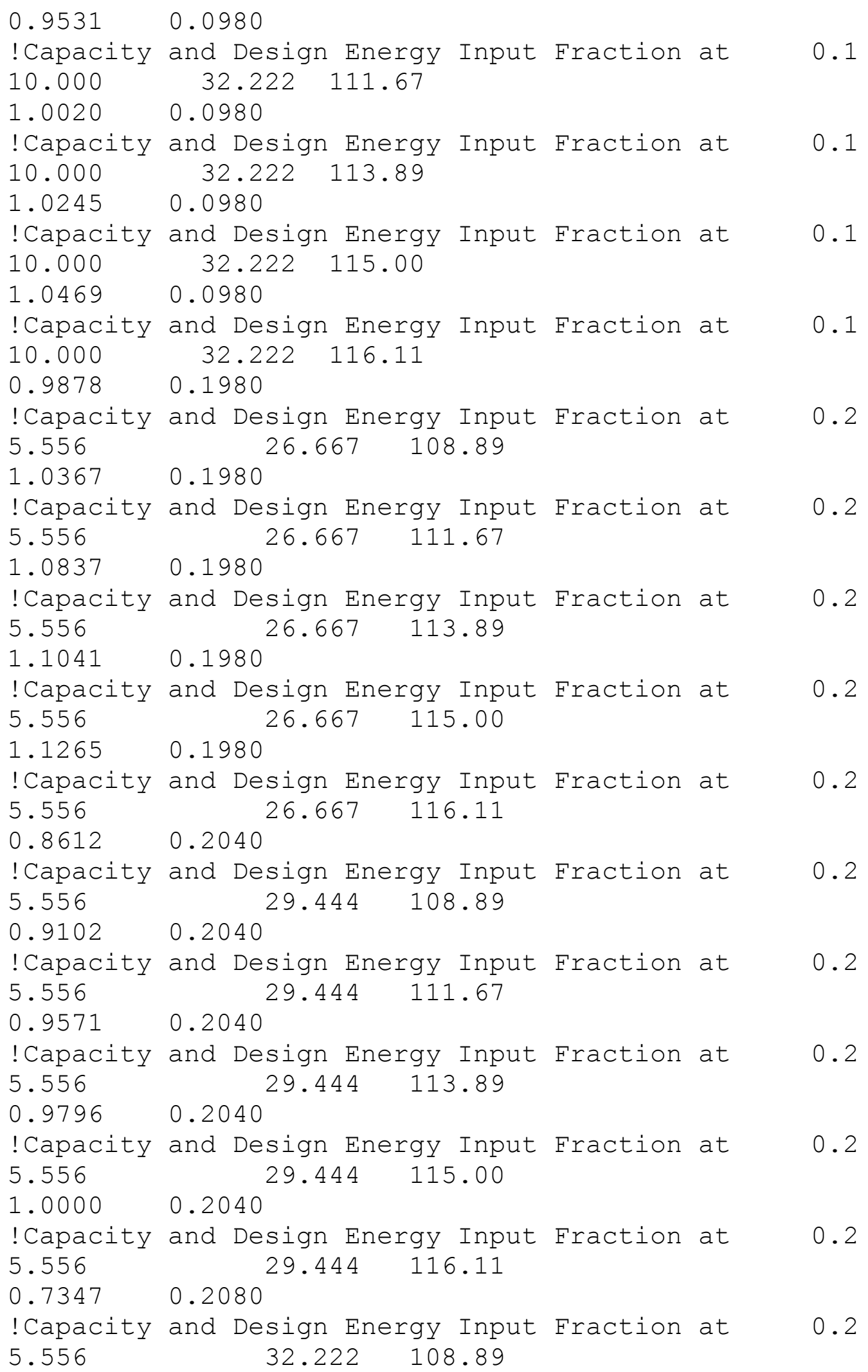




\section{Appendix C: Chiller performance data}

$0.7857 \quad 0.2080$

!Capacity and Design Energy Input Fraction at 0.2

$\begin{array}{lll}5.556 & 32.222 & 111.67\end{array}$

$0.8327 \quad 0.2080$

!Capacity and Design Energy Input Fraction at 0.2

$\begin{array}{lll}5.556 & 32.222 & 113.89\end{array}$

$0.8531 \quad 0.2080$

!Capacity and Design Energy Input Fraction at 0.2

$\begin{array}{lll}5.556 & 32.222 & 115.00\end{array}$

$0.8735 \quad 0.2080$

!Capacity and Design Energy Input Fraction at 0.2

$5.556 \quad 32.222 \quad 116.11$

$1.0102 \quad 0.1960$

!Capacity and Design Energy Input Fraction at 0.2

$6.111 \quad 26.667 \quad 108.89$

$1.0592 \quad 0.1960$

!Capacity and Design Energy Input Fraction at 0.2

$\begin{array}{lll}6.111 & 26.667 & 111.67\end{array}$

$1.1061 \quad 0.1960$

!Capacity and Design Energy Input Fraction at 0.2

$\begin{array}{lll}6.111 & 26.667 & 113.89\end{array}$

$1.1286 \quad 0.1960$

!Capacity and Design Energy Input Fraction at 0.2

$\begin{array}{lll}6.111 \quad 26.667 & 115.00\end{array}$

$1.1490 \quad 0.1960$

!Capacity and Design Energy Input Fraction at 0.2

$\begin{array}{lll}6.111 & 26.667 & 116.11\end{array}$

$0.8837 \quad 0.2020$

!Capacity and Design Energy Input Fraction at 0.2

$\begin{array}{lll}6.111 & 29.444 & 108.89\end{array}$

$0.9327 \quad 0.2020$

!Capacity and Design Energy Input Fraction at 0.2

$\begin{array}{lll}6.111 & 29.444 & 111.67\end{array}$

$0.9776 \quad 0.2020$

!Capacity and Design Energy Input Fraction at 0.2

$\begin{array}{lll}6.111 & 29.444 & 113.89\end{array}$

$1.0000 \quad 0.2020$

!Capacity and Design Energy Input Fraction at 0.2

$\begin{array}{lll}6.111 & 29.444 & 115.00\end{array}$

$1.0224 \quad 0.2020$

!Capacity and Design Energy Input Fraction at 0.2

$\begin{array}{lll}6.111 & 29.444 & 116.11\end{array}$

$0.7571 \quad 0.2080$

!Capacity and Design Energy Input Fraction at 0.2

$\begin{array}{lll}6.111 & 32.222 & 108.89\end{array}$ 


\section{Appendix C: Chiller performance data}

$0.8061 \quad 0.2080$

!Capacity and Design Energy Input Fraction at 0.2

$\begin{array}{lll}6.111 & 32.222 & 111.67\end{array}$

$0.8531 \quad 0.2080$

!Capacity and Design Energy Input Fraction at 0.2

$\begin{array}{lll}6.111 & 32.222 & 113.89\end{array}$

$0.8735 \quad 0.2080$

!Capacity and Design Energy Input Fraction at 0.2

$\begin{array}{lll}6.111 & 32.222 & 115.00\end{array}$

$0.8959 \quad 0.2080$

!Capacity and Design Energy Input Fraction at 0.2

$\begin{array}{lll}6.111 & 32.222 & 116.11\end{array}$

$1.0306 \quad 0.1960$

!Capacity and Design Energy Input Fraction at 0.2

$6.667 \quad 26.667 \quad 108.89$

$\begin{array}{ll}1.0816 & 0.1960\end{array}$

!Capacity and Design Energy Input Fraction at 0.2

$6.667 \quad 26.667 \quad 111.67$

$1.1286 \quad 0.1960$

!Capacity and Design Energy Input Fraction at 0.2

$6.667 \quad 26.667 \quad 113.89$

$1.1510 \quad 0.1960$

!Capacity and Design Energy Input Fraction at 0.2

$6.667 \quad 26.667 \quad 115.00$

$1.1714 \quad 0.1960$

!Capacity and Design Energy Input Fraction at 0.2

$6.667 \quad 26.667 \quad 116.11$

$0.9041 \quad 0.2000$

!Capacity and Design Energy Input Fraction at 0.2

$\begin{array}{lll}6.667 & 29.444 & 108.89\end{array}$

$0.9531 \quad 0.2000$

!Capacity and Design Energy Input Fraction at 0.2

$6.667 \quad 29.444 \quad 111.67$

$1.0000 \quad 0.2000$

!Capacity and Design Energy Input Fraction at 0.2

$6.667 \quad 29.444 \quad 113.89$

1.02240 .2000

!Capacity and Design Energy Input Fraction at 0.2

$6.667 \quad 29.444 \quad 115.00$

$1.0449 \quad 0.2000$

!Capacity and Design Energy Input Fraction at 0.2

$6.667 \quad 29.444 \quad 116.11$

$0.7776 \quad 0.2060$

!Capacity and Design Energy Input Fraction at 0.2

$\begin{array}{lll}6.667 & 32.222 & 108.89\end{array}$ 


\section{Appendix C: Chiller performance data}

$0.8265 \quad 0.2060$

!Capacity and Design Energy Input Fraction at 0.2 $\begin{array}{lll}6.667 & 32.222 & 111.67\end{array}$

$0.8735 \quad 0.2060$

!Capacity and Design Energy Input Fraction at 0.2

$\begin{array}{lll}6.667 & 32.222 & 113.89\end{array}$

$0.8959 \quad 0.2060$

!Capacity and Design Energy Input Fraction at 0.2

$\begin{array}{lll}6.667 & 32.222 & 115.00\end{array}$

$0.9163 \quad 0.2060$

!Capacity and Design Energy Input Fraction at 0.2

$6.667 \quad 32.222 \quad 116.11$

$1.0531 \quad 0.1940$

!Capacity and Design Energy Input Fraction at 0.2

$\begin{array}{lll}7.222 & 26.667 & 108.89\end{array}$

$\begin{array}{ll}1.1041 & 0.1940\end{array}$

!Capacity and Design Energy Input Fraction at 0.2

$\begin{array}{lll}7.222 & 26.667 & 111.67\end{array}$

$1.1510 \quad 0.1940$

!Capacity and Design Energy Input Fraction at 0.2

$\begin{array}{lll}7.222 & 26.667 & 113.89\end{array}$

$1.1735 \quad 0.1940$

!Capacity and Design Energy Input Fraction at 0.2

$\begin{array}{lll}7.222 & 26.667 & 115.00\end{array}$

1.19590 .1940

!Capacity and Design Energy Input Fraction at 0.2

$\begin{array}{lll}7.222 & 26.667 & 116.11\end{array}$

$0.9245 \quad 0.1980$

!Capacity and Design Energy Input Fraction at 0.2

$\begin{array}{lll}7.222 & 29.444 & 108.89\end{array}$

$0.9755 \quad 0.1980$

!Capacity and Design Energy Input Fraction at 0.2

$\begin{array}{lll}7.222 & 29.444 & 111.67\end{array}$

1.02240 .1980

!Capacity and Design Energy Input Fraction at 0.2

$\begin{array}{lll}7.222 & 29.444 & 113.89\end{array}$

$1.0449 \quad 0.1980$

!Capacity and Design Energy Input Fraction at 0.2

$\begin{array}{lll}7.222 & 29.444 & 115.00\end{array}$

$\begin{array}{ll}1.0673 & 0.1980\end{array}$

!Capacity and Design Energy Input Fraction at 0.2

$\begin{array}{lll}7.222 & 29.444 & 116.11\end{array}$

$0.7980 \quad 0.2040$

!Capacity and Design Energy Input Fraction at 0.2

$\begin{array}{lll}7.222 & 32.222 & 108.89\end{array}$ 


\section{Appendix C: Chiller performance data}

$0.8469 \quad 0.2040$

!Capacity and Design Energy Input Fraction at 0.2

7.222

$32.222 \quad 111.67$

0.8939

0.2040

!Capacity and Design Energy Input Fraction at

0.2

7.222

$32.222 \quad 113.89$

0.9163

0.2040

!Capacity and Design Energy Input Fraction at

0.2

7.222

$32.222 \quad 115.00$

0.9388

0.2040

!Capacity and Design Energy Input Fraction at

0.2

7.222

$32.222 \quad 116.11$

1.0755

0.1920

!Capacity and Design Energy Input Fraction at

0.2

$\begin{array}{lll}7.778 & 26.667 & 108.89\end{array}$

$1.1265 \quad 0.1920$

!Capacity and Design Energy Input Fraction at 0.2

7.778

$26.667 \quad 111.67$

1.1755

0.1920

!Capacity and Design Energy Input Fraction at

0.2

7.778 $26.667 \quad 113.89$

1.1980

0.1920

!Capacity and Design Energy Input Fraction at

7.778 $26.667 \quad 115.00$

1.2184

0.1920

!Capacity and Design Energy Input Fraction at

7.778 $26.667 \quad 116.11$

0.9469

0.1960

!Capacity and Design Energy Input Fraction at

7.778

$29.444 \quad 108.89$

0.9980

0.1960

!Capacity and Design Energy Input Fraction at

7.778

$29.444 \quad 111.67$

1.0449

0.1960

!Capacity and Design Energy Input Fraction at

7.778

$29.444 \quad 113.89$

1.0673

0.1960

!Capacity and Design Energy Input Fraction at

7.778

$29.444 \quad 115.00$

1.0898

0.1960

!Capacity and Design Energy Input Fraction at

0.2

7.778 $29.444 \quad 116.11$

0.8184

0.2020

!Capacity and Design Energy Input Fraction at 7.778

$32.222 \quad 108.89$

0.2

0.2

0.2

0.2

0.2

0.2

0.2 


\section{Appendix C: Chiller performance data}

$0.8694 \quad 0.2020$

!Capacity and Design Energy Input Fraction at 0.2

$\begin{array}{lll}7.778 & 32.222 & 111.67\end{array}$

$0.9163 \quad 0.2020$

!Capacity and Design Energy Input Fraction at 0.2

$\begin{array}{lll}7.778 & 32.222 & 113.89\end{array}$

$0.9388 \quad 0.2020$

!Capacity and Design Energy Input Fraction at 0.2

$\begin{array}{lll}7.778 & 32.222 & 115.00\end{array}$

$0.9592 \quad 0.2020$

!Capacity and Design Energy Input Fraction at 0.2

$\begin{array}{lll}7.778 & 32.222 & 116.11\end{array}$

$1.1204 \quad 0.1900$

!Capacity and Design Energy Input Fraction at 0.2

$8.889 \quad 26.667 \quad 108.89$

$1.1735 \quad 0.1900$

!Capacity and Design Energy Input Fraction at 0.2

$8.889 \quad 26.667 \quad 111.67$

$1.2204 \quad 0.1900$

!Capacity and Design Energy Input Fraction at 0.2

$\begin{array}{lll}8.889 & 26.667 & 113.89\end{array}$

$1.2449 \quad 0.1900$

!Capacity and Design Energy Input Fraction at 0.2

$\begin{array}{lll}8.889 & 26.667 & 115.00\end{array}$

$1.2673 \quad 0.1900$

!Capacity and Design Energy Input Fraction at 0.2

$8.889 \quad 26.667 \quad 116.11$

$0.9898 \quad 0.1940$

!Capacity and Design Energy Input Fraction at 0.2

$8.889 \quad 29.444 \quad 108.89$

$1.0408 \quad 0.1940$

!Capacity and Design Energy Input Fraction at 0.2

$\begin{array}{lll}8.889 & 29.444 & 111.67\end{array}$

$1.0898 \quad 0.1940$

!Capacity and Design Energy Input Fraction at 0.2

$8.889 \quad 29.444 \quad 113.89$

$1.1122 \quad 0.1940$

!Capacity and Design Energy Input Fraction at 0.2

$8.889 \quad 29.444 \quad 115.00$

$1.1347 \quad 0.1940$

!Capacity and Design Energy Input Fraction at 0.2

$8.889 \quad 29.444 \quad 116.11$

$0.8592 \quad 0.2000$

!Capacity and Design Energy Input Fraction at 0.2

$\begin{array}{lll}8.889 & 32.222 & 108.89\end{array}$ 


\section{Appendix C: Chiller performance data}

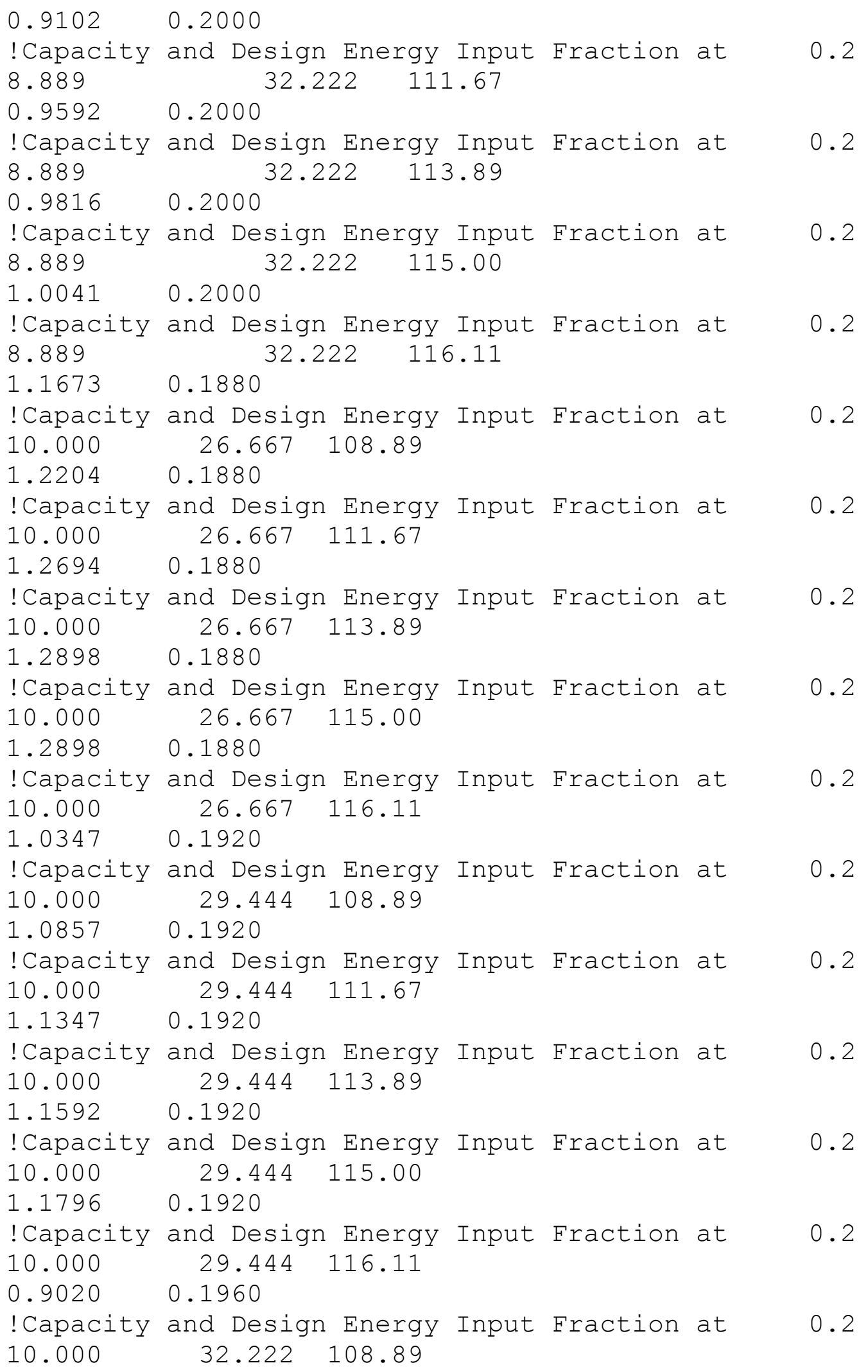




\section{Appendix C: Chiller performance data}

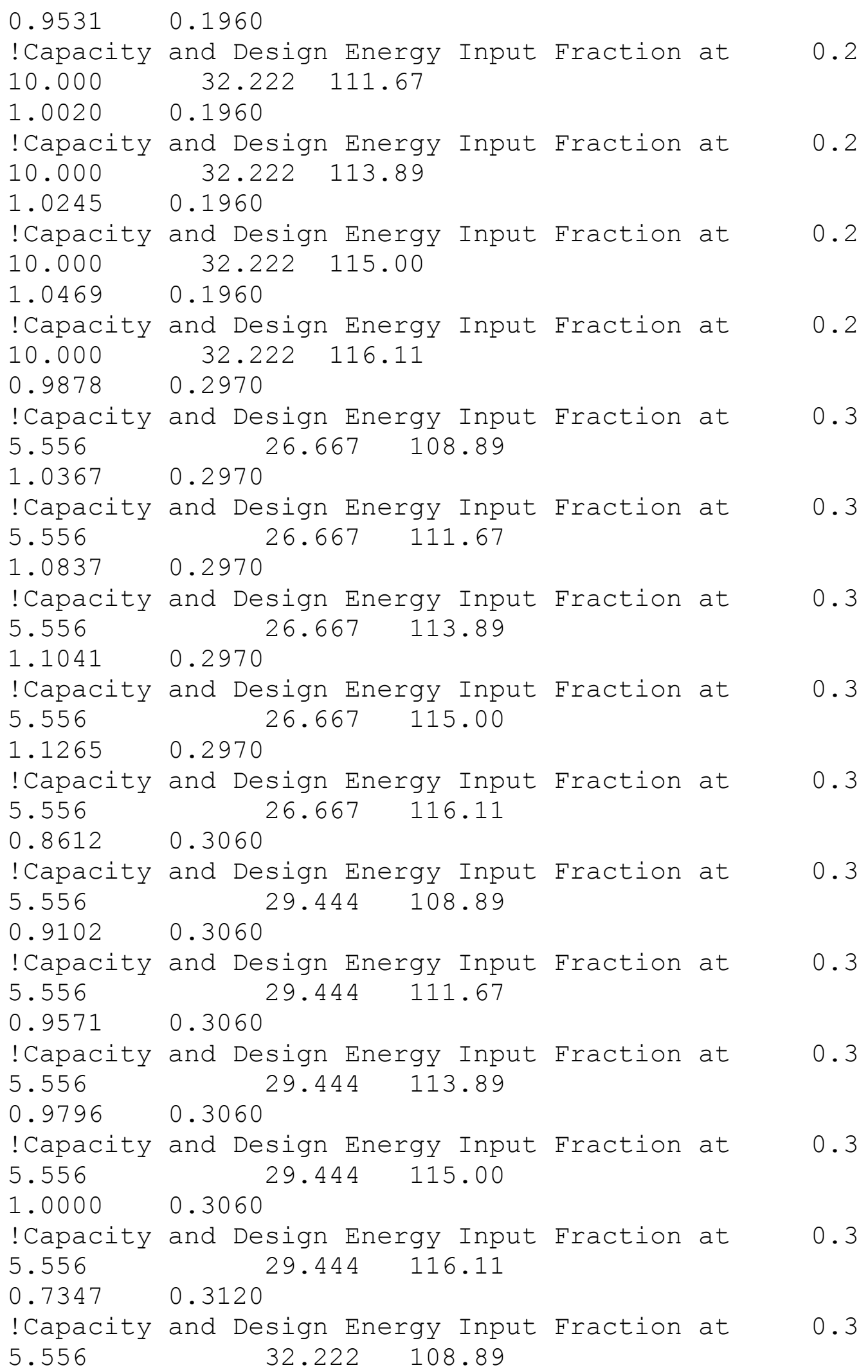




\section{Appendix C: Chiller performance data}

$0.7857 \quad 0.3120$

!Capacity and Design Energy Input Fraction at 0.3

$\begin{array}{lll}5.556 & 32.222 & 111.67\end{array}$

$0.8327 \quad 0.3120$

!Capacity and Design Energy Input Fraction at 0.3

$\begin{array}{lll}5.556 & 32.222 & 113.89\end{array}$

$0.8531 \quad 0.3120$

!Capacity and Design Energy Input Fraction at 0.3

$\begin{array}{lll}5.556 & 32.222 & 115.00\end{array}$

$0.8735 \quad 0.3120$

!Capacity and Design Energy Input Fraction at 0.3

$5.556 \quad 32.222 \quad 116.11$

$1.0102 \quad 0.2940$

!Capacity and Design Energy Input Fraction at 0.3

$\begin{array}{lll}6.111 & 26.667 & 108.89\end{array}$

$1.0592 \quad 0.2940$

!Capacity and Design Energy Input Fraction at 0.3

$\begin{array}{lll}6.111 & 26.667 & 111.67\end{array}$

$1.1061 \quad 0.2940$

!Capacity and Design Energy Input Fraction at 0.3

$\begin{array}{lll}6.111 & 26.667 & 113.89\end{array}$

$1.1286 \quad 0.2940$

!Capacity and Design Energy Input Fraction at 0.3

$\begin{array}{lll}6.111 & 26.667 & 115.00\end{array}$

$1.1490 \quad 0.2940$

!Capacity and Design Energy Input Fraction at 0.3

$\begin{array}{lll}6.111 & 26.667 & 116.11\end{array}$

$0.8837 \quad 0.3030$

!Capacity and Design Energy Input Fraction at 0.3

$\begin{array}{lll}6.111 & 29.444 & 108.89\end{array}$

$0.9327 \quad 0.3030$

!Capacity and Design Energy Input Fraction at 0.3

$\begin{array}{lll}6.111 & 29.444 & 111.67\end{array}$

$0.9776 \quad 0.3030$

!Capacity and Design Energy Input Fraction at 0.3

$\begin{array}{lll}6.111 & 29.444 & 113.89\end{array}$

$1.0000 \quad 0.3030$

!Capacity and Design Energy Input Fraction at 0.3

$\begin{array}{lll}6.111 & 29.444 & 115.00\end{array}$

$1.0224 \quad 0.3030$

!Capacity and Design Energy Input Fraction at 0.3

$\begin{array}{lll}6.111 & 29.444 & 116.11\end{array}$

$0.7571 \quad 0.3120$

!Capacity and Design Energy Input Fraction at 0.3

$\begin{array}{lll}6.111 & 32.222 & 108.89\end{array}$ 


\section{Appendix C: Chiller performance data}

$0.8061 \quad 0.3120$

!Capacity and Design Energy Input Fraction at 0.3

$\begin{array}{lll}6.111 & 32.222 & 111.67\end{array}$

$0.8531 \quad 0.3120$

!Capacity and Design Energy Input Fraction at 0.3

$\begin{array}{lll}6.111 & 32.222 & 113.89\end{array}$

$0.8735 \quad 0.3120$

!Capacity and Design Energy Input Fraction at 0.3

$\begin{array}{lll}6.111 & 32.222 & 115.00\end{array}$

$0.8959 \quad 0.3120$

!Capacity and Design Energy Input Fraction at 0.3

$\begin{array}{lll}6.111 & 32.222 & 116.11\end{array}$

$1.0306 \quad 0.2940$

!Capacity and Design Energy Input Fraction at 0.3

$6.667 \quad 26.667 \quad 108.89$

$1.0816 \quad 0.2940$

!Capacity and Design Energy Input Fraction at 0.3

$6.667 \quad 26.667 \quad 111.67$

$1.1286 \quad 0.2940$

!Capacity and Design Energy Input Fraction at 0.3

$6.667 \quad 26.667 \quad 113.89$

$1.1510 \quad 0.2940$

!Capacity and Design Energy Input Fraction at 0.3

$\begin{array}{lll}6.667 & 26.667 & 115.00\end{array}$

1.17140 .2940

!Capacity and Design Energy Input Fraction at 0.3

$6.667 \quad 26.667 \quad 116.11$

$0.9041 \quad 0.3000$

!Capacity and Design Energy Input Fraction at 0.3

$\begin{array}{lll}6.667 & 29.444 & 108.89\end{array}$

$0.9531 \quad 0.3000$

!Capacity and Design Energy Input Fraction at 0.3

$\begin{array}{lll}6.667 & 29.444 & 111.67\end{array}$

$1.0000 \quad 0.3000$

!Capacity and Design Energy Input Fraction at 0.3

$6.667 \quad 29.444 \quad 113.89$

1.02240 .3000

!Capacity and Design Energy Input Fraction at 0.3

$\begin{array}{lll}6.667 & 29.444 & 115.00\end{array}$

$1.0449 \quad 0.3000$

!Capacity and Design Energy Input Fraction at 0.3

$\begin{array}{lll}6.667 & 29.444 & 116.11\end{array}$

$0.7776 \quad 0.3090$

!Capacity and Design Energy Input Fraction at 0.3

$\begin{array}{lll}6.667 & 32.222 \quad 108.89\end{array}$ 


\section{Appendix C: Chiller performance data}

$0.8265 \quad 0.3090$

!Capacity and Design Energy Input Fraction at 0.3 $\begin{array}{lll}6.667 & 32.222 & 111.67\end{array}$

$0.8735 \quad 0.3090$

!Capacity and Design Energy Input Fraction at 0.3

$\begin{array}{lll}6.667 & 32.222 & 113.89\end{array}$

$0.8959 \quad 0.3090$

!Capacity and Design Energy Input Fraction at 0.3

$\begin{array}{lll}6.667 & 32.222 & 115.00\end{array}$

$0.9163 \quad 0.3090$

!Capacity and Design Energy Input Fraction at 0.3

$6.667 \quad 32.222 \quad 116.11$

$\begin{array}{ll}1.0531 & 0.2910\end{array}$

!Capacity and Design Energy Input Fraction at 0.3

$\begin{array}{lll}7.222 & 26.667 & 108.89\end{array}$

$\begin{array}{ll}1.1041 & 0.2910\end{array}$

!Capacity and Design Energy Input Fraction at 0.3

$\begin{array}{lll}7.222 & 26.667 & 111.67\end{array}$

$\begin{array}{ll}1.1510 & 0.2910\end{array}$

!Capacity and Design Energy Input Fraction at 0.3

$\begin{array}{lll}7.222 & 26.667 & 113.89\end{array}$

$1.1735 \quad 0.2910$

!Capacity and Design Energy Input Fraction at 0.3

$\begin{array}{lll}7.222 & 26.667 & 115.00\end{array}$

$1.1959 \quad 0.2910$

!Capacity and Design Energy Input Fraction at 0.3

$\begin{array}{lll}7.222 & 26.667 & 116.11\end{array}$

$0.9245 \quad 0.2970$

!Capacity and Design Energy Input Fraction at 0.3

$\begin{array}{lll}7.222 & 29.444 & 108.89\end{array}$

$0.9755 \quad 0.2970$

!Capacity and Design Energy Input Fraction at 0.3

$\begin{array}{lll}7.222 & 29.444 & 111.67\end{array}$

1.02240 .2970

!Capacity and Design Energy Input Fraction at 0.3

$\begin{array}{lll}7.222 & 29.444 & 113.89\end{array}$

$1.0449 \quad 0.2970$

!Capacity and Design Energy Input Fraction at 0.3

$\begin{array}{lll}7.222 & 29.444 & 115.00\end{array}$

$1.0673 \quad 0.2970$

!Capacity and Design Energy Input Fraction at 0.3

$\begin{array}{lll}7.222 & 29.444 & 116.11\end{array}$

$0.7980 \quad 0.3060$

!Capacity and Design Energy Input Fraction at 0.3

$\begin{array}{lll}7.222 & 32.222 & 108.89\end{array}$ 


\section{Appendix C: Chiller performance data}

$0.8469 \quad 0.3060$

!Capacity and Design Energy Input Fraction at 0.3

7.222

$32.222 \quad 111.67$

0.8939

0.3060

!Capacity and Design Energy Input Fraction at

0.3

7.222

$32.222 \quad 113.89$

0.9163

0.3060

!Capacity and Design Energy Input Fraction at

0.3

7.222

$32.222 \quad 115.00$

0.9388

0.3060

!Capacity and Design Energy Input Fraction at

0.3

7.222

$32.222 \quad 116.11$

1.0755

0.2880

!Capacity and Design Energy Input Fraction at

0.3

$\begin{array}{lll}7.778 & 26.667 & 108.89\end{array}$

$\begin{array}{ll}1.1265 & 0.2880\end{array}$

!Capacity and Design Energy Input Fraction at

7.778

$26.667 \quad 111.67$

1.1755

0.2880

!Capacity and Design Energy Input Fraction at $\begin{array}{lll}7.778 & 26.667 & 113.89\end{array}$

$\begin{array}{ll}1.1980 & 0.2880\end{array}$

!Capacity and Design Energy Input Fraction at

7.778

$26.667 \quad 115.00$

1.2184

0.2880

!Capacity and Design Energy Input Fraction at

7.778

$26.667 \quad 116.11$

0.9469

0.2940

!Capacity and Design Energy Input Fraction at

7.778

$29.444 \quad 108.89$

0.9980

0.2940

!Capacity and Design Energy Input Fraction at

7.778

$29.444 \quad 111.67$

1.0449

0.2940

!Capacity and Design Energy Input Fraction at

7.778

$29.444 \quad 113.89$

1.0673

0.2940

!Capacity and Design Energy Input Fraction at

7.778

$29.444 \quad 115.00$

1.0898

0.2940

!Capacity and Design Energy Input Fraction at

0.3

7.778 $29.444 \quad 116.11$

0.8184

0.3030

!Capacity and Design Energy Input Fraction at

0.3

7.778

$32.222 \quad 108.89$

0.3

0.3

0.3

0.3

0.3

0.3

0.3

0.3 


\section{Appendix C: Chiller performance data}

$0.8694 \quad 0.3030$

!Capacity and Design Energy Input Fraction at 0.3

$\begin{array}{lll}7.778 & 32.222 & 111.67\end{array}$

$0.9163 \quad 0.3030$

!Capacity and Design Energy Input Fraction at 0.3

$\begin{array}{lll}7.778 & 32.222 & 113.89\end{array}$

$0.9388 \quad 0.3030$

!Capacity and Design Energy Input Fraction at 0.3

$\begin{array}{lll}7.778 & 32.222 & 115.00\end{array}$

$0.9592 \quad 0.3030$

!Capacity and Design Energy Input Fraction at 0.3

$\begin{array}{lll}7.778 & 32.222 & 116.11\end{array}$

$1.1204 \quad 0.2850$

!Capacity and Design Energy Input Fraction at 0.3

$8.889 \quad 26.667 \quad 108.89$

$\begin{array}{ll}1.1735 & 0.2850\end{array}$

!Capacity and Design Energy Input Fraction at 0.3

$8.889 \quad 26.667 \quad 111.67$

$1.2204 \quad 0.2850$

!Capacity and Design Energy Input Fraction at 0.3

$\begin{array}{lll}8.889 & 26.667 & 113.89\end{array}$

$1.2449 \quad 0.2850$

!Capacity and Design Energy Input Fraction at 0.3

$8.889 \quad 26.667 \quad 115.00$

$\begin{array}{ll}1.2673 & 0.2850\end{array}$

!Capacity and Design Energy Input Fraction at 0.3

$8.889 \quad 26.667 \quad 116.11$

$0.9898 \quad 0.2910$

!Capacity and Design Energy Input Fraction at 0.3

$\begin{array}{lll}8.889 & 29.444 & 108.89\end{array}$

$1.0408 \quad 0.2910$

!Capacity and Design Energy Input Fraction at 0.3

$\begin{array}{lll}8.889 & 29.444 & 111.67\end{array}$

$1.0898 \quad 0.2910$

!Capacity and Design Energy Input Fraction at 0.3

$8.889 \quad 29.444 \quad 113.89$

$1.1122 \quad 0.2910$

!Capacity and Design Energy Input Fraction at 0.3

$\begin{array}{lll}8.889 & 29.444 & 115.00\end{array}$

$1.1347 \quad 0.2910$

!Capacity and Design Energy Input Fraction at 0.3

$8.889 \quad 29.444 \quad 116.11$

$0.8592 \quad 0.3000$

!Capacity and Design Energy Input Fraction at 0.3

$\begin{array}{lll}8.889 & 32.222 & 108.89\end{array}$ 


\section{Appendix C: Chiller performance data}

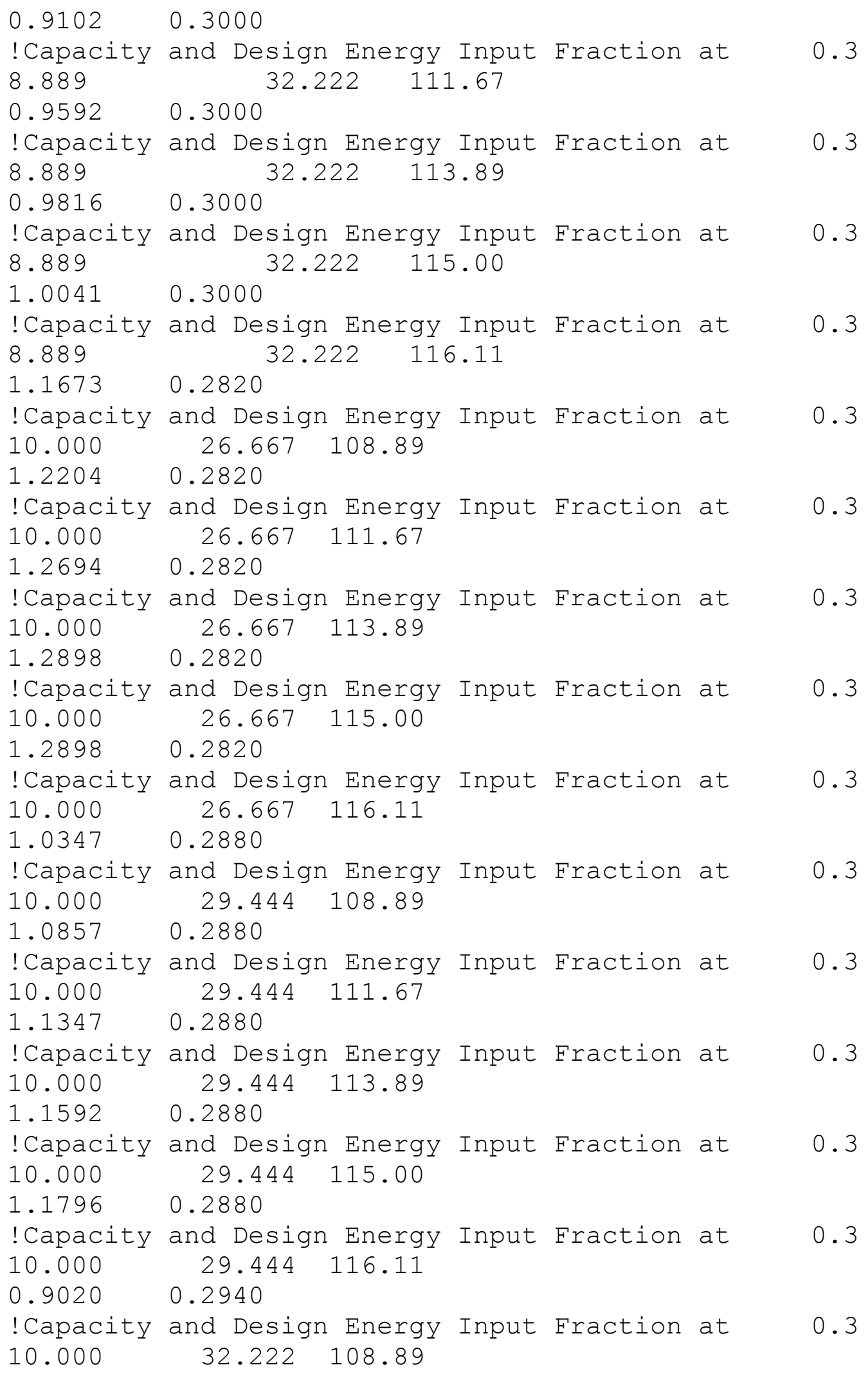




\section{Appendix C: Chiller performance data}

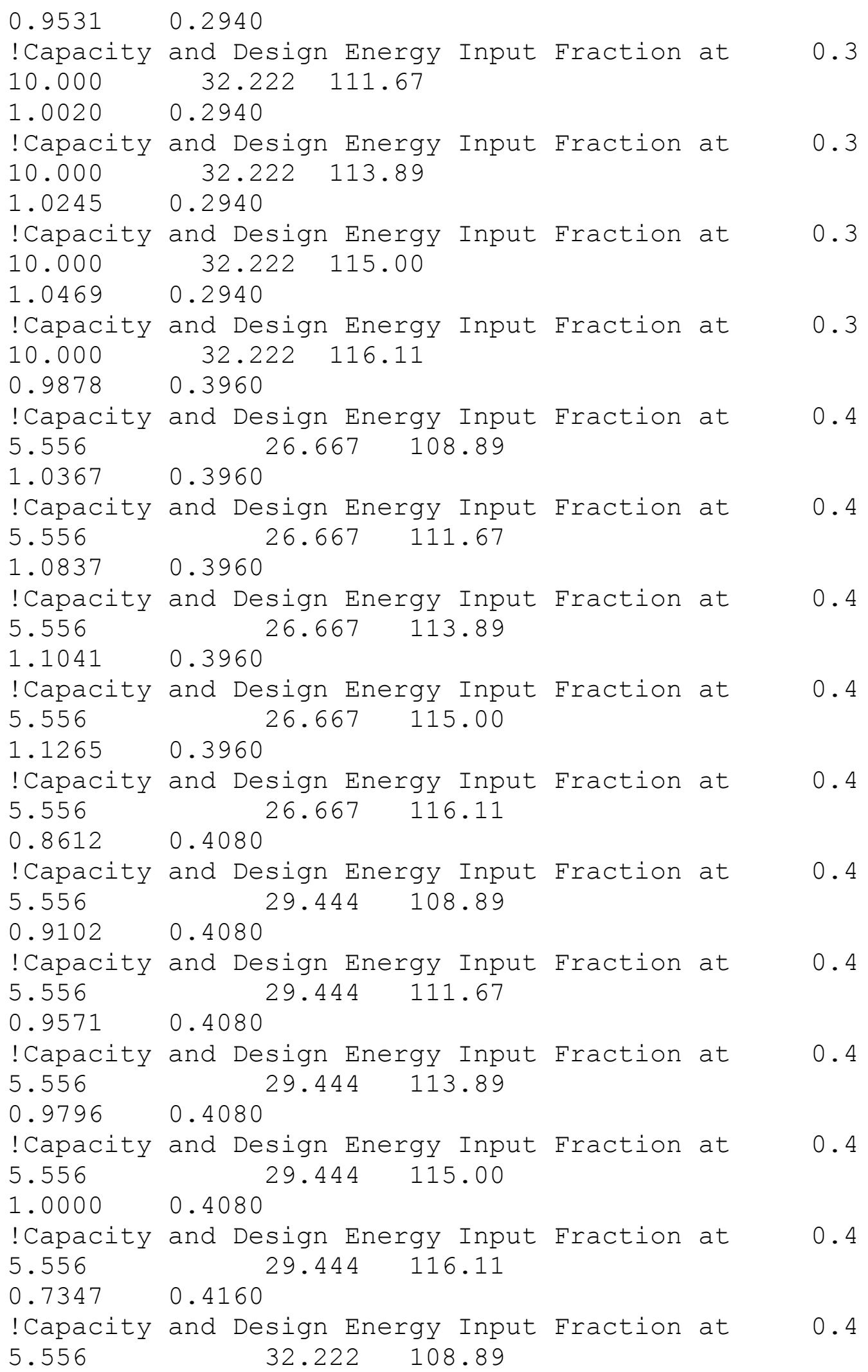




\section{Appendix C: Chiller performance data}

$0.7857 \quad 0.4160$

!Capacity and Design Energy Input Fraction at 0.4

$\begin{array}{lll}5.556 & 32.222 & 111.67\end{array}$

$0.8327 \quad 0.4160$

!Capacity and Design Energy Input Fraction at 0.4

$\begin{array}{lll}5.556 & 32.222 & 113.89\end{array}$

$0.8531 \quad 0.4160$

!Capacity and Design Energy Input Fraction at 0.4

$\begin{array}{lll}5.556 & 32.222 & 115.00\end{array}$

$0.8735 \quad 0.4160$

!Capacity and Design Energy Input Fraction at 0.4

$\begin{array}{lll}5.556 & 32.222 & 116.11\end{array}$

$1.0102 \quad 0.3920$

!Capacity and Design Energy Input Fraction at 0.4

$\begin{array}{lll}6.111 & 26.667 & 108.89\end{array}$

$\begin{array}{ll}1.0592 & 0.3920\end{array}$

!Capacity and Design Energy Input Fraction at 0.4

$\begin{array}{lll}6.111 & 26.667 & 111.67\end{array}$

$\begin{array}{ll}1.1061 & 0.3920\end{array}$

!Capacity and Design Energy Input Fraction at 0.4

$\begin{array}{lll}6.111 & 26.667 & 113.89\end{array}$

$1.1286 \quad 0.3920$

!Capacity and Design Energy Input Fraction at 0.4

$\begin{array}{lll}6.111 & 26.667 & 115.00\end{array}$

$1.1490 \quad 0.3920$

!Capacity and Design Energy Input Fraction at 0.4

$\begin{array}{lll}6.111 & 26.667 & 116.11\end{array}$

$0.8837 \quad 0.4040$

!Capacity and Design Energy Input Fraction at 0.4

$\begin{array}{lll}6.111 \quad 29.444 & 108.89\end{array}$

$0.9327 \quad 0.4040$

!Capacity and Design Energy Input Fraction at 0.4

$\begin{array}{lll}6.111 & 29.444 & 111.67\end{array}$

$0.9776 \quad 0.4040$

!Capacity and Design Energy Input Fraction at 0.4

$\begin{array}{lll}6.111 \quad 29.444 & 113.89\end{array}$

$1.0000 \quad 0.4040$

!Capacity and Design Energy Input Fraction at 0.4

$\begin{array}{lll}6.111 & 29.444 & 115.00\end{array}$

1.02240 .4040

!Capacity and Design Energy Input Fraction at 0.4

$6.111 \quad 29.444 \quad 116.11$

$0.7571 \quad 0.4160$

!Capacity and Design Energy Input Fraction at 0.4

$\begin{array}{lll}6.111 & 32.222 & 108.89\end{array}$ 


\section{Appendix C: Chiller performance data}

$0.8061 \quad 0.4160$

!Capacity and Design Energy Input Fraction at 0.4

$\begin{array}{lll}6.111 & 32.222 & 111.67\end{array}$

$0.8531 \quad 0.4160$

!Capacity and Design Energy Input Fraction at 0.4

$\begin{array}{lll}6.111 & 32.222 & 113.89\end{array}$

$0.8735 \quad 0.4160$

!Capacity and Design Energy Input Fraction at 0.4

$\begin{array}{lll}6.111 & 32.222 & 115.00\end{array}$

0.89590 .4160

!Capacity and Design Energy Input Fraction at 0.4

$\begin{array}{lll}6.111 & 32.222 & 116.11\end{array}$

$\begin{array}{ll}1.0306 & 0.3920\end{array}$

!Capacity and Design Energy Input Fraction at 0.4

$\begin{array}{lll}6.667 & 26.667 & 108.89\end{array}$

$\begin{array}{ll}1.0816 & 0.3920\end{array}$

!Capacity and Design Energy Input Fraction at 0.4

$\begin{array}{lll}6.667 & 26.667 & 111.67\end{array}$

$\begin{array}{ll}1.1286 & 0.3920\end{array}$

!Capacity and Design Energy Input Fraction at 0.4

$\begin{array}{lll}6.667 & 26.667 & 113.89\end{array}$

$\begin{array}{ll}1.1510 & 0.3920\end{array}$

!Capacity and Design Energy Input Fraction at 0.4

$\begin{array}{lll}6.667 & 26.667 & 115.00\end{array}$

$1.1714 \quad 0.3920$

!Capacity and Design Energy Input Fraction at 0.4

$6.667 \quad 26.667 \quad 116.11$

$0.9041 \quad 0.4000$

!Capacity and Design Energy Input Fraction at 0.4

$\begin{array}{lll}6.667 & 29.444 & 108.89\end{array}$

$0.9531 \quad 0.4000$

!Capacity and Design Energy Input Fraction at 0.4

$6.667 \quad 29.444 \quad 111.67$

$1.0000 \quad 0.4000$

!Capacity and Design Energy Input Fraction at 0.4

$6.667 \quad 29.444 \quad 113.89$

1.02240 .4000

!Capacity and Design Energy Input Fraction at 0.4

$6.667 \quad 29.444 \quad 115.00$

$1.0449 \quad 0.4000$

!Capacity and Design Energy Input Fraction at 0.4

$6.667 \quad 29.444 \quad 116.11$

$0.7776 \quad 0.4120$

!Capacity and Design Energy Input Fraction at 0.4
6.667
$32.222 \quad 108.89$ 


\section{Appendix C: Chiller performance data}

\begin{tabular}{|c|c|c|c|c|}
\hline \multirow{3}{*}{$\begin{array}{l}0.8265 \\
\text { ! Capacity } \\
6.667 \\
0.8735\end{array}$} & \multicolumn{4}{|c|}{0.4120} \\
\hline & $\begin{array}{l}\text { and Design Energy Input } \\
32.222 \quad 111.67\end{array}$ & Fraction a & & 0.4 \\
\hline & 0.4120 & & & \\
\hline !Capacity & and Design Energy Input & Fraction a & at & 0.4 \\
\hline $\begin{array}{l}.667 \\
.8959\end{array}$ & $0.4120^{32.222}$ & & & \\
\hline Capacity & and Design Energy Input & Fraction a & at & 0.4 \\
\hline 667 & $32.222 \quad 115.00$ & & & \\
\hline 9163 & 0.4120 & & & \\
\hline $\begin{array}{l}\text { Capacity } \\
.667\end{array}$ & $\begin{array}{c}\text { and Design Energy Input } \\
32.222116 .11\end{array}$ & Fraction a & at & 0.4 \\
\hline 0531 & 0.3880 & & & \\
\hline $\begin{array}{l}\text { !Capacity } \\
7.222\end{array}$ & $\begin{array}{c}\text { and Design Energy Input } \\
26.667 \quad 108.89\end{array}$ & Fraction a & at & 0.4 \\
\hline .1041 & 0.3880 & & & \\
\hline $\begin{array}{l}\text { !Capacity } \\
7.222\end{array}$ & $\begin{array}{c}\text { and Design Energy Input } \\
26.667 \quad 111.67\end{array}$ & Fraction a & at & 0.4 \\
\hline .1510 & 0.3880 & & & \\
\hline ! Capacity & and Design Energy Input & Fraction a & at & 0.4 \\
\hline .222 & $26.667 \quad 113.89$ & & & \\
\hline .1735 & 0.3880 & & & \\
\hline !Capacity & and Design Energy Input & Fraction a & at & 0.4 \\
\hline $\begin{array}{l}.222 \\
.1959\end{array}$ & $0.3880^{26.667} 11$ & & & \\
\hline $\begin{array}{l}\text { !Capacity } \\
7.222\end{array}$ & $\begin{array}{c}\text { and Design Energy Input } \\
26.667 \quad 116.11\end{array}$ & Fraction a & at & 0.4 \\
\hline 0.9245 & 0.3960 & & & \\
\hline $\begin{array}{l}\text { ! Capacity } \\
7.222 \\
0.9755\end{array}$ & $\begin{array}{l}\text { and Design Energy Input } \\
29.444 \quad 108.89 \\
0.3960\end{array}$ & Fraction a & at & 0.4 \\
\hline $\begin{array}{l}\text { ! Capacity } \\
7.222\end{array}$ & $\begin{array}{c}\text { and Design Energy Input } \\
29.444 \quad 111.67\end{array}$ & Fraction a & at & 0.4 \\
\hline 1.0224 & 0.3960 & & & \\
\hline $\begin{array}{l}\text { !Capacity } \\
7.222\end{array}$ & $\begin{array}{c}\text { and Design Energy Input } \\
29.444 \quad 113.89\end{array}$ & Fraction a & at & 0.4 \\
\hline .0449 & 0.3960 & & & \\
\hline ! Capacity & and Design Energy Input & Fraction & at & 0.4 \\
\hline 7.222 & & & & \\
\hline 1.0673 & 0.3960 & & & \\
\hline $\begin{array}{l}\text { ! Capacity } \\
7.222 \\
0.7980\end{array}$ & $\begin{array}{l}\text { and Design Energy Input } \\
29.444 \quad 116.11 \\
0.4080\end{array}$ & Fraction a & at & 0.4 \\
\hline $\begin{array}{l}\text { Capacity } \\
.222\end{array}$ & $\begin{array}{l}\text { and Design Energy Input } \\
32.222108 .89\end{array}$ & Fraction a & $a$ & \\
\hline
\end{tabular}




\section{Appendix C: Chiller performance data}

$0.8469 \quad 0.4080$

!Capacity and Design Energy Input Fraction at 0.4

7.222

$32.222 \quad 111.67$

0.8939

0.4080

!Capacity and Design Energy Input Fraction at

0.4

7.222

$32.222 \quad 113.89$

0.9163

0.4080

!Capacity and Design Energy Input Fraction at

0.4

7.222

$32.222 \quad 115.00$

0.9388

0.4080

!Capacity and Design Energy Input Fraction at

7.222

$32.222 \quad 116.11$

1.0755

0.3840

!Capacity and Design Energy Input Fraction at $\begin{array}{lll}7.778 & 26.667 & 108.89\end{array}$

$1.1265 \quad 0.3840$

!Capacity and Design Energy Input Fraction at

7.778

$26.667 \quad 111.67$

1.1755

0.3840

!Capacity and Design Energy Input Fraction at $\begin{array}{lll}7.778 & 26.667 & 113.89\end{array}$

$\begin{array}{ll}1.1980 & 0.3840\end{array}$

!Capacity and Design Energy Input Fraction at

7.778

$26.667 \quad 115.00$

1.2184

0.3840

!Capacity and Design Energy Input Fraction at

7.778

$26.667 \quad 116.11$

0.9469

0.3920

!Capacity and Design Energy Input Fraction at

7.778

$29.444 \quad 108.89$

0.9980

0.3920

!Capacity and Design Energy Input Fraction at

7.778

$29.444 \quad 111.67$

1.0449

0.3920

!Capacity and Design Energy Input Fraction at

7.778

$29.444 \quad 113.89$

1.0673

0.3920

!Capacity and Design Energy Input Fraction at

7.778

$29.444 \quad 115.00$

1.0898

0.3920

!Capacity and Design Energy Input Fraction at

0.4

7.778

$29.444 \quad 116.11$

0.8184

0.4040

!Capacity and Design Energy Input Fraction at 7.778

$32.222 \quad 108.89$

0.4

0.4

0.4

0.4

0.4

0.4

0.4

0.4

0.4

0.4

0.4 


\section{Appendix C: Chiller performance data}

$0.8694 \quad 0.4040$

!Capacity and Design Energy Input Fraction at 0.4

$\begin{array}{lll}7.778 & 32.222 & 111.67\end{array}$

$0.9163 \quad 0.4040$

!Capacity and Design Energy Input Fraction at 0.4

$\begin{array}{lll}7.778 & 32.222 & 113.89\end{array}$

$0.9388 \quad 0.4040$

!Capacity and Design Energy Input Fraction at 0.4

$\begin{array}{lll}7.778 & 32.222 & 115.00\end{array}$

$0.9592 \quad 0.4040$

!Capacity and Design Energy Input Fraction at 0.4

$\begin{array}{lll}7.778 & 32.222 & 116.11\end{array}$

$1.1204 \quad 0.3800$

!Capacity and Design Energy Input Fraction at 0.4

$8.889 \quad 26.667 \quad 108.89$

$\begin{array}{ll}1.1735 & 0.3800\end{array}$

!Capacity and Design Energy Input Fraction at 0.4

$\begin{array}{lll}8.889 & 26.667 & 111.67\end{array}$

$1.2204 \quad 0.3800$

!Capacity and Design Energy Input Fraction at 0.4

$\begin{array}{lll}8.889 & 26.667 & 113.89\end{array}$

$1.2449 \quad 0.3800$

!Capacity and Design Energy Input Fraction at 0.4

$\begin{array}{lll}8.889 & 26.667 & 115.00\end{array}$

$1.2673 \quad 0.3800$

!Capacity and Design Energy Input Fraction at 0.4

$8.889 \quad 26.667 \quad 116.11$

$0.9898 \quad 0.3880$

!Capacity and Design Energy Input Fraction at 0.4

$\begin{array}{lll}8.889 & 29.444 & 108.89\end{array}$

$1.0408 \quad 0.3880$

!Capacity and Design Energy Input Fraction at 0.4

$\begin{array}{lll}8.889 & 29.444 & 111.67\end{array}$

$1.0898 \quad 0.3880$

!Capacity and Design Energy Input Fraction at 0.4

$\begin{array}{lll}8.889 & 29.444 & 113.89\end{array}$

$1.1122 \quad 0.3880$

!Capacity and Design Energy Input Fraction at 0.4

$\begin{array}{lll}8.889 & 29.444 & 115.00\end{array}$

$1.1347 \quad 0.3880$

!Capacity and Design Energy Input Fraction at 0.4

$8.889 \quad 29.444 \quad 116.11$

$0.8592 \quad 0.4000$

!Capacity and Design Energy Input Fraction at 0.4

$\begin{array}{lll}8.889 & 32.222 & 108.89\end{array}$ 


\section{Appendix C: Chiller performance data}

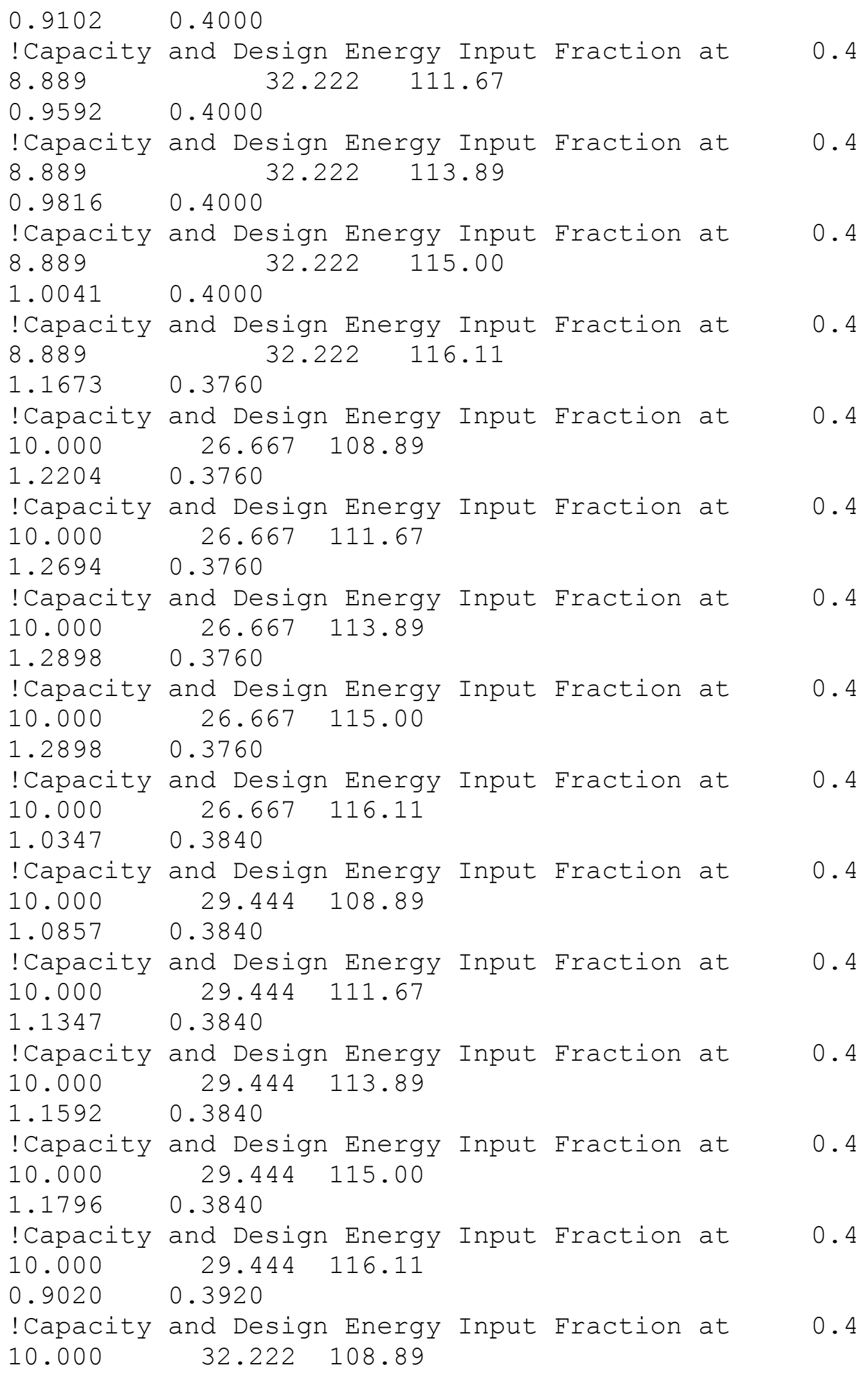




\section{Appendix C: Chiller performance data}

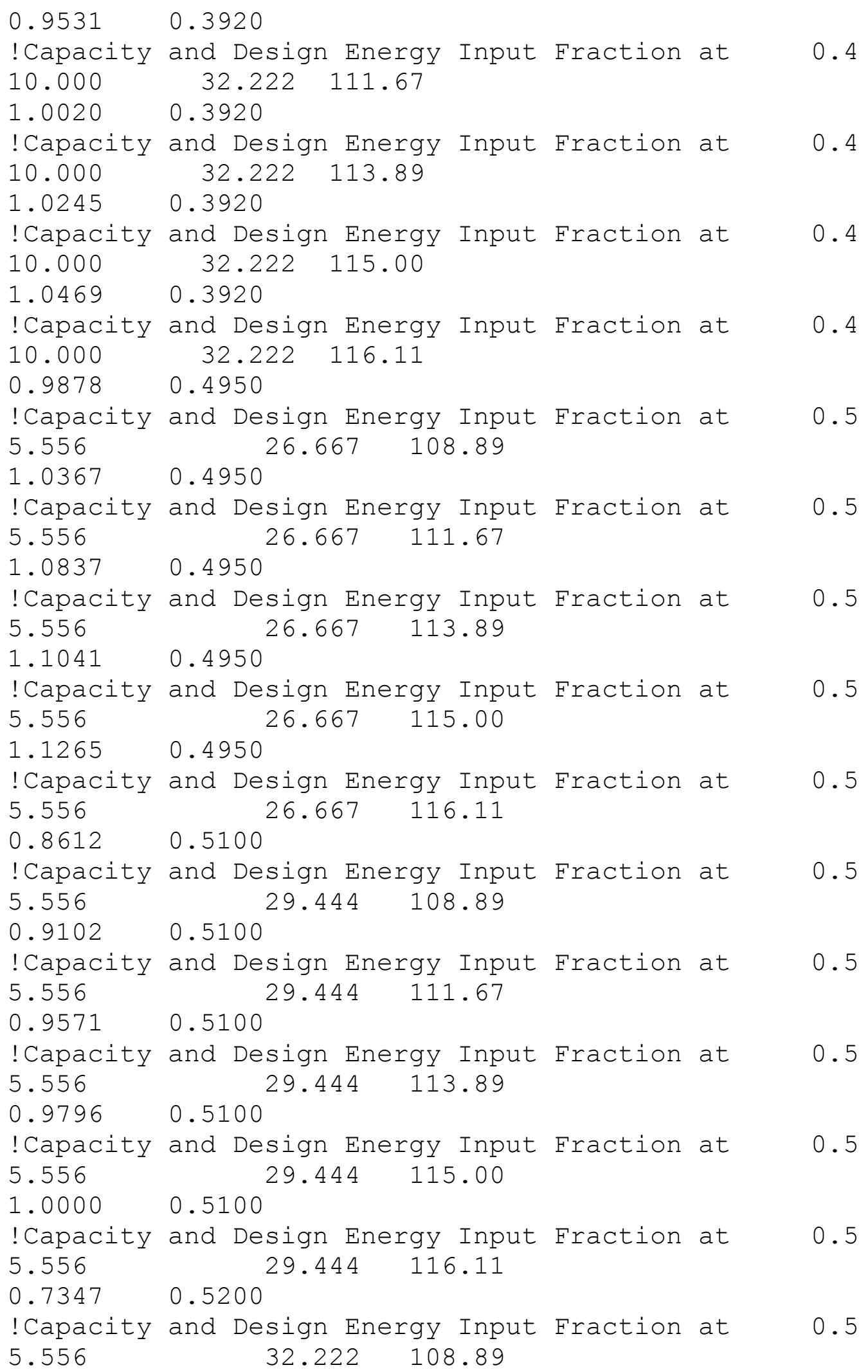




\section{Appendix C: Chiller performance data}

$0.7857 \quad 0.5200$

!Capacity and Design Energy Input Fraction at 0.5

$\begin{array}{lll}5.556 & 32.222 & 111.67\end{array}$

$0.8327 \quad 0.5200$

!Capacity and Design Energy Input Fraction at 0.5

$\begin{array}{lll}5.556 & 32.222 & 113.89\end{array}$

$0.8531 \quad 0.5200$

!Capacity and Design Energy Input Fraction at 0.5

$\begin{array}{lll}5.556 & 32.222 & 115.00\end{array}$

$0.8735 \quad 0.5200$

!Capacity and Design Energy Input Fraction at 0.5

$5.556 \quad 32.222 \quad 116.11$

$1.0102 \quad 0.4900$

!Capacity and Design Energy Input Fraction at 0.5

$\begin{array}{lll}6.111 & 26.667 & 108.89\end{array}$

$1.0592 \quad 0.4900$

!Capacity and Design Energy Input Fraction at 0.5

$\begin{array}{lll}6.111 & 26.667 & 111.67\end{array}$

$1.1061 \quad 0.4900$

!Capacity and Design Energy Input Fraction at 0.5

$\begin{array}{lll}6.111 & 26.667 & 113.89\end{array}$

$\begin{array}{ll}1.1286 & 0.4900\end{array}$

!Capacity and Design Energy Input Fraction at 0.5

$\begin{array}{lll}6.111 & 26.667 & 115.00\end{array}$

$1.1490 \quad 0.4900$

!Capacity and Design Energy Input Fraction at 0.5

$\begin{array}{lll}6.111 & 26.667 & 116.11\end{array}$

$0.8837 \quad 0.5050$

!Capacity and Design Energy Input Fraction at 0.5

$\begin{array}{lll}6.111 & 29.444 & 108.89\end{array}$

$0.9327 \quad 0.5050$

!Capacity and Design Energy Input Fraction at 0.5

$\begin{array}{lll}6.111 & 29.444 & 111.67\end{array}$

$0.9776 \quad 0.5050$

!Capacity and Design Energy Input Fraction at 0.5

$\begin{array}{lll}6.111 & 29.444 & 113.89\end{array}$

$1.0000 \quad 0.5050$

!Capacity and Design Energy Input Fraction at 0.5

$\begin{array}{lll}6.111 & 29.444 & 115.00\end{array}$

$1.0224 \quad 0.5050$

!Capacity and Design Energy Input Fraction at 0.5

$\begin{array}{lll}6.111 & 29.444 & 116.11\end{array}$

$0.7571 \quad 0.5200$

!Capacity and Design Energy Input Fraction at 0.5
6.111
$32.222 \quad 108.89$ 


\section{Appendix C: Chiller performance data}

$0.8061 \quad 0.5200$

!Capacity and Design Energy Input Fraction at 0.5

$\begin{array}{lll}6.111 & 32.222 & 111.67\end{array}$

$0.8531 \quad 0.5200$

!Capacity and Design Energy Input Fraction at 0.5

$\begin{array}{lll}6.111 & 32.222 & 113.89\end{array}$

$0.8735 \quad 0.5200$

!Capacity and Design Energy Input Fraction at 0.5

$\begin{array}{lll}6.111 & 32.222 & 115.00\end{array}$

$0.8959 \quad 0.5200$

!Capacity and Design Energy Input Fraction at 0.5

$\begin{array}{lll}6.111 & 32.222 & 116.11\end{array}$

$1.0306 \quad 0.4900$

!Capacity and Design Energy Input Fraction at 0.5

$6.667 \quad 26.667 \quad 108.89$

$1.0816 \quad 0.4900$

!Capacity and Design Energy Input Fraction at 0.5

$\begin{array}{lll}6.667 & 26.667 & 111.67\end{array}$

$1.1286 \quad 0.4900$

!Capacity and Design Energy Input Fraction at 0.5

$6.667 \quad 26.667 \quad 113.89$

$\begin{array}{ll}1.1510 & 0.4900\end{array}$

!Capacity and Design Energy Input Fraction at 0.5

$\begin{array}{lll}6.667 & 26.667 & 115.00\end{array}$

$1.1714 \quad 0.4900$

!Capacity and Design Energy Input Fraction at 0.5

$6.667 \quad 26.667 \quad 116.11$

$0.9041 \quad 0.5000$

!Capacity and Design Energy Input Fraction at 0.5

$6.667 \quad 29.444 \quad 108.89$

$0.9531 \quad 0.5000$

!Capacity and Design Energy Input Fraction at 0.5

$6.667 \quad 29.444 \quad 111.67$

$1.0000 \quad 0.5000$

!Capacity and Design Energy Input Fraction at 0.5

$6.667 \quad 29.444 \quad 113.89$

1.02240 .5000

!Capacity and Design Energy Input Fraction at 0.5

$6.667 \quad 29.444 \quad 115.00$

$1.0449 \quad 0.5000$

!Capacity and Design Energy Input Fraction at 0.5

$\begin{array}{lll}6.667 & 29.444 & 116.11\end{array}$

$0.7776 \quad 0.5150$

!Capacity and Design Energy Input Fraction at 0.5
6.667
$32.222 \quad 108.89$ 


\section{Appendix C: Chiller performance data}

$0.8265 \quad 0.5150$

!Capacity and Design Energy Input Fraction at 0.5 $\begin{array}{lll}6.667 & 32.222 & 111.67\end{array}$

$0.8735 \quad 0.5150$

!Capacity and Design Energy Input Fraction at 0.5

$\begin{array}{lll}6.667 & 32.222 & 113.89\end{array}$

$0.8959 \quad 0.5150$

!Capacity and Design Energy Input Fraction at 0.5

$\begin{array}{lll}6.667 & 32.222 & 115.00\end{array}$

$0.9163 \quad 0.5150$

!Capacity and Design Energy Input Fraction at 0.5

$6.667 \quad 32.222 \quad 116.11$

$1.0531 \quad 0.4850$

!Capacity and Design Energy Input Fraction at 0.5

$\begin{array}{lll}7.222 & 26.667 & 108.89\end{array}$

$1.1041 \quad 0.4850$

!Capacity and Design Energy Input Fraction at 0.5

$\begin{array}{lll}7.222 & 26.667 & 111.67\end{array}$

$1.1510 \quad 0.4850$

!Capacity and Design Energy Input Fraction at 0.5

$\begin{array}{lll}7.222 & 26.667 & 113.89\end{array}$

$1.1735 \quad 0.4850$

!Capacity and Design Energy Input Fraction at 0.5

$\begin{array}{lll}7.222 & 26.667 & 115.00\end{array}$

1.19590 .4850

!Capacity and Design Energy Input Fraction at 0.5

$\begin{array}{lll}7.222 & 26.667 & 116.11\end{array}$

$0.9245 \quad 0.4950$

!Capacity and Design Energy Input Fraction at 0.5

$\begin{array}{lll}7.222 & 29.444 & 108.89\end{array}$

$0.9755 \quad 0.4950$

!Capacity and Design Energy Input Fraction at 0.5

$\begin{array}{lll}7.222 & 29.444 & 111.67\end{array}$

1.02240 .4950

!Capacity and Design Energy Input Fraction at 0.5

$\begin{array}{lll}7.222 & 29.444 & 113.89\end{array}$

$1.0449 \quad 0.4950$

!Capacity and Design Energy Input Fraction at 0.5

$\begin{array}{lll}7.222 & 29.444 & 115.00\end{array}$

$1.0673 \quad 0.4950$

!Capacity and Design Energy Input Fraction at 0.5

$\begin{array}{lll}7.222 & 29.444 & 116.11\end{array}$

$0.7980 \quad 0.5100$

!Capacity and Design Energy Input Fraction at 0.5

$\begin{array}{lll}7.222 & 32.222 & 108.89\end{array}$ 


\section{Appendix C: Chiller performance data}

$0.8469 \quad 0.5100$

!Capacity and Design Energy Input Fraction at 0.5

7.222

$32.222 \quad 111.67$

0.8939

0.5100

!Capacity and Design Energy Input Fraction at

0.5

7.222

$32.222 \quad 113.89$

0.9163

0.5100

!Capacity and Design Energy Input Fraction at

0.5

7.222

$32.222 \quad 115.00$

0.9388

0.5100

!Capacity and Design Energy Input Fraction at

0.5

7.222

$32.222 \quad 116.11$

1.0755

0.4800

!Capacity and Design Energy Input Fraction at

0.5

$\begin{array}{lll}7.778 & 26.667 & 108.89\end{array}$

$\begin{array}{ll}1.1265 & 0.4800\end{array}$

!Capacity and Design Energy Input Fraction at 0.5

7.778

$26.667 \quad 111.67$

1.1755

0.4800

!Capacity and Design Energy Input Fraction at

0.5

7.778 $26.667 \quad 113.89$

1.1980

0.4800

!Capacity and Design Energy Input Fraction at

7.778 $26.667 \quad 115.00$

1.2184

0.4800

!Capacity and Design Energy Input Fraction at

7.778 $26.667 \quad 116.11$

0.9469 0.4900

!Capacity and Design Energy Input Fraction at

7.778 $29.444 \quad 108.89$

0.9980

0.4900

!Capacity and Design Energy Input Fraction at

7.778

$29.444 \quad 111.67$

1.0449

0.4900

!Capacity and Design Energy Input Fraction at

7.778

$29.444 \quad 113.89$

1.0673

0.4900

!Capacity and Design Energy Input Fraction at

7.778

$29.444 \quad 115.00$

1.0898

0.4900

!Capacity and Design Energy Input Fraction at

0.5

7.778 $29.444 \quad 116.11$

0.8184

0.5050

!Capacity and Design Energy Input Fraction at 7.778

$32.222 \quad 108.89$

0.5

0.5

0.5

0.5

0.5

0.5

0.5 


\section{Appendix C: Chiller performance data}

$0.8694 \quad 0.5050$

!Capacity and Design Energy Input Fraction at 0.5

$\begin{array}{lll}7.778 & 32.222 & 111.67\end{array}$

$0.9163 \quad 0.5050$

!Capacity and Design Energy Input Fraction at 0.5

$\begin{array}{lll}7.778 & 32.222 & 113.89\end{array}$

$0.9388 \quad 0.5050$

!Capacity and Design Energy Input Fraction at 0.5

$\begin{array}{lll}7.778 & 32.222 & 115.00\end{array}$

$0.9592 \quad 0.5050$

!Capacity and Design Energy Input Fraction at 0.5

$\begin{array}{lll}7.778 & 32.222 & 116.11\end{array}$

$1.1204 \quad 0.4750$

!Capacity and Design Energy Input Fraction at 0.5

$8.889 \quad 26.667 \quad 108.89$

$1.1735 \quad 0.4750$

!Capacity and Design Energy Input Fraction at 0.5

$\begin{array}{lll}8.889 & 26.667 & 111.67\end{array}$

$1.2204 \quad 0.4750$

!Capacity and Design Energy Input Fraction at 0.5

$\begin{array}{lll}8.889 & 26.667 & 113.89\end{array}$

$1.2449 \quad 0.4750$

!Capacity and Design Energy Input Fraction at 0.5

$8.889 \quad 26.667 \quad 115.00$

$1.2673 \quad 0.4750$

!Capacity and Design Energy Input Fraction at 0.5

$8.889 \quad 26.667 \quad 116.11$

$0.9898 \quad 0.4850$

!Capacity and Design Energy Input Fraction at 0.5

$8.889 \quad 29.444 \quad 108.89$

$1.0408 \quad 0.4850$

!Capacity and Design Energy Input Fraction at 0.5

$\begin{array}{lll}8.889 & 29.444 & 111.67\end{array}$

$1.0898 \quad 0.4850$

!Capacity and Design Energy Input Fraction at 0.5

$8.889 \quad 29.444 \quad 113.89$

$1.1122 \quad 0.4850$

!Capacity and Design Energy Input Fraction at 0.5

$\begin{array}{lll}8.889 & 29.444 & 115.00\end{array}$

$1.1347 \quad 0.4850$

!Capacity and Design Energy Input Fraction at 0.5

$8.889 \quad 29.444 \quad 116.11$

$0.8592 \quad 0.5000$

!Capacity and Design Energy Input Fraction at 0.5
8.889
$32.222 \quad 108.89$ 


\section{Appendix C: Chiller performance data}

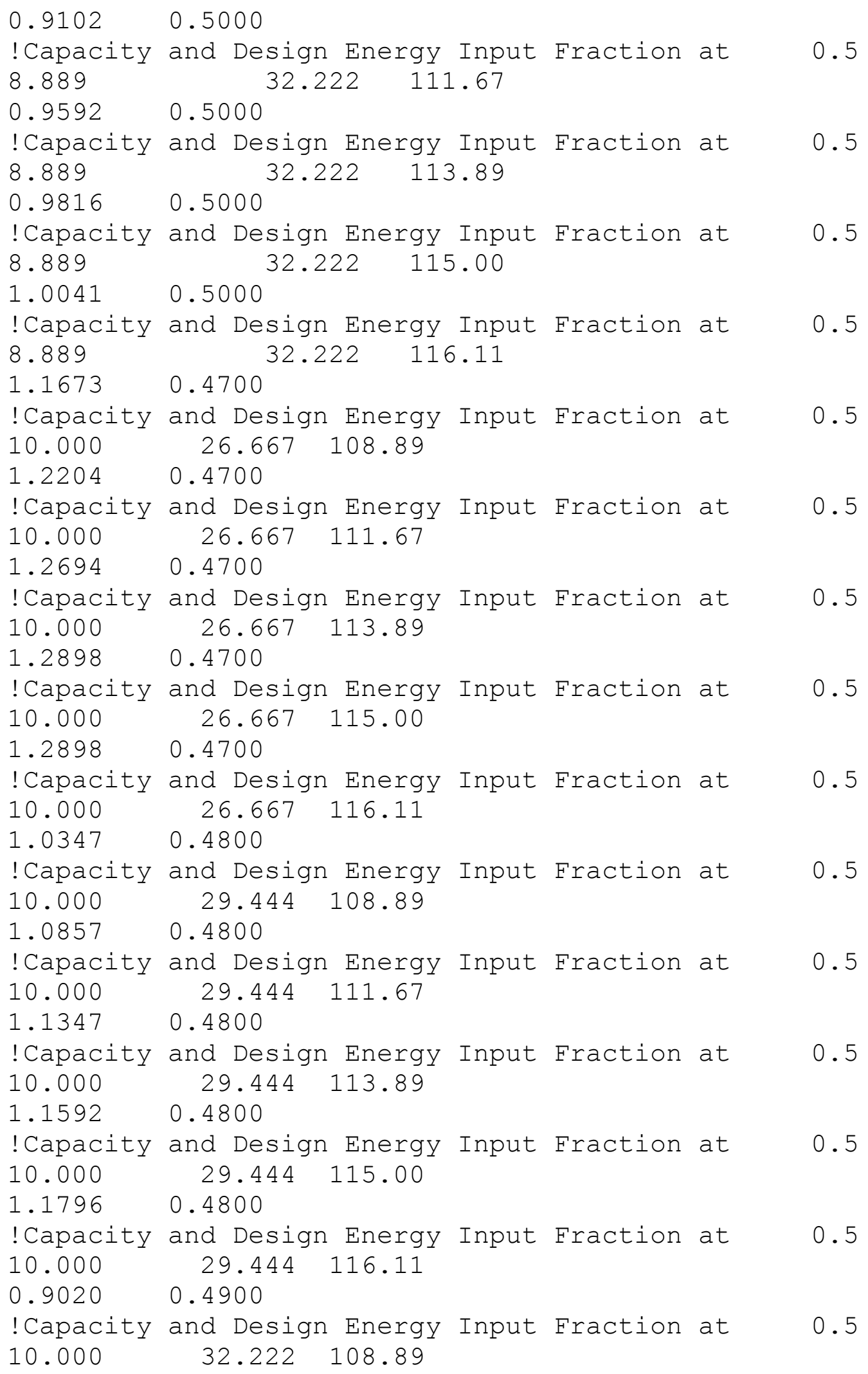




\section{Appendix C: Chiller performance data}

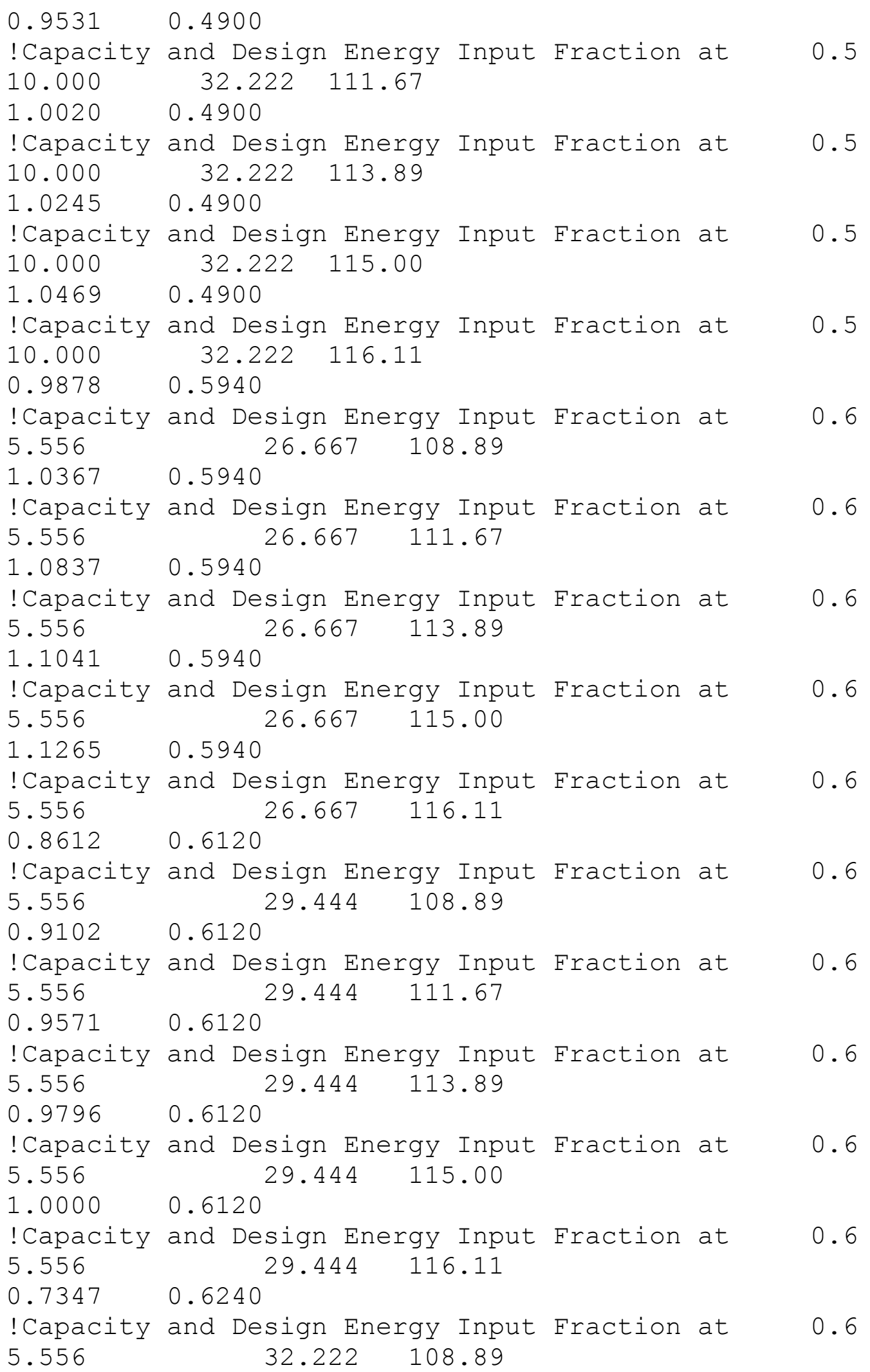




\section{Appendix C: Chiller performance data}

$0.7857 \quad 0.6240$

!Capacity and Design Energy Input Fraction at 0.6

$\begin{array}{lll}5.556 & 32.222 & 111.67\end{array}$

$0.8327 \quad 0.6240$

!Capacity and Design Energy Input Fraction at 0.6

$\begin{array}{lll}5.556 & 32.222 & 113.89\end{array}$

$0.8531 \quad 0.6240$

!Capacity and Design Energy Input Fraction at 0.6

$\begin{array}{lll}5.556 & 32.222 & 115.00\end{array}$

$0.8735 \quad 0.6240$

!Capacity and Design Energy Input Fraction at 0.6

$\begin{array}{lll}5.556 & 32.222 & 116.11\end{array}$

$1.0102 \quad 0.5880$

!Capacity and Design Energy Input Fraction at 0.6

$\begin{array}{lll}6.111 & 26.667 & 108.89\end{array}$

$1.0592 \quad 0.5880$

!Capacity and Design Energy Input Fraction at 0.6

6.111

$26.667 \quad 111.67$

$1.1061 \quad 0.5880$

!Capacity and Design Energy Input Fraction at 0.6

$\begin{array}{lll}6.111 & 26.667 & 113.89\end{array}$

$\begin{array}{ll}1.1286 & 0.5880\end{array}$

!Capacity and Design Energy Input Fraction at 0.6

$\begin{array}{lll}6.111 & 26.667 & 115.00\end{array}$

$1.1490 \quad 0.5880$

!Capacity and Design Energy Input Fraction at 0.6

$\begin{array}{lll}6.111 & 26.667 & 116.11\end{array}$

$0.8837 \quad 0.6060$

!Capacity and Design Energy Input Fraction at 0.6

$\begin{array}{lll}6.111 \quad 29.444 & 108.89\end{array}$

$0.9327 \quad 0.6060$

!Capacity and Design Energy Input Fraction at 0.6

$\begin{array}{lll}6.111 & 29.444 & 111.67\end{array}$

$0.9776 \quad 0.6060$

!Capacity and Design Energy Input Fraction at 0.6

$\begin{array}{lll}6.111 \quad 29.444 & 113.89\end{array}$

$1.0000 \quad 0.6060$

!Capacity and Design Energy Input Fraction at 0.6

$\begin{array}{lll}6.111 & 29.444 & 115.00\end{array}$

$1.0224 \quad 0.6060$

!Capacity and Design Energy Input Fraction at 0.6

$6.111 \quad 29.444 \quad 116.11$

$0.7571 \quad 0.6240$

!Capacity and Design Energy Input Fraction at 0.6

$\begin{array}{lll}6.111 & 32.222 & 108.89\end{array}$ 


\section{Appendix C: Chiller performance data}

$0.8061 \quad 0.6240$

!Capacity and Design Energy Input Fraction at 0.6

$\begin{array}{lll}6.111 & 32.222 & 111.67\end{array}$

$0.8531 \quad 0.6240$

!Capacity and Design Energy Input Fraction at 0.6

$\begin{array}{lll}6.111 & 32.222 & 113.89\end{array}$

$0.8735 \quad 0.6240$

!Capacity and Design Energy Input Fraction at 0.6

$\begin{array}{lll}6.111 & 32.222 & 115.00\end{array}$

$0.8959 \quad 0.6240$

!Capacity and Design Energy Input Fraction at 0.6

$\begin{array}{lll}6.111 & 32.222 & 116.11\end{array}$

$1.0306 \quad 0.5880$

!Capacity and Design Energy Input Fraction at 0.6

$6.667 \quad 26.667 \quad 108.89$

$\begin{array}{ll}1.0816 & 0.5880\end{array}$

!Capacity and Design Energy Input Fraction at 0.6

$\begin{array}{lll}6.667 & 26.667 & 111.67\end{array}$

$1.1286 \quad 0.5880$

!Capacity and Design Energy Input Fraction at 0.6

$\begin{array}{lll}6.667 & 26.667 & 113.89\end{array}$

$\begin{array}{ll}1.1510 & 0.5880\end{array}$

!Capacity and Design Energy Input Fraction at 0.6

$\begin{array}{lll}6.667 & 26.667 & 115.00\end{array}$

$1.1714 \quad 0.5880$

!Capacity and Design Energy Input Fraction at 0.6

$6.667 \quad 26.667 \quad 116.11$

$0.9041 \quad 0.6000$

!Capacity and Design Energy Input Fraction at 0.6

$\begin{array}{lll}6.667 & 29.444 & 108.89\end{array}$

$0.9531 \quad 0.6000$

!Capacity and Design Energy Input Fraction at 0.6

$6.667 \quad 29.444 \quad 111.67$

$1.0000 \quad 0.6000$

!Capacity and Design Energy Input Fraction at 0.6

$6.667 \quad 29.444 \quad 113.89$

1.02240 .6000

!Capacity and Design Energy Input Fraction at 0.6

$6.667 \quad 29.444 \quad 115.00$

$1.0449 \quad 0.6000$

!Capacity and Design Energy Input Fraction at 0.6

$6.667 \quad 29.444 \quad 116.11$

$0.7776 \quad 0.6180$

!Capacity and Design Energy Input Fraction at 0.6
6.667
$32.222 \quad 108.89$ 


\section{Appendix C: Chiller performance data}

$0.8265 \quad 0.6180$

!Capacity and Design Energy Input Fraction at 0.6 $\begin{array}{lll}6.667 & 32.222 & 111.67\end{array}$

$0.8735 \quad 0.6180$

!Capacity and Design Energy Input Fraction at 0.6

$\begin{array}{lll}6.667 & 32.222 & 113.89\end{array}$

$0.8959 \quad 0.6180$

!Capacity and Design Energy Input Fraction at 0.6

$\begin{array}{lll}6.667 & 32.222 & 115.00\end{array}$

$0.9163 \quad 0.6180$

!Capacity and Design Energy Input Fraction at 0.6

$6.667 \quad 32.222 \quad 116.11$

$\begin{array}{ll}1.0531 & 0.5820\end{array}$

!Capacity and Design Energy Input Fraction at 0.6

$\begin{array}{lll}7.222 & 26.667 & 108.89\end{array}$

$\begin{array}{ll}1.1041 & 0.5820\end{array}$

!Capacity and Design Energy Input Fraction at 0.6

$\begin{array}{lll}7.222 & 26.667 & 111.67\end{array}$

$1.1510 \quad 0.5820$

!Capacity and Design Energy Input Fraction at 0.6

$\begin{array}{lll}7.222 & 26.667 & 113.89\end{array}$

$1.1735 \quad 0.5820$

!Capacity and Design Energy Input Fraction at 0.6

$\begin{array}{lll}7.222 & 26.667 & 115.00\end{array}$

$1.1959 \quad 0.5820$

!Capacity and Design Energy Input Fraction at 0.6

$\begin{array}{lll}7.222 & 26.667 & 116.11\end{array}$

$0.9245 \quad 0.5940$

!Capacity and Design Energy Input Fraction at 0.6

$\begin{array}{lll}7.222 & 29.444 & 108.89\end{array}$

$0.9755 \quad 0.5940$

!Capacity and Design Energy Input Fraction at 0.6

$\begin{array}{lll}7.222 & 29.444 & 111.67\end{array}$

1.02240 .5940

!Capacity and Design Energy Input Fraction at 0.6

$\begin{array}{lll}7.222 & 29.444 & 113.89\end{array}$

$1.0449 \quad 0.5940$

!Capacity and Design Energy Input Fraction at 0.6

$\begin{array}{lll}7.222 & 29.444 & 115.00\end{array}$

$1.0673 \quad 0.5940$

!Capacity and Design Energy Input Fraction at 0.6

$\begin{array}{lll}7.222 & 29.444 & 116.11\end{array}$

$0.7980 \quad 0.6120$

!Capacity and Design Energy Input Fraction at 0.6

$\begin{array}{lll}7.222 & 32.222 & 108.89\end{array}$ 


\section{Appendix C: Chiller performance data}

$0.8469 \quad 0.6120$

!Capacity and Design Energy Input Fraction at 0.6

$\begin{array}{lll}7.222 & 32.222 & 111.67\end{array}$

0.89390 .6120

!Capacity and Design Energy Input Fraction at 0.6

$\begin{array}{lll}7.222 & 32.222 & 113.89\end{array}$

$0.9163 \quad 0.6120$

!Capacity and Design Energy Input Fraction at 0.6

$\begin{array}{lll}7.222 & 32.222 & 115.00\end{array}$

$0.9388 \quad 0.6120$

!Capacity and Design Energy Input Fraction at 0.6

$\begin{array}{lll}7.222 & 32.222 & 116.11\end{array}$

$1.0755 \quad 0.5760$

!Capacity and Design Energy Input Fraction at 0.6

$\begin{array}{lll}7.778 & 26.667 & 108.89\end{array}$

$1.1265 \quad 0.5760$

!Capacity and Design Energy Input Fraction at 0.6

$\begin{array}{lll}7.778 & 26.667 & 111.67\end{array}$

$1.1755 \quad 0.5760$

!Capacity and Design Energy Input Fraction at 0.6

$\begin{array}{lll}7.778 & 26.667 & 113.89\end{array}$

$1.1980 \quad 0.5760$

!Capacity and Design Energy Input Fraction at 0.6

$\begin{array}{lll}7.778 & 26.667 & 115.00\end{array}$

$1.2184 \quad 0.5760$

!Capacity and Design Energy Input Fraction at 0.6

$\begin{array}{lll}7.778 & 26.667 & 116.11\end{array}$

$0.9469 \quad 0.5880$

!Capacity and Design Energy Input Fraction at 0.6

$\begin{array}{lll}7.778 & 29.444 & 108.89\end{array}$

$0.9980 \quad 0.5880$

!Capacity and Design Energy Input Fraction at 0.6

$\begin{array}{lll}7.778 & 29.444 & 111.67\end{array}$

$1.0449 \quad 0.5880$

!Capacity and Design Energy Input Fraction at 0.6

$\begin{array}{lll}7.778 & 29.444 & 113.89\end{array}$

$1.0673 \quad 0.5880$

!Capacity and Design Energy Input Fraction at 0.6

$\begin{array}{lll}7.778 & 29.444 & 115.00\end{array}$

$1.0898 \quad 0.5880$

!Capacity and Design Energy Input Fraction at 0.6

$\begin{array}{lll}7.778 & 29.444 & 116.11\end{array}$

$0.8184 \quad 0.6060$

!Capacity and Design Energy Input Fraction at 0.6

$\begin{array}{lll}7.778 & 32.222 & 108.89\end{array}$ 


\section{Appendix C: Chiller performance data}

$0.8694 \quad 0.6060$

!Capacity and Design Energy Input Fraction at 0.6

$\begin{array}{lll}7.778 & 32.222 & 111.67\end{array}$

$0.9163 \quad 0.6060$

!Capacity and Design Energy Input Fraction at 0.6

$\begin{array}{lll}7.778 & 32.222 & 113.89\end{array}$

$0.9388 \quad 0.6060$

!Capacity and Design Energy Input Fraction at 0.6

$\begin{array}{lll}7.778 & 32.222 & 115.00\end{array}$

$0.9592 \quad 0.6060$

!Capacity and Design Energy Input Fraction at 0.6

$\begin{array}{lll}7.778 & 32.222 & 116.11\end{array}$

$1.1204 \quad 0.5700$

!Capacity and Design Energy Input Fraction at 0.6

$8.889 \quad 26.667 \quad 108.89$

$\begin{array}{ll}1.1735 & 0.5700\end{array}$

!Capacity and Design Energy Input Fraction at 0.6

$8.889 \quad 26.667 \quad 111.67$

$1.2204 \quad 0.5700$

!Capacity and Design Energy Input Fraction at 0.6

$\begin{array}{lll}8.889 & 26.667 & 113.89\end{array}$

$1.2449 \quad 0.5700$

!Capacity and Design Energy Input Fraction at 0.6

$\begin{array}{lll}8.889 & 26.667 & 115.00\end{array}$

$1.2673 \quad 0.5700$

!Capacity and Design Energy Input Fraction at 0.6

$8.889 \quad 26.667 \quad 116.11$

$0.9898 \quad 0.5820$

!Capacity and Design Energy Input Fraction at 0.6

$\begin{array}{lll}8.889 & 29.444 & 108.89\end{array}$

$1.0408 \quad 0.5820$

!Capacity and Design Energy Input Fraction at 0.6

$\begin{array}{lll}8.889 & 29.444 & 111.67\end{array}$

$1.0898 \quad 0.5820$

!Capacity and Design Energy Input Fraction at 0.6

$8.889 \quad 29.444 \quad 113.89$

$1.1122 \quad 0.5820$

!Capacity and Design Energy Input Fraction at 0.6

$\begin{array}{lll}8.889 & 29.444 & 115.00\end{array}$

$1.1347 \quad 0.5820$

!Capacity and Design Energy Input Fraction at 0.6

$8.889 \quad 29.444 \quad 116.11$

$0.8592 \quad 0.6000$

!Capacity and Design Energy Input Fraction at 0.6

$\begin{array}{lll}8.889 & 32.222 & 108.89\end{array}$ 


\section{Appendix C: Chiller performance data}

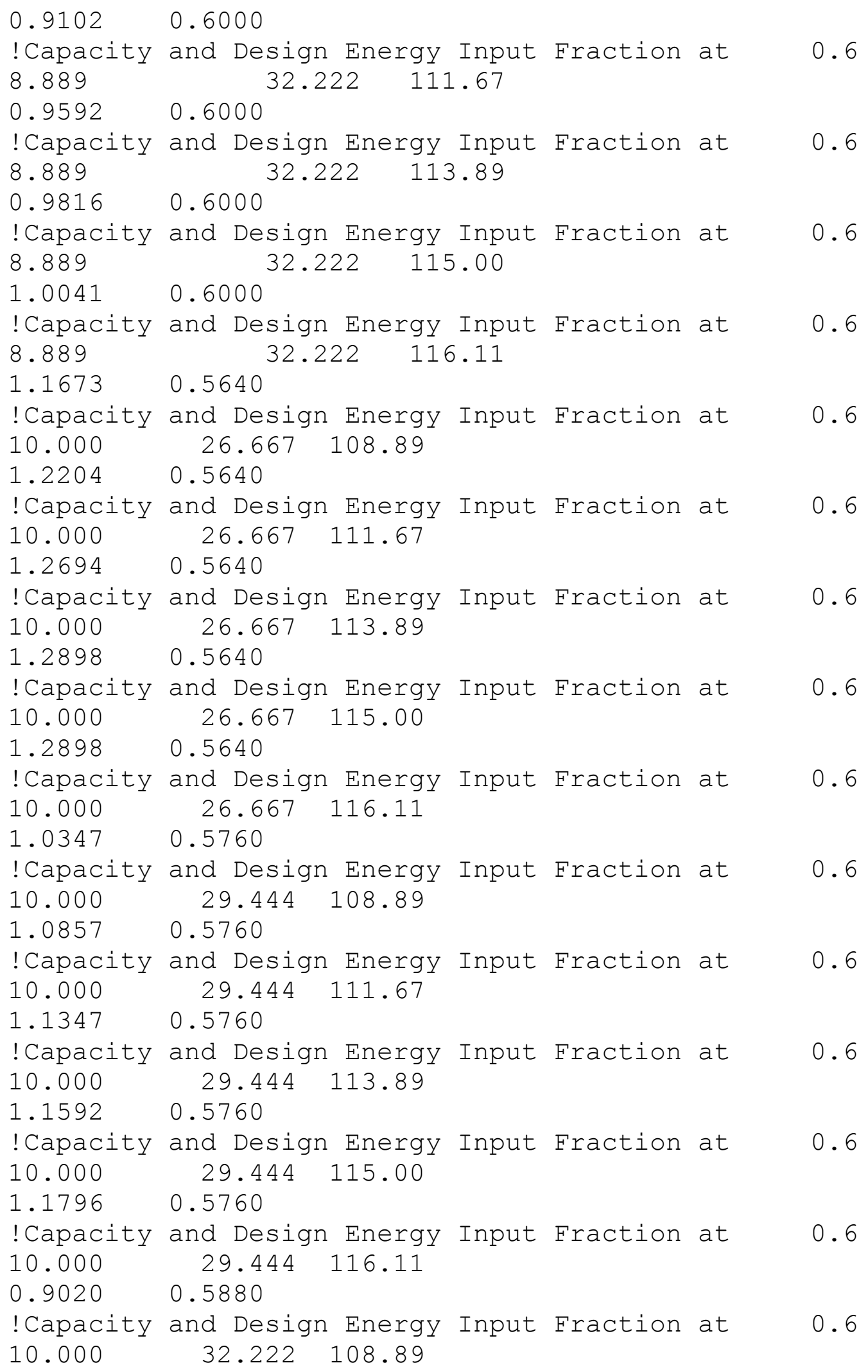




\section{Appendix C: Chiller performance data}

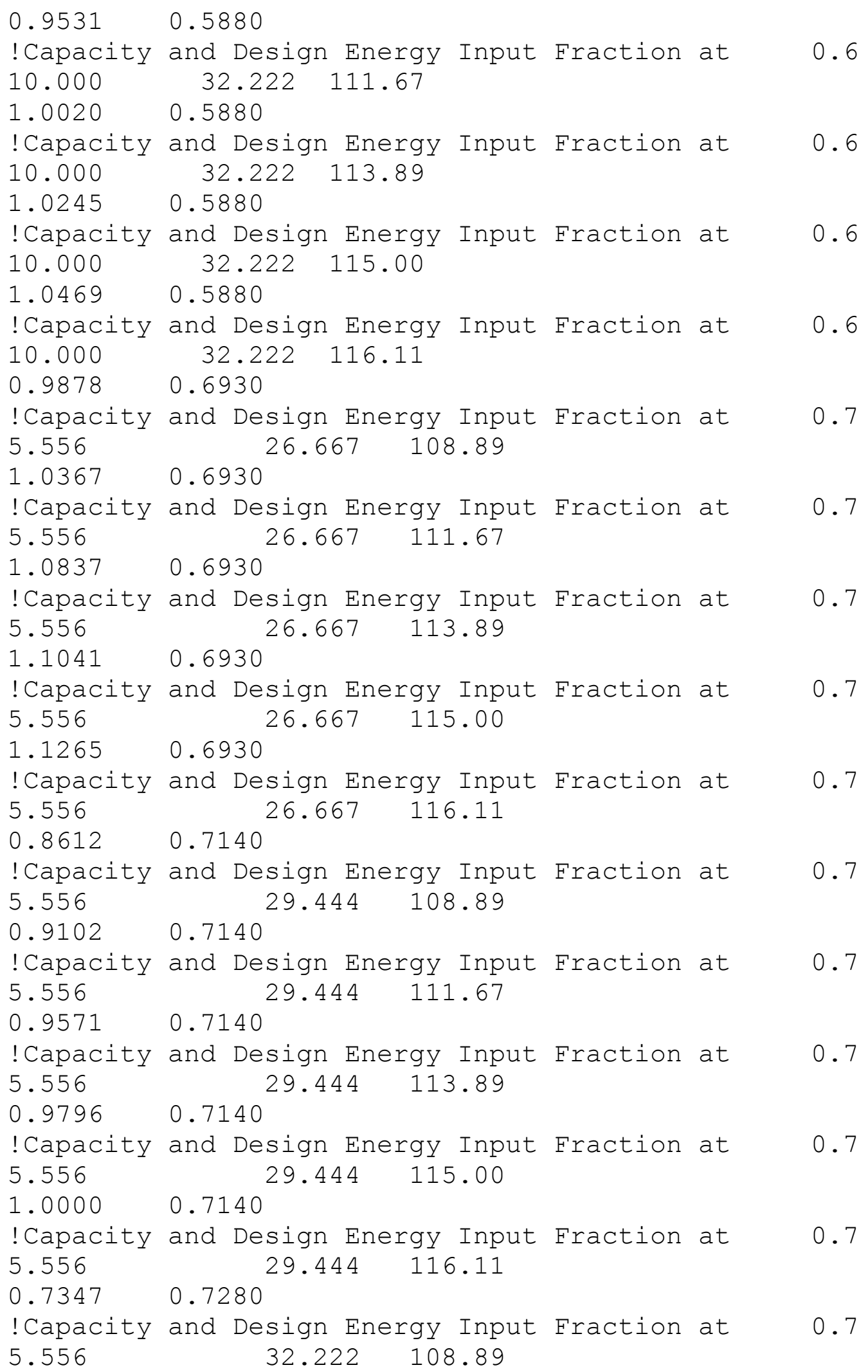




\section{Appendix C: Chiller performance data}

$0.7857 \quad 0.7280$

!Capacity and Design Energy Input Fraction at 0.7

$\begin{array}{lll}5.556 & 32.222 & 111.67\end{array}$

$0.8327 \quad 0.7280$

!Capacity and Design Energy Input Fraction at 0.7

$\begin{array}{lll}5.556 & 32.222 & 113.89\end{array}$

$0.8531 \quad 0.7280$

!Capacity and Design Energy Input Fraction at 0.7

$\begin{array}{lll}5.556 & 32.222 & 115.00\end{array}$

$0.8735 \quad 0.7280$

!Capacity and Design Energy Input Fraction at 0.7

$5.556 \quad 32.222 \quad 116.11$

$1.0102 \quad 0.6860$

!Capacity and Design Energy Input Fraction at 0.7

$\begin{array}{lll}6.111 & 26.667 & 108.89\end{array}$

$1.0592 \quad 0.6860$

!Capacity and Design Energy Input Fraction at 0.7

$\begin{array}{lll}6.111 & 26.667 & 111.67\end{array}$

$1.1061 \quad 0.6860$

!Capacity and Design Energy Input Fraction at 0.7

$\begin{array}{lll}6.111 & 26.667 & 113.89\end{array}$

$1.1286 \quad 0.6860$

!Capacity and Design Energy Input Fraction at 0.7

$\begin{array}{lll}6.111 & 26.667 & 115.00\end{array}$

$1.1490 \quad 0.6860$

!Capacity and Design Energy Input Fraction at 0.7

$\begin{array}{lll}6.111 & 26.667 & 116.11\end{array}$

$0.8837 \quad 0.7070$

!Capacity and Design Energy Input Fraction at 0.7

$\begin{array}{lll}6.111 & 29.444 & 108.89\end{array}$

$0.9327 \quad 0.7070$

!Capacity and Design Energy Input Fraction at 0.7

$\begin{array}{lll}6.111 & 29.444 & 111.67\end{array}$

$0.9776 \quad 0.7070$

!Capacity and Design Energy Input Fraction at 0.7

$\begin{array}{lll}6.111 \quad 29.444 & 113.89\end{array}$

$1.0000 \quad 0.7070$

!Capacity and Design Energy Input Fraction at 0.7

$\begin{array}{lll}6.111 & 29.444 & 115.00\end{array}$

$1.0224 \quad 0.7070$

!Capacity and Design Energy Input Fraction at 0.7

$\begin{array}{lll}6.111 & 29.444 & 116.11\end{array}$

$0.7571 \quad 0.7280$

!Capacity and Design Energy Input Fraction at 0.7
6.111
$32.222 \quad 108.89$ 


\section{Appendix C: Chiller performance data}

$0.8061 \quad 0.7280$

!Capacity and Design Energy Input Fraction at 0.7

$\begin{array}{lll}6.111 & 32.222 & 111.67\end{array}$

$0.8531 \quad 0.7280$

!Capacity and Design Energy Input Fraction at 0.7

$\begin{array}{lll}6.111 & 32.222 & 113.89\end{array}$

$0.8735 \quad 0.7280$

!Capacity and Design Energy Input Fraction at 0.7

$\begin{array}{lll}6.111 & 32.222 & 115.00\end{array}$

$0.8959 \quad 0.7280$

!Capacity and Design Energy Input Fraction at 0.7

$\begin{array}{lll}6.111 & 32.222 & 116.11\end{array}$

$1.0306 \quad 0.6860$

!Capacity and Design Energy Input Fraction at 0.7

$6.667 \quad 26.667 \quad 108.89$

$1.0816 \quad 0.6860$

!Capacity and Design Energy Input Fraction at 0.7

$6.667 \quad 26.667 \quad 111.67$

$1.1286 \quad 0.6860$

!Capacity and Design Energy Input Fraction at 0.7

$6.667 \quad 26.667 \quad 113.89$

$1.1510 \quad 0.6860$

!Capacity and Design Energy Input Fraction at 0.7

$6.667 \quad 26.667 \quad 115.00$

1.17140 .6860

!Capacity and Design Energy Input Fraction at 0.7

$6.667 \quad 26.667 \quad 116.11$

$0.9041 \quad 0.7000$

!Capacity and Design Energy Input Fraction at 0.7

$\begin{array}{lll}6.667 & 29.444 & 108.89\end{array}$

$0.9531 \quad 0.7000$

!Capacity and Design Energy Input Fraction at 0.7

$\begin{array}{lll}6.667 & 29.444 & 111.67\end{array}$

$1.0000 \quad 0.7000$

!Capacity and Design Energy Input Fraction at 0.7

$6.667 \quad 29.444 \quad 113.89$

1.02240 .7000

!Capacity and Design Energy Input Fraction at 0.7

$\begin{array}{lll}6.667 & 29.444 & 115.00\end{array}$

$1.0449 \quad 0.7000$

!Capacity and Design Energy Input Fraction at 0.7

$\begin{array}{lll}6.667 & 29.444 & 116.11\end{array}$

$0.7776 \quad 0.7210$

!Capacity and Design Energy Input Fraction at 0.7
6.667
$32.222 \quad 108.89$ 


\section{Appendix C: Chiller performance data}

$0.8265 \quad 0.7210$

!Capacity and Design Energy Input Fraction at 0.7

$\begin{array}{lll}6.667 & 32.222 & 111.67\end{array}$

$0.8735 \quad 0.7210$

!Capacity and Design Energy Input Fraction at 0.7

$\begin{array}{lll}6.667 & 32.222 & 113.89\end{array}$

$0.8959 \quad 0.7210$

!Capacity and Design Energy Input Fraction at 0.7

$\begin{array}{lll}6.667 & 32.222 & 115.00\end{array}$

$0.9163 \quad 0.7210$

!Capacity and Design Energy Input Fraction at 0.7

$6.667 \quad 32.222 \quad 116.11$

$\begin{array}{ll}1.0531 & 0.6790\end{array}$

!Capacity and Design Energy Input Fraction at 0.7

$\begin{array}{lll}7.222 & 26.667 & 108.89\end{array}$

$\begin{array}{ll}1.1041 & 0.6790\end{array}$

!Capacity and Design Energy Input Fraction at 0.7

$\begin{array}{lll}7.222 & 26.667 & 111.67\end{array}$

$1.1510 \quad 0.6790$

!Capacity and Design Energy Input Fraction at 0.7

$\begin{array}{lll}7.222 & 26.667 & 113.89\end{array}$

$1.1735 \quad 0.6790$

!Capacity and Design Energy Input Fraction at 0.7

$\begin{array}{lll}7.222 & 26.667 & 115.00\end{array}$

$1.1959 \quad 0.6790$

!Capacity and Design Energy Input Fraction at 0.7

$\begin{array}{lll}7.222 & 26.667 & 116.11\end{array}$

$0.9245 \quad 0.6930$

!Capacity and Design Energy Input Fraction at 0.7

$\begin{array}{lll}7.222 & 29.444 & 108.89\end{array}$

$0.9755 \quad 0.6930$

!Capacity and Design Energy Input Fraction at 0.7

$\begin{array}{lll}7.222 & 29.444 & 111.67\end{array}$

1.02240 .6930

!Capacity and Design Energy Input Fraction at 0.7

$\begin{array}{lll}7.222 & 29.444 & 113.89\end{array}$

$1.0449 \quad 0.6930$

!Capacity and Design Energy Input Fraction at 0.7

$\begin{array}{lll}7.222 & 29.444 & 115.00\end{array}$

$1.0673 \quad 0.6930$

!Capacity and Design Energy Input Fraction at 0.7

$\begin{array}{lll}7.222 & 29.444 & 116.11\end{array}$

$0.7980 \quad 0.7140$

!Capacity and Design Energy Input Fraction at 0.7

$\begin{array}{lll}7.222 & 32.222 & 108.89\end{array}$ 


\section{Appendix C: Chiller performance data}

$0.8469 \quad 0.7140$

!Capacity and Design Energy Input Fraction at 0.7

$\begin{array}{lll}7.222 & 32.222 & 111.67\end{array}$

0.89390 .7140

!Capacity and Design Energy Input Fraction at 0.7

$\begin{array}{lll}7.222 & 32.222 & 113.89\end{array}$

$0.9163 \quad 0.7140$

!Capacity and Design Energy Input Fraction at 0.7

$\begin{array}{lll}7.222 & 32.222 & 115.00\end{array}$

$0.9388 \quad 0.7140$

!Capacity and Design Energy Input Fraction at 0.7

$\begin{array}{lll}7.222 & 32.222 & 116.11\end{array}$

$1.0755 \quad 0.6720$

!Capacity and Design Energy Input Fraction at 0.7

$\begin{array}{lll}7.778 & 26.667 & 108.89\end{array}$

$1.1265 \quad 0.6720$

!Capacity and Design Energy Input Fraction at 0.7

$\begin{array}{lll}7.778 & 26.667 & 111.67\end{array}$

$1.1755 \quad 0.6720$

!Capacity and Design Energy Input Fraction at 0.7

$\begin{array}{lll}7.778 & 26.667 & 113.89\end{array}$

$1.1980 \quad 0.6720$

!Capacity and Design Energy Input Fraction at 0.7

$\begin{array}{lll}7.778 & 26.667 & 115.00\end{array}$

$1.2184 \quad 0.6720$

!Capacity and Design Energy Input Fraction at 0.7

$\begin{array}{lll}7.778 & 26.667 & 116.11\end{array}$

$0.9469 \quad 0.6860$

!Capacity and Design Energy Input Fraction at 0.7

$\begin{array}{lll}7.778 & 29.444 & 108.89\end{array}$

$0.9980 \quad 0.6860$

!Capacity and Design Energy Input Fraction at 0.7

$\begin{array}{lll}7.778 & 29.444 & 111.67\end{array}$

$1.0449 \quad 0.6860$

!Capacity and Design Energy Input Fraction at 0.7

$\begin{array}{lll}7.778 & 29.444 & 113.89\end{array}$

$1.0673 \quad 0.6860$

!Capacity and Design Energy Input Fraction at 0.7

$\begin{array}{lll}7.778 & 29.444 & 115.00\end{array}$

$1.0898 \quad 0.6860$

!Capacity and Design Energy Input Fraction at 0.7

$\begin{array}{lll}7.778 & 29.444 & 116.11\end{array}$

$0.8184 \quad 0.7070$

!Capacity and Design Energy Input Fraction at 0.7

$\begin{array}{lll}7.778 & 32.222 & 108.89\end{array}$ 


\section{Appendix C: Chiller performance data}

$0.8694 \quad 0.7070$

!Capacity and Design Energy Input Fraction at 0.7

$\begin{array}{lll}7.778 & 32.222 & 111.67\end{array}$

$0.9163 \quad 0.7070$

!Capacity and Design Energy Input Fraction at 0.7

$\begin{array}{lll}7.778 & 32.222 & 113.89\end{array}$

$0.9388 \quad 0.7070$

!Capacity and Design Energy Input Fraction at 0.7

$\begin{array}{lll}7.778 & 32.222 & 115.00\end{array}$

$0.9592 \quad 0.7070$

!Capacity and Design Energy Input Fraction at 0.7

$\begin{array}{lll}7.778 & 32.222 & 116.11\end{array}$

$1.1204 \quad 0.6650$

!Capacity and Design Energy Input Fraction at 0.7

$8.889 \quad 26.667 \quad 108.89$

$1.1735 \quad 0.6650$

!Capacity and Design Energy Input Fraction at 0.7

$8.889 \quad 26.667 \quad 111.67$

$1.2204 \quad 0.6650$

!Capacity and Design Energy Input Fraction at 0.7

$8.889 \quad 26.667 \quad 113.89$

$1.2449 \quad 0.6650$

!Capacity and Design Energy Input Fraction at 0.7

$8.889 \quad 26.667 \quad 115.00$

$1.2673 \quad 0.6650$

!Capacity and Design Energy Input Fraction at 0.7

$8.889 \quad 26.667 \quad 116.11$

$0.9898 \quad 0.6790$

!Capacity and Design Energy Input Fraction at 0.7

$\begin{array}{lll}8.889 & 29.444 & 108.89\end{array}$

$1.0408 \quad 0.6790$

!Capacity and Design Energy Input Fraction at 0.7

$\begin{array}{lll}8.889 & 29.444 & 111.67\end{array}$

$1.0898 \quad 0.6790$

!Capacity and Design Energy Input Fraction at 0.7

$8.889 \quad 29.444 \quad 113.89$

$1.1122 \quad 0.6790$

!Capacity and Design Energy Input Fraction at 0.7

$\begin{array}{lll}8.889 & 29.444 & 115.00\end{array}$

$1.1347 \quad 0.6790$

!Capacity and Design Energy Input Fraction at 0.7

$8.889 \quad 29.444 \quad 116.11$

$0.8592 \quad 0.7000$

!Capacity and Design Energy Input Fraction at 0.7

$\begin{array}{lll}8.889 & 32.222 & 108.89\end{array}$ 


\section{Appendix C: Chiller performance data}

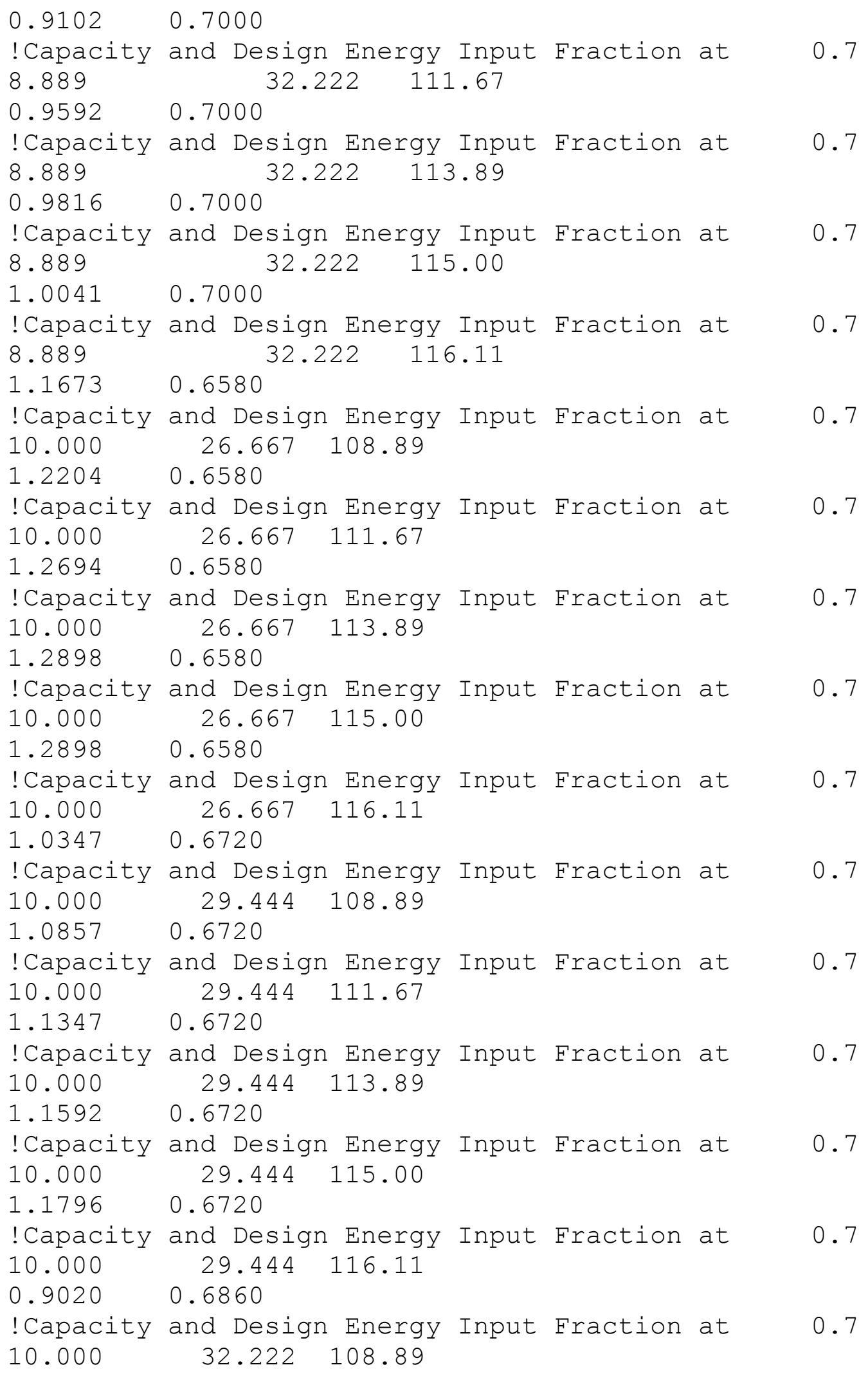




\section{Appendix C: Chiller performance data}

\begin{tabular}{|c|c|c|c|c|}
\hline 0.9531 & 0.6860 & & & \\
\hline ! Capacity & and Design Energy & Input & Fraction at & 0.7 \\
\hline 10.000 & $32.222 \quad 111.67$ & & & \\
\hline .0020 & 0.6860 & & & \\
\hline ! Capacity & and Design Energy & Input & Fraction at & 0.7 \\
\hline 10.000 & $32.222 \quad 113.89$ & & & \\
\hline 1.0245 & 0.6860 & & & \\
\hline ! Capacity & and Design Energy & Input & Fraction at & 0.7 \\
\hline 10.000 & $32.222 \quad 115.00$ & & & \\
\hline .0469 & 0.6860 & & & \\
\hline ! Capacity & and Design Energy & Input & Fraction at & 0.7 \\
\hline 10.000 & $32.222 \quad 116.11$ & & & \\
\hline .9878 & 0.7920 & & & \\
\hline ! Capacity & and Design Energy & Input & Fraction at & 0.8 \\
\hline 5.556 & $26.667 \quad 10$ & 8.89 & & \\
\hline .0367 & 0.7920 & & & \\
\hline ! Capacity & and Design Energy & Input & Fraction at & 0.8 \\
\hline 5.556 & $26.667 \quad 11$ & 1.67 & & \\
\hline .0837 & 0.7920 & & & \\
\hline ! Capacity & and Design Energy & Input & Fraction at & 0.8 \\
\hline 5.556 & $26.667 \quad 11$ & 3.89 & & \\
\hline 1.1041 & 0.7920 & & & \\
\hline ! Capacity & and Design Energy & Input & Fraction at & 0.8 \\
\hline 5.556 & $26.667 \quad 11$ & 5.00 & & \\
\hline 1.1265 & 0.7920 & & & \\
\hline ! Capacity & and Design Energy & Input & Fraction at & 0.8 \\
\hline 5.556 & $26.667 \quad 11$ & 6.11 & & \\
\hline 0.8612 & 0.8160 & & & \\
\hline ! Capacity & and Design Energy & Input & Fraction at & 0.8 \\
\hline 5.556 & $29.444 \quad 10$ & 8.89 & & \\
\hline 0.9102 & 0.8160 & & & \\
\hline ! Capacity & and Design Energy & Input & Fraction at & 0.8 \\
\hline 5.556 & 29.444 & 1.67 & & \\
\hline 0.9571 & 0.8160 & & & \\
\hline ! Capacity & and Design Energy & Input & Fraction at & 0.8 \\
\hline 5.556 & $29.444 \quad 11$ & 3.89 & & \\
\hline 0.9796 & 0.8160 & & & \\
\hline ! Capacity & and Design Energy & Input & Fraction at & 0.8 \\
\hline & $29.444 \quad 11$ & 5.00 & & \\
\hline 1.0000 & 0.8160 & & & \\
\hline ! Capacity & and Design Energy & Input & Fraction at & 0.8 \\
\hline 5.556 & $29.444 \quad 11$ & 6.11 & & \\
\hline 0.7347 & 0.8320 & & & \\
\hline $\begin{array}{l}\text { ! Capacity } \\
5.556\end{array}$ & $\begin{array}{c}\text { and Design Energy } \\
32.222\end{array}$ & $\begin{array}{l}\text { Input } \\
8.89\end{array}$ & Fraction at & 0.8 \\
\hline
\end{tabular}




\section{Appendix C: Chiller performance data}

$0.7857 \quad 0.8320$

!Capacity and Design Energy Input Fraction at 0.8

$\begin{array}{lll}5.556 & 32.222 & 111.67\end{array}$

$0.8327 \quad 0.8320$

!Capacity and Design Energy Input Fraction at 0.8

$\begin{array}{lll}5.556 & 32.222 & 113.89\end{array}$

$0.8531 \quad 0.8320$

!Capacity and Design Energy Input Fraction at 0.8

$\begin{array}{lll}5.556 & 32.222 & 115.00\end{array}$

$0.8735 \quad 0.8320$

!Capacity and Design Energy Input Fraction at 0.8

$\begin{array}{lll}5.556 & 32.222 & 116.11\end{array}$

$1.0102 \quad 0.7840$

!Capacity and Design Energy Input Fraction at 0.8

$\begin{array}{lll}6.111 & 26.667 & 108.89\end{array}$

$\begin{array}{ll}1.0592 & 0.7840\end{array}$

!Capacity and Design Energy Input Fraction at 0.8

$\begin{array}{lll}6.111 & 26.667 & 111.67\end{array}$

$1.1061 \quad 0.7840$

!Capacity and Design Energy Input Fraction at 0.8

$\begin{array}{lll}6.111 & 26.667 & 113.89\end{array}$

$1.1286 \quad 0.7840$

!Capacity and Design Energy Input Fraction at 0.8

$\begin{array}{lll}6.111 \quad 26.667 & 115.00\end{array}$

$1.1490 \quad 0.7840$

!Capacity and Design Energy Input Fraction at 0.8

$\begin{array}{lll}6.111 & 26.667 & 116.11\end{array}$

$0.8837 \quad 0.8080$

!Capacity and Design Energy Input Fraction at 0.8

$\begin{array}{lll}6.111 \quad 29.444 & 108.89\end{array}$

$0.9327 \quad 0.8080$

!Capacity and Design Energy Input Fraction at 0.8

$\begin{array}{lll}6.111 & 29.444 & 111.67\end{array}$

$0.9776 \quad 0.8080$

!Capacity and Design Energy Input Fraction at 0.8

$\begin{array}{lll}6.111 \quad 29.444 & 113.89\end{array}$

$1.0000 \quad 0.8080$

!Capacity and Design Energy Input Fraction at 0.8

$\begin{array}{lll}6.111 & 29.444 & 115.00\end{array}$

$1.0224 \quad 0.8080$

!Capacity and Design Energy Input Fraction at 0.8

$6.111 \quad 29.444 \quad 116.11$

$0.7571 \quad 0.8320$

!Capacity and Design Energy Input Fraction at 0.8

$\begin{array}{lll}6.111 & 32.222 & 108.89\end{array}$ 


\section{Appendix C: Chiller performance data}

$0.8061 \quad 0.8320$

!Capacity and Design Energy Input Fraction at 0.8

$\begin{array}{lll}6.111 & 32.222 & 111.67\end{array}$

$0.8531 \quad 0.8320$

!Capacity and Design Energy Input Fraction at 0.8

$\begin{array}{lll}6.111 & 32.222 & 113.89\end{array}$

$0.8735 \quad 0.8320$

!Capacity and Design Energy Input Fraction at 0.8

$\begin{array}{lll}6.111 & 32.222 & 115.00\end{array}$

$0.8959 \quad 0.8320$

!Capacity and Design Energy Input Fraction at 0.8

$\begin{array}{lll}6.111 & 32.222 & 116.11\end{array}$

$\begin{array}{ll}1.0306 & 0.7840\end{array}$

!Capacity and Design Energy Input Fraction at 0.8

$\begin{array}{lll}6.667 & 26.667 & 108.89\end{array}$

$\begin{array}{ll}1.0816 & 0.7840\end{array}$

!Capacity and Design Energy Input Fraction at 0.8

$\begin{array}{lll}6.667 & 26.667 & 111.67\end{array}$

$\begin{array}{ll}1.1286 & 0.7840\end{array}$

!Capacity and Design Energy Input Fraction at 0.8

$\begin{array}{lll}6.667 & 26.667 & 113.89\end{array}$

$\begin{array}{ll}1.1510 & 0.7840\end{array}$

!Capacity and Design Energy Input Fraction at 0.8

$\begin{array}{lll}6.667 & 26.667 & 115.00\end{array}$

$1.1714 \quad 0.7840$

!Capacity and Design Energy Input Fraction at 0.8

$6.667 \quad 26.667 \quad 116.11$

$0.9041 \quad 0.8000$

!Capacity and Design Energy Input Fraction at 0.8

$\begin{array}{lll}6.667 & 29.444 & 108.89\end{array}$

$0.9531 \quad 0.8000$

!Capacity and Design Energy Input Fraction at 0.8

$6.667 \quad 29.444 \quad 111.67$

$1.0000 \quad 0.8000$

!Capacity and Design Energy Input Fraction at 0.8

$6.667 \quad 29.444 \quad 113.89$

1.02240 .8000

!Capacity and Design Energy Input Fraction at 0.8

$\begin{array}{lll}6.667 & 29.444 & 115.00\end{array}$

$1.0449 \quad 0.8000$

!Capacity and Design Energy Input Fraction at 0.8

$6.667 \quad 29.444 \quad 116.11$

$0.7776 \quad 0.8240$

!Capacity and Design Energy Input Fraction at 0.8

$\begin{array}{lll}6.667 & 32.222 \quad 108.89\end{array}$ 


\section{Appendix C: Chiller performance data}

$0.8265 \quad 0.8240$

!Capacity and Design Energy Input Fraction at 0.8 $\begin{array}{lll}6.667 & 32.222 & 111.67\end{array}$

$0.8735 \quad 0.8240$

!Capacity and Design Energy Input Fraction at 0.8

$\begin{array}{lll}6.667 & 32.222 & 113.89\end{array}$

$0.8959 \quad 0.8240$

!Capacity and Design Energy Input Fraction at 0.8

$\begin{array}{lll}6.667 & 32.222 & 115.00\end{array}$

$0.9163 \quad 0.8240$

!Capacity and Design Energy Input Fraction at 0.8

$\begin{array}{lll}6.667 & 32.222 & 116.11\end{array}$

$\begin{array}{ll}1.0531 & 0.7760\end{array}$

!Capacity and Design Energy Input Fraction at 0.8

$\begin{array}{lll}7.222 & 26.667 & 108.89\end{array}$

$\begin{array}{ll}1.1041 & 0.7760\end{array}$

!Capacity and Design Energy Input Fraction at 0.8

$\begin{array}{lll}7.222 & 26.667 & 111.67\end{array}$

$1.1510 \quad 0.7760$

!Capacity and Design Energy Input Fraction at 0.8

$\begin{array}{lll}7.222 & 26.667 & 113.89\end{array}$

$1.1735 \quad 0.7760$

!Capacity and Design Energy Input Fraction at 0.8

$\begin{array}{lll}7.222 & 26.667 & 115.00\end{array}$

1.19590 .7760

!Capacity and Design Energy Input Fraction at 0.8

$\begin{array}{lll}7.222 & 26.667 & 116.11\end{array}$

$0.9245 \quad 0.7920$

!Capacity and Design Energy Input Fraction at 0.8

$\begin{array}{lll}7.222 & 29.444 & 108.89\end{array}$

$0.9755 \quad 0.7920$

!Capacity and Design Energy Input Fraction at 0.8

$\begin{array}{lll}7.222 & 29.444 & 111.67\end{array}$

1.02240 .7920

!Capacity and Design Energy Input Fraction at 0.8

$\begin{array}{lll}7.222 & 29.444 & 113.89\end{array}$

$1.0449 \quad 0.7920$

!Capacity and Design Energy Input Fraction at 0.8

$\begin{array}{lll}7.222 & 29.444 & 115.00\end{array}$

$\begin{array}{ll}1.0673 & 0.7920\end{array}$

!Capacity and Design Energy Input Fraction at 0.8

$\begin{array}{lll}7.222 & 29.444 & 116.11\end{array}$

$0.7980 \quad 0.8160$

!Capacity and Design Energy Input Fraction at 0.8

$\begin{array}{lll}7.222 & 32.222 & 108.89\end{array}$ 


\section{Appendix C: Chiller performance data}

$0.8469 \quad 0.8160$

!Capacity and Design Energy Input Fraction at 0.8

$\begin{array}{lll}7.222 & 32.222 & 111.67\end{array}$

0.89390 .8160

!Capacity and Design Energy Input Fraction at 0.8

$\begin{array}{lll}7.222 & 32.222 & 113.89\end{array}$

$0.9163 \quad 0.8160$

!Capacity and Design Energy Input Fraction at 0.8

$\begin{array}{lll}7.222 & 32.222 & 115.00\end{array}$

$0.9388 \quad 0.8160$

!Capacity and Design Energy Input Fraction at 0.8

$\begin{array}{lll}7.222 & 32.222 & 116.11\end{array}$

1.07550 .7680

!Capacity and Design Energy Input Fraction at 0.8

$\begin{array}{lll}7.778 & 26.667 & 108.89\end{array}$

$1.1265 \quad 0.7680$

!Capacity and Design Energy Input Fraction at 0.8

$\begin{array}{lll}7.778 & 26.667 & 111.67\end{array}$

$1.1755 \quad 0.7680$

!Capacity and Design Energy Input Fraction at 0.8

$\begin{array}{lll}7.778 & 26.667 & 113.89\end{array}$

$1.1980 \quad 0.7680$

!Capacity and Design Energy Input Fraction at 0.8

$\begin{array}{lll}7.778 & 26.667 & 115.00\end{array}$

$1.2184 \quad 0.7680$

!Capacity and Design Energy Input Fraction at 0.8

$\begin{array}{lll}7.778 & 26.667 & 116.11\end{array}$

$0.9469 \quad 0.7840$

!Capacity and Design Energy Input Fraction at 0.8

$\begin{array}{lll}7.778 & 29.444 & 108.89\end{array}$

$0.9980 \quad 0.7840$

!Capacity and Design Energy Input Fraction at 0.8

$\begin{array}{lll}7.778 & 29.444 & 111.67\end{array}$

1.04490 .7840

!Capacity and Design Energy Input Fraction at 0.8

$\begin{array}{lll}7.778 & 29.444 & 113.89\end{array}$

$1.0673 \quad 0.7840$

!Capacity and Design Energy Input Fraction at 0.8

$\begin{array}{lll}7.778 & 29.444 & 115.00\end{array}$

$1.0898 \quad 0.7840$

!Capacity and Design Energy Input Fraction at 0.8

$\begin{array}{lll}7.778 & 29.444 & 116.11\end{array}$

$0.8184 \quad 0.8080$

!Capacity and Design Energy Input Fraction at 0.8

$\begin{array}{lll}7.778 & 32.222 & 108.89\end{array}$ 


\section{Appendix C: Chiller performance data}

$0.8694 \quad 0.8080$

!Capacity and Design Energy Input Fraction at 0.8

$\begin{array}{lll}7.778 & 32.222 & 111.67\end{array}$

$0.9163 \quad 0.8080$

!Capacity and Design Energy Input Fraction at 0.8

$\begin{array}{lll}7.778 & 32.222 & 113.89\end{array}$

$0.9388 \quad 0.8080$

!Capacity and Design Energy Input Fraction at 0.8

$\begin{array}{lll}7.778 & 32.222 & 115.00\end{array}$

$0.9592 \quad 0.8080$

!Capacity and Design Energy Input Fraction at 0.8

$\begin{array}{lll}7.778 & 32.222 & 116.11\end{array}$

$1.1204 \quad 0.7600$

!Capacity and Design Energy Input Fraction at 0.8

$8.889 \quad 26.667 \quad 108.89$

$\begin{array}{ll}1.1735 & 0.7600\end{array}$

!Capacity and Design Energy Input Fraction at 0.8

$\begin{array}{lll}8.889 & 26.667 & 111.67\end{array}$

$1.2204 \quad 0.7600$

!Capacity and Design Energy Input Fraction at 0.8

$\begin{array}{lll}8.889 & 26.667 & 113.89\end{array}$

$1.2449 \quad 0.7600$

!Capacity and Design Energy Input Fraction at 0.8

$\begin{array}{lll}8.889 & 26.667 & 115.00\end{array}$

$1.2673 \quad 0.7600$

!Capacity and Design Energy Input Fraction at 0.8

$8.889 \quad 26.667 \quad 116.11$

$0.9898 \quad 0.7760$

!Capacity and Design Energy Input Fraction at 0.8

$\begin{array}{lll}8.889 & 29.444 & 108.89\end{array}$

$1.0408 \quad 0.7760$

!Capacity and Design Energy Input Fraction at 0.8

$\begin{array}{lll}8.889 & 29.444 & 111.67\end{array}$

$1.0898 \quad 0.7760$

!Capacity and Design Energy Input Fraction at 0.8

$8.889 \quad 29.444 \quad 113.89$

$\begin{array}{ll}1.1122 & 0.7760\end{array}$

!Capacity and Design Energy Input Fraction at 0.8

$\begin{array}{lll}8.889 & 29.444 & 115.00\end{array}$

$1.1347 \quad 0.7760$

!Capacity and Design Energy Input Fraction at 0.8

$8.889 \quad 29.444 \quad 116.11$

$0.8592 \quad 0.8000$

!Capacity and Design Energy Input Fraction at 0.8

$\begin{array}{lll}8.889 & 32.222 & 108.89\end{array}$ 


\section{Appendix C: Chiller performance data}

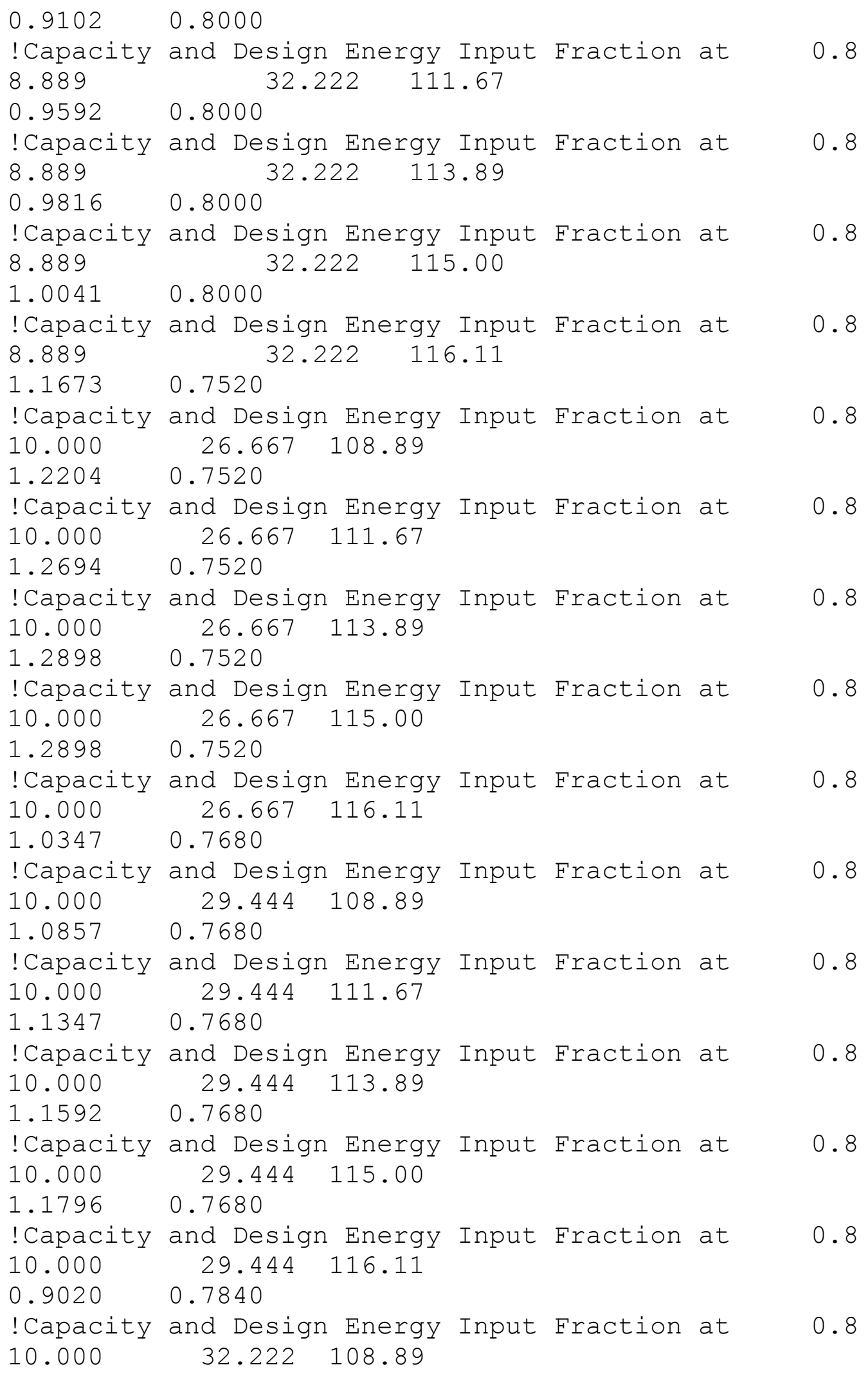




\section{Appendix C: Chiller performance data}

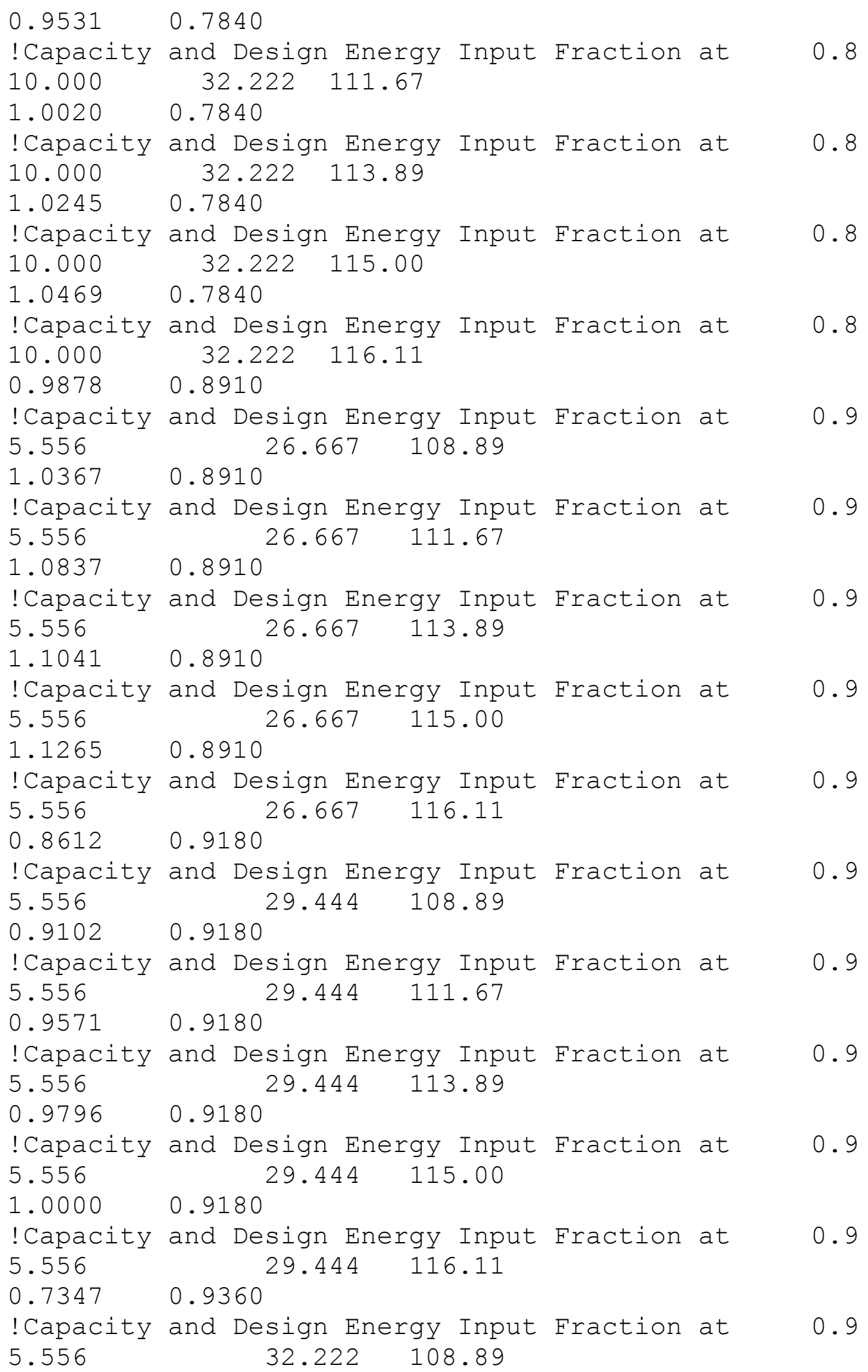




\section{Appendix C: Chiller performance data}

$0.7857 \quad 0.9360$

!Capacity and Design Energy Input Fraction at 0.9

$\begin{array}{lll}5.556 & 32.222 & 111.67\end{array}$

$0.8327 \quad 0.9360$

!Capacity and Design Energy Input Fraction at 0.9

$\begin{array}{lll}5.556 & 32.222 & 113.89\end{array}$

$0.8531 \quad 0.9360$

!Capacity and Design Energy Input Fraction at 0.9

$\begin{array}{lll}5.556 & 32.222 & 115.00\end{array}$

$0.8735 \quad 0.9360$

!Capacity and Design Energy Input Fraction at 0.9

$\begin{array}{lll}5.556 & 32.222 & 116.11\end{array}$

$1.0102 \quad 0.8820$

!Capacity and Design Energy Input Fraction at 0.9

$\begin{array}{lll}6.111 & 26.667 & 108.89\end{array}$

$\begin{array}{ll}1.0592 & 0.8820\end{array}$

!Capacity and Design Energy Input Fraction at 0.9

$\begin{array}{lll}6.111 & 26.667 & 111.67\end{array}$

$1.1061 \quad 0.8820$

!Capacity and Design Energy Input Fraction at 0.9

$\begin{array}{lll}6.111 & 26.667 & 113.89\end{array}$

$1.1286 \quad 0.8820$

!Capacity and Design Energy Input Fraction at 0.9

$\begin{array}{lll}6.111 & 26.667 & 115.00\end{array}$

$1.1490 \quad 0.8820$

!Capacity and Design Energy Input Fraction at 0.9

$6.111 \quad 26.667 \quad 116.11$

$0.8837 \quad 0.9090$

!Capacity and Design Energy Input Fraction at 0.9

$\begin{array}{lll}6.111 \quad 29.444 & 108.89\end{array}$

$0.9327 \quad 0.9090$

!Capacity and Design Energy Input Fraction at 0.9

$\begin{array}{lll}6.111 & 29.444 & 111.67\end{array}$

$0.9776 \quad 0.9090$

!Capacity and Design Energy Input Fraction at 0.9

$6.111 \quad 29.444 \quad 113.89$

$1.0000 \quad 0.9090$

!Capacity and Design Energy Input Fraction at 0.9

$\begin{array}{lll}6.111 & 29.444 & 115.00\end{array}$

$1.0224 \quad 0.9090$

!Capacity and Design Energy Input Fraction at 0.9

$6.111 \quad 29.444 \quad 116.11$

$0.7571 \quad 0.9360$

!Capacity and Design Energy Input Fraction at 0.9

$\begin{array}{lll}6.111 & 32.222 & 108.89\end{array}$ 


\section{Appendix C: Chiller performance data}

$0.8061 \quad 0.9360$

!Capacity and Design Energy Input Fraction at 0.9

$\begin{array}{lll}6.111 & 32.222 & 111.67\end{array}$

$0.8531 \quad 0.9360$

!Capacity and Design Energy Input Fraction at 0.9

$\begin{array}{lll}6.111 & 32.222 & 113.89\end{array}$

$0.8735 \quad 0.9360$

!Capacity and Design Energy Input Fraction at 0.9

$\begin{array}{lll}6.111 & 32.222 & 115.00\end{array}$

$0.8959 \quad 0.9360$

!Capacity and Design Energy Input Fraction at 0.9

$\begin{array}{lll}6.111 & 32.222 & 116.11\end{array}$

$\begin{array}{ll}1.0306 & 0.8820\end{array}$

!Capacity and Design Energy Input Fraction at 0.9

$6.667 \quad 26.667 \quad 108.89$

$\begin{array}{ll}1.0816 & 0.8820\end{array}$

!Capacity and Design Energy Input Fraction at 0.9

$\begin{array}{lll}6.667 & 26.667 & 111.67\end{array}$

$\begin{array}{ll}1.1286 & 0.8820\end{array}$

!Capacity and Design Energy Input Fraction at 0.9

$\begin{array}{lll}6.667 & 26.667 & 113.89\end{array}$

$\begin{array}{ll}1.1510 & 0.8820\end{array}$

!Capacity and Design Energy Input Fraction at 0.9

$\begin{array}{lll}6.667 & 26.667 & 115.00\end{array}$

$1.1714 \quad 0.8820$

!Capacity and Design Energy Input Fraction at 0.9

$6.667 \quad 26.667 \quad 116.11$

$0.9041 \quad 0.9000$

!Capacity and Design Energy Input Fraction at 0.9

$6.667 \quad 29.444 \quad 108.89$

$0.9531 \quad 0.9000$

!Capacity and Design Energy Input Fraction at 0.9

$6.667 \quad 29.444 \quad 111.67$

$1.0000 \quad 0.9000$

!Capacity and Design Energy Input Fraction at 0.9

$6.667 \quad 29.444 \quad 113.89$

1.02240 .9000

!Capacity and Design Energy Input Fraction at 0.9

$6.667 \quad 29.444 \quad 115.00$

$1.0449 \quad 0.9000$

!Capacity and Design Energy Input Fraction at 0.9

$6.667 \quad 29.444 \quad 116.11$

$0.7776 \quad 0.9270$

!Capacity and Design Energy Input Fraction at 0.9

$\begin{array}{lll}6.667 & 32.222 \quad 108.89\end{array}$ 


\section{Appendix C: Chiller performance data}

$0.8265 \quad 0.9270$

!Capacity and Design Energy Input Fraction at 0.9 $\begin{array}{lll}6.667 & 32.222 & 111.67\end{array}$

$0.8735 \quad 0.9270$

!Capacity and Design Energy Input Fraction at 0.9

$\begin{array}{lll}6.667 & 32.222 & 113.89\end{array}$

$0.8959 \quad 0.9270$

!Capacity and Design Energy Input Fraction at 0.9

$\begin{array}{lll}6.667 & 32.222 & 115.00\end{array}$

$0.9163 \quad 0.9270$

!Capacity and Design Energy Input Fraction at 0.9

$\begin{array}{lll}6.667 & 32.222 & 116.11\end{array}$

$\begin{array}{ll}1.0531 & 0.8730\end{array}$

!Capacity and Design Energy Input Fraction at 0.9

$\begin{array}{lll}7.222 & 26.667 & 108.89\end{array}$

$\begin{array}{ll}1.1041 & 0.8730\end{array}$

!Capacity and Design Energy Input Fraction at 0.9

$\begin{array}{lll}7.222 & 26.667 & 111.67\end{array}$

$\begin{array}{ll}1.1510 & 0.8730\end{array}$

!Capacity and Design Energy Input Fraction at 0.9

$\begin{array}{lll}7.222 & 26.667 & 113.89\end{array}$

$\begin{array}{ll}1.1735 & 0.8730\end{array}$

!Capacity and Design Energy Input Fraction at 0.9

$\begin{array}{lll}7.222 & 26.667 & 115.00\end{array}$

$1.1959 \quad 0.8730$

!Capacity and Design Energy Input Fraction at 0.9

$\begin{array}{lll}7.222 & 26.667 & 116.11\end{array}$

$0.9245 \quad 0.8910$

!Capacity and Design Energy Input Fraction at 0.9

$\begin{array}{lll}7.222 & 29.444 & 108.89\end{array}$

$0.9755 \quad 0.8910$

!Capacity and Design Energy Input Fraction at 0.9

$\begin{array}{lll}7.222 & 29.444 & 111.67\end{array}$

1.02240 .8910

!Capacity and Design Energy Input Fraction at 0.9

$\begin{array}{lll}7.222 & 29.444 & 113.89\end{array}$

$1.0449 \quad 0.8910$

!Capacity and Design Energy Input Fraction at 0.9

$\begin{array}{lll}7.222 & 29.444 & 115.00\end{array}$

$1.0673 \quad 0.8910$

!Capacity and Design Energy Input Fraction at 0.9

$\begin{array}{lll}7.222 & 29.444 & 116.11\end{array}$

$0.7980 \quad 0.9180$

!Capacity and Design Energy Input Fraction at 0.9

$\begin{array}{lll}7.222 & 32.222 & 108.89\end{array}$ 


\section{Appendix C: Chiller performance data}

$0.8469 \quad 0.9180$

!Capacity and Design Energy Input Fraction at 0.9

7.222

$32.222 \quad 111.67$

0.8939

0.9180

!Capacity and Design Energy Input Fraction at

0.9

7.222

$32.222 \quad 113.89$

0.9163

0.9180

!Capacity and Design Energy Input Fraction at

0.9

7.222

$32.222 \quad 115.00$

0.9388

0.9180

!Capacity and Design Energy Input Fraction at

0.9

7.222

$32.222 \quad 116.11$

1.0755

0.8640

!Capacity and Design Energy Input Fraction at

0.9

$\begin{array}{lll}7.778 & 26.667 & 108.89\end{array}$

$\begin{array}{ll}1.1265 & 0.8640\end{array}$

!Capacity and Design Energy Input Fraction at 0.9

7.778

$26.667 \quad 111.67$

1.1755

0.8640

!Capacity and Design Energy Input Fraction at

0.9

7.778

$26.667 \quad 113.89$

1.1980

0.8640

!Capacity and Design Energy Input Fraction at

7.778

$26.667 \quad 115.00$

1.2184

0.8640

!Capacity and Design Energy Input Fraction at

7.778 $26.667 \quad 116.11$

0.9469

0.8820

!Capacity and Design Energy Input Fraction at

7.778

$29.444 \quad 108.89$

0.9980

0.8820

!Capacity and Design Energy Input Fraction at

7.778

$29.444 \quad 111.67$

1.0449

0.8820

!Capacity and Design Energy Input Fraction at

7.778

$29.444 \quad 113.89$

1.0673

0.8820

!Capacity and Design Energy Input Fraction at

7.778

$29.444 \quad 115.00$

1.0898

0.8820

!Capacity and Design Energy Input Fraction at

0.9

7.778 $29.444 \quad 116.11$

0.8184

0.9090

!Capacity and Design Energy Input Fraction at 7.778

$32.222 \quad 108.89$

0.9

0.9

0.9

0.9

0.9

0.9

0.9 


\section{Appendix C: Chiller performance data}

$0.8694 \quad 0.9090$

!Capacity and Design Energy Input Fraction at 0.9

7.778

$32.222 \quad 111.67$

0.9163

0.9090

!Capacity and Design Energy Input Fraction at

0.9

7.778

$32.222 \quad 113.89$

0.9388

0.9090

!Capacity and Design Energy Input Fraction at

0.9

7.778

$32.222 \quad 115.00$

0.9592

0.9090

!Capacity and Design Energy Input Fraction at

0.9

7.778

$32.222 \quad 116.11$

1.1204

0.8550

!Capacity and Design Energy Input Fraction at

0.9

8.889

$26.667 \quad 108.89$

1.1735

0.8550

!Capacity and Design Energy Input Fraction at

8.889

$26.667 \quad 111.67$

1.2204

0.8550

!Capacity and Design Energy Input Fraction at

8.889

$26.667 \quad 113.89$

1.2449

0.8550

!Capacity and Design Energy Input Fraction at

8.889

$26.667 \quad 115.00$

1.2673

0.8550

!Capacity and Design Energy Input Fraction at

8.889

$26.667 \quad 116.11$

0.9898

0.8730

!Capacity and Design Energy Input Fraction at

8.889

$29.444 \quad 108.89$

1.0408

0.8730

!Capacity and Design Energy Input Fraction at

8.889

$29.444 \quad 111.67$

1.0898

0.8730

!Capacity and Design Energy Input Fraction at

8.889

$29.444 \quad 113.89$

1.1122

0.8730

!Capacity and Design Energy Input Fraction at

8.889

$29.444 \quad 115.00$

1.1347

0.8730

!Capacity and Design Energy Input Fraction at

0.9

8.889

$29.444 \quad 116.11$

0.8592

0.9000

!Capacity and Design Energy Input Fraction at

0.9

8.889

$32.222 \quad 108.89$

0.9

0.9

0.9

0.9

0.9

0.9

0.9

0.9 


\section{Appendix C: Chiller performance data}

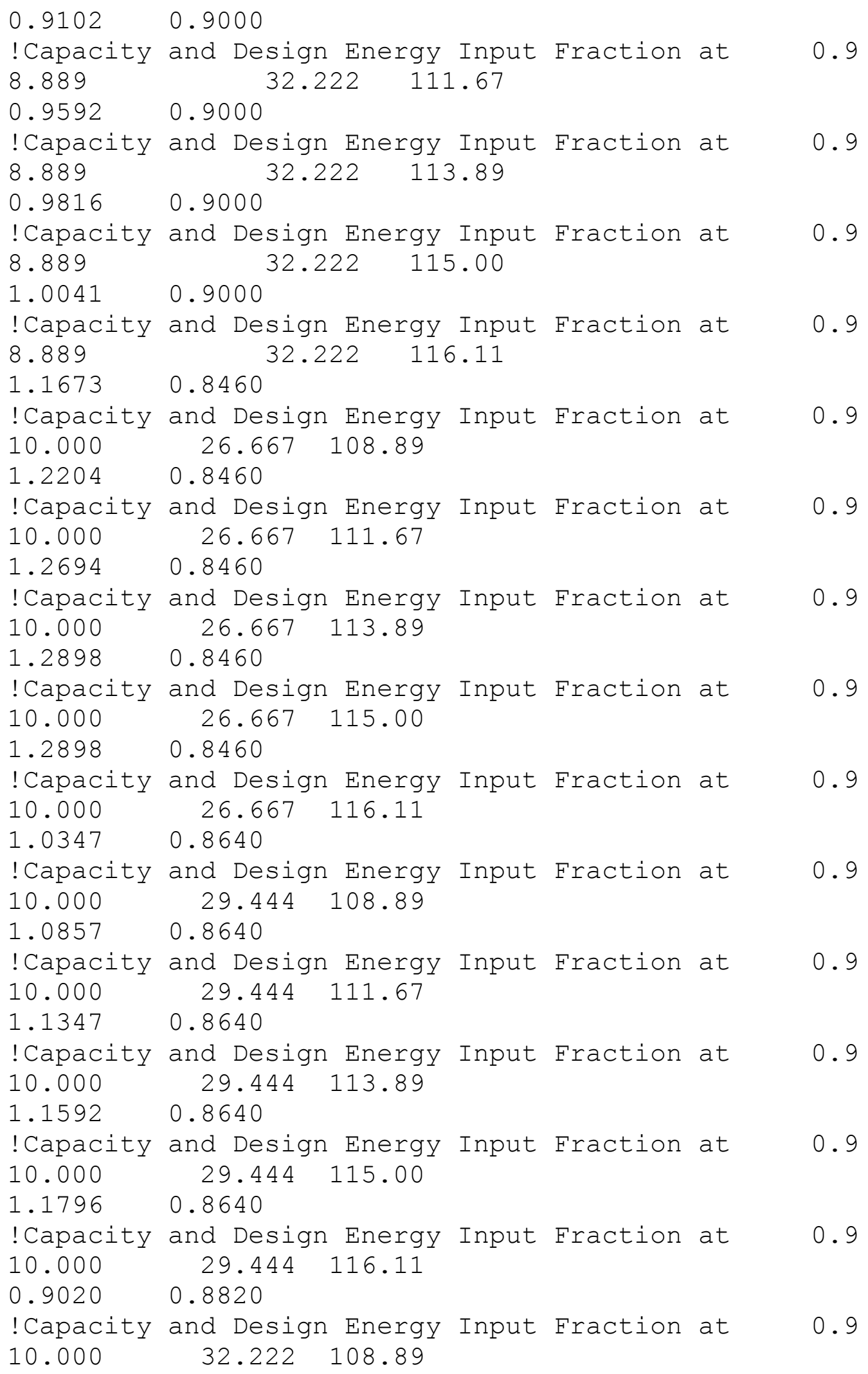




\section{Appendix C: Chiller performance data}

\begin{tabular}{|c|c|c|c|c|}
\hline 0.9531 & 0.8820 & & & \\
\hline ! Capacity & and Design Energy & Input & Fraction at & 0.9 \\
\hline 10.000 & $32.222 \quad 111.67$ & & & \\
\hline 1.0020 & 0.8820 & & & \\
\hline ! Capacity & and Design Energy & Input & Fraction at & 0.9 \\
\hline 10.000 & $32.222 \quad 113.89$ & & & \\
\hline 1.0245 & 0.8820 & & & \\
\hline ! Capacity & and Design Energy & Input & Fraction at & 0.9 \\
\hline 10.000 & $32.222 \quad 115.00$ & & & \\
\hline 1.0469 & 0.8820 & & & \\
\hline ! Capacity & and Design Energy & Input & Fraction at & 0.9 \\
\hline 10.000 & $32.222 \quad 116.11$ & & & \\
\hline 0.9878 & 0.9900 & & & \\
\hline ! Capacity & and Design Energy & Input & Fraction at & 1 \\
\hline 5.556 & $26.667 \quad 10$ & 8.89 & & \\
\hline 1.0367 & 0.9900 & & & \\
\hline ! Capacity & and Design Energy & Input & Fraction at & 1 \\
\hline 5.556 & $26.667 \quad 11$ & 1.67 & & \\
\hline 1.0837 & 0.9900 & & & \\
\hline ! Capacity & and Design Energy & Input & Fraction at & 1 \\
\hline 5.556 & $26.667 \quad 11$ & 3.89 & & \\
\hline 1.1041 & 0.9900 & & & \\
\hline ! Capacity & and Design Energy & Input & Fraction at & 1 \\
\hline 5.556 & $\begin{array}{rr}26.667 & 11\end{array}$ & 5.00 & & \\
\hline 1.1265 & 0.9900 & & & \\
\hline ! Capacity & and Design Energy & Input & Fraction at & 1 \\
\hline 5.556 & $26.667 \quad 11$ & 6.11 & & \\
\hline 0.8612 & 1.0200 & & & \\
\hline ! Capacity & and Design Energy & Input & Fraction at & 1 \\
\hline 5.556 & $29.444 \quad 10$ & 8.89 & & \\
\hline 0.9102 & 1.0200 & & & \\
\hline ! Capacity & and Design Energy & Input & Fraction at & 1 \\
\hline 5.556 & 29.444 & 1.67 & & \\
\hline 0.9571 & 1.0200 & & & \\
\hline ! Capacity & and Design Energy & Input & Fraction at & 1 \\
\hline 5.556 & 29.444 & 3.89 & & \\
\hline 0.9796 & 1.0200 & & & \\
\hline ! Capacity & and Design Energy & Input & Fraction at & 1 \\
\hline 5.556 & $29.444 \quad 11$ & 5.00 & & \\
\hline 1.0000 & 1.0200 & & & \\
\hline ! Capacity & and Design Energy & Input & Fraction at & 1 \\
\hline 5.556 & $29.444 \quad 11$ & 6.11 & & \\
\hline 0.7347 & 1.0400 & & & \\
\hline ! Capacity & and Design Energy & Input & Fraction at & 1 \\
\hline 5.556 & $32.222 \quad 10$ & 8.89 & & \\
\hline
\end{tabular}




\section{Appendix C: Chiller performance data}

$0.7857 \quad 1.0400$

!Capacity and Design Energy Input Fraction at 1

$\begin{array}{lll}5.556 & 32.222 & 111.67\end{array}$

$0.8327 \quad 1.0400$

!Capacity and Design Energy Input Fraction at 1

$\begin{array}{lll}5.556 & 32.222 & 113.89\end{array}$

$0.8531 \quad 1.0400$

!Capacity and Design Energy Input Fraction at 1

$\begin{array}{lll}5.556 & 32.222 & 115.00\end{array}$

$0.8735 \quad 1.0400$

!Capacity and Design Energy Input Fraction at 1

$\begin{array}{lll}5.556 & 32.222 & 116.11\end{array}$

$1.0102 \quad 0.9800$

!Capacity and Design Energy Input Fraction at 1

$\begin{array}{lll}6.111 & 26.667 & 108.89\end{array}$

$\begin{array}{ll}1.0592 & 0.9800\end{array}$

!Capacity and Design Energy Input Fraction at 1

$\begin{array}{lll}6.111 & 26.667 & 111.67\end{array}$

$1.1061 \quad 0.9800$

!Capacity and Design Energy Input Fraction at 1

$\begin{array}{lll}6.111 & 26.667 & 113.89\end{array}$

$\begin{array}{ll}1.1286 & 0.9800\end{array}$

!Capacity and Design Energy Input Fraction at 1

$\begin{array}{lll}6.111 & 26.667 & 115.00\end{array}$

$1.1490 \quad 0.9800$

!Capacity and Design Energy Input Fraction at 1

$\begin{array}{lll}6.111 & 26.667 & 116.11\end{array}$

$0.8837 \quad 1.0100$

!Capacity and Design Energy Input Fraction at 1

$\begin{array}{lll}6.111 & 29.444 & 108.89\end{array}$

$0.9327 \quad 1.0100$

!Capacity and Design Energy Input Fraction at 1

$6.111 \quad 29.444 \quad 111.67$

$0.9776 \quad 1.0100$

!Capacity and Design Energy Input Fraction at 1

$6.111 \quad 29.444 \quad 113.89$

$1.0000 \quad 1.0100$

!Capacity and Design Energy Input Fraction at 1

$6.111 \quad 29.444 \quad 115.00$

$1.0224 \quad 1.0100$

!Capacity and Design Energy Input Fraction at 1

$6.111 \quad 29.444 \quad 116.11$

$0.7571 \quad 1.0400$

!Capacity and Design Energy Input Fraction at 1
6.111
$32.222 \quad 108.89$ 


\section{Appendix C: Chiller performance data}

$0.8061 \quad 1.0400$

!Capacity and Design Energy Input Fraction at 1

$\begin{array}{lll}6.111 & 32.222 & 111.67\end{array}$

$0.8531 \quad 1.0400$

!Capacity and Design Energy Input Fraction at 1

$\begin{array}{lll}6.111 & 32.222 & 113.89\end{array}$

$0.8735 \quad 1.0400$

!Capacity and Design Energy Input Fraction at 1

$\begin{array}{lll}6.111 & 32.222 & 115.00\end{array}$

0.89591 .0400

!Capacity and Design Energy Input Fraction at 1

$\begin{array}{lll}6.111 & 32.222 & 116.11\end{array}$

$1.0306 \quad 0.9800$

!Capacity and Design Energy Input Fraction at 1

$6.667 \quad 26.667 \quad 108.89$

$\begin{array}{ll}1.0816 & 0.9800\end{array}$

!Capacity and Design Energy Input Fraction at 1

$6.667 \quad 26.667 \quad 111.67$

$1.1286 \quad 0.9800$

!Capacity and Design Energy Input Fraction at 1

$\begin{array}{lll}6.667 & 26.667 & 113.89\end{array}$

$1.1510 \quad 0.9800$

!Capacity and Design Energy Input Fraction at 1

$6.667 \quad 26.667 \quad 115.00$

$1.1714 \quad 0.9800$

!Capacity and Design Energy Input Fraction at 1

$6.667 \quad 26.667 \quad 116.11$

$0.9041 \quad 1.0000$

!Capacity and Design Energy Input Fraction at 1

$6.667 \quad 29.444 \quad 108.89$

$0.9531 \quad 1.0000$

!Capacity and Design Energy Input Fraction at 1

$6.667 \quad 29.444 \quad 111.67$

$1.0000 \quad 1.0000$

!Capacity and Design Energy Input Fraction at 1

$6.667 \quad 29.444 \quad 113.89$

$1.0224 \quad 1.0000$

!Capacity and Design Energy Input Fraction at 1

$\begin{array}{lll}6.667 & 29.444 & 115.00\end{array}$

$1.0449 \quad 1.0000$

!Capacity and Design Energy Input Fraction at 1

$6.667 \quad 29.444 \quad 116.11$

$0.7776 \quad 1.0300$

!Capacity and Design Energy Input Fraction at 1
6.667
$32.222 \quad 108.89$ 


\section{Appendix C: Chiller performance data}

$0.8265 \quad 1.0300$

!Capacity and Design Energy Input Fraction at 1 $\begin{array}{lll}6.667 & 32.222 & 111.67\end{array}$

$0.8735 \quad 1.0300$

!Capacity and Design Energy Input Fraction at 1 $\begin{array}{lll}6.667 & 32.222 \quad 113.89\end{array}$

$0.8959 \quad 1.0300$

!Capacity and Design Energy Input Fraction at 1 $\begin{array}{lll}6.667 & 32.222 & 115.00\end{array}$

$0.9163 \quad 1.0300$

!Capacity and Design Energy Input Fraction at 1 $\begin{array}{lll}6.667 & 32.222 & 116.11\end{array}$

$1.0531 \quad 0.9700$

!Capacity and Design Energy Input Fraction at 1 $\begin{array}{lll}7.222 & 26.667 & 108.89\end{array}$

$\begin{array}{ll}1.1041 & 0.9700\end{array}$

!Capacity and Design Energy Input Fraction at 1

$\begin{array}{lll}7.222 & 26.667 & 111.67\end{array}$

$1.1510 \quad 0.9700$

!Capacity and Design Energy Input Fraction at 1

$\begin{array}{lll}7.222 & 26.667 & 113.89\end{array}$

$\begin{array}{ll}1.1735 & 0.9700\end{array}$

!Capacity and Design Energy Input Fraction at 1

$\begin{array}{lll}7.222 & 26.667 & 115.00\end{array}$

$1.1959 \quad 0.9700$

!Capacity and Design Energy Input Fraction at 1

$\begin{array}{lll}7.222 & 26.667 & 116.11\end{array}$

$0.9245 \quad 0.9900$

!Capacity and Design Energy Input Fraction at 1

$\begin{array}{lll}7.222 & 29.444 & 108.89\end{array}$

$0.9755 \quad 0.9900$

!Capacity and Design Energy Input Fraction at 1

$\begin{array}{lll}7.222 & 29.444 & 111.67\end{array}$

$1.0224 \quad 0.9900$

!Capacity and Design Energy Input Fraction at 1

$\begin{array}{lll}7.222 & 29.444 & 113.89\end{array}$

$1.0449 \quad 0.9900$

!Capacity and Design Energy Input Fraction at 1

$\begin{array}{lll}7.222 & 29.444 & 115.00\end{array}$

$1.0673 \quad 0.9900$

!Capacity and Design Energy Input Fraction at 1

$\begin{array}{lll}7.222 & 29.444 & 116.11\end{array}$

$0.7980 \quad 1.0200$

!Capacity and Design Energy Input Fraction at 1
7.222
$32.222 \quad 108.89$ 


\section{Appendix C: Chiller performance data}

$0.8469 \quad 1.0200$

!Capacity and Design Energy Input Fraction at 1

$\begin{array}{lll}7.222 & 32.222 & 111.67\end{array}$

$0.8939 \quad 1.0200$

!Capacity and Design Energy Input Fraction at 1

$\begin{array}{lll}7.222 & 32.222 & 113.89\end{array}$

$0.9163 \quad 1.0200$

!Capacity and Design Energy Input Fraction at 1

$\begin{array}{lll}7.222 & 32.222 & 115.00\end{array}$

$0.9388 \quad 1.0200$

!Capacity and Design Energy Input Fraction at 1

$\begin{array}{lll}7.222 & 32.222 & 116.11\end{array}$

$1.0755 \quad 0.9600$

!Capacity and Design Energy Input Fraction at 1

$\begin{array}{lll}7.778 & 26.667 & 108.89\end{array}$

$\begin{array}{ll}1.1265 & 0.9600\end{array}$

!Capacity and Design Energy Input Fraction at 1

$\begin{array}{lll}7.778 & 26.667 & 111.67\end{array}$

$1.1755 \quad 0.9600$

!Capacity and Design Energy Input Fraction at 1

$\begin{array}{lll}7.778 & 26.667 & 113.89\end{array}$

$1.1980 \quad 0.9600$

!Capacity and Design Energy Input Fraction at 1

$\begin{array}{lll}7.778 & 26.667 & 115.00\end{array}$

$1.2184 \quad 0.9600$

!Capacity and Design Energy Input Fraction at 1

$\begin{array}{lll}7.778 & 26.667 & 116.11\end{array}$

$0.9469 \quad 0.9800$

!Capacity and Design Energy Input Fraction at 1

$\begin{array}{lll}7.778 & 29.444 & 108.89\end{array}$

$0.9980 \quad 0.9800$

!Capacity and Design Energy Input Fraction at 1

$\begin{array}{lll}7.778 & 29.444 & 111.67\end{array}$

1.04490 .9800

!Capacity and Design Energy Input Fraction at 1

$\begin{array}{lll}7.778 & 29.444 & 113.89\end{array}$

$1.0673 \quad 0.9800$

!Capacity and Design Energy Input Fraction at 1

$\begin{array}{lll}7.778 & 29.444 & 115.00\end{array}$

$\begin{array}{ll}1.0898 & 0.9800\end{array}$

!Capacity and Design Energy Input Fraction at 1

$\begin{array}{lll}7.778 & 29.444 & 116.11\end{array}$

$0.8184 \quad 1.0100$

!Capacity and Design Energy Input Fraction at 1
7.778
$32.222 \quad 108.89$ 


\section{Appendix C: Chiller performance data}

$0.8694 \quad 1.0100$

!Capacity and Design Energy Input Fraction at 1

$\begin{array}{lll}7.778 & 32.222 & 111.67\end{array}$

$0.9163 \quad 1.0100$

!Capacity and Design Energy Input Fraction at 1

$\begin{array}{lll}7.778 & 32.222 & 113.89\end{array}$

$0.9388 \quad 1.0100$

!Capacity and Design Energy Input Fraction at 1

$\begin{array}{lll}7.778 & 32.222 & 115.00\end{array}$

$0.9592 \quad 1.0100$

!Capacity and Design Energy Input Fraction at 1

$\begin{array}{lll}7.778 & 32.222 & 116.11\end{array}$

$1.1204 \quad 0.9500$

!Capacity and Design Energy Input Fraction at 1

$8.889 \quad 26.667 \quad 108.89$

$\begin{array}{ll}1.1735 & 0.9500\end{array}$

!Capacity and Design Energy Input Fraction at 1

$8.889 \quad 26.667 \quad 111.67$

$1.2204 \quad 0.9500$

!Capacity and Design Energy Input Fraction at 1

$\begin{array}{lll}8.889 & 26.667 & 113.89\end{array}$

$1.2449 \quad 0.9500$

!Capacity and Design Energy Input Fraction at 1

$8.889 \quad 26.667 \quad 115.00$

$1.2673 \quad 0.9500$

!Capacity and Design Energy Input Fraction at 1

$8.889 \quad 26.667 \quad 116.11$

$0.9898 \quad 0.9700$

!Capacity and Design Energy Input Fraction at 1

$\begin{array}{lll}8.889 & 29.444 & 108.89\end{array}$

$1.0408 \quad 0.9700$

!Capacity and Design Energy Input Fraction at 1

$\begin{array}{lll}8.889 & 29.444 & 111.67\end{array}$

$\begin{array}{ll}1.0898 & 0.9700\end{array}$

!Capacity and Design Energy Input Fraction at 1

$\begin{array}{lll}8.889 & 29.444 & 113.89\end{array}$

$1.1122 \quad 0.9700$

!Capacity and Design Energy Input Fraction at 1

$\begin{array}{lll}8.889 & 29.444 & 115.00\end{array}$

$1.1347 \quad 0.9700$

!Capacity and Design Energy Input Fraction at 1

$8.889 \quad 29.444 \quad 116.11$

$0.8592 \quad 1.0000$

!Capacity and Design Energy Input Fraction at 1
8.889
$32.222 \quad 108.89$ 


\section{Appendix C: Chiller performance data}

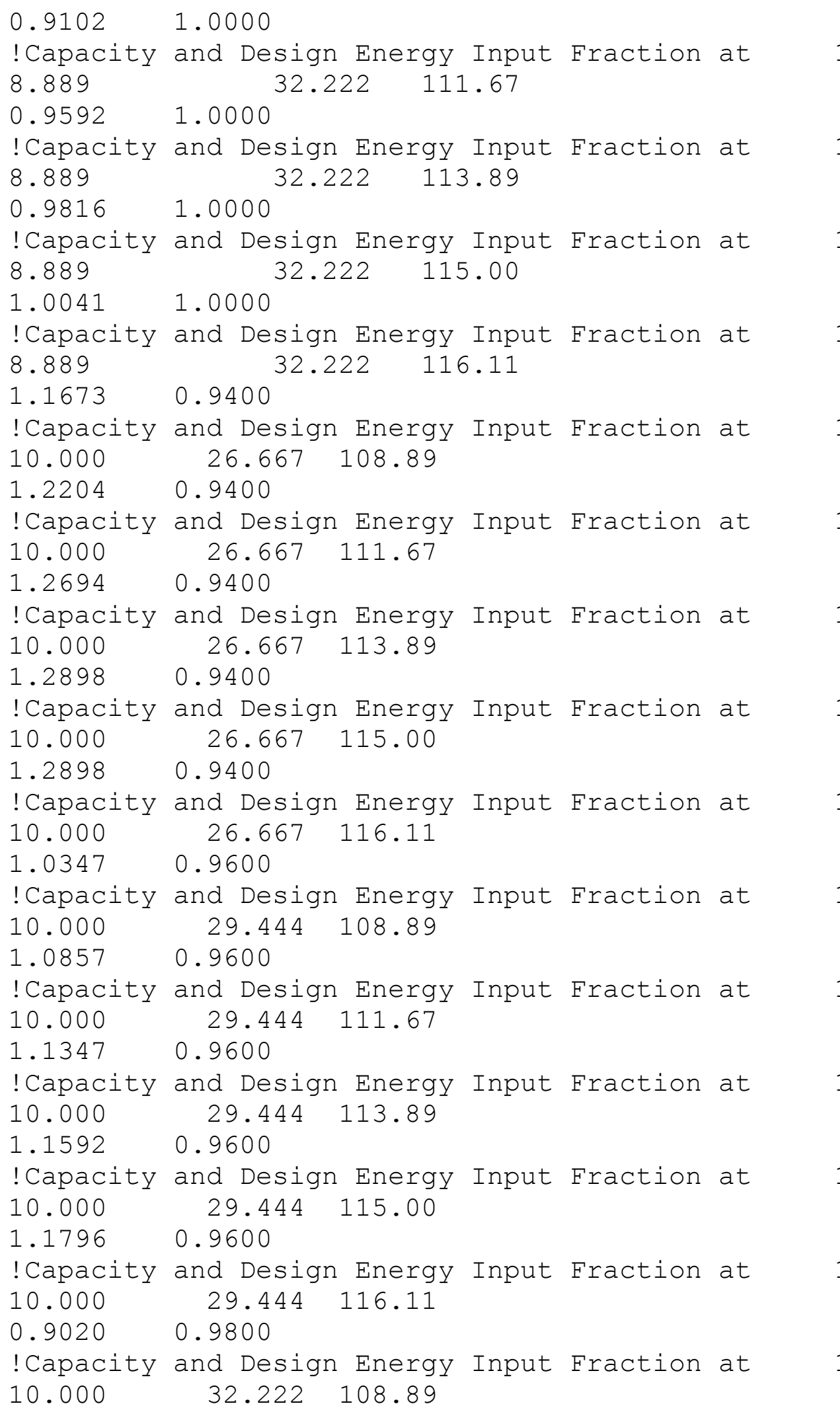




\section{Appendix C: Chiller performance data}

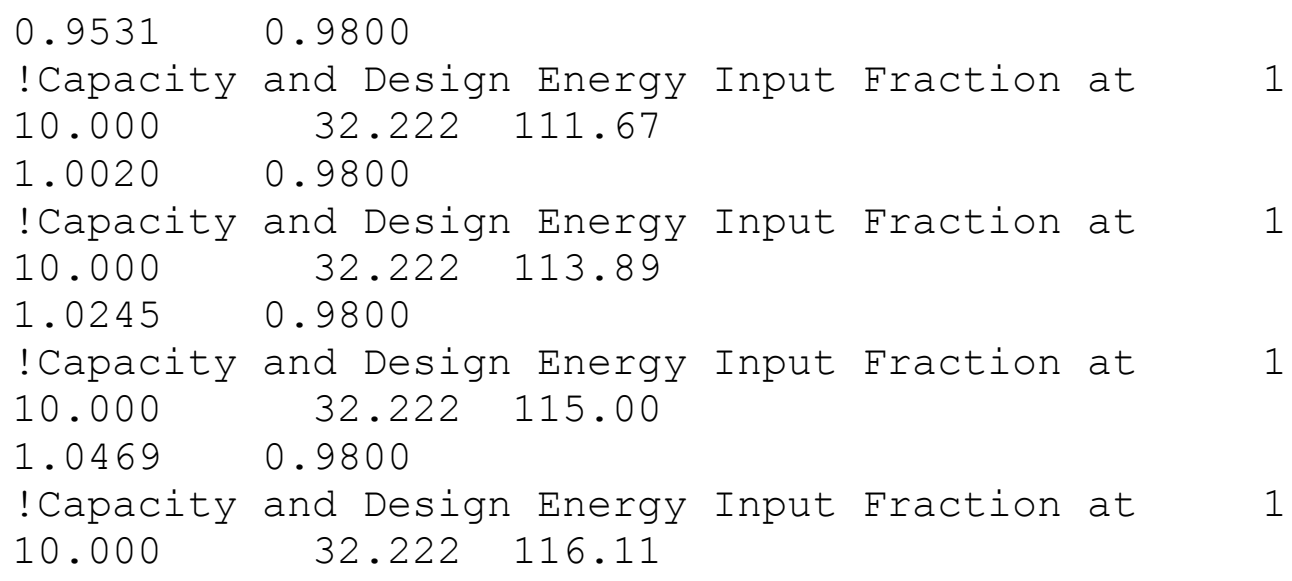




\section{Appendix D: Heat pump manufacturer data sheets}

\section{Appendix D: Heat pump manufacturer data sheets}

TMW LARGE SERIES 6D HZ - HFC-41DA SUBMITTAL DATA ENG/I-P Unit Features

THE TRANQUILITY ${ }^{\circ}$ LARGE WATER-TO-WATER (TMW) SERIES

The Tranquility ${ }^{\circledR}$ Large Water-to-Water (TMW) Series offers high efficiency and high capacity with advanced features, quiet operation and application flexibility at competitive prices. As ClimateMaster's largest waterto-water unit, the TMW Large Series can be used for radiant floor heating, snow/ice melt, chilled or hot water for fan coils, industrial process control, potable hot water generation*, hot/chilled water for make-up air, and many other types of HVAC and industrial applications that require cost effective heated or chilled water.

The Tranquility ${ }^{\mathbb{D}}$ Large Water-to-Water (TMW) Series exceeds ASHRAE 90.1 efficiencies, and also uses EarthPure ${ }^{\circledR}$ (HFC-410A) zero ozone depletion refrigerant making it an extremely environmentally-friendly option. The unit is eligible for additional LEED ${ }^{\circledR}$ (Leadership in Energy and Environmental Design) points because of the "green" technology design.

Available in 30,50 , and 70 ton capacities $(105.6 \mathrm{~kW}$. $176 \mathrm{~kW}$, and $246 \mathrm{~kW}$ ), the TMW Large Series provides high capacity in a small footprint, which saves mechanical room space. The TMW Large Series has an extended range refrigerant circuit (refrigerant and water circuit insulation is standard), capable of ground loop (geothermal) applications as well as water loop (boiler-tower) applications. Standard features are many. Microprocessor controls, galvanized steel cabinet, polyester powder coat paint, modulating motorized water valve on source side, and TXV refrigerant metering device are just some of the features of the flexible TMW Large Series. The brazed plate heat exchangers constructed of 316 stainless steel are designed for many years of reliable operation.

Scroll compressor(s) operate quietly, and provide part load operation for capacity control. For ease of installation and service, access to the refrigeration service and electrical control panel is located at the front of the unit, allowing units to be installed side-by-side for large capacity applications.

TMW Large Series is controlled by a (BAS) Building Automation System or BACview6. BAS or BACview6 is used to monitor, change operating setpoints, check faults, and service diagnostics of the TMW.

The TMW Series water-to-water heat pumps are designed to meet the challenges of to day's HVAC demands with a high efficiency, high value solution.

\section{UNIT FEATURES}

- Sizes 360 (30 tons, $105.6 \mathrm{~kW}$ ), 600 (50 tons, 176 kW), and $840(70$ tons, $246 \mathrm{~kW})$

- Copeland scroll compressor(s)

- Dual independent refrigeration circuits

- Exceeds ASHRAE 90.1 efficiencies

- Brazed plate heat exchanger for both source and load

- Exclusive front and back service access allows multiple units to be installed side-by-side for large capacity installations

- Top water connections, staggered for ease of manifolding multiple units

- Fully insulated water and refrigerant circuits

- Heavy gauge galvanized steel construction with polyester powder coat paint

- Insulated compressor compartment

- Small footprint

- TXV metering devices

- Extended range $\left(30\right.$ to $120^{\circ} \mathrm{F},-1.1$ to $\left.48.9^{\circ} \mathrm{C}\right)$ operation

- Microprocessor controls standard

- BACnet, Modbus, and Johnson N2 compatibility for DDC controls

- Lights on the front of the cabinet indicate unit power, fault, compressor 1 and 2 in operation

- Eleven safeties standard to protect the compressors and brazed plate heat exchangers

- Differential pressure sensors (2) for proof of water flow for Load and Source, factory installed.

- Optional modulating motorized water valve on Source side to maintain compressor head pressure

- Optional motorized valve on Load side for variable speed pumping.

- BACview 6 controller is used to set up unit controller at start up, and to monitor, change default settings, or service unit.

- Accessory 60 Mesh $Y$ and basket strainers to mount external of unit.

*Requires field supplied secondary heat exchanger.

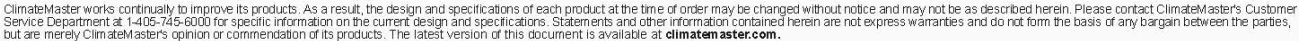
LC975 - 4

Rev.: 05, March 2015

Page of 


\section{Appendix D: Heat pump manufacturer data sheets}

TMW LARGE SERIES 6D HZ - HFC-41DA SUBMITTAL DATA ENG/I-P Selection Procedure

Reference Calculations

\begin{tabular}{|c|c|}
\hline $\begin{array}{c}\text { Heating } \\
L W T=E W T-\frac{H E}{G P M} \times 500\end{array}$ & $\begin{array}{c}\text { Cooling } \\
L W T\end{array}=\mathrm{EWT}+\frac{\mathrm{HR}}{\mathrm{GPM} \times 500}$ \\
\hline
\end{tabular}

Legend and Glossary of Abbreviations

BTUH = BTU ( British Thermal Unit $)$ per hour

$\mathrm{COP}=$ coefficient of performance $=\mathrm{BTUH}$ output $/ \mathrm{BTUH}$ input

$\mathrm{HC}=$ heating capacity, BTUH

$H R=$ total heat of rejection, $B T U H$

EER $=$ energy efficiency ratio $=\mathrm{BTUH}$ output $/$ Watt input

FPT $=$ female pipe thread

MPT = male pipe thread

$\mathrm{KW}=$ total power unit input, kilowatts

$E S P=$ external static pressure (inches w.g.)

$\mathrm{EWT}=$ entering water temperature

$\mathrm{LWT}=$ leaving water temperature, ${ }^{\circ} \mathrm{F}$

GPM = water flow in U.S. gallons/minute

MBTUH $=1000$ BTU per hour

$\mathrm{TC}=$ total cooling capacity, BTUH

$\mathrm{HE}=$ total heat of extraction, BTUH

WPD = waterside pressure drop (psi \& fft. of hd.)

Conversion Table - to convert inch-pound (English) to S-I (Metric)

\begin{tabular}{|c|c|}
\hline Water Flow & Water Pressure Drop \\
\hline Water Flow $(\mathrm{Ls})=\mathrm{gpm} \times 0.0631$ & $\mathrm{PD}(\mathrm{kPa})=\mathrm{PD}(\mathrm{t}$ of hd $) \times 2.99$ \\
\hline
\end{tabular}

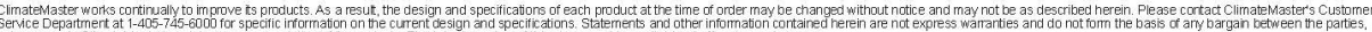
but are merey Climatem aster's coirion or commendation of ts products. The latest version of this document is avallable at climatemaster.
$\begin{aligned} & \text { LC975 - } 5 \\ & \text { Rev.: 05, March } 2015\end{aligned}$

Page of 


\section{Appendix D: Heat pump manufacturer data sheets}

TMW LARGE SERIES 6D HZ - HFC-41DA SUBMITTAL DATA ENG/I-P Performance Data - AHRI/ASHRAE/ISO 13256-2

TMW 360-840 Performance Data ASHRAE/AHRI/ISO 13256-2 English (I-P) Units

\begin{tabular}{|c|c|c|c|c|c|c|c|c|c|c|c|c|}
\hline \multirow{4}{*}{ Model } & \multicolumn{4}{|c|}{ Water Loop Heat Pump } & \multicolumn{4}{|c|}{ Ground Water Heat Pump } & \multicolumn{4}{|c|}{ Ground Loop Heat Pump } \\
\hline & \multicolumn{2}{|c|}{ Cooling } & \multicolumn{2}{|c|}{ Heating } & \multicolumn{2}{|c|}{ Cooling } & \multicolumn{2}{|c|}{ Heating } & \multicolumn{2}{|c|}{ Cooling } & \multicolumn{2}{|c|}{ Heating } \\
\hline & \multicolumn{2}{|c|}{$\begin{array}{l}\text { Indoor } 53.6^{\circ} \mathrm{F} \\
\text { Outdoor } 86^{\circ} \mathrm{F}\end{array}$} & \multicolumn{2}{|c|}{$\begin{array}{l}\text { Indoor } 104^{\circ} \mathrm{F} \\
\text { outdoor } 68^{\circ} \mathrm{F}\end{array}$} & \multicolumn{2}{|c|}{$\begin{array}{l}\text { Indoor } 53.6^{\circ} \mathrm{F} \\
\text { Outdoor } 59^{\circ} \mathrm{F}\end{array}$} & \multicolumn{2}{|c|}{$\begin{array}{l}\text { Indooor } 104^{\circ} \mathrm{F} \\
\text { Outdoor } 50^{\circ} \mathrm{F}\end{array}$} & \multicolumn{2}{|c|}{$\begin{array}{l}\text { Indoor } 53.6^{\circ} \mathrm{F} \\
\text { Outdoor } 77^{\circ} \mathrm{F}\end{array}$} & \multicolumn{2}{|c|}{$\begin{array}{l}\text { Indoor } 104^{\circ} \mathrm{F} \\
\text { Outdoor } 32^{\circ} \mathrm{F}\end{array}$} \\
\hline & $\begin{array}{c}\text { Capacity } \\
\text { Btuh }\end{array}$ & $\begin{array}{l}\text { EER } \\
\text { Btuh } W\end{array}$ & $\begin{array}{l}\text { Capacity } \\
\text { Btuh }\end{array}$ & COP & $\begin{array}{l}\text { Capacity } \\
\text { Btuh }\end{array}$ & $\begin{array}{l}\text { EER } \\
\text { Btuh } /\end{array}$ & $\begin{array}{l}\text { Capacity } \\
\text { Btuh }\end{array}$ & COP & $\begin{array}{c}\text { Capacity } \\
\text { Btuh }\end{array}$ & $\begin{array}{l}\text { EER } \\
\text { Btuhiw }\end{array}$ & $\begin{array}{c}\text { Capacity } \\
\text { Btuh }\end{array}$ & COP \\
\hline TMNN360 & 380,300 & 16.00 & 531,000 & 5.10 & 438,000 & 24.20 & 416,000 & 4.20 & 399,600 & 18.40 & 316,000 & 3.40 \\
\hline TMN600 & 619,800 & 16.00 & 873,000 & 5.20 & 707,400 & 23.20 & 680,000 & 4.30 & 649,600 & 18.20 & 517,000 & 3.40 \\
\hline TMN840 & 814,800 & 16.20 & $1,141,000$ & 5.30 & 925,700 & 23.30 & 894,000 & 4.40 & 852,600 & 18.40 & 677,000 & 3.40 \\
\hline
\end{tabular}

All TMW360 ratings @ 90GPM Load w/90 GPM Source.

All TMW600 ratings @ 150GPM Load w/150 GPM Source.

All TMW840 ratings @ $210 \mathrm{GPM}$ Load w/210 GPM Source.

All ratings based upon operation at lower voltage of dual voltage rated models.

TMW 360-840 Performance Data ASHRAE/AHRI/ISO 13256-2 Metric (S-I) Units

\begin{tabular}{|c|c|c|c|c|c|c|c|c|c|c|c|c|}
\hline \multirow{4}{*}{ Model } & \multicolumn{4}{|c|}{ Water Loop Heat Pump } & \multicolumn{4}{|c|}{ Ground Water Heat Pump } & \multicolumn{4}{|c|}{ Ground Loop Heat Pump } \\
\hline & \multicolumn{2}{|c|}{ Cooling } & \multicolumn{2}{|c|}{ Heating } & \multicolumn{2}{|c|}{ Cooling } & \multicolumn{2}{|c|}{ Heating } & \multicolumn{2}{|c|}{ Cooling } & \multicolumn{2}{|c|}{ Heating } \\
\hline & \multicolumn{2}{|c|}{$\begin{array}{l}\text { Indoor } 12^{\circ} \mathrm{C} \\
\text { Outdoor } 30^{\circ} \mathrm{C}\end{array}$} & \multicolumn{2}{|c|}{$\begin{array}{l}\text { Indoor } 40^{\circ} \mathrm{C} \\
\text { Outdoor } 20^{\circ} \mathrm{C}\end{array}$} & \multicolumn{2}{|c|}{$\begin{array}{l}\text { Indoor } 12^{\circ} \mathrm{C} \\
\text { Outdoor } 15^{\circ} \mathrm{C}\end{array}$} & \multicolumn{2}{|c|}{$\begin{array}{l}\text { Indoor } 40^{\circ} \mathrm{C} \\
\text { Outdoor } 10^{\circ} \mathrm{C}\end{array}$} & \multicolumn{2}{|c|}{$\begin{array}{l}\text { Indoor } 12^{\circ} \mathrm{C} \\
\text { Outdoor } 25^{\circ} \mathrm{C}\end{array}$} & \multicolumn{2}{|c|}{$\begin{array}{l}\text { Indoor } 40^{\circ} \mathrm{C} \\
\text { Outdoor } 0^{\circ} \mathrm{C}\end{array}$} \\
\hline & $\begin{array}{l}\text { Capacity } \\
\text { KW }\end{array}$ & $\begin{array}{l}\text { EER } \\
\text { W/W }\end{array}$ & $\begin{array}{l}\text { Capacity } \\
\text { KW }\end{array}$ & COP & $\begin{array}{l}\text { Capacity } \\
\text { kW }\end{array}$ & $\begin{array}{l}\text { EER } \\
\text { WNW }\end{array}$ & $\begin{array}{l}\text { Capacity } \\
\text { KWW }\end{array}$ & COP & $\begin{array}{l}\text { Capacity } \\
\text { KW }\end{array}$ & $\begin{array}{l}\text { EER } \\
\text { WMW }\end{array}$ & $\begin{array}{l}\text { Capacity } \\
\text { KW }\end{array}$ & COP \\
\hline TMN 360 & 111.46 & 4.70 & 155.63 & 5.10 & 128.37 & 7.10 & 121.92 & 4.20 & 117.12 & 5.39 & 92.61 & 3.40 \\
\hline TMN 600 & 181.65 & 4.70 & 255.86 & 5.20 & 207.33 & 6.80 & 199.30 & 4.30 & 190.39 & 5.33 & 151.52 & 3.40 \\
\hline TMN 840 & 238.80 & 4.75 & 334.41 & 5.30 & 271.31 & 6.83 & 262.02 & 4.40 & 249.88 & 5.39 & 198.42 & 3.40 \\
\hline
\end{tabular}

All TMW360 ratings@ $5.68 \mathrm{l} / \mathrm{s}$ Load w/5.68 I/s Source.

All TMW600 ratings @ $9.47 \mathrm{l} / \mathrm{s}$ Load w/9.47 1/s Source.

All TMW840 ratings@ $13.25 \mathrm{l} / \mathrm{s}$ Load w/13.25 l/s Source.

All ratings based upon operation at lower voltage of dual voltage rated models. 


\section{Appendix D: Heat pump manufacturer data sheets}

TMW LARgE SERIES 6D HZ - HFC-41DA SUBMITTAL DATA ENG/I-P Performance Data - TMW360 (60Hz I-P) - Cooling

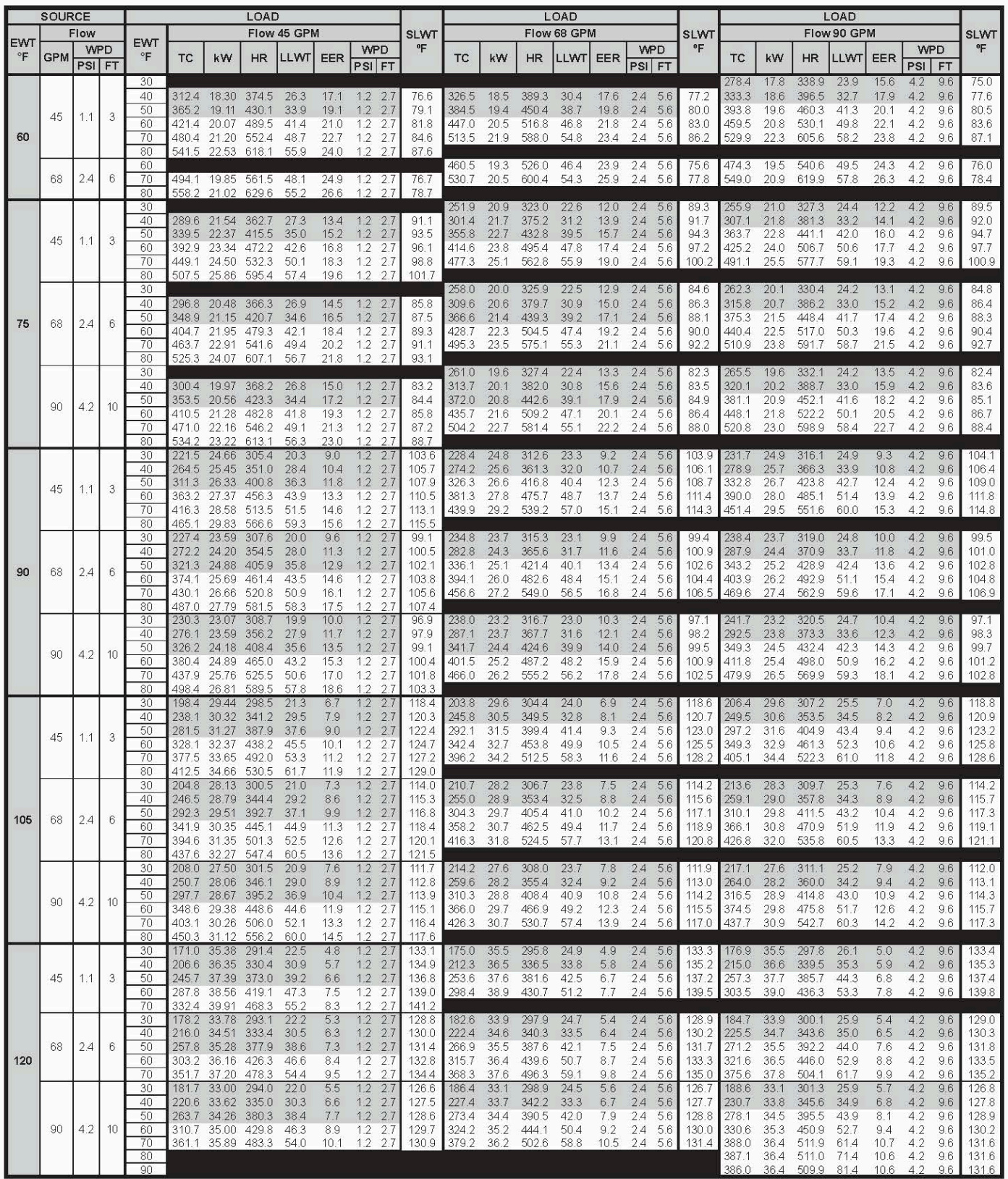

Interpolation is pemissible; extrapolation is not.

All pertormance is based upon the lower voltage of dual voliage rated units

thery the power supply varies from the rated

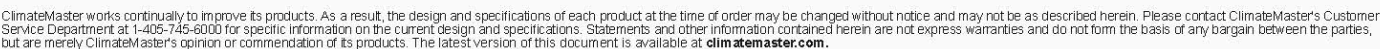
LC975 - 9 


\section{Appendix D: Heat pump manufacturer data sheets}

TMW LARGE SERIES 6D HZ - HFC-41DA SUBMITTAL DATA ENG/I-P Performance Data - TMW360 (60 Hz I-P) - Heating

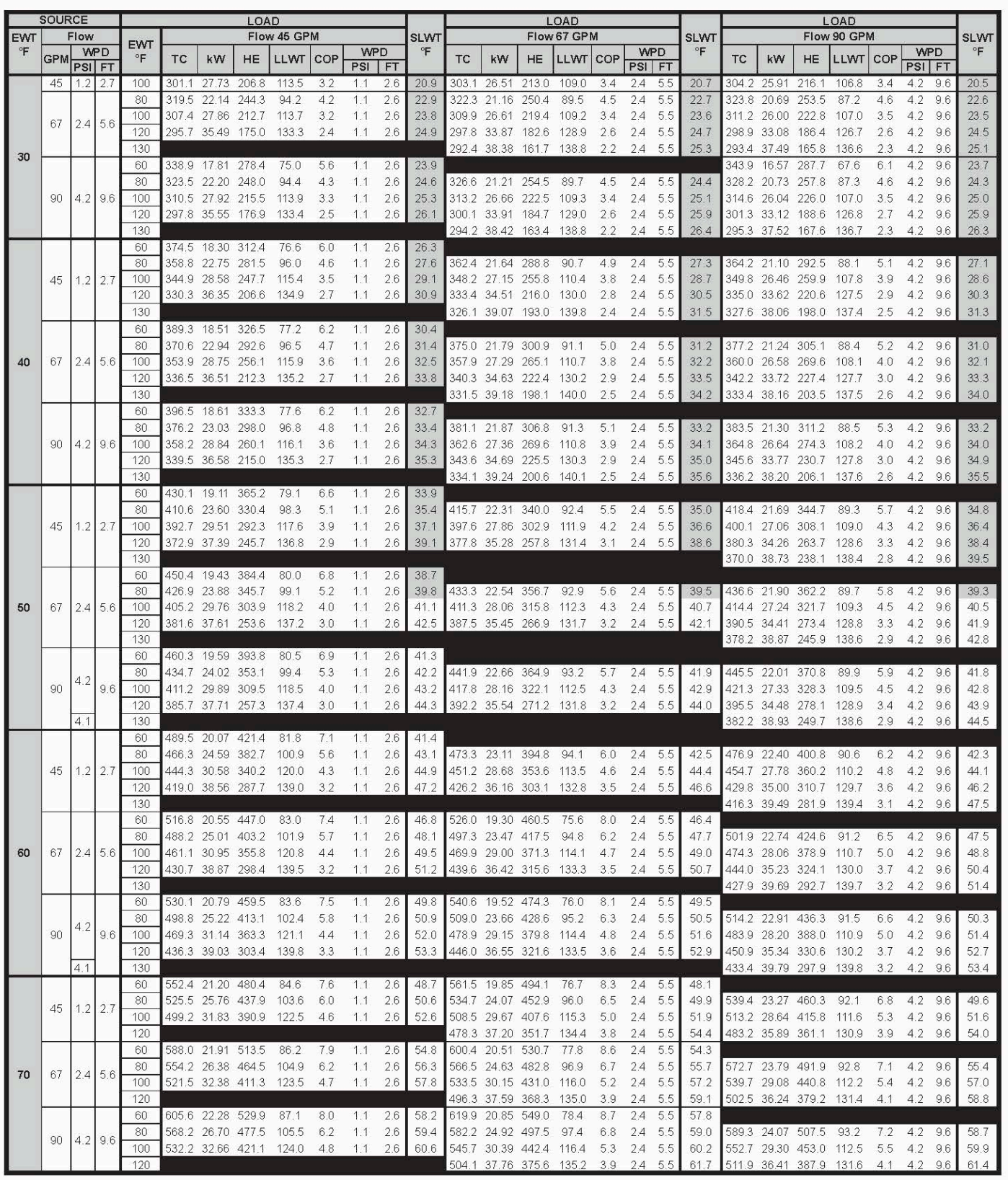

Interpolation is permis sible; extrapolation is not

All performance is based upon the lower voltage of dual voltage rated units.

Performance stated is at the rated power supply; performance may vary as the power supply varies from the rated

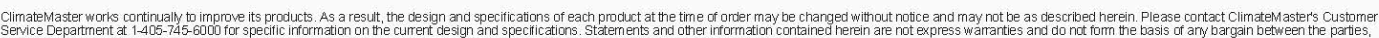

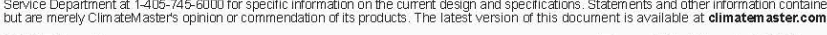

LC975 - 10

Rev: 05, March 2015

Page

of 


\section{Appendix D: Heat pump manufacturer data sheets}

TMW LARGE SERIES 6D HZ - HFC-41DA SUBMITTAL DATA ENG/I-P Antifreeze Correction Table

\begin{tabular}{|c|c|c|c|c|c|c|c|}
\hline \multirow{3}{*}{ Antifreeze Type } & \multirow{3}{*}{$\begin{array}{c}\text { Antifreeze } \\
\%\end{array}$} & \multirow{2}{*}{\multicolumn{3}{|c|}{$\begin{array}{l}\text { Cooling } \\
\text { EWT } 90^{\circ} \mathrm{F}\end{array}$}} & \multirow{2}{*}{\multicolumn{2}{|c|}{$\begin{array}{l}\text { Heating } \\
\text { EWT } 30^{\circ} \mathrm{F}\end{array}$}} & \multirow{3}{*}{$\begin{array}{c}\text { WPD } \\
\text { Corr. Fct. } \\
\text { EWT } 30^{\circ} \mathrm{F}\end{array}$} \\
\hline & & & & & & & \\
\hline & & $\begin{array}{l}\text { Total } \\
\text { Cap }\end{array}$ & $\begin{array}{l}\text { Sens } \\
\text { Cap }\end{array}$ & Power & $\begin{array}{l}\mathrm{Htg} \\
\text { Cap }\end{array}$ & Power & \\
\hline Water & 0 & 1.000 & 1.000 & 1.000 & 1.000 & 1.000 & 1.000 \\
\hline \multirow{3}{*}{ Propylene Glycol } & 5 & 0.995 & 0.995 & 1.003 & 0.989 & 0.997 & 1.070 \\
\hline & 15 & 0.986 & 0.986 & 1.009 & 0.968 & 0.990 & 1.210 \\
\hline & 25 & 0.978 & 0.978 & 1.014 & 0.947 & 0.983 & 1.360 \\
\hline \multirow{3}{*}{ Methanol } & 5 & 0.997 & 0.997 & 1.002 & 0.989 & 0.997 & 1.070 \\
\hline & 15 & 0.990 & 0.990 & 1.007 & 0.968 & 0.990 & 1.160 \\
\hline & 25 & 0.982 & 0.982 & 1.012 & 0.949 & 0.984 & 1.220 \\
\hline \multirow{3}{*}{ Ethanol } & 5 & 0.998 & 0.998 & 1.002 & 0.981 & 0.994 & 1.140 \\
\hline & 15 & 0.994 & 0.994 & 1.005 & 0.944 & 0.983 & 1.300 \\
\hline & 25 & 0.986 & 0.986 & 1.009 & 0.917 & 0.974 & 1.360 \\
\hline \multirow{3}{*}{ Ethylene Glycol } & 5 & 0.998 & 0.998 & 1.002 & 0.993 & 0.998 & 1.040 \\
\hline & 15 & 0.994 & 0.994 & 1.004 & 0.980 & 0.994 & 1.120 \\
\hline & 25 & 0.988 & 0.988 & 1.008 & 0.966 & 0.990 & 1.200 \\
\hline
\end{tabular}




\section{Appendix D: Heat pump manufacturer data sheets}

TMW LARGE SERIES 6D HZ - HFC-41DA SUBMITTAL DATA ENG/I-P Physical \& Electrical Data

Physical Data

\begin{tabular}{|c|c|c|c|c|}
\hline Model & TRM 360 & \multicolumn{2}{|c|}{ TMN600 } & TMW 840 \\
\hline Compressor (qy) & Scroll (2) & \multicolumn{2}{|c|}{ Scroll (2) } & Scroll (2) \\
\hline \multirow{2}{*}{ Compressor Oil Type } & ALL & REVA & REVB & ALL \\
\hline & POE & POE & PVE & PVE \\
\hline Factory Charge HFC-410A (bs) [kg] / circuit & $15[6.8]$ & \multicolumn{2}{|c|}{$27.5[12.5]$} & $33.8[15.4]$ \\
\hline Indoor / Load Water connection sizes FPT (in) & 2 & \multicolumn{2}{|c|}{$2-1 / 2$} & $2-1 / 2$ \\
\hline Outdoor / Source Water connection size FPT (in) & 2 & \multicolumn{2}{|c|}{$2-1 / 2$} & $2-1 / 2$ \\
\hline Weight - Operating (lbs) [kg] & 1400 [635] & \multicolumn{2}{|c|}{2055 [932] } & 2305 [1042] \\
\hline Weight - Shipping (lbs) [kg] & 1325 [601] & \multicolumn{2}{|c|}{1925 [873] } & 2175 [983] \\
\hline \multicolumn{5}{|l|}{ Water Volume (Source) } \\
\hline Gallons [Liters] & $4.7[17.8]$ & \multicolumn{2}{|c|}{$8.3[31.4]$} & $9.5[36]$ \\
\hline \multicolumn{2}{|l|}{ Water Volume (Load) } & & & \\
\hline Gallons [Liters] & $4.4[16.7]$ & \multicolumn{2}{|c|}{$7.3[27.6]$} & $8.5[32.2]$ \\
\hline
\end{tabular}

\begin{tabular}{|l|c|}
\hline \multicolumn{2}{|l|}{ Unit Maximum Water Working Pressure } \\
\hline Options & Max Working Pressure PSIG [kPa] \\
\hline Base Unit & $300[2,068]$ \\
\hline Motorized Valves & $300[2,068]$ \\
\hline
\end{tabular}

TMW Electrical Data

\begin{tabular}{|c|c|c|c|c|c|c|c|c|c|}
\hline \multirow{2}{*}{ Model } & \multirow{2}{*}{$\begin{array}{l}\text { Voltage } \\
\text { Code }\end{array}$} & \multirow{2}{*}{ Voltage } & \multirow{2}{*}{$\begin{array}{l}\text { Voltage } \\
\text { Min/Max }\end{array}$} & \multicolumn{3}{|c|}{ Compressor } & \multirow{2}{*}{$\begin{array}{l}\text { Total Unit } \\
\text { FLA }\end{array}$} & \multirow{2}{*}{$\begin{array}{l}\text { Min Circuit } \\
\text { Amps }\end{array}$} & \multirow{2}{*}{$\begin{array}{c}\text { Max } \\
\text { UL/CSA } \\
\text { HACR }\end{array}$} \\
\hline & & & & Qty & $\begin{array}{l}\text { RLA } \\
\text { (EA) }\end{array}$ & $\begin{array}{l}\text { LRA } \\
\text { (EA) }\end{array}$ & & & \\
\hline \multirow{3}{*}{ TMW360 } & $\mathrm{H}$ & $208-230 / 60 / 3$ & $187 / 254$ & 2 & 56.4 & 425 & 113 & 127 & 175 \\
\hline & $\mathrm{F}$ & $460 / 60 / 3$ & $414 / 506$ & 2 & 25.5 & 173 & 51 & 57 & 80 \\
\hline & N & $575 / 60 / 3$ & $518 / 633$ & 2 & 20.4 & 128 & 41 & 46 & 60 \\
\hline \multirow{3}{*}{ TMW600 } & $\mathrm{H}$ & $208-230 / 60 / 3$ & $187 / 254$ & 2 & 94.7 & 605 & 189 & 213 & 300 \\
\hline & $\mathrm{F}$ & $460 / 60 / 3$ & $414 / 506$ & 2 & 42.8 & 272 & 86 & 96 & 125 \\
\hline & N & $575 / 60 / 3$ & $518 / 633$ & 2 & 34.3 & 238 & 69 & 77 & 110 \\
\hline \multirow{3}{*}{ TMW840 } & $\mathrm{H}$ & $208-230 / 60 / 3$ & $187 / 254$ & 2 & 124.3 & 599 & 249 & 280 & 400 \\
\hline & $\mathrm{F}$ & $460 / 60 / 3$ & $414 / 506$ & 2 & 56.2 & 310 & 112 & 126 & 175 \\
\hline & $\mathrm{N}$ & $575 / 60 / 3$ & $518 / 633$ & 2 & 45.0 & 239 & 90 & 101 & 125 \\
\hline
\end{tabular}

HACR circuit breaker in USA only

TMW Corner Weights (control box is on front) lbs [kg]

\begin{tabular}{|c|c|c|c|c|}
\hline Model & Left Front & Left Rear & Right Front & Right Rear \\
\hline TMW360 & $345[156]$ & $350[159]$ & $275[125]$ & $355[161]$ \\
\hline TMW600 & $492[223]$ & $500[227]$ & $400[181]$ & $533[242]$ \\
\hline TMW840 & $557[252]$ & $565[255]$ & $452[204]$ & $601[271]$ \\
\hline
\end{tabular}

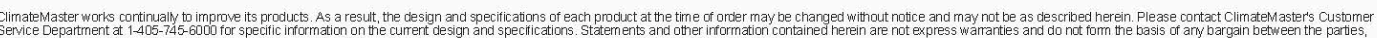

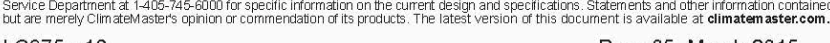




\section{Appendix D: Heat pump manufacturer data sheets}

TMW LARGE SERIES 6D HZ - HFC-41DA SUBMITTAL DATA ENG/I-P Dimensional Data - TMW360 - 840
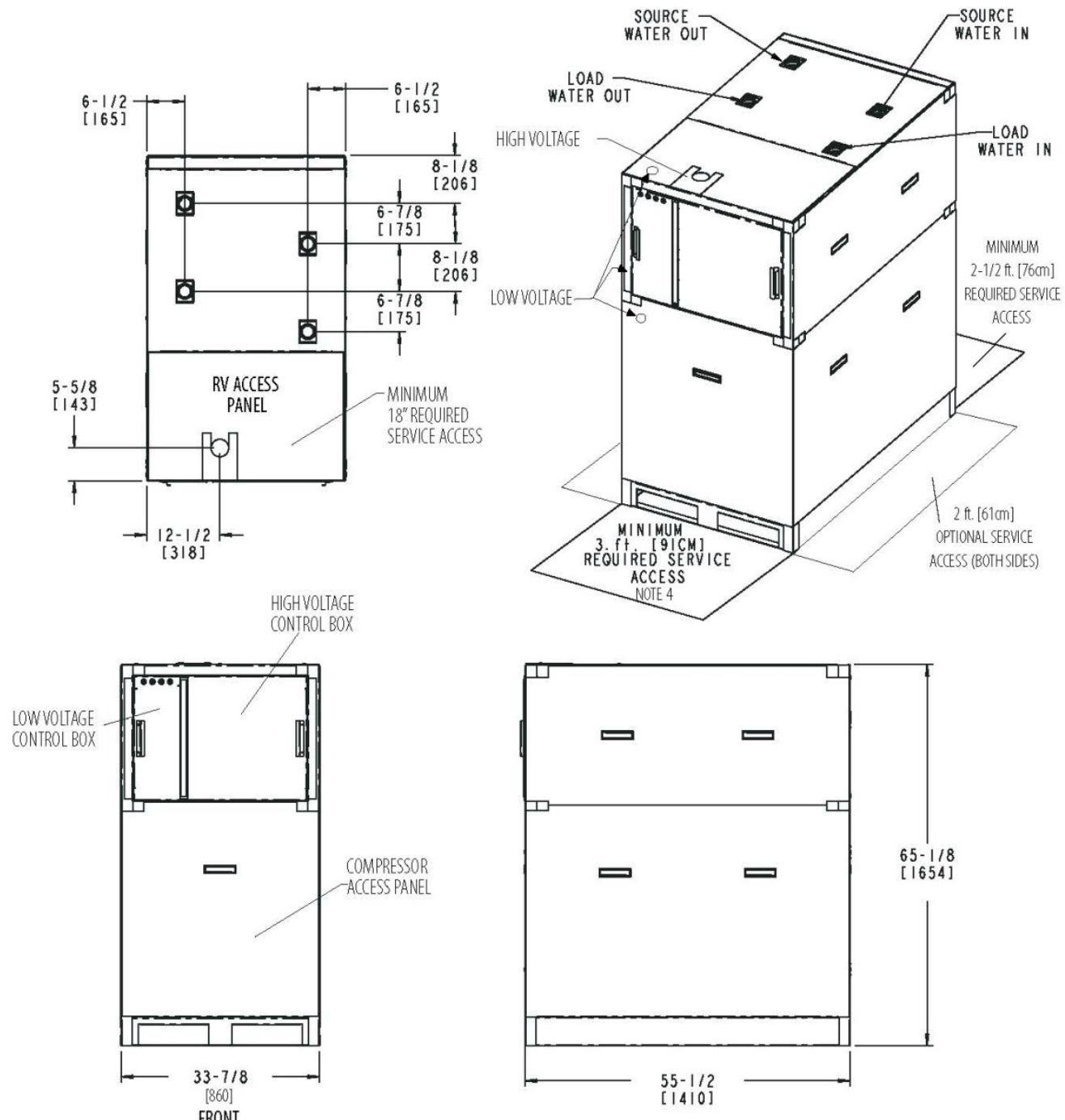

NOTE:

1. DIMENSIONS SHOWN IN INCHES AND [MILLIMETERS]

2. TMW360 WATER CONNECTIONS ARE 2“FPT.

3. TMW600 AND 840 WATER CONNECTIONS ARE $2.5^{*}$ FPT.

4. FOR MULTIPLE UNITS PLACED SIDE BY SIDE. ALLOW SUFFIIENT SPACE FRONT OR BACK TO REMOVE UNIT

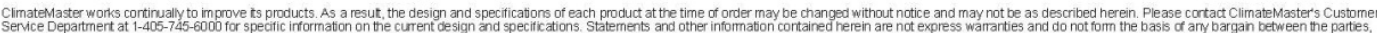
LC975 - 17

Rev: 05, March 2015

Page

of 


\section{Appendix D: Heat pump manufacturer data sheets}

TMW LARgE SERIEG GD HZ - HFC-41DA SUBMITTAL DATA ENG/I-P TMW Large Series - Sound Data and Wiring Diagram Matrix

Sound Power Data

\begin{tabular}{|c|c|}
\hline Model & dBA \\
\hline TMW 360 & 67 \\
\hline TMW600 & 70 \\
\hline TMW 800 & 72 \\
\hline
\end{tabular}

Wiring Diagrams

\begin{tabular}{|c|c|c|c|c|}
\hline Model & Refrigerant & $\begin{array}{c}\text { Wiring Diagram } \\
\text { Part Number }\end{array}$ & Electrical & Agency \\
\hline TMW 360-840 & $\begin{array}{c}\text { EarthPure } \\
\text { HFC-410A }\end{array}$ & $96 \mathrm{~B} 0152 \mathrm{~N} 01$ & $\begin{array}{c}208-200 / 60 / 3 \\
460 / 60 / 3 \\
575 / 60 / 3\end{array}$ & UL \\
\hline
\end{tabular}

All current diagrams may be downloaded at www.climatemaster.com/ commercial-wiring 


\section{Appendix E: Heat pump performance data}

\section{Appendix E: Heat pump performance data}

\section{! Heating mode data}

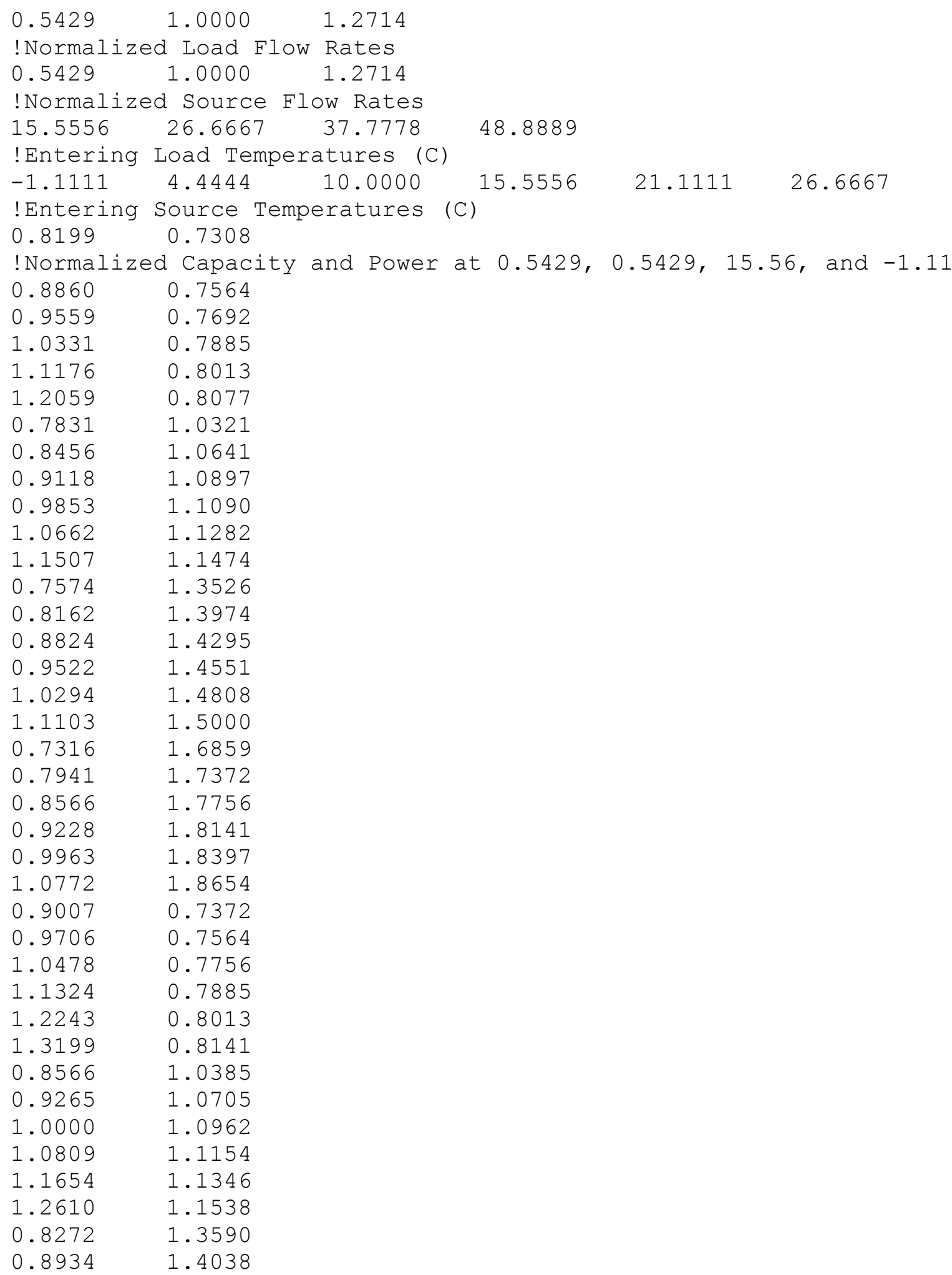




\section{Appendix E: Heat pump performance data}

! Heating Normalized Capacity and Power (continued...)

$0.9669 \quad 1.4359$

$1.0441 \quad 1.4615$

$1.1250 \quad 1.4872$

$1.2169 \quad 1.5064$

$0.8015 \quad 1.6923$

$0.8676 \quad 1.7436$

$0.9375 \quad 1.7885$

$1.0110 \quad 1.8205$

$1.0919 \quad 1.8526$

$1.1801 \quad 1.8782$

$0.9118 \quad 0.7436$

$0.9853 \quad 0.7628$

$1.0625 \quad 0.7821$

$1.1471 \quad 0.7949$

$\begin{array}{ll}1.2390 & 0.8077\end{array}$

$1.3382 \quad 0.8205$

$0.8713 \quad 1.0513$

$0.9412 \quad 1.0833$

$1.0147 \quad 1.1090$

$1.0956 \quad 1.1282$

$1.1838 \quad 1.1474$

$1.2794 \quad 1.1603$

$0.8382 \quad 1.3718$

$0.9081 \quad 1.4167$

$0.9779 \quad 1.4487$

$1.0588 \quad 1.4744$

$1.1434 \quad 1.5000$

$1.2316 \quad 1.5192$

$0.8162 \quad 1.7115$

$0.8787 \quad 1.7628$

$0.9522 \quad 1.8013$

$1.0257 \quad 1.8397$

$1.1103 \quad 1.8654$

$1.1949 \quad 1.8974$

$0.8199 \quad 0.6667$

$0.8860 \quad 0.6859$

$0.9559 \quad 0.7051$

$\begin{array}{ll}1.0331 & 0.7179\end{array}$

$\begin{array}{ll}1.1176 & 0.7308\end{array}$

$\begin{array}{ll}1.2059 & 0.7372\end{array}$

$\begin{array}{ll}0.7831 & 0.9423\end{array}$

$0.8456 \quad 0.9744$

$0.9118 \quad 0.9936$

$0.9853 \quad 1.0128$

$1.0662 \quad 1.0321$

$1.1507 \quad 1.0449$

$0.7574 \quad 1.2372$

$0.8162 \quad 1.2756$

$0.8824 \quad 1.3013$

$0.9522 \quad 1.3269$

$1.0294 \quad 1.3526$ 


\section{Appendix E: Heat pump performance data}

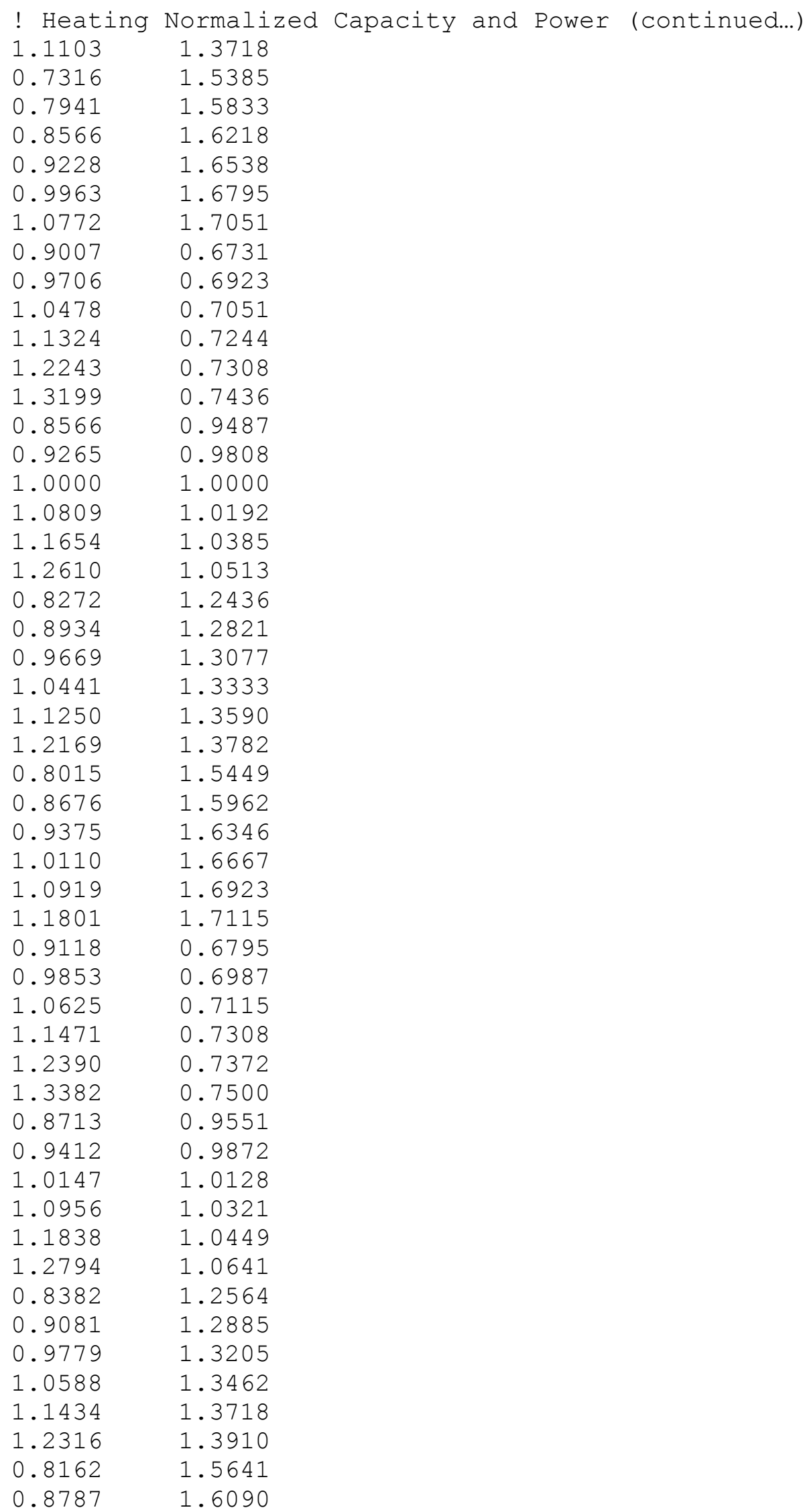




\section{Appendix E: Heat pump performance data}

! Heating Normalized Capacity and Power (continued...)

$0.9522 \quad 1.6474$

$1.0257 \quad 1.6795$

$1.1103 \quad 1.7051$

$1.1949 \quad 1.7308$

$0.8199 \quad 0.6474$

$0.8860 \quad 0.6667$

$0.9559 \quad 0.6859$

$1.0331 \quad 0.6987$

$1.1176 \quad 0.7051$

$\begin{array}{ll}1.2059 & 0.7179\end{array}$

$\begin{array}{ll}0.7831 & 0.9167\end{array}$

$0.8456 \quad 0.9423$

$0.9118 \quad 0.9679$

$0.9853 \quad 0.9872$

$1.0662 \quad 1.0000$

$1.1507 \quad 1.0128$

$0.7574 \quad 1.1987$

$0.8162 \quad 1.2372$

$0.8824 \quad 1.2628$

$0.9522 \quad 1.2885$

$1.0294 \quad 1.3077$

$1.1103 \quad 1.3269$

$0.7316 \quad 1.4936$

$0.7941 \quad 1.5385$

$0.8566 \quad 1.5769$

$0.9228 \quad 1.6090$

$0.9963 \quad 1.6346$

$1.0772 \quad 1.6538$

$0.9007 \quad 0.6538$

$0.9706 \quad 0.6731$

$1.0478 \quad 0.6859$

$1.1324 \quad 0.6987$

$1.2243 \quad 0.7115$

$1.3199 \quad 0.7244$

$0.8566 \quad 0.9231$

$0.9265 \quad 0.9487$

$1.0000 \quad 0.9744$

$1.0809 \quad 0.9872$

$1.1654 \quad 1.0064$

$1.2610 \quad 1.0192$

$0.8272 \quad 1.2051$

$0.8934 \quad 1.2436$

$0.9669 \quad 1.2692$

$1.0441 \quad 1.2949$

$1.1250 \quad 1.3141$

$1.2169 \quad 1.3333$

$0.8015 \quad 1.5000$

$0.8676 \quad 1.5449$

$0.9375 \quad 1.5833$

$1.0110 \quad 1.6154$

$1.0919 \quad 1.6410$ 


\section{Appendix E: Heat pump performance data}

! Heating Normalized Capacity and Power (continued...)

$1.1801 \quad 1.6667$

$\begin{array}{ll}0.9118 & 0.6538\end{array}$

$0.9853 \quad 0.6795$

$1.0625 \quad 0.6923$

$\begin{array}{ll}1.1471 & 0.7051\end{array}$

$\begin{array}{ll}1.2390 & 0.7179\end{array}$

$\begin{array}{ll}1.3382 & 0.7308\end{array}$

$\begin{array}{ll}0.8713 & 0.9295\end{array}$

$0.9412 \quad 0.9551$

$1.0147 \quad 0.9808$

$1.0956 \quad 1.0000$

$1.1838 \quad 1.0128$

$1.2794 \quad 1.0321$

$0.8382 \quad 1.2179$

$\begin{array}{ll}0.9081 & 1.2564\end{array}$

$0.9779 \quad 1.2821$

$1.0588 \quad 1.3077$

$1.1434 \quad 1.3269$

$1.2316 \quad 1.3462$

$0.8162 \quad 1.5128$

$0.8787 \quad 1.5641$

$0.9522 \quad 1.5962$

$1.0257 \quad 1.6282$

$1.1103 \quad 1.6538$

$1.1949 \quad 1.6795$

!Format Load flow, Source flow, Load EWT, Source EWT, Capacity Ratio, Power Ratio 


\section{Appendix E: Heat pump performance data}

\section{!Cooling mode data}

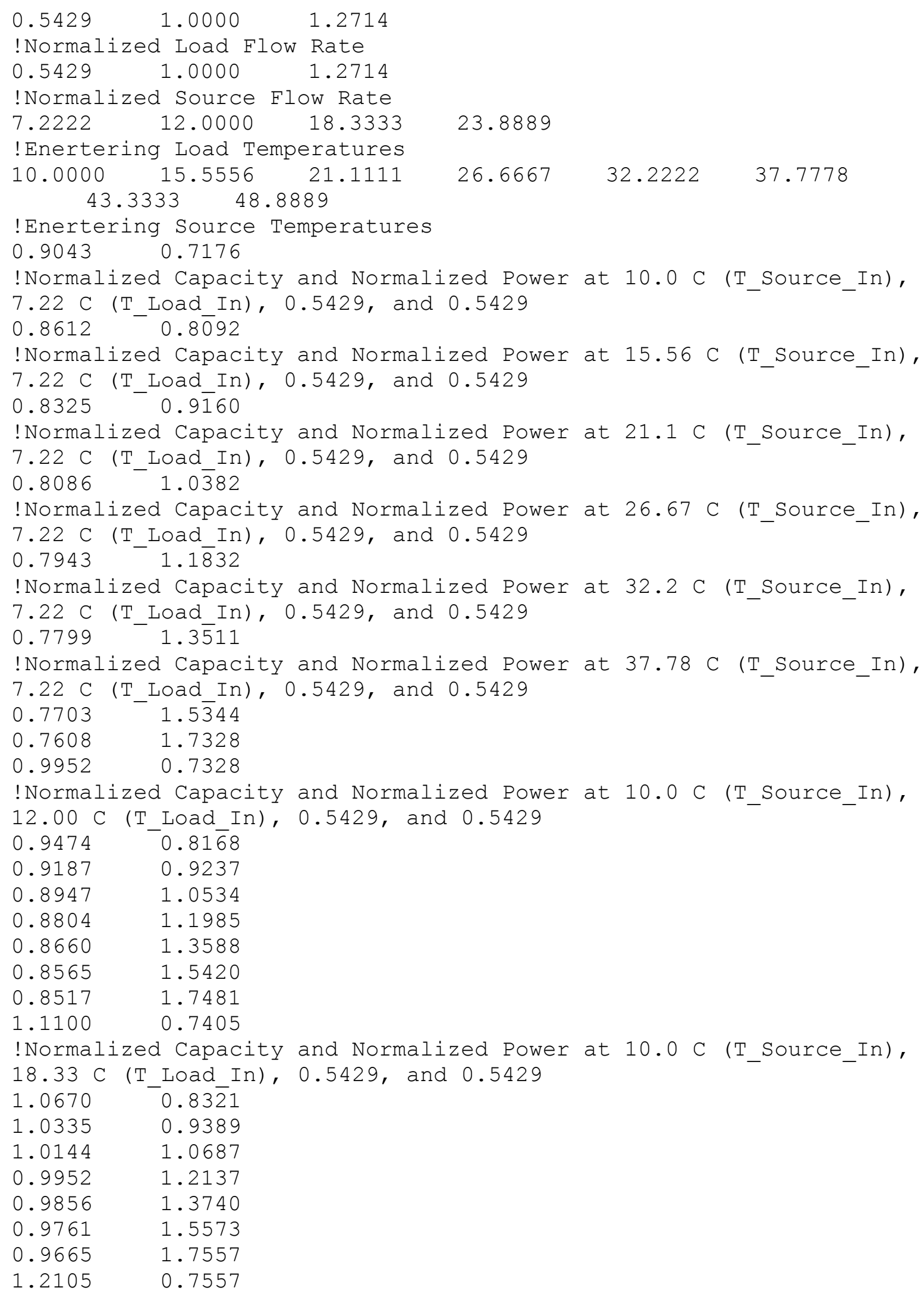




\section{Appendix E: Heat pump performance data}

! Cooling Normalized Capacity and Power (continued...)

$\begin{array}{ll}1.1675 & 0.8397\end{array}$

$1.1388 \quad 0.9542$

$1.1148 \quad 1.0763$

$1.1005 \quad 1.2214$

$1.0861 \quad 1.3893$

$1.0766 \quad 1.5649$

$1.0670 \quad 1.7710$

$0.9187 \quad 0.6718$

$0.8708 \quad 0.7557$

$0.8421 \quad 0.8550$

$0.8182 \quad 0.9695$

$0.8038 \quad 1.1069$

$0.7895 \quad 1.2595$

$0.7799 \quad 1.4275$

$0.7703 \quad 1.6183$

$1.0048 \quad 0.6794$

$0.9617 \quad 0.7634$

$0.9282 \quad 0.8626$

$0.9091 \quad 0.9847$

$0.8900 \quad 1.1221$

$0.8804 \quad 1.2748$

$0.8660 \quad 1.4427$

$0.8612 \quad 1.6260$

$1.1244 \quad 0.6947$

$1.0766 \quad 0.7786$

$1.0478 \quad 0.8779$

$\begin{array}{ll}1.0239 & 0.9924\end{array}$

$1.0096 \quad 1.1298$

$0.9952 \quad 1.2824$

$0.9856 \quad 1.4504$

$0.9761 \quad 1.6412$

$1.2249 \quad 0.7023$

$1.1818 \quad 0.7863$

$\begin{array}{ll}1.1531 & 0.8855\end{array}$

$1.1292 \quad 1.0076$

$1.1100 \quad 1.1374$

$1.1005 \quad 1.2901$

$1.0909 \quad 1.4656$

$1.0813 \quad 1.6489$

$0.9234 \quad 0.6565$

$\begin{array}{ll}0.8756 & 0.7405\end{array}$

$\begin{array}{ll}0.8469 & 0.8397\end{array}$

$0.8230 \quad 0.9542$

$0.8086 \quad 1.0840$

$0.7943 \quad 1.2366$

$0.7847 \quad 1.4046$

$0.7751 \quad 1.5878$

$\begin{array}{ll}1.0144 & 0.6641\end{array}$

$\begin{array}{ll}0.9665 & 0.7481\end{array}$

$\begin{array}{ll}0.9378 & 0.8473\end{array}$

$0.9139 \quad 0.9618$ 


\section{Appendix E: Heat pump performance data}

! Cooling Normalized Capacity and Power (continued...)

$\begin{array}{ll}0.8995 & 1.0992 \\ 0.8852 & 1.2443 \\ 0.8756 & 1.4122 \\ 0.8660 & 1.5954 \\ 1.1292 & 0.6794 \\ 1.0861 & 0.7634 \\ 1.0526 & 0.8626 \\ 1.0335 & 0.9771 \\ 1.0144 & 1.1069 \\ 1.0048 & 1.2595 \\ 0.9952 & 1.4275 \\ 0.9856 & 1.6107 \\ 1.2344 & 0.6870 \\ 1.1914 & 0.7710 \\ 1.1579 & 0.8702 \\ 1.1388 & 0.9847 \\ 1.1196 & 1.1221 \\ 1.1053 & 1.2672 \\ 1.0957 & 1.4351 \\ 1.0909 & 1.6183 \\ 0.9952 & 0.7328 \\ 0.9474 & 0.8244 \\ 0.9139 & 0.9313 \\ 0.8900 & 1.0611 \\ 0.8708 & 1.2061 \\ 0.8612 & 1.3740 \\ 0.8469 & 1.5649 \\ 0.8373 & 1.7634 \\ 1.0957 & 0.7405 \\ 1.0431 & 0.8321 \\ 1.0096 & 0.9466 \\ 0.9856 & 1.0763 \\ 0.9713 & 1.2214 \\ 0.9569 & 1.3893 \\ 0.9426 & 1.5725 \\ 0.9378 & 1.7786 \\ 1.2201 & 0.7557 \\ 1.1722 & 0.8473 \\ 1.1388 & 0.9618 \\ 1.1148 & 1.0916 \\ 1.0957 & 1.2366 \\ 1.0861 & 1.4046 \\ 1.0718 & 1.5878 \\ 1.0622 & 1.7939 \\ 1.3349 & 0.7710 \\ 1.2871 & 0.8626 \\ 1.2536 & 0.9695 \\ 1.2297 & 1.0992 \\ 1.2105 & 1.2443 \\ 1.1962 & 1.4122 \\ 1 & \\ 0\end{array}$




\section{Appendix E: Heat pump performance data}

! Cooling Normalized Capacity and Power (continued...)

$\begin{array}{ll}1.1866 & 1.5954 \\ 1.1770 & 1.8015 \\ 1.0096 & 0.6794 \\ 0.9569 & 0.7634 \\ 0.9234 & 0.8702 \\ 0.8995 & 0.9924 \\ 0.8852 & 1.1298 \\ 0.8708 & 1.2824 \\ 0.8565 & 1.4580 \\ 0.8469 & 1.6489 \\ 1.1053 & 0.6947 \\ 1.0574 & 0.7786 \\ 1.0239 & 0.8855 \\ 1.0000 & 1.0000 \\ 0.9809 & 1.1374 \\ 0.9665 & 1.2977 \\ 0.9569 & 1.4656 \\ 0.9474 & 1.6565 \\ 1.2344 & 0.7099 \\ 1.1866 & 0.7939 \\ 1.1531 & 0.8931 \\ 1.1292 & 1.0153 \\ 1.1100 & 1.1527 \\ 1.0957 & 1.3130 \\ 1.0861 & 1.4809 \\ 1.0766 & 1.6718 \\ 1.3493 & 0.7176 \\ 1.3014 & 0.8015 \\ 1.2679 & 0.9084 \\ 1.2440 & 1.0229 \\ 1.2249 & 1.1603 \\ 1.2105 & 1.3206 \\ 1.2010 & 1.4962 \\ 1.1914 & 1.6794 \\ 1.0144 & 0.6718 \\ 0.9665 & 0.7557 \\ 0.9330 & 0.8550 \\ 0.9091 & 0.9695 \\ 0.8900 & 1.1069 \\ 0.8756 & 1.2595 \\ 0.8660 & 1.4275 \\ 0.8565 & 1.6183 \\ 1.1148 & 0.6794 \\ 1.0622 & 0.7634 \\ 1.0287 & 0.8626 \\ 1.0048 & 0.9847 \\ 0.9856 & 1.1221 \\ 0.9761 & 1.2748 \\ 0.9617 & 1.4427 \\ 0.9522 & 1.6260 \\ 1 & \end{array}$




\section{Appendix E: Heat pump performance data}

! Cooling Normalized Capacity and Power (continued...)

$\begin{array}{ll}1.2440 & 0.6947 \\ 1.1962 & 0.7786 \\ 1.1627 & 0.8779 \\ 1.1388 & 1.0000 \\ 1.1196 & 1.1298 \\ 1.1053 & 1.2824 \\ 1.0909 & 1.4580 \\ 1.0861 & 1.6412 \\ 1.3589 & 0.7023 \\ 1.3110 & 0.7863 \\ 1.2775 & 0.8855 \\ 1.2536 & 1.0076 \\ 1.2344 & 1.1450 \\ 1.2201 & 1.2977 \\ 1.2057 & 1.4656 \\ 1.1962 & 1.6489 \\ 1.0335 & 0.7328 \\ 0.9809 & 0.8244 \\ 0.9474 & 0.9389 \\ 0.9234 & 1.0611 \\ 0.9043 & 1.2137 \\ 0.8900 & 1.3817 \\ 0.8756 & 1.5649 \\ 0.8660 & 1.7710 \\ 1.1340 & 0.7481 \\ 1.0813 & 0.8397 \\ 1.0478 & 0.9466 \\ 1.0239 & 1.0763 \\ 1.0048 & 1.2290 \\ 0.9904 & 1.3969 \\ 0.9761 & 1.5802 \\ 0.9665 & 1.7863 \\ 1.2632 & 0.7634 \\ 1.2153 & 0.8550 \\ 1.1818 & 0.9618 \\ 1.1531 & 1.0916 \\ 1.1340 & 1.2366 \\ 1.1196 & 1.4046 \\ 1.1100 & 1.5954 \\ 1.1005 & 1.8015 \\ 1.3828 & 0.7710 \\ 1.3301 & 0.8626 \\ 1.2967 & 0.9695 \\ 1.2727 & 1.0992 \\ 1.2536 & 1.2519 \\ 1.2392 & 1.4198 \\ 1.2249 & 1.6031 \\ 1.2153 & 1.8092 \\ 1.0431 & 0.6870 \\ 0.9904 & 0.7710 \\ 1 & \end{array}$




\section{Appendix E: Heat pump performance data}

! Cooling Normalized Capacity and Power (continued...)

$\begin{array}{ll}0.9569 & 0.8702 \\ 0.9330 & 0.9924 \\ 0.9139 & 1.1298 \\ 0.8995 & 1.2901 \\ 0.8900 & 1.4656 \\ 0.8804 & 1.6565 \\ 1.1435 & 0.6947 \\ 1.0957 & 0.7786 \\ 1.0574 & 0.8855 \\ 1.0335 & 1.0076 \\ 1.0144 & 1.1450 \\ 1.0000 & 1.2977 \\ 0.9904 & 1.4733 \\ 0.9809 & 1.6641 \\ 1.2775 & 0.7099 \\ 1.2297 & 0.7939 \\ 1.1914 & 0.9008 \\ 1.1675 & 1.0153 \\ 1.1483 & 1.1603 \\ 1.1340 & 1.3130 \\ 1.1244 & 1.4885 \\ 1.1148 & 1.6794 \\ 1.3971 & 0.7176 \\ 1.3445 & 0.8015 \\ 1.3110 & 0.9084 \\ 1.2871 & 1.0305 \\ 1.2679 & 1.1679 \\ 1.2536 & 1.3206 \\ 1.2392 & 1.4962 \\ 1.2297 & 1.6870 \\ 1.0526 & 0.6718 \\ 1.0000 & 0.7557 \\ 0.9665 & 0.8550 \\ 0.9378 & 0.9771 \\ 0.9187 & 1.1145 \\ 0.9043 & 1.2672 \\ 0.8947 & 1.4351 \\ 0.8852 & 1.6260 \\ 1.1531 & 0.6870 \\ 1.1005 & 0.7710 \\ 1.0670 & 0.8702 \\ 1.0431 & 0.9847 \\ 1.0239 & 1.1221 \\ 1.0096 & 1.2748 \\ 0.9952 & 1.4504 \\ 0.9856 & 1.6336 \\ 1.2871 & 0.6947 \\ 1.2344 & 0.7786 \\ 1.2010 & 0.8779 \\ 1.1770 & 1.0000 \\ 1 & \end{array}$




\section{Appendix E: Heat pump performance data}

! Cooling Normalized Capacity and Power (continued...)

$1.1579 \quad 1.1374$

$1.1435 \quad 1.2901$

$1.1292 \quad 1.4580$

$1.1196 \quad 1.6489$

$1.4067 \quad 0.7023$

$1.3541 \quad 0.7863$

$1.3206 \quad 0.8931$

$1.2967 \quad 1.0076$

$1.2775 \quad 1.1450$

$1.2632 \quad 1.2977$

$1.2488 \quad 1.4733$

$1.2392 \quad 1.6565$

!Normalized Capacity and Normalized Power at 48.89 C (T_Source_In), 23.89 C (T_Load_In), 1.2714, and 1.2714

!Format Loād flōw, Source flow, Load EWT, Source EWT, Capacity Ratio, Power Ratio 


\section{Appendix F: Photovoltaic Panels manufacturer data sheets}

\section{Appendix F: Photovoltaic panel manufacturer data sheets}

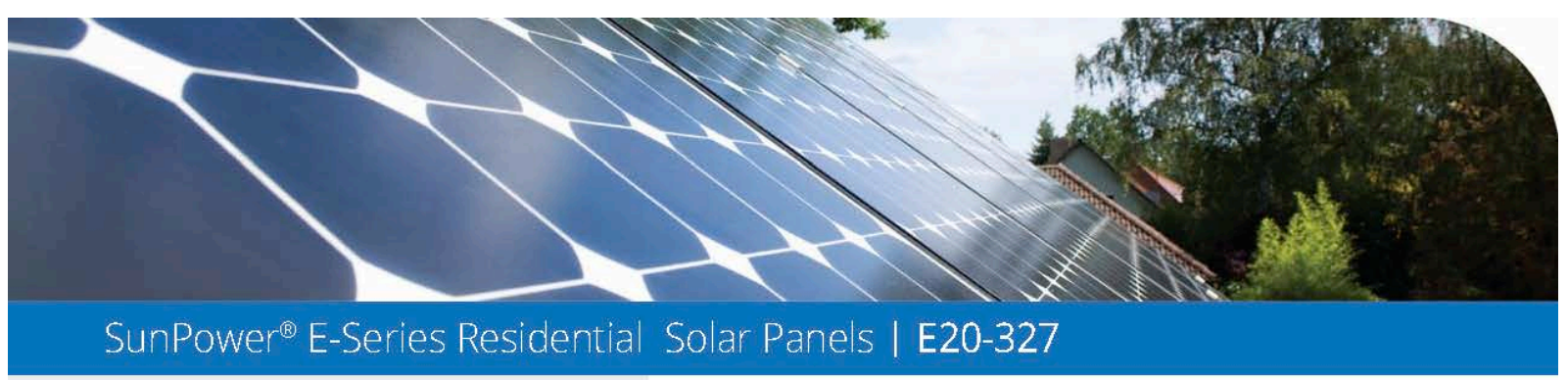

More than 20\% Efficiency

Ideal for roofs where space is at a premium or where future expansion might be needed.

High Performance

Delivers excellent performance in real-world conditions, such as high temperatures, clouds and low light. ${ }^{1,2,4}$

Proven Value

Designed for residential rooftops, E-Series panels deliver the features, value and performance for any home.

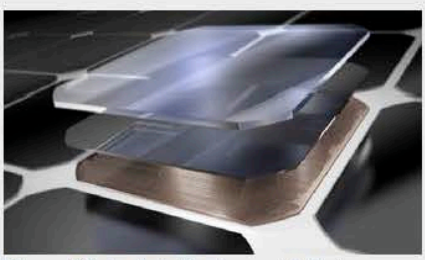

Maxeon` Solar Cells: Fundamentally better Engineered for performance, designed for durability.

Engineered for Peace of Mind Designed to deliver consistent, trouble-free energy over a very long lifetime. ${ }^{3,4}$

Designed for Durability

The SunPower Maxeon Solar Cell is the only cell built on a solid copper foundation. Virtually impervious to the corrosion and cracking that degrade conventional panels. ${ }^{3}$

\#1 Rank in Fraunhofer durability test. 9 $100 \%$ power maintained in Atlas $25+$ comprehensive durability test. ${ }^{10}$
High Performance \& Excellent Durability
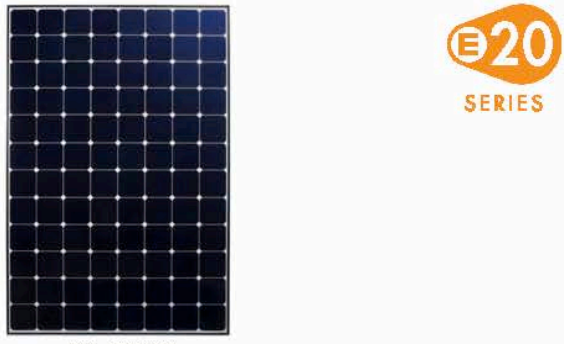

SERIES

\section{High Efficiency}

Generate more energy per square foot

E-Series residential panels convert more sunlight to electricity by producing $31 \%$ more power per panel ${ }^{1}$ and $60 \%$ more energy per square foot over 25 years. ${ }^{1,23}$

High Energy Production ${ }^{6}$

\section{Produce more energy per rated watt}

High year-one performance delvers $7-9 \%$ more energy per rated watt. ${ }^{2}$ This advantage increases over time, producing $20 \%$ more energy over the first 25 years to meet your needs. ${ }^{3}$
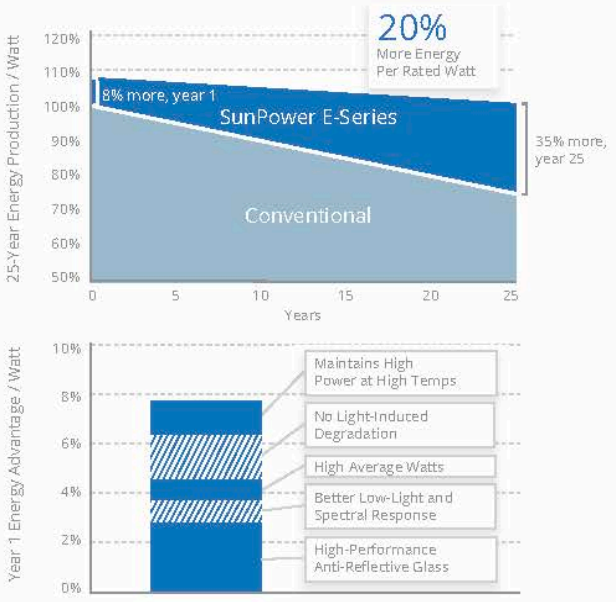


\section{Appendix F: Photovoltaic Panels manufacturer data sheets}

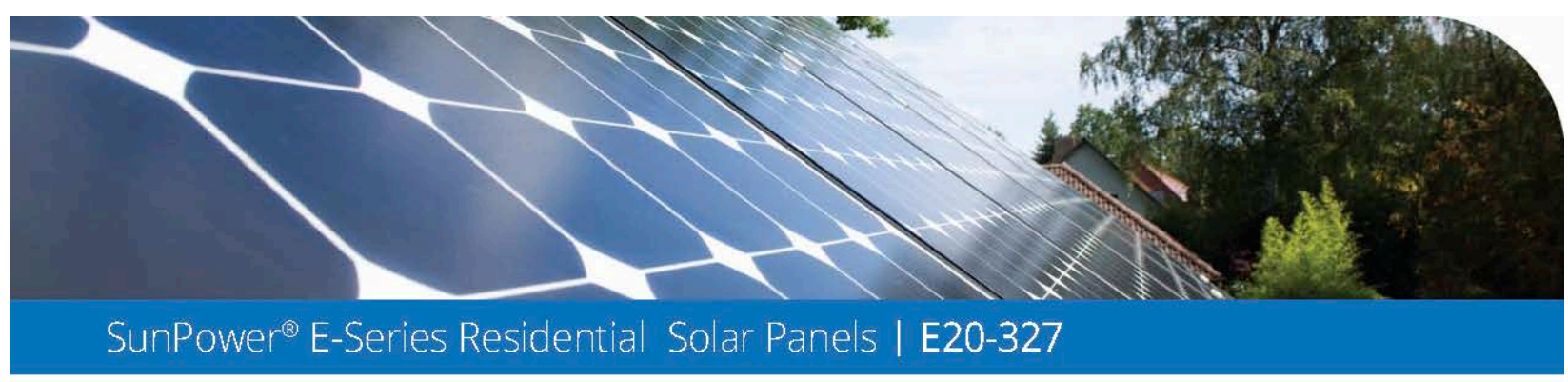

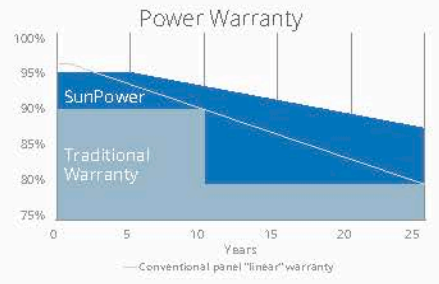

More guar anteed power: $95 \%$ for first 5 years, $-0.4 \% / y r$ to year 25

\begin{tabular}{|c|c|c|}
\hline \multicolumn{3}{|c|}{ Electrical Data } \\
\hline & SPR-E20-327 & SPR-E19-320 \\
\hline Nominal Power (Pnom) 11 & $327 W$ & $320 \mathrm{~W}$ \\
\hline Power Tolerance & $+5 /-0 \%$ & $+5 /-0 \%$ \\
\hline Avg. Panel Efficiency ${ }^{12}$ & $20.4 \%$ & $19.9 \%$ \\
\hline Rated Voltage (Vmpp) & $54.7 \mathrm{~V}$ & $54.7 \mathrm{~V}$ \\
\hline Rated Current (Impp) & $5.98 \mathrm{~A}$ & $5.86 \mathrm{~A}$ \\
\hline Open-Circuit Voltage (Voc) & $64.9 \mathrm{~V}$ & $64.8 \mathrm{~V}$ \\
\hline Short-Circuit Current (ISC) & $6.46 \mathrm{~A}$ & $6.24 \mathrm{~A}$ \\
\hline Max. System Voltage & \multicolumn{2}{|c|}{600 VUL \& 1000 VIEC } \\
\hline Maximum Series Fuse & \multicolumn{2}{|c|}{$15 \mathrm{~A}$} \\
\hline Power Temp Coef. & \multicolumn{2}{|c|}{$-0.38 \% /{ }^{\circ} \mathrm{C}$} \\
\hline Voltage Temp Coef. & \multicolumn{2}{|c|}{$-176.6 \mathrm{mv} /{ }^{\circ} \mathrm{C}$} \\
\hline Current Temp Coef. & \multicolumn{2}{|c|}{$3.5 \mathrm{~mA} /{ }^{\circ} \mathrm{C}$} \\
\hline
\end{tabular}

REFERENCES:

1 All comparisons are SPR-E20-327 vs. a representative conventional panel: $250 \mathrm{~W}$, approx. $1.6 \mathrm{~m}^{2}$ $15.3 \%$ efficiency

2 Typically 7-9 \$2 more energy per watt, BEW/DNV Engineering "Sun Power Yield Report," |an 2013. 3 SunPower 0.25\%/yr degradation vs. $1.0 \$ \mathrm{hy}$ conv. panel. Campeau, Z. et al. "SunPower Module Degradation Rate," SunPower white paper, Feb 2013; Jordan, Dirk "SunPower Test Report," NREL, Q1-2015.

4 "SunPower Module 40-Year Useful Life" SunPower white paper, May 2015. Useful Ife is 99 out of 100 panels operating at more than 70 \% of rated power

5 Second highest, after SunPower X-Series, of aver 3,200 silicon solar panek, Photon Module Survey, Feb 2014

6886 more energy than the average of the top 10 panel companies tested in 2012 (151 panek, 102 companies), Photon International, Feb 2013 .

7 Compared with the top 15 manufacturers. SunPower Warranty Review, May 2015. $850 \mathrm{me}$ restrictions and exclusions may apply. See war ranty for detaik.

95 of top 8 panel manufacturers tested in 2013 report, 3 additional panels in 2014. Ferrara, $C_{\text {, e }}$ ef I. 'Fraunhofer PV Durability Initiative for Solar Modules: Part 2'. Photovoltaics International, 2014

10 Compared with the non-stress-tested control panel. Atlas 25+ Durability test report, Feb 2013. SOMS current, LACC5 FF and Voltage.

12 Based on average of measured power values during production.

13 Type 2 fire rating per UL1703:2013, Claș Cfire rating per UL1703:2002.

4 see salesperson for detais.

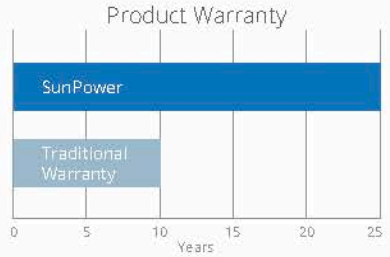

Combined Power and Product defect 25-year coverage that includes panel replacement costs ${ }^{8}$

\begin{tabular}{|ll|}
\hline & Tests And Certifications \\
\hline Standard Tests ${ }^{13}$ & UL1703 (Type 2 Fire Rating), IEC 61215, IEC 61730 \\
\hline Quality Certs & ISO 9001:2008, ISO 14001:2004 \\
\hline EHS Compliance & $\begin{array}{l}\text { RoHS, OHSAS 18001:2007, lead free, REACH } \\
\text { SVHC-163, PV Cycle }\end{array}$ \\
\hline Sustainabilicy & Cradle to Cradle (eligible for LEED points) ${ }^{1 / 4}$ \\
\hline Ammonia Test & IEC 62716 \\
\hline Desert Test & 10.1109/PVSC.2013.6744437 \\
\hline Salt Spray Test & IEC 61701 (maximum severity) \\
\hline PID Test & Potential-Induced Degradation free: 1000 V ${ }^{9}$ \\
\hline Available Listings & UL, TUV, JET, MCS, CSA, FSEC, CEC \\
\hline
\end{tabular}

\begin{tabular}{|c|c|}
\hline \multicolumn{2}{|c|}{ Operating Condition And Mechanical Data } \\
\hline Impact Resistance & 1 inch $(25 \mathrm{~mm})$ diameter hail at $52 \mathrm{mph}(23 \mathrm{~m} / \mathrm{s})$ \\
\hline Appearance & Class A \\
\hline Solar Cells & 96 Monocrystalline Maxeon Gen II \\
\hline Tempered Glass & High-transmission tempered anti-reflective \\
\hline Junction $\mathrm{Box}$ & IP-65, MC4 compatible \\
\hline Weight & $41 \mathrm{lbs}(18.6 \mathrm{~kg})$ \\
\hline Max. Load & $\begin{array}{l}\text { G5 Frame: Wind: } 62 \text { psf, } 3000 \mathrm{~Pa} \text { front \& back } \\
\text { Snow: } 125 \text { psf, } 6000 \text { Pa front } \\
\text { G3 Frame: Wind: } 50 \text { psf, } 2400 \mathrm{~Pa} \text { front \& back } \\
\text { Snow: } 112 \text { psf, } 5400 \mathrm{~Pa} \text { front }\end{array}$ \\
\hline Frame & Class 1 black anodized (highest AAMA rating) \\
\hline
\end{tabular}

Frame Class 1 black anodized (highest AAMA rating)
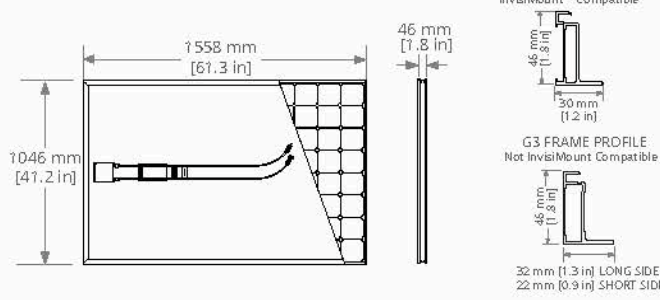

G5 frames have no mounting holes. Please read the safety and installation guide

Document \& 504860 Rev E/LTR US 


\section{References}

ASHRAE 90.1 (2007), American Society of Heating, Refrigerating and Air-Conditioning Engineers, Inc. ASHRAE Standard 90.1. Atlanta, GA.

ASHRAE Handbook (2010), Society of Heating, Refrigerating and Air-Conditioning Engineers, Inc., "Absorption Equipment”, Refrigeration Volume, Chapter 18, Atlanta, GA.

ASHRAE Standard 93-2010 "Methods of testing to determine the performance of solar collectors”, ASHRAE, Atlanta, 2010.

Austin W. A. (1998). "Development of an in-situ system for measurement of ground thermal properties", Department of Mechanical Engineering, Oklahoma State University, Still- water, OK, USA, M.Sc. thesis.

Baldwin C., Cruickshank C. (2012), "A review of solar cooling technologies for residential applications in Canada”, Energy Procedia 30- pp. 495-504.

Bauer D., Marx R., Nußbicker-Lux J., Ochs F., Heidemann W., Müller-Steinhagen H. (2010), "German Central solar heating plants with seasonal heat storage”, Solar Energy, 84:612-623.

Bennet J., Claesson J. and Hellstrom G. (1987), "Multipole method to compute the conductive heat flows to and between pipes in a composite cylinder" In Notes on Heat Transfer 3-1987, departments of Building Physics and Mathematical Physics, Lund Institute of Technology, Box 118, SE-221 00 Lund, Sweden.

Broad U.S.A. Inc. (2015), “Thermally driven absorption solution”, Hackensack, NJ, USA. http://www.broadusa.com/

Campbell G.S. (1985), "Soil Physics with Basic", New York, Elsevier.

Clapp R.B. and Hornberger, G.M. (1978), "Empirical Equations for Some Soil Hydraulic Properties", Water Resources Research, 14, 601-604.

Chapius S., Bernier M. (2009), "Seasonal storage of solar energy in borehole heat exchangers, In Proc”, IBPSA Conf. Building Simulations 2009, Glasgow, Scotland, 599-606.

ClimateMaster Inc. 2016) “geothermal heating and cooling manufacturer”, Oklahoma City, OK, USA. http://www.climatemaster.com/

Dalenback J.O. (1988), “Large-scale Swedish solar heating technology-system design and rating”, Swedish Council for Building Research, ISBN 91-540-4859-1, D6:1988.

Dalenback J.O., Werner S. (2012), “market for solar district heating”, SDH, WP2- European market study, CIT Energy Management AB, Gothenburg, Sweden. 
Delorme M., Six R., and al., (2004), "Solar air conditioning guide”, Europe Commission and the Rhone-Alpes Regional Council, France, 2004.

DeSoto, W., Klein, S.A. and Beckman, W.A. (2007), “Improvement and Validation of a Model for PV Array Performance", Solar Energy, vol. 81, no. 1, p. 150.

Duffie, JA, and Beckman, W.A (1991), “Solar Engineering of Thermal Processes", Wiley Publication, 1991.

Enbridge Gas (2106), Enbridge Gas Distribution Inc., Ontario, Canada, https://www.enbridgegas.com/homes/accounts-billing/residential-gas-rates/purchasing-gas-fromenbridge.aspx

Enerworks Inc.(2015), "Solar Water Heating Solutions”, Dorchester, Ontario, Canada. http://www.enerworks.com and www.solar-rating.org

Eskilson P. (1987), “Thermal analyses of heat extraction boreholes”, Department of Mathematical Physics, Lund Institute of Technology, Box 118, SE-221 00 Lund, Sweden, Thesis.

Eskilson P. and Claesson J. (1988), "Simulation model for thermally interacting heat extraction boreholes”, Numerical Heat Transfer 13, 149.

ESTTP, European Solar Thermal Technology Platform (2007), "Solar Heating and Cooling for a Sustainable Energy Future in Europe”, Renewable energy house, Brussels, Belguim.

Evans D.J., Reay D.M., Mitchell W.I., Busby J., (2006), “Appraisal of underground energy storage potential in Northern Ireland, Keyworth, Nottingham British Geological Survey.

Fisch M. N., Guigas M., Dalenbäck J. O. (1998), “A review of large-scale solar heating systems in Europe" Sol Energy, 63(6): pp. 355-366.

Giessener Geologische Schriften Nr. 67, Lenz-Verlag, Giessen, ISSN 0340-0654

Schmidt T., Miedaner O. (2012), "Solar district heating guidelines-Storage", SHF fact Sheet 7.2 , pp. 1-13.

Ghaebi H, Bahadori MN, Saidi MH. (2014), Performance analysis and parametric study of thermal energy storage in an aquifer coupled with a heat pump and solar collectors, for a residential complex in Tehran, Iran. Applied Thermal Engineering 62:156-70 2014.

Grossman G. (2002), "Solar-powered systems for cooling, dehumidification and airconditioning”, Solar Energy, 72 (1), pp. 53-62.

GSHP, Ground Source Heat Pump association (2011), "Closed-loop vertical borehole design, installation \& Material standards” UK National Energy Centre, issue 1.0, p.14. 
Hahne, E. (2000), "The IWT solar heating system: an old-timer fully in action", Solar Energy 69(6): pp. 469- 493.

Hasib Z.M., Ekrami N., Lele P. Dworkin S., Fung A., Naylor D. (2012), "Residential micro trigeneration system based on thermo chemical accumulator (TCA)", $11^{\text {th }}$ Int. Conference on sustainable energy technologies, Vancouver Canada.

Heier J., Bales C., Sotnikov A., Ponomarova G. (2011), "Evaluation of a high temperature solar thermal seasonal borehole storage”, ISES Solar world conference, Kassel, Germany.

Hellstrom G. (1991), "Ground Heat Storage, Thermal Analyses of Duct Storage Systems", Department of Mathematical Physics, University of Lund, Box 118, SE-211 00 Lund, Sweden, Thesis.

Hellstrom G. and Sanner B. (1997), “EED - Earth energy designer, version 1.0”, User's Manual, Prof. Dr. Knoblich \&Partner GmbH, Virchowstrasse 4, D-35578 Wetzlar, Germany.

Hellstrom G., Sanner B., Klugescheid M., Gonka T., Martensson S. (1997), "Experiences with the borehole heat exchanger software EED” In Proceedings of Megastock'97, June 19 -22, Sapporo, Japan.

Hellstrom G., Tsang C. F. and Claesson J. (1988), "Buoyancy flow at a two-fluid interface in a porous medium: analytical studies" Water Resources Res. 24(4), 493.

Henning H.M. (2004), "Design and performance of a new thermally driven air conditioning system for Mediterranean climates", in: VII Euro-Mediterranean Conference, Local Utilities and Sustainable Development in the Mediterranean Area, Palermo.

Henning H.M. (2004), "Solar-Assisted Air-Conditioning in Buildings" A Handbook for Planners. Springer, New York, NY, USA, p. 136.

Henning H.M. (2007), "Solar assisted air conditioning of buildings - an overview", Applied Thermal Engineering, 27, pp. 1734-1749.

Hesaraki A., Holmberg S., Haghighat F., (2015), "Seasonal thermal energy storage with heat pumps and low temperatures in building projects - A comparative review", Renewable and Sustainable Energy Reviews 43 1199-1213.

AEE INTEC (2008), HIGH-COMBI "High solar fraction heating and cooling systems with combination of innovative components and methods, State of art of similar applications", work package WP 2, deliverable D6, AEE Institute for sustainable technologies.

IEA (2012), “Technology road map- solar heating and cooling”, International Energy Agency, Paris, France.

James J. Hirsch \& Associates (2015), DOE-2 Software, http://www.doe2.com, 
Kavanaugh, S. P. and Rafferty K., 1997. “Ground-Source Heat Pumps”, ASHRAE, Atlanta, Georgia, p27.

Klein, S.A. et al., (2010), TRNSYS 17: A Transient System Simulation Program, Solar Energy Laboratory, University of Wisconsin, Madison, USA, http://sel.me.wisc.edu/trnsys

Leong W.H., Tamawski, V.R. and A.Aittomakil, (1998), Effect of soil type and moisture content on ground heat pump performance, International Journal of Refrigeration, Vol.21, No.8, pp. 595606.

Leong W.H. and Tarnawski V.R. (2010), "Effects of Simultaneous Heat and Moisture Transfer in Soils on the Performance of a Ground Source Heat Pump System", ASME-ATI-UIT 2010 Conference on Thermal and Environmental Issues in Energy Systems, Sorrento, Italy, May 2010.

Lottner V., Schulz M. E., Hahne E. (2000), "Solar-assisted district heating plants: Status of the German programme Solarthermie-2000”, Solar Energy, 69(6), pp. 449-459.

Lund P. (1985), "Effect of groundwater flow on the performance of long-term pipe heat storage in the ground”, In Report TKK-F-A 586, Helsinki University of Technology, Finland.

Lundin S. (Editor, 1985), "Large-scale thermal energy storage projects- in operation or under construction", Swedish Council for Building Research, D18:1985.

Lundh M., Dalenbäck J. O. (2008), "Swedish solar heated residential area with seasonal storage in rock: Initial evaluation”, Renewable Energy, 33:pp. 703-711.

Manickam A., Dharapuram M., Delahoussaye R. D., Spitler J. D. (1997), “GLHEPRO for Windows, The Professional Ground Loop Heat Exchanger Design Software, Version 2.02”, International Ground Source Heat Pump Association, Stillwater, OK, USA.

Mangold D. (2007), "Seasonal storage - a German success story”, Sun \& Wind Energy, 1: pp. 48-58.

Mazzarella L. (1989), “Duct storage model for TRNSYS 1989 version”, ITW, Stuttgart Univ., Dipartimento di Energetica, Politechnico di Milano, Italy.

Mazzarella L. (1990), “The MINSUN Simulation and Optimization Program”, User's Manual, Dipartimento di Energetica, Polytecnico di Milano, Italy.

McClain T. and Collins R. (2010), "Successful geothermal grouting”, The groundwater association, Water Well journal, February 2010, pp. 25-28.

McDowell T. P., Thornton J. W. (2008), "Simulation and model calibration of a large-scale solar seasonal storage system", In Proc. 3rd National conference of IBPSAUSA, Berkeley (California), USA. 
Mitchell, J.W. and J.E. Braun (1997),"Design analysis, and control of space conditioning equipment and systems", Solar Energy Laboratory, University of Wisconsin, Madison USA.

Nielsen K. (2003), "Thermal energy storage: A state-of-art", a report within the research program Smart Energy-Efficient Buildings at NTNU and SINTEF 2002-2006.

Nordell B. (2000). “Large-scale thermal energy storage”, WinterCities'2000, Luleå, Sweden.

Nordell B., Hellstorm G. (2000)."High temperature solar heated seasonal storage system for low-temperature heating of buildings", Solar Energy Vol. 69(6), pp. 511-523.

Natural Resources Canada, (2012), Office of Energy Efficiency, R-2000 Standard, 2012 edition, Cat. No. M144-223/2012E-PDF (On-line), ISBN 978-1-100-20133-7.

Pahud D. (1995), "Development of System Simulation Tools of Central Solar Heating Plants with a Seasonal Duct Store in the Ground", Department of Mathematical Physics, University of Lund, Box 118, SE-211 00 Lund, Sweden.

OEB, Ontario Energy Board Canada (2016), Electricity Bill Calculator http://www.ontarioenergyboard.ca/OEB/Consumers/Electricity/Your+Electricity+Utility

Pahud D., Hellstrom G. (1996), "The new duct ground heat model for TRNSYS”, In Proceedings of Eurotherm, Seminar 49, 'Physical Models for Thermal Energy Store', March 25 -27, Eindhoven, the Netherlands.

Pal S., Epstein C., Stiles L., Taylor H., Mowbray C. (1997), "Simulation of large geothermal field”, In Proceedings of Megastock'97, June 18 -21, Sapporo, Japan, p.121.

Paul N. D. (1996). "The effect of grout thermal conductivity on vertical geothermal heat exchanger design and performance", South Dakota University, M.Sc. Thesis.

Pavlov G., Olesen B. (2011), "Seasonal solar thermal energy storage through ground heat exchanger-Review of systems and applications", $6^{\text {th }}$ Dubrovnik Conference on Sustainable Development of Energy, Water and Environment Systems, Croatia, Dubrovnik.

Rad F.M., Fung A.S., Leong W.H. (2014), Effects of Weather Parameters on Vertical Ground Heat Exchanger Design, ASHRAE Transactions, vol. 120 (PT 2), pp. 184-194.

RETScreen, (2016), "Clean Energy Project Analysis Software", version 4, Natural Resources Canada. www.retscreen.net

Reuss M., Beck M., Muller J.P. (1997), "Design of a seasonal thermal energy storage in the ground”, Solar Energy Vol. 59, Nos. 4-6, pp. 247-257. 
RSMeans Mechanical Data Cost (2013), RS Means Engineering Department, $36^{\text {th }}$ edition, ISBN10: 1936335689.

Sanner B. (Editor, 1999),"High temperature underground thermal energy storage - state of the art and prospects" A review within ECES Annex 12 of the International Energy Agency IEA.

SAIC Canada (2012), “Science Applications International Corporation”, Drake Landing Solar Community Annual Report for 2011-2012, November 2012.

Schmidt T., Mangold D., Muller-Steinhagen H. (2004), “Central solar heating plants with seasonal storage in Germany”, Solar Energy, 76, pp. 165-174.

Schmidt T., Mangold D., Muller- Steinhagen H. (2003), "Seasonal thermal energy storage in Germany, ISES Solar World Congres, Goteborg, Schweden.

Schmidt T., Mangold D., Muller- Steinhagen H. (2001), "Central solar heating plants with seasonal storage in Germany”, Proceedings of ISES Solar World Congress, 25-30 November, Adelaide, Australia.

Schmidt T., Miedaner O (2012), "Solar district heating guidelines- Storage”, SDH, solar district heating Fact Sheet 7.2, pp. 1-13, http://solar-district-heating.eu

Sibbitt B., Onne T., McClenahan D., Thornton J., Brunger A., Kokko J., Wong B. (2007), “The Drake Landing Solar Community Project-early results”, In Proc. 2-nd Canadian Sol. Build. Conf., Calgary, Canada.

Sibbitt B., McClenahan D., Djebbar R., Thornton J., Kokko J., Wong B., Carriere J., (2012), "The performance of a high solar fraction seasonal storage district heating system- five years of operation”, ScienceDirect, Energy Procedia, Vol 30, pp. 856-865.

Sibbitt B., McClenahan D., NRCan, (2015), "Seasonal borehole thermal energy storageguideline for design \& construction”, International Energy Agency, solar heating and cooling program (SHC), IEA-SHC, TECH SHEET 45.B.3.1, pp. 3-15.

Socaciu L. (2011), "Seasonal sensible thermal energy storage solutions", Leonardo Electronic Journal of Practices and Technologies, Issue 19, pp. 49-76.

SunPower Corp. (2016), "Solar photovoltaic panel manufacturer", San Jose, California, USA. http://us.sunpower.com/

Tarnawski V. R., Leong W. H. (1990), “Computer simulation of ground coupled heat pump systems", Final report to National Research Council, Ottawa, Canada (Contract 989-44104R), pp. 1-167.

Tarnawski V.R., Leong W.H. (1993), "Computer analysis, design and simulation of horizontal ground heat exchangers", International Journal of Energy Research, Vol. 17, pp. 467-4 77. 
U.S. Department of Energy office of energy efficiency \& renewable energy (2012), "Building energy software tools" DOE-2 software (ASHRAE 90).

Van Genuchten M.Th. (1980), “A closed-form equation for predicting the hydraulic conductivity of unsaturated soils”, Soil Sci. Soc. Am. J. 44, pp. 892- 898.

van Meurs, G. A. M., (1986), "Seasonal Heat Storage in the Soil”, Thesis, Department of Applied Physics, University of Technology Delft.

Wang, E., Fung, A.S, Qi, C., Leong, W.H., (2012), "Performance prediction of a hybrid solar ground-source heat pump system", Energy and Building, Vol 47, pp. $600-611$

Wiemken E. (Editor), (2009), "market review and analysis of small and medium-sized solar airconditioning applications”, SOLAIR, EIE/06/034/S12.446612, www.solair-project.eu. 